\title{
In-Home Demonstration of the Reduction of Woodstove Emissions from the Use of Densified Logs
}




\section{In-Home Demonstration of the Reduction of Woodstove Emissions from the Use of Densified Logs}

Prepared for: Oregon Department of Energy and the U.S. Envirommental Protection Agency

Prepared by: Stockton G. Barnett

Roger D. Bighouse

OMNI Environmental Services, Inc.

10074 Southwest Arctic Drive

Beaverton, Oregon 97005

July 7,1992

80117.06 


\section{Disclaimer}

Funds were provided by the U.S. Department of Energy under Grant No. DE-FG79-83BP35836, through the Pacific Northwest and Alaska Regional Bioenergy Program administered by the Borneville Power Aćministration.

No warranty or legal responsibility, either express or implied, is made or assumed by the U.S. Department of Energy (USDOE), Bonn :ville Power Administration (BPA), Oregon Department of Energy (ODOE), and their employees or contractors, for the accuracy, cornpleteness or usefulness of any information disclosed in this directon "; nor is it represented that its unauthorized use would not infringe on privately-owned rights. The mention of any business, product or process in this report does not imply endorsement, approval or disapproval by USDOE, BPA or ODOE. 


\section{Acknowledgements}

This contractor wishes to express thanks for advice, manuscript editing, and guidance provided by:

Alex Sifford of Oregon DOE and Bob MLCrillis of the U.S. EPA.

The following people are acknowledged for their generosity and participation:

Mernbers of the volunteer households

The manufacturers of Pres-to-Logs and Eco-Logs, who generously provided the logs used in the study

Hearth Products Association, for assistance in home selection and for supplying Phase II stoves to all conventional stove homeowners at the end of the test

Michelle Armstrong, for laboratory analysis and equipment maintenance

Alisa Davis, for graphic assistance

Catherine Murphy, for typing and editing the manuscript

Lucy Barnett, for editing the manuscript

Patrick Vaughan, John Crouch, Derafl Kuhnhausen, Ted Shideler, and Alex Sifford, for reviewing the manuscript 


\section{Executive Summary}

This report summarizes work conducted by OMNI Environmental Services, Inc. on the tirst in-home evaluation of the performance of densified fuels in conventional and Phase II EPA certified wondstoves. The work was completed in Klamath Falls, Oregon under contract to the Oregon Department of Energy and the U.S. Environmental Protection Agency. Other participants included the Hearth Products Association, Spokane Pres-to-Logs, and Wood Energy, Inc.

The rate of reduction in ambient particulate matter (PM) emissions in airsheds that are heavily polluted by woodstove burning has generally been slow. A major reason is the slow replacement rate of the many existing conventional woodstoves with Phase II EPA-certified stoves or other forms of clean-burning heat. There is a need to reduce emissions from conventional stoves in the short-term while stove replacement takes place over the longer term. One possibility is to use fuels that would hurn cleaner than cordwood. Densified fuels have been commercially available for years and offer such a possibility. An additional benefit of these fuels is that they are made from wood processing wastes.

The objective of the current project was to evaluate the emissions and efficiency performance of two commercially available densified log types in homes and compare their performance with cordwood.

The two brands of logs used in this study are nearly identical except for the feedstock material. The logs are $10.8 \mathrm{~cm}\left(4^{1} / 4\right.$ in.) in diameter and $33 \mathrm{~cm}\left(13 \mathrm{in}\right.$.) $1 \mathrm{ong}$, with a density of 1.06 to $1.07 \mathrm{~g} / \mathrm{cm}^{3}(66 \mathrm{to}$ $\left.67 \mathrm{lb} / \mathrm{ft}^{3}\right)$ and a higher heating value of $8600 \mathrm{BTU} / \mathrm{lh}$. The moisture content of the logs ranged from approximately 8 to $10 \%$. Both brands use wood shavings as their feedstock and are produced on the same type of Hyster log-forming machine. One log, the Eco-Log, uses Douglas fir, and the other log, Pres-to-Log, uses $40 \%$ Ponderosa pine and a $60 \%$ mixture of red fir and larch.

Nine stoves in the Klamath Falls, Oregon area were chosen for the study. Five of the stoves were Phase II EPA-certified, with two being catalytic and three noncatalytic. The other four were representative conventional stoves for that area. Homeowners were asked to operate their stoves as they normally did for the cordwood test. Since the densified logs were new to the homeowners, they were provided with the log manufacturer's general product information and instruction sheet and asked to practice burning for several days before the first densifjed log emissions test began.

Researchers measured PM, carbon monoxide (CO), and volatile organic matter (VOC) emissions. Both total VOC and methane values are presented. Each home used OMNI's Automated Wondstove Emissions Sampler (AWES) system, developed for the EPA and Bonneville Power Administration (BPA), in a series of four week-long tests for each stove. The sequence of tests in each stove was cordwood, Pres-to-Logs, Eco-Logs, and a second, confirming test using Pres-to-Logs.

Results show an average reduction of $52 \%$ in PM grams per hour emissions overall fol: the nine stoves using Pres-to-Logs. All nine stoves displayed a reduction in PM emissions. CO emissions were more modestly reduced by $27 \%$, and VOCs were reduced $39 \%$. The emissions reduction percentage was similar for both types of stoves (conventional and Phase II catalytic).

PM emissions reduction from the use of the Eco-Logs was only $24 \%$, whereas CCl and total VOC emissions reductions were similar to those of the Pres-to-Logs, $22 \%$ and $37 \%$, respectively. 
Overall energy efficiency was not significantly improved by the use of either of the log types. The operating cost from the use of these densified logs (at $\$ 150$ per $909 \mathrm{~kg}[2000 \mathrm{lb}]$ pallet) is a relatively high $\$ 14.50$ per million delivered BTU. This is 2.2 times greater than the cost of using lodgepole pine cordwood in Klamath Falls and 1.4 times as much as the cost of using Douglas tir or oak in the Willamette Valley. In those areas where cordwood is more expensive, use of the densified logs could be economically feasible.

Given their significant effectiveness but relatively high cost, an effective regulatory strategy could be to require usage of densified logs before and during high pollution episodes or providing a subsidy on the usage of densified fuels.

In conclusion, these limited in-home tests indicate that densified logs may significantly reduce emissions from woodstoves while providing the same amount of energy. These logs could prove effective as a temporary or permanent emissions control strategy in heavily woodsmoke-polluted airsheds. Caution it adopting this strategy must be exercised, however, because emissions performance may vary significantly from brand to brand of densified log due to such factors as fuel composition, particle size, compaction, $\log$ size, and the type of manufacturing process used. In this study we found that the feed stock composition affected performance. The other factors have not yet been evaluated. Idealiy, all these factors should he taken into account, along with feedstock availability, to develop a product that optimizes emissions control.

Efforts should be made to evaluate the emissions reduction potential of densified logs made from biomass wastes associated with landfill and/or field burning problems. Examples include wheat, rice and grass straw and logging wastes. 


\section{Table of Contents}

Acknowledgements $\ldots \ldots \ldots \ldots \ldots \ldots \ldots \ldots \ldots \ldots \ldots \ldots \ldots \ldots$

Executive Summary $\ldots \ldots \ldots \ldots \ldots \ldots \ldots \ldots \ldots \ldots \ldots \ldots \ldots$

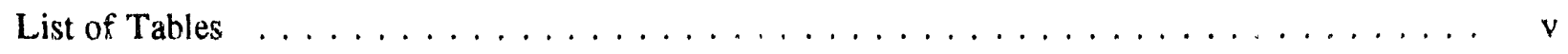

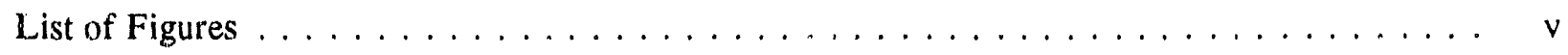

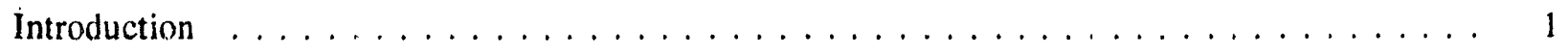

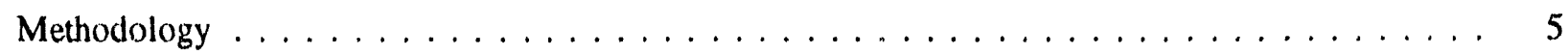

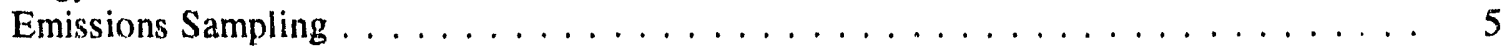

The AWES Emission Sampling System for Woodstoves . . . . . . . . . . 5

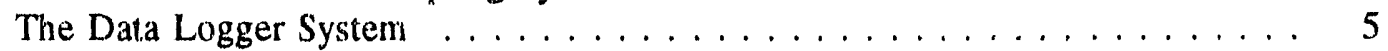

Equipment Preparation and Sample Processing Procedures . . . . . . . . . 8

Data Processing and Quality Assurance . . . . . . . . . . . . . . . 9

Uncertainty in Emissions Results . . . . . . . . . . . . . . . 13

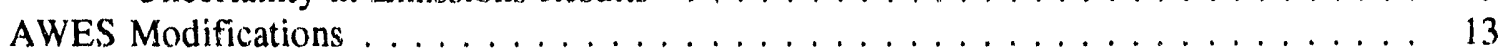

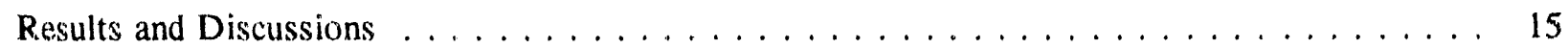

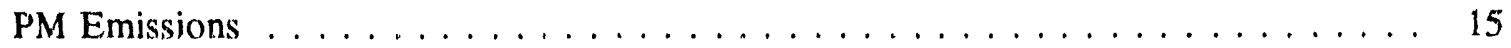

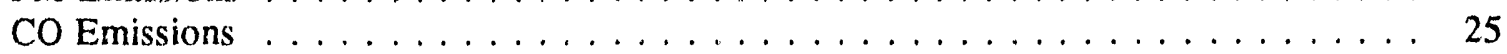

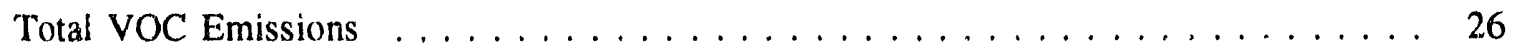

Net Energy Efficiency . . . . . . . . . . . . . . . . . . . . . . . . . . . . . . 29

Comparison of Stove Operating Costs Using Cordwood vs. Densified Logs . . . . . . . 30

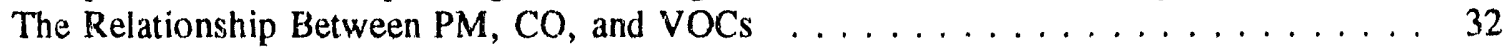

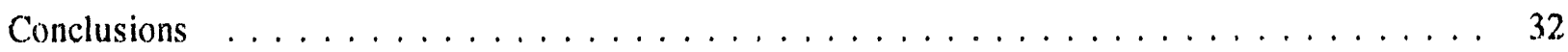

Future Research Needs . . . . . . . . . . . . . . . . . . . 38

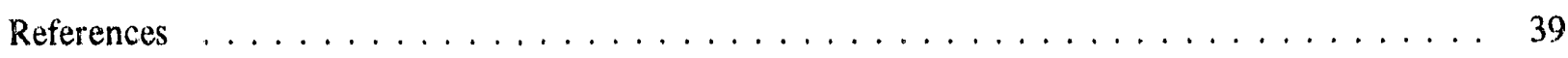

Appendices

Appendix A Photographs of Stove Installacions

Appendix B Graphs of Data from Emissions Tests

Appendix C Homeowner Comments on Densified Fuels 


\section{List of Tables}

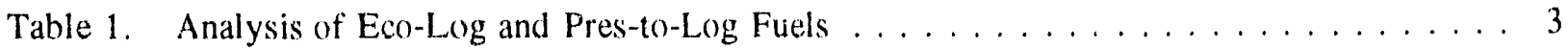

Table 2. Results for the five Phase II stoves using cordwood and densified fuels . . . . . . . . 16

Table 3. Results for the four conventional stoves using cordwood and densified fuels . . . . . . 17

Table 4. Average values for all measured parameters for Phase II and conventional stoves

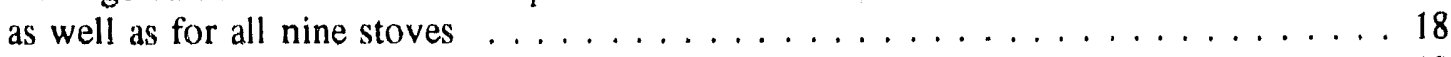

Table 5. PM emissions $(\mathrm{g} / \mathrm{hr})$ from the Conventional and Phase II Stoves . . . . . . . . . . . 19

Table 6. Percent Reduction of PM g/hr Emissions Using Densified Fuels vs. Cordwood in the Conventional and Phase II Stoves . . . . . . . . . . . . . . . . . . 19

Table 7. Matrix of Student's $t$ test results showing whether the difference in mean emissions values between fuel types is statistically significant at the $95 \%$ confidence level . . . . 22

Table 8. Burn rate (dry kg/hr) for the Conventional and Phase II Stoves Using Cordwood and Densified Fuels . . . . . . . . . . . . . . . . . . . . . . . . . . . 24

Table 9. CO Emissions ( $\mathrm{g} / \mathrm{hr}$ ) From the Conventional and Phase II Stoves Using Cordwood and Densified Fuels . . . . . . . . . . . . . . . . . . . . . . . . . . . . 25

Table 10. Percent Reducion in CO Emissions Using Densified Fuels vs. Cordwood in the Conventional and Phase II Stoves . . . . . . . . . . . . . . . . . . . . . 26

Table 11. Total VOC Emissions $(\mathrm{g} / \mathrm{hr}$ ) from the Conventional and Phase II Stoves Using Cordwood and Densified Fuels . . . . . . . . . . . . . . . . . . . . . . . . . . . . . 29

Table 12. Percent Reduction of Total VOC $\mathrm{g} / \mathrm{hr}$ Emissions Using Densified Fuels vs. Cordwood in the Conventional and Phase II Stoves . . . . . . . . . . . . . . . . . . . 29

Table 13. Net Efficiency Using Stack Exit Temperature for Conventional and Phase II Stoves Using Cordwond and Densified Fuels . . . . . . . . . . . . . . . . 30

\section{List of Figures}

Figure 1. Schematic of AWES/Data logger system $\ldots \ldots \ldots \ldots \ldots \ldots$

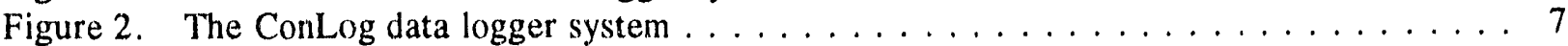

Figure 3. Schematic of AWES system modified for woodstove application . . . . . . . . . 14

Figure 4. Overall percentage of emissions from the use of densified fuels vs. cordwood in all Klamath Falls stoves . . . . . . . . . . . . . . . . . . . . . 20

Figure 5. PM g/hr emissions for all nine stoves, using cordwood, Pres-to-Logs, and EcoLogs . . . . . . . . . . . . . . . . . . . . . . . . . . . . . . . . . 21

Figure 6. Comparison of PM emissions (g/hr) for the five Phase Il stoves using cordwood when new (1990) vs. after two years of use (1992) . . . . . . . . . . . . . 23

Figure 7. $\mathrm{CO} \mathrm{g} / \mathrm{hr}$ emissions for all nine stoves, using cordwood, Pres-to-Logs, and EcoLogs . . . . . . . . . . . . . . . . . . . . . . . . . . . . . . . . . 27

Figure 8. Total VOC g/hr emissions for ail nine stoves, using cordwood, Pres-to-Logs, and

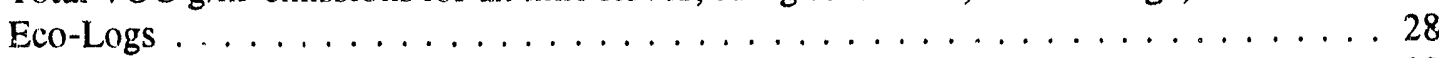

Figure 9. $\mathrm{CO} \mathrm{g} / \mathrm{kg}$ vs. $\mathrm{PM}$ from several field projects $\ldots \ldots \ldots \ldots \ldots \ldots \ldots$

Figure 10. CO g/kg vs. PM. All tests, Klamath Falls densified fuels project . . . . . . . . 34

Figure 11. Total VOC $\mathrm{g} / \mathrm{kg}$ vs. CO. All tests, Klamath Fails densified fuels project . . . . . 35

Figure 12. Total VOC $\mathrm{g} / \mathrm{kg}$ vs. PM. Aill tests, Klamath Falls densified fuels project. . . . . . 36 


\section{Introduction}

This report summarizes work conducted by OMNI Environmental Strvices, Inc. on the first in-home evaluation of the performance of densified fuels in conventional and Phase II EPA certified woodstoves. The work was completed in Klamath Falls, Oregon under contract to the Oregon Department of Energy and the U.S. Environmental Protection Agency. Other participants included the Hearth Products Association, Spokane Pres-to-Logs, and Wood Energy Inc.

The rate of reduction in ambient particulate matter (PM) emissions in airsheds that are heavily polluted by woodstove burning has generally been slow. A major reason is the slow replacement rate of the many existing conventional woodstoves with Phase II EPA certified stoves or other forms of clean-burning heat. Therefore, there is a strong need to reduce emissions from the conventional stove base in the short-term while stove replacement takes place over a longer period of time. Additionally, even after Phase II stoves become abundant, there could still be a need for further pollution reduction. One possible solution is to use fuels that can burn cleaner than cordwood in both conventional and Phase II stoves. Densified fuels have been commercially available for years and offer such a possibility. An additional benefit of these fuels is that they are made from wood processing waste.

There is only one published report on the use of densified logs in woodstoves (Hayden and Braaten, 1991). This was a laboratory study using a single small noncatalytic stove and two log types. Because the $\log$ and stove brand names were not noted, interpretation of the results is difficult. The $70 \%$ reduction in emissions reported from the use of the densified logs is, however, suggestive.

The objective of the current project was to evaluate the in-bome emissions and efficiency performance of two commercially available densitied log types and to compare their performances with cordwood. This project was designed primarily to demonstrate whether or not densified fuels can be used effectively to both provide heat and reduce emissions in currently installed stoves. Therefore, the project used commercially available densified logs. If an emissions reduction is shown, then additional types of densified logs can be investigated. Feedstock for these logs might include logging waste that is currently being burned in the field, logging and lumber waste that is currently being landfilled, or agricultural waste that is currently being burned in the fields. 
The annual sales volumes of the three dominant $4 \frac{1}{4}$ in. diameter log brands (Pres-to-Logs, Eco-Logs, and Energy Logs) have heen estimated to be 17,000-19,000 pallets (1900 lb each) in Washington; 1,000 pallets in Oregon; and 3,000 4,000 pallets in California.'

The two brands of logs used in this study are Pres-to-Log logs (manufactured in Spokane, Washington) and Eco-Logs (manufactured in Tacoma, Washington). Both of these logs use wood shavings from sawmill operations as their feedstock. Eco-Logs use Douglas fir and Pres-to-Log logs use approximately $40 \%$ Ponderosa pine and a $60 \%$ mixture of red fir and larch. Both logs were manufactured on the same type of log-producing device, a Hyster machine. All logs are $10.8 \mathrm{~cm}\left(4 \frac{1}{4} \mathrm{in}\right.$.) in diameter, $33 \mathrm{~cm}(13$ in.) long, have a density of 1.06 to $1.07 \mathrm{~g} / \mathrm{cm}^{3}\left(66 \mathrm{to} 67 \mathrm{lh} / \mathrm{ft}^{3}\right)$, and have a higher heating value of 8600 BTUs per pound (Table 1). The moisture content of the Pres-to-Logs averaged $9.4 \%$ and the Eco-Logs averaged $7.7 \%$. Baseline cordwood tests utilized wood that homeowners had collected for the 1991-1992 season's use. Almost all wood was beetle-kill indgepole pine averaging $12.8 \%$ moisture content. This is quite representative of Klamath Falls fuel but dryer than the fuel generally supplied to the Portland area.

Nine stoves in the Klamath Falls, Oregon area were chosen for the study. Five of the stoves were 1990 Phase II EPA certified (the strictest and final EPA certification level), with two being catalytic and three noncataiytic. All five of these stoves were installed in January 1990 and were studied by OMNI in projects sponsored by the Wood Heating Alliance and the Canadian Combustion Research Laboratory (Barnett, 1990 and Derntrach, 1990). The other four stoves were representative conventional stoves for the Klamath Falls area. Efforts were made to identify conventional stoves through a chimney sweep and two stove dealers in the area. The primary conventional stove type that was available in the area was the Earth Stove 101, a large air-tight stove which is thermostatically controlled. Three of these stoves were used in this project. The fourth conventional stove was a small, apparently locally made box stove. Photographs of all of the stoves can he seen in Appendix A.

Homeowners were asked to operate their stoves as they normally did. Because densified logs were new to all or many homeowners, they were provided with the manufacturer's general product information and an instruction sheet. Researchers asked the homeowners to practice burning the densified logs for several

1. Personal communication, Derald Kuhnhausen of Spokane Pres-to-Log, 1992. 
Table 1. Analysis of Eco-Log and Pres-to-Log Fuels

\begin{tabular}{|c|c|c|}
\hline \multirow{2}{*}{ Analysis Type } & Eco-Log & Spokane Pres-to-Log \\
\hline & Dry Basis & Dry Basis \\
\hline \multicolumn{3}{|l|}{ Proximate Analysis } \\
\hline$\%$ Ash & 0.39 & 0.36 \\
\hline$\%$ Volatile & 84.76 & 83.15 \\
\hline \% Fixed Carbon & 14.74 & 16.49 \\
\hline Total \% & 100.00 & 100.00 \\
\hline BTU/lb & 8529 & 8629 \\
\hline$\%$ Sulfur & 0.17 & 0.22 \\
\hline \multicolumn{3}{|l|}{ Ultimate Analysis } \\
\hline$\%$ Carbon & 51.69 & 51.81 \\
\hline$\%$ Hydrogen & 6.49 & 6.4 \\
\hline$\%$ Nitrogen & 0.11 & 0.11 \\
\hline$\%$ Sulfur & 0.17 & 0.22 \\
\hline$\%$ Ash & 0.39 & 0.36 \\
\hline$\%$ Oxygen & 41.85 & 41.10 \\
\hline Total \% & 100.00 & 100.00 \\
\hline Dry Density & $67 \mathrm{lb} / \mathrm{cu} \mathrm{ft}$ & $66 \mathrm{lb} / \mathrm{cu} \mathrm{ft}$. \\
\hline
\end{tabular}


days before the first densified log emissions test. The instructions suggested that a single log should be ourned at a time. The graphs in Appendix B show the woodloading patterns of all homeowners in histogram form. Because each $\log$ is about $3.6 \mathrm{~kg}(8 \mathrm{lb})$, it can be seen that while smaller Phase II stoves used one or two logs at a time, the conventional stoves often used two or three.

The sequence of week-long tests was the same for each stove. During the first week, homes burned cordwood to obtain a baseline for comparison. In the second week, Pres-to-Logs were burned. In the third week, the Eco-Logs were burned. In the fourth week, a second test was conducted using Pres-toLogs.

OMNI used its Automated Woodstove Emissions Sampler (AWES) and data logger to conduct the sampling. By doing so, a direct comparison can be made to numerous published studies on woodstoves, pellet stoves, fireplaces and masonry heaters. This system collects samples for PM and carbon monoxide (CO) emissions determination. In addition to producing emission results, the AWES uniquely collects real-time temperature information on the home's ambient and stack temperatures. For stoves with catalytic converters, the AWES collects pre- and post-catalytic temperatures. Real-time data on stack oxygen content and fuel loading patterns are also collected. This data enables efficiency calculations to be determined. Graphs showing the trends in the above variables are shown in Appendix A.

An additional parameter, volatile organic compounds (VOC), was measured for the first time in these tests. The AWES pumps flue gases that have been cleaned by its filtration system into a Tedlar hag. The contents of this bag have customarily been analyzed for $\mathrm{CO}$, oxygen $\left(\mathrm{O}_{2}\right)$, and carbon dioxide $\left(\mathrm{CO}_{2}\right)$. For this test, VOC were also measured and emission factors calculated. 


\section{Methodology}

\section{Emissions Sampling}

\section{The AWES Emission Sampling System for Woodstoves}

Figure 1 shows a schematic of the AWES/data logger syster. as used for woodstove sampling. The AWES unit draws flue gases through a 38 to $46 \mathrm{~cm}$ (1.5 to $18 \mathrm{in}$.) $10 \mathrm{gg}, 1.0 \mathrm{~cm}(3 / 8$ in.) O.D. stainless steel probe which samples from the center of the flue aboll $30 \mathrm{~cm}(1 \mathrm{ft})$ above the woodstove's flue collar. The sample then travels through a $1.0 \mathrm{~cm}$ O.D Teflon line and a heated U.S. EPA Method 5type filter for collection of PM, followed by a sorbent resin (XAD-2) trap for semi-volatile hydrocarbons. Water vapor is removed by a silica gel trap. Flue gas oxygen concentrations, which are used to determine flue gas volume, were measured hy an electrochemical cell (Lynn Instruments). The AWES uses a critical orifice (Millipore $\# X \times 500001$ ) to maintain a nominal sampling rate of 1.0 liter per minute $(0.035 \mathrm{~cm})$. Each AWES critical orifice is calibrated to determine the exact sampling rate.

The AWES unit returns particle-free exhaust gas after it has passed through the filter and XAD-2 resin trap to the flue via a $0.6 \mathrm{~cm}(1 / 4$ in.) Teflon liate and a $38 \mathrm{~cm}$ (15 in.) stainless steel probe inserted in the que. Some flue gas exiting the AWES is pumped into a 22-liter Tedlar hag (for later gas analysis) under positive pressure, since the inlet to the bag is on the positive side of the pump. The flow to the bag is controlled by a solenoid valve connected to the pump circuit, a temperature controller, and a rotameter with a flow-controlling orifice. The solenoid valve is open only when the pump is activated and the temperature of the stack exceeds $100^{\circ} \mathrm{F}$. The rotameter controls the rate of flow into the bag and is adjusted to acquire the optimum amount of gas over the entire fest without over-pressurizing the bag.

\section{The Data Logerer System}

The data logger system, known as the CONLOG data logger system, is a second-generation data logging and emission sampler controlling system developed in 1990 by OMNI. The system (Figure 2) consists of a bost personal computer (PC) containing a data processing board, a terminal box, and specialized data acquisition software. 


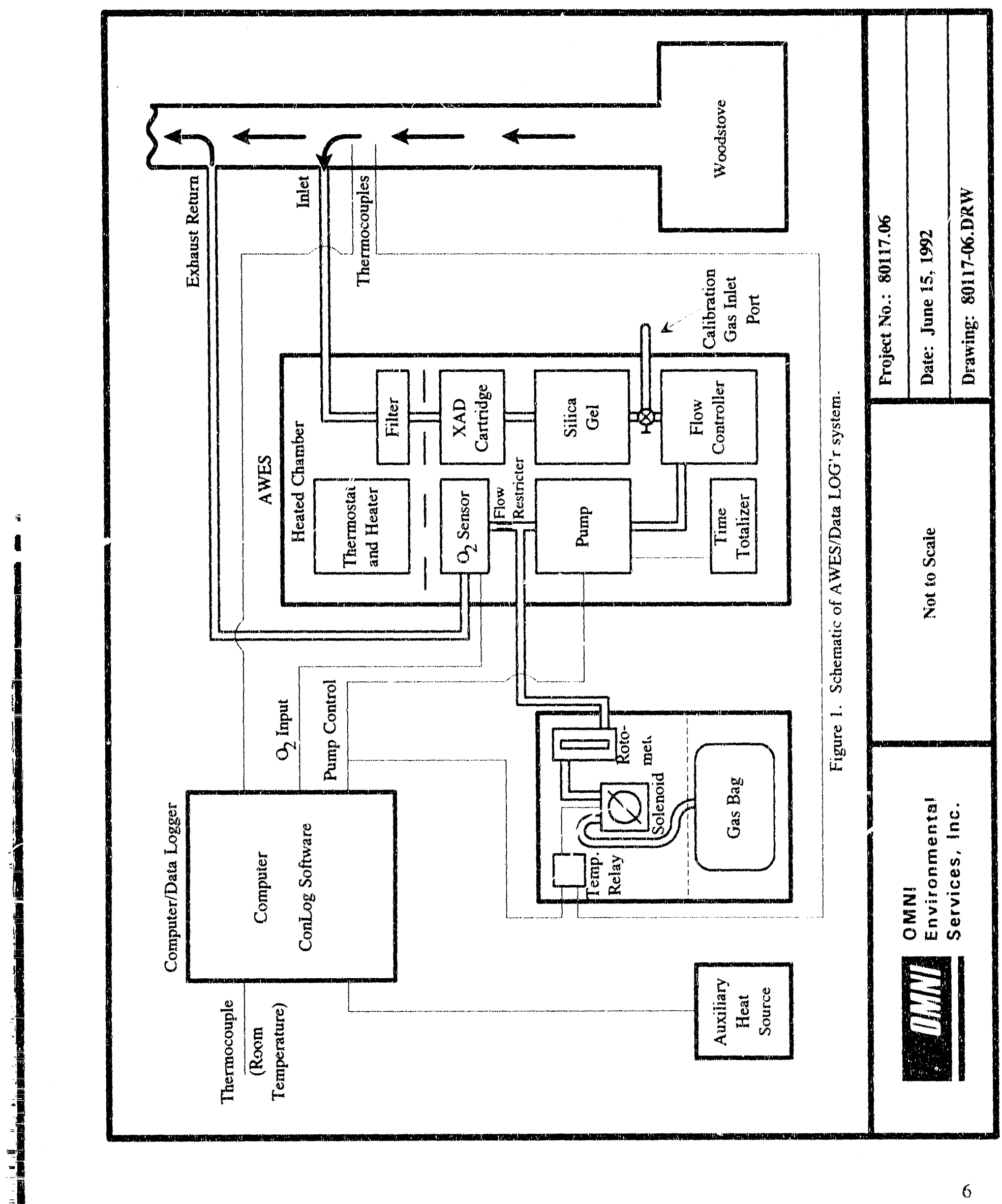




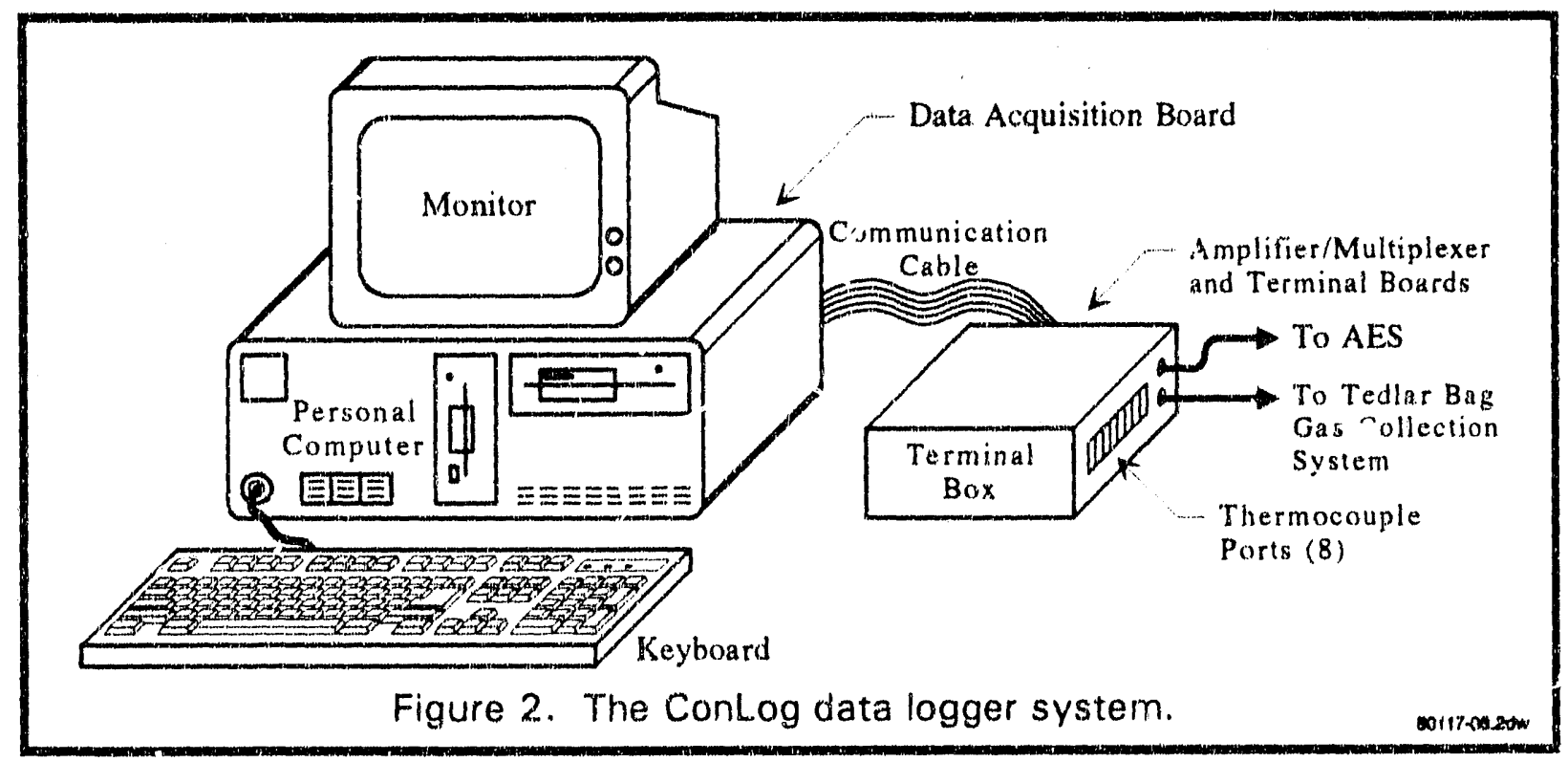

The CONLOG software is written in a high-level programmir ${ }_{g}$ language (C). The CONLOG program controls the sarnpling process and stores the following software settings and data:

- Establish starting and ending date and length of sampling period

- Establish pump cycle length and thermocouple (TC) cycle recording interval

- Record date and time at pre-selected intervals

- Record four temperatures-two flue gas temperatures, the catalyst temperature, and the precatalyst temperature, averaged over pre-selected intervals

- Record ambient temperature (room temperature), averaged over pre-selected intervals

- Record flue gas oxygen measurements, averaged over pre-selected intervals

- Save the recorded data as an ASCII file with PRN suffix on 3.5" disk

The system status screen displays instantaneous readings of real-time data: date, time, temperature for TCs 1 through 5, and flue gas oxygen percent. It also displays the most recent 15 sets of recorded data.

For woodstoves, the AWES records ambient, stack, exit stack, catalyst, and precatalyst (the latter two for catalytic stoves) temperatures at five-minute intervals. The sampling pump operates for one minute on followed by 14 minutes off. This procedure collects a sample of 672 liters during the week-long test. 
The CONLOG system uses external temperature sensors which generate analog voltages that are processed by the PC microprocessor's data acquisition hoard. For this project, type $\mathbf{K}$ ground-isolated, stainless-steel-sheathed TC (Pyrocom IK-27-5-U) thermocouples were used.

The keyboard and screen were left installed in the home during the sampling period. The presence of the display screen's real-rime data generated considerable interest on the part of the participants in the project and was a positive experience. The CONLOG program was software-locked to prevent possible interference. However, historically, on a few occasions homeowners have been given the password and "walked through" minor program modifications over the telephone to solve a problem that may have occurred during a sampling period. This proved successful and saved considerable field technician time.

\section{Equipment Preparation and Sample Processing Procedures}

Prior to emissions testing, OMNI cleaned each AWES unit and loaded a new fiberglass filter and an XAD-2 sorbent resin cartridge. This was done in OMNI's laboratory facility at Beaverton, Oregon. After each sampling period, the stainless steel sampling probe, Teflon sampling line, filter holder, and XAD-2 cartridges were removed from the home and transported to OMNI's laboratory for processing. The AWES sampler component processing was as follows:

1. Filters: The glass fiber filters (102 $\mathrm{mm}$ in diameter) were removed from the AWES filter housings and placed in Petri dishes for desiccation and gravimetric analysis for particulate catch.

2. XAD-2 sorbent resin: The sorhent resin cartridges were extracted in the Soxhlet extractor with dichloromethane for 24 hours. The extraction solvent was transferred to a tared glass beaker, evaporated in an ambient air dryer, and desiccated. The extractable residue was then weighed on a Mettler AE160 balance.

3. AWES hardware: All hardware which was in the sample stream (stainless steel probe, Teflon sampling line, stainless steel filter housing, and all other Teflon and stainless steel fittings) through the base of the sorhent resin cartridge was rinsed with a 50/50 mixture of dichloromethane and methanol solvents. The solvents were placed in tared glass 
beakers. The solvents were evaporated in an ambient air dryer, desiccated, and weighed to determine the residue fraction weight.

4. A new Tedlar bag was installed and the system was leak-checked.

OMNI followed EPA Method 5 procedures for desiccation and the weighing time schedule for 1 through 3 above.

OMNI personnel serviced the sampling equipment at the start and end of each sampling period. At the start of each sampling period, the AWES unit was installed; leak checks wire performed; the thermocouples, woodhasket/scale unit, and oxygen cell were calibrated; and the data logger was programmed with the proper sampling interval and start/stop times. Data loggers were programmed to activate the AWES units for one minute on and 14 minutes off for seven consecutive days. At the end of each sampling period, final calibration and leak-check procedures were performed, and the AWES, sampling line, filter housing, XAD-2 cartridge, and sampling probe were removed and sent to the lab.

One promising result of this project involves a new sampling system. Throughout this project, a "lowcost" emissions sampling system was installed in one of the homes. This system separates the AWES components into two sample boxes. The "front" box contains the probe, sample line, filter, and XAD-2 cartridge only. This unit is "quick-disconnected" to the "main" AWES box. The homeowner disconnects the front box and sends it to OMNI for processing, thus greatly reducing field technician labor. The homeowner installs a new front box for the next test. This system worked flawlessly during the four test runs of this project. Based on this experience, OMNI wrote a complete set of low-cost ernissions sampling system instructions for the homeowner.

\section{Data Processing and Quality Assurance}

Data files stored on the data logger's 3.5" computer diskette were analyzed by computer at OMNI's lab. Each data file was reviewed immediately to check for proper equipment operation. Data logger data files, $\log$ books, and records maintained by field staff were reviewed to ensure sample integrity. 
Data logger files were used in conjunction with the AWES particulate sample to calculate particulate emission rates, daily temperature profiles of the various flue temperatures, woodstove operation time, burn rates, etc. In addition, computer program outputs for each file include graphical representations of parameters and parameter interrelationships (see Appendix B).

\section{PM Emissions Calculutions}

The basic PM emissions equation produces grams per dry kilogram of fuel hurned $(\mathrm{g} / \mathrm{kg})$. The basic $\mathrm{g} / \mathrm{kg}$ equation includes the following components:

1. Particulate mass: The total mass, in grams, of particulate caught on the filter, XAD-2 resin trap, and in the probe rinse.

2. Sample time: The number of minutes the sampler operated during the sampling week when the stack temperature was greater than $38^{\circ} \mathrm{C}\left(100{ }^{\circ} \mathrm{F}\right)$.

3. Sampler's flow rate: This is controlled by the critical orifice in the sampler. Flow values vary slightly for the various samplers and average about one liter per minute.

4. Stoichiometric volume: The volume of flue gas produced by completely combusting one dry kilogram of wood with no excess air. This value is calculated using a carbon halance for each sample but averages about 4,500-5,000 liters at standard temperature and pressure for woodstoves.

5. Dilution factor: The degree to which the sampled combustion gases have been diluted in the stack by the presence of excess air. The dilution factor is obtained by using the sample period's average oxygen value in the following equation. Dilution factors range from about 2 to 5 .

$$
\text { Dilution Factor }=((20.9 /(20.9-\text { Average oxygen }))
$$

PM emissions, in $\mathrm{g} / \mathrm{kg}$, are then calculated by the following equation: 


$$
\text { PM emissions }(\mathrm{g} / \mathrm{kg})=\frac{\text { (Particulates)(Stoich. Vol.)(Dilution Factor) }}{(\text { Sample Time)(Sampler Flow) }}
$$

Multiplying the above equation by the burn rate (dry $\mathrm{kg} / \mathrm{hr}$ ) yields PM emissions in grams per hour.

\section{CO Emissions Calculations}

The basic CO emissions equation produces grams CO per dry kilogram of fuel burned. The grams per kilogram equation includes some components described earlier as well as the following:

1. Fraction CO: The fraction of $\mathrm{CO}$ measured in the gas bag. Usually reported in percent, it must be divided by 100 to give the fraction $\mathrm{CO}$.

2. Molecular weight $\mathrm{CO}$ : The gram moleculd. weight of $\mathrm{CO}, 28.0 \mathrm{~g} / \mathrm{mole}$.

3. Temperature: The temperature at which the concentration of $\mathrm{CO}$ was measured in Celsius.

CO ernissions, in $\mathrm{g} / \mathrm{kg}$, are calculated by the following equation:

$$
\text { CO emissions }(\mathrm{g} / \mathrm{kg})=\frac{(\text { Fraction CO })(\text { Stoich. Vol. })(\text { Dilution Factor })(\text { Molec. Wt. CO })}{(22.4 \mathrm{~L} / \text { mole })([273 \mathrm{C}+\text { Tennp }] / 273 \mathrm{C})}
$$

Multiplying the above equation by the burn rate (dry $\mathrm{kg} / \mathrm{hr}$ ) yields grams per hour $\mathrm{CO}$ emissions.

\section{VOC Emissions Calculations}

The VOC emissions equation yields grams VOC per dry kilogram of fuel burned. Both total VOC and methane are calculated. In addition to the previously described components, the basic VOC emissions equation contains two additional components:

1. Fraction VOC: The fraction of VOC measured in the Tedlar bag (either total VOC or methane). Usually reported in parts per million, this value must be divided by $10^{6}$ to give fraction VOC. 
2. Molecular weight VOC: Since the VOC is reported as if it were composed entirely of methane, we use the gram molecular weight of methane, $16.0 \mathrm{~g} / \mathrm{mole}$.

VOC emissions, in $\mathrm{g} / \mathrm{kg}$, are calculated by the following equation:

$$
\text { VOC emissions }(\mathrm{g} / \mathrm{kg})=\frac{(\text { Fraction VOC })(\text { Stoich. Vol.) }(\text { Dilution Factor })(\text { Molec. Wt. VOC })}{(22.4 \mathrm{~L} / \mathrm{mole})([273 \mathrm{C}+\mathrm{Temp}) / 273 \mathrm{C})}
$$

To obtain the equation for VOC emissions in grams per hour, simply multiply by the burn rate (dry $\mathrm{kg} / \mathrm{hr}$ ).

Efficiency Calculations

Woodstove efficiency was determined using the "Condar method" described by Barnett (1985). This method uses CO and PM emissions, stack dilution (based on excess air), exit stack temperature, wood type, and wood moisture to calculate combustion, heat transfer, and overall efficiencies as well as net output in BTU/hour.

All previnus field studies of woodstoves, masonry fireplaces, pellet stoves, and masonry heaters conducted by OMNI used this method. A stack temperature probe was placed in the woodstove's flue near the hom's exit location for the flue (the "exit stack temperature"), so the measured efficiency includes essentially all of the heat energy that the heater contributes to the home.

Efficiency is reported in two ways. One method uses the stack temperature $30 \mathrm{~cm}$ (1 foot) above the flue collar, as previous AWES studies have. It is presented here for comparative reference to older studies. The other uses the exit stack temperature obtained where the stack leaves the home's heated space. This efficiency value is both higher and more representative of the stove's efficiency in that particular house than using the $30 \mathrm{~cm}$ height. One can also determine the effectiveness of the various flue pipe arrangements by comparing the two efficiencies. 


\section{Uncertainty in Emissions Results}

PM emission values are presented along with their associated uncertainty levels. Each measurement used in the ernissions calculations has some degree of uncertainty which is propagated to determine the cumulative level of uncertainty attached to each calculated PM emission rate. Criteria, procedures, and calculations used in evaluating uncertainty are summarized in a previous report (Barnett and Fields, 1991). Within the range of emissions values encountered in this project, uncertainty is generally about 10 to $15 \%$ of the stated value.

Barnett (1990) previously investigated the issue of sample-blank-induced error. The values determined in that study are used here. They include a probable error at the $95 \%$ confidence level of $\pm 4.88 \mathrm{mg}$ and an average blank value of $3.9 \mathrm{mg}$.

Oxygen-cell-induced error was also investigated by Barnett (1990). The probable error contribution to emission values of $\pm 7 \%$ at the $95 \%$ confidence level is used in this study.

For a detailed treatment of these and other sources of uncertainty and QA procedures utilized, see Appendix C of Barnett and Fields (1991).

\section{AWES Modifications}

A modification that was made in 1990 was the addition of a flue gas Tedlar bag collection system (Figure 3). Carbon dioxide, carbon monoxide, and oxygen data are generated from this collection system, allowing for calculation of carbon monoxide emission factors. Carbon balance equations using carbon dioxide and carbon monoxide were used to calculate the stack dilution factor which in turn is used in the emissions equations. An NDIR analyzer measured Tedlar bag gases. The Tedlar bag collection is astivated when the AWES system's pump is on and the stack temperature exceeds $38^{\circ} \mathrm{C}\left(100{ }^{\circ} \mathrm{F}\right)$.

The project conducted VOC analysis for the first time on woodstoves in the field. VOCs were collected in new Tedlar bags and analyzed using gas chromatography and a flame ionization detector. VOCs are reported as total VOC and the methane fraction, following the format of EPA Methods 25 and 25a. The detection limit is $10 \mathrm{ppm}$. A sample blank was run and no VOCs were detected. 


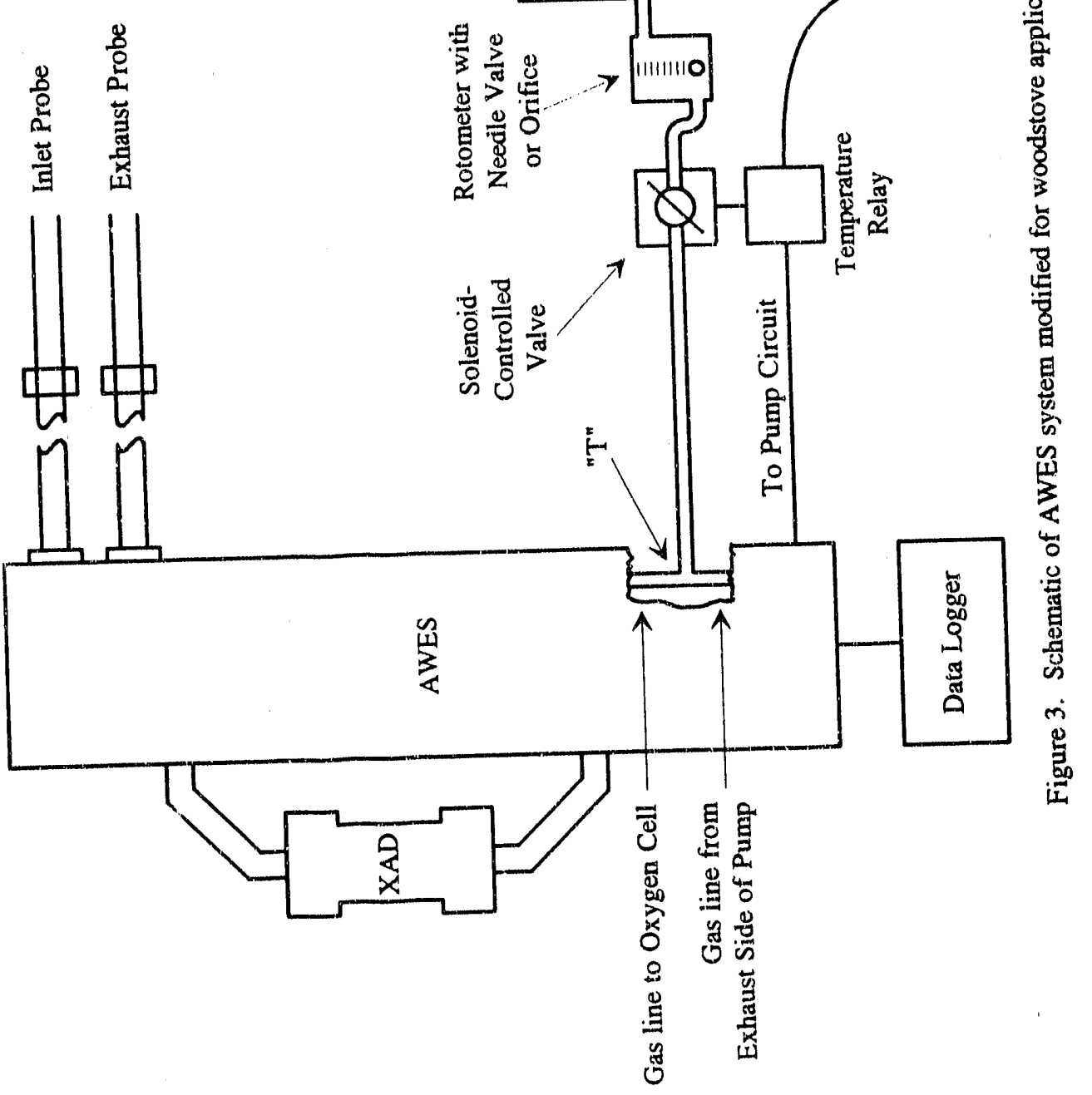




\section{Results and Discussions}

\section{PM Emissions}

Tables 2-4 show the detailed results for the 36 emissions tests. Tables 5 and 6 show the summary of the PM results. Figure 4 summarizes these results and Figure 5 details them. Table 7 shows the statistical significance of all Student's $t$ comparisons.

The average PM emissions for the five Phase II stoves using cordwood were $7.8 \mathrm{~g} / \mathrm{hr}^{2}{ }^{2}$ This is higher than the $5.4 \mathrm{~g} / \mathrm{hr}$ when these stovıs were new two years ago (Dernbach, 1990; Barnett, 1990). The cause of the increase appears to be catalytic stove performance deterioration (Figure 6). The average PM emissions of two test runs using the Pres-to- $\log$ was $4.7 \mathrm{~g} / \mathrm{hr}$ for the Phase II stoves, a reduction of $40 \%$. The Eco-Log produced PM emissions of $8.0 \mathrm{~g} / \mathrm{hr}$ in Phase II stoves, a 3.5\% increase over the cordwood baseline. It should be noted that the Jotul Alpha catalytic stove had deteriorated significantly in performance since 1990 (Figure 6) and it is possible that it continued to deteriorate during this test series. $^{3}$ The fact that cordwood was tested first may explain why this stove did not perform as well with either the Pres-to-Logs or the Eco-Logs, as one would expect.

2. PM grams per hour emissions values reported here are "AWES" values that have not been recalculated to EPA Method 5H equivalents. AWES and EPA $5 \mathrm{H}$ equivalent values are very similar. Recalculation involves two equations: AWES to EPA Method 5G and then EPA $5 \mathrm{G}$ to EPA 5H. The equations are EPA5G = 0.8635 (AWES ${ }^{\wedge} 0.9288$ ) (Barnett, 1990) and EPA 5H = $1.619\left(5 \mathrm{G}^{\wedge} 0.905\right)$ (McCrillis and Jaasma, 1991). Caution is urged to avoid extrapolation because no AWES grams per hour values greater than 30 were used to establish the relationship. The following AWES-EPA 5H equivalents should be of some guidance. $5($ AWES $)=5.5(5 \mathrm{H}), 10($ AWES $)=9.8(5 \mathrm{H}), 15($ AWES $)=13.8(5 \mathrm{H}$, $20(\mathrm{AWES})=17.6(5 \mathrm{H})$, and $30(\mathrm{AWES})=24.7(5 \mathrm{H})$.

3. The catalyst was replaced and tightly sealed with Kaowool by the OMNI field representative prior to all field emissions test series in 1990 and 1992. The homeowner had removed the catalyst and vacuurned dust from it twice between 1990 and 1992. 


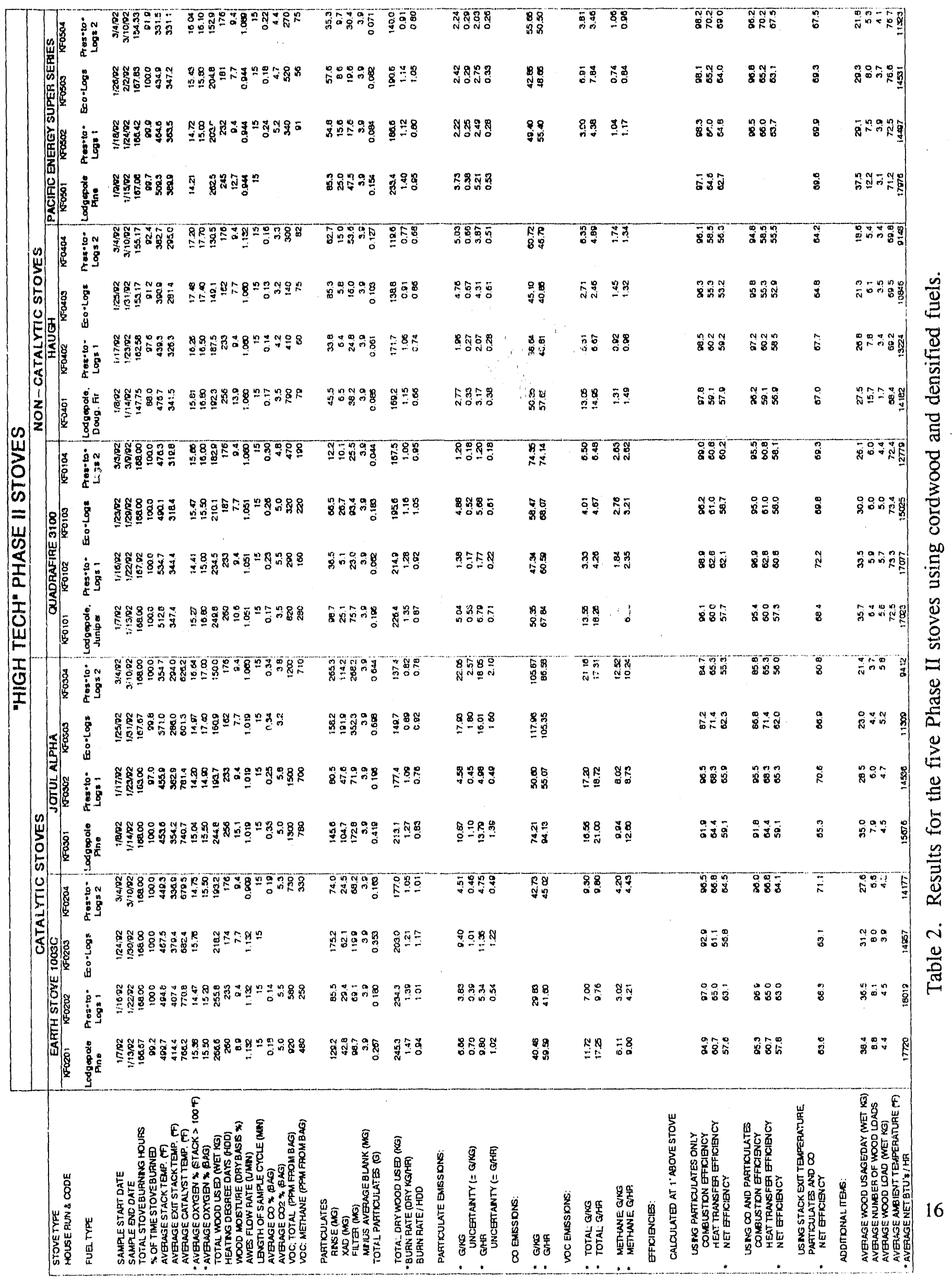




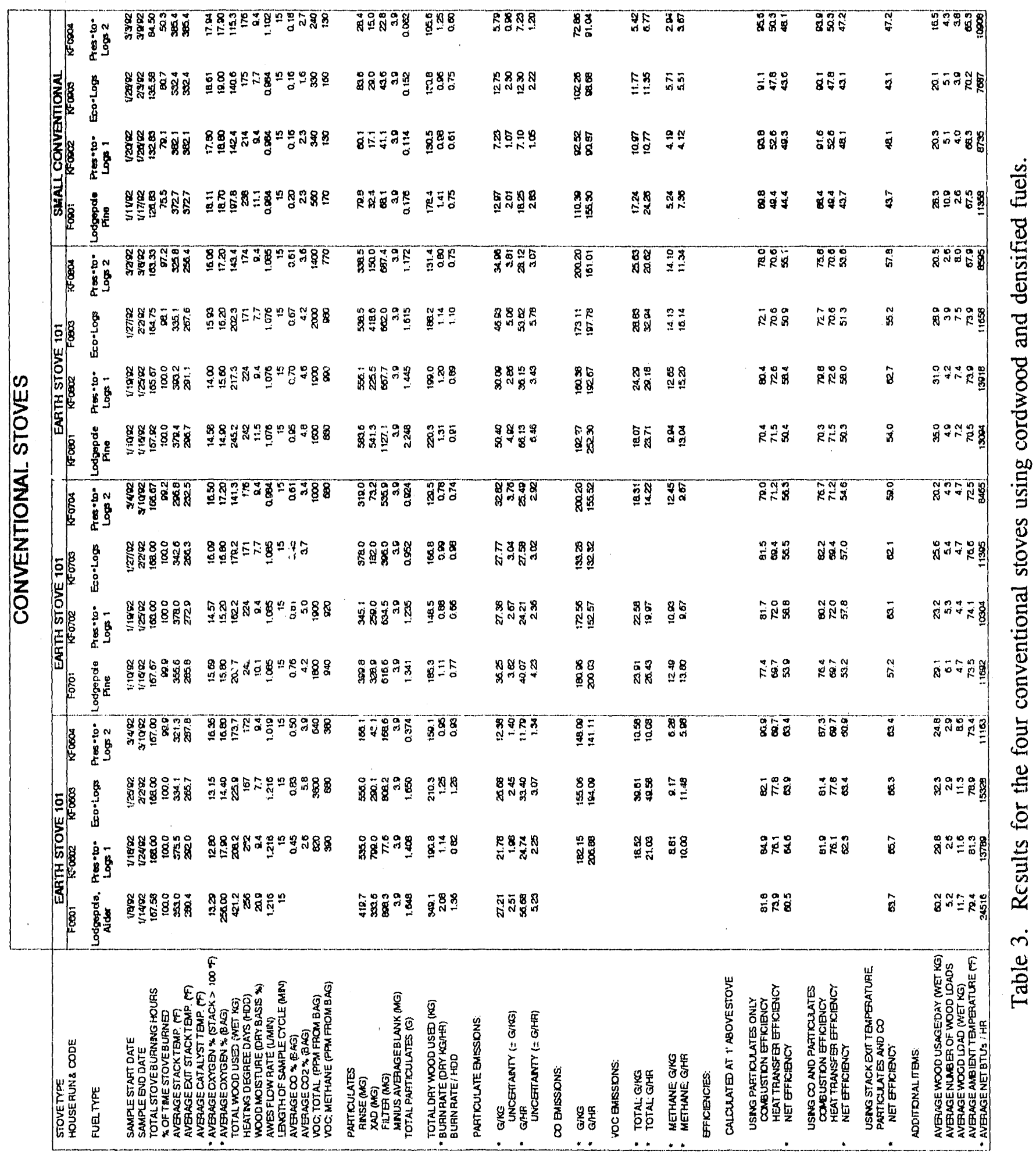




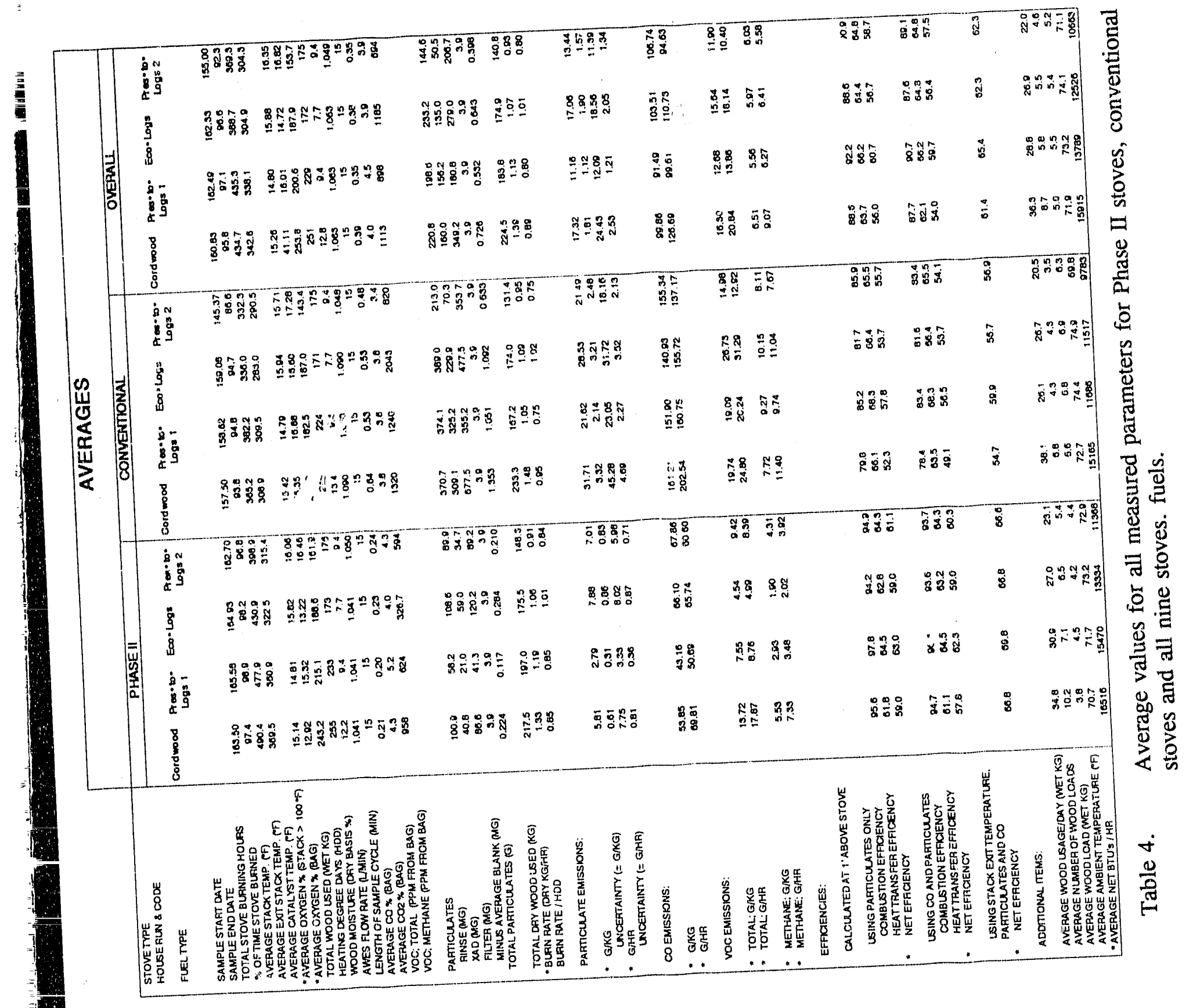


Table 5. Average PM Emissions $\left(\mathrm{g} / \mathrm{hr}\right.$ ) from the Conventional and Phase II Stoves ${ }^{\mathrm{a}}$

\begin{tabular}{|l|c|c|c|c|c|}
\hline \multicolumn{1}{|c|}{ Stove Type } & Cordwood & Pres-to-Logs 1 & Pres-to-Logs 2 & Pres-to-Logs Ave. & EcouLogs \\
\hline Phase II & $7.8(5)$ & $3.3(5)$ & $6.0(5)$ & $4.7(5)$ & $8.0(5)$ \\
\hline Conventional & $45.3(4)$ & $23.0(4)$ & $18.2(4)$ & $20.6(4)$ & $31.7(4)$ \\
\hline Overall & $24.4(9)$ & $12.1(9)$ & $11.4(9)$ & $11.7(9)$ & $18.6(9)$ \\
\hline
\end{tabular}

a. Numbers in parentheses are the sample size.

Table 6. Average Percent Reduction of PM g/hr Emissions Using Densified Fuels vs. Cordwood in the Conventional and Phase II Stoves"

\begin{tabular}{|l|c|c|c|c|}
\hline Stove Type & Pres-to-Logs 1 & Pres-to-Logs 2 & Pres-to-Logs Ave. & Eco-Logs \\
\hline Phase II & $57.1(5)$ & $22.9(5)$ & $40.0(5)$ & $+3.5(5)$ \\
\hline Conventional & $49.1(4)$ & $59.9(4)$ & $54.5(4)$ & $29.9(4)$ \\
\hline Overall b $^{b}$ & $50.5(9)$ & $53.4(9)$ & $51.9(9)$ & $24.1(9)$ \\
\hline
\end{tabular}

a. All numbers in parentheses are the sample size.

b. The overall average percent reduction wis frund by calculating the percent reduction of the total emissions of all nine homes combined. 


\section{PERCENTAGE OF CORDWOOD EMISSIONS}

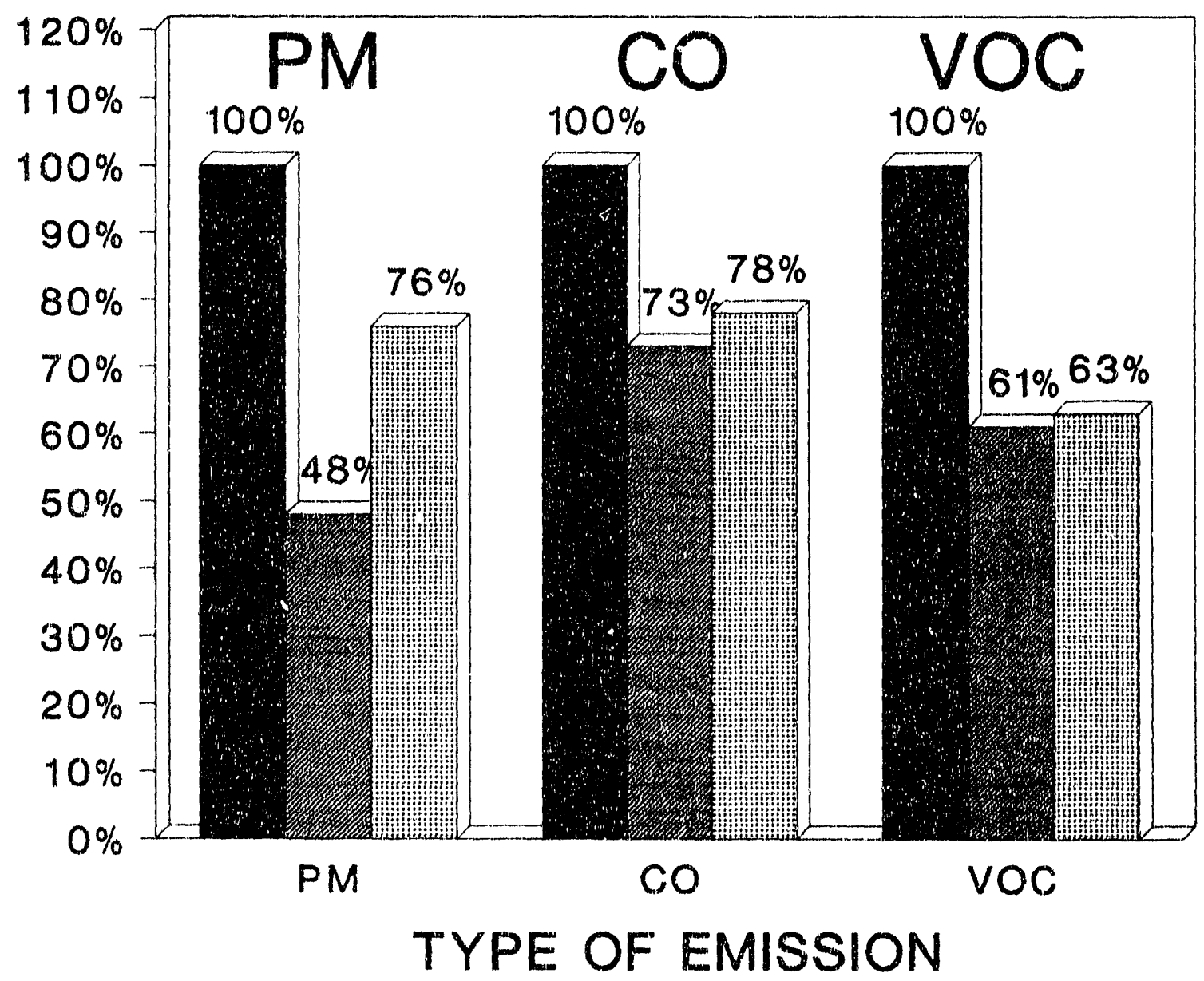
W CORDWO OD
PRES-TO-LOGS

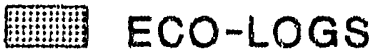

Cordwood emissions are expressed as $100 \%$ in all cases.

Figure 4. Overall percentage of Ernissions from the use of densified fuels vs. cordwond in all Klamath Falls stoves. 


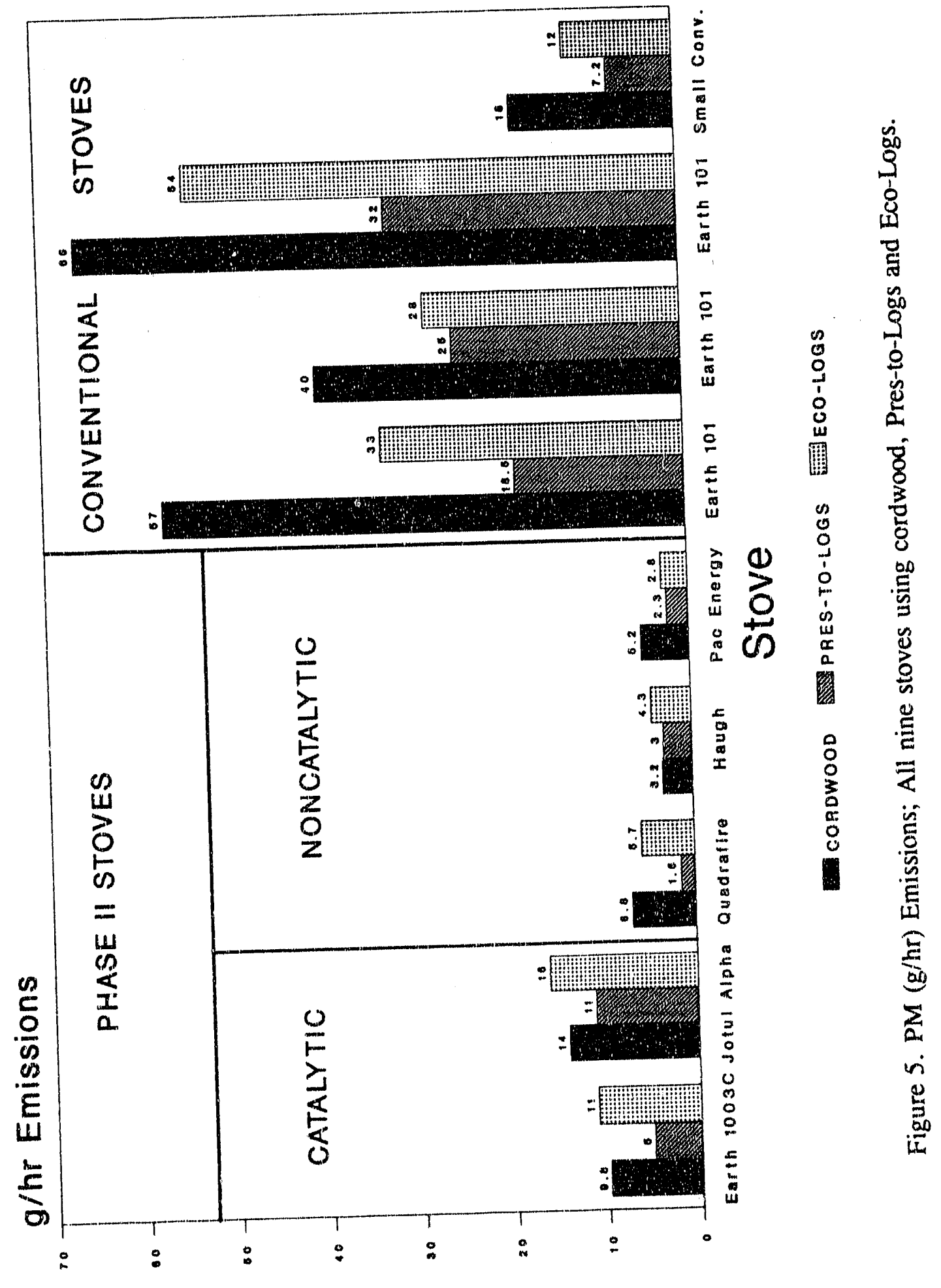


Table 7. Matrix of Student's $t$ test results showing whether the difference in mean emissions values between fuel types is statistically significant at the $95 \%$ confidence level. Comparisons of emissions are shown between the different fuel types for different stove caregories.

\begin{tabular}{|c|c|c|c|}
\hline \multicolumn{4}{|c|}{ PM (g/hr) } \\
\hline \multirow[b]{2}{*}{ Stove Category } & \multicolumn{3}{|c|}{ Fuels } \\
\hline & $\begin{array}{c}\text { Cordwood vs. } \\
\text { Pres-to-Log }\end{array}$ & $\begin{array}{l}\text { Cordwood vs. } \\
\text { Eco-Log }\end{array}$ & $\begin{array}{l}\text { Eco-Log vs. } \\
\text { Pres-to-Log }\end{array}$ \\
\hline $\begin{array}{l}\text { Phase II } \\
\text { Conventional } \\
\text { Overall }\end{array}$ & $\begin{array}{l}\text { SIGNIFICANT } \\
\text { SIGNIFICANT } \\
\text { SIGNIFICANT }\end{array}$ & $\begin{array}{l}\text { not significant } \\
\text { SIGNIFICANT } \\
\text { not significant }\end{array}$ & $\begin{array}{l}\text { SIGNIFICANT } \\
\text { not significant } \\
\text { SIGNIFICANT }\end{array}$ \\
\hline
\end{tabular}

\begin{tabular}{|c|c|c|c|}
\hline \multirow[b]{2}{*}{ Stove Category } & \multicolumn{3}{|c|}{ Fuels } \\
\hline & $\begin{array}{c}\text { Cordwood vs. } \\
\text { Pres-to-Log }\end{array}$ & $\begin{array}{l}\text { Cordwood vs. } \\
\text { Eco-Log }\end{array}$ & $\begin{array}{l}\text { Eco-Log vs. } \\
\text { Pres-to-Log }\end{array}$ \\
\hline $\begin{array}{l}\text { Phase II } \\
\text { Conventional } \\
\text { Overall }\end{array}$ & $\begin{array}{l}\text { not significant } \\
\text { SIGNIFICANT } \\
\text { SIGNIFICANT }\end{array}$ & $\begin{array}{l}\text { not significant } \\
\text { SiGNIFICANT } \\
\text { not significant }\end{array}$ & $\begin{array}{l}\text { not significant } \\
\text { not significant } \\
\text { not significant }\end{array}$ \\
\hline
\end{tabular}

Total VOC $(\mathrm{g} / \mathrm{hr})$

\begin{tabular}{|l|l|l|l|}
\hline \multirow{2}{*}{ Stove Category } & \multicolumn{3}{|c|}{ Fuels } \\
\cline { 2 - 4 } & \multicolumn{1}{|c|}{$\begin{array}{c}\text { Cordwood vs. } \\
\text { Pres-fo-Log }\end{array}$} & $\begin{array}{c}\text { Cordwood vs. } \\
\text { Eco-Log }\end{array}$ & $\begin{array}{c}\text { Eco-Log vs. } \\
\text { Pres-to-Log }\end{array}$ \\
\hline $\begin{array}{l}\text { Phase II } \\
\begin{array}{l}\text { Conventional } \\
\text { Overall }\end{array}\end{array}$ & $\begin{array}{l}\text { SIGNifiCANT } \\
\text { not significant } \\
\text { SigNIFICANT }\end{array}$ & $\begin{array}{l}\text { SigNifiCANT } \\
\text { not significant } \\
\text { not significant }\end{array}$ & $\begin{array}{l}\text { not significant } \\
\text { not significant } \\
\text { not significant }\end{array}$ \\
\hline
\end{tabular}

Bold $=$ significant at the $99 \%$ level. 


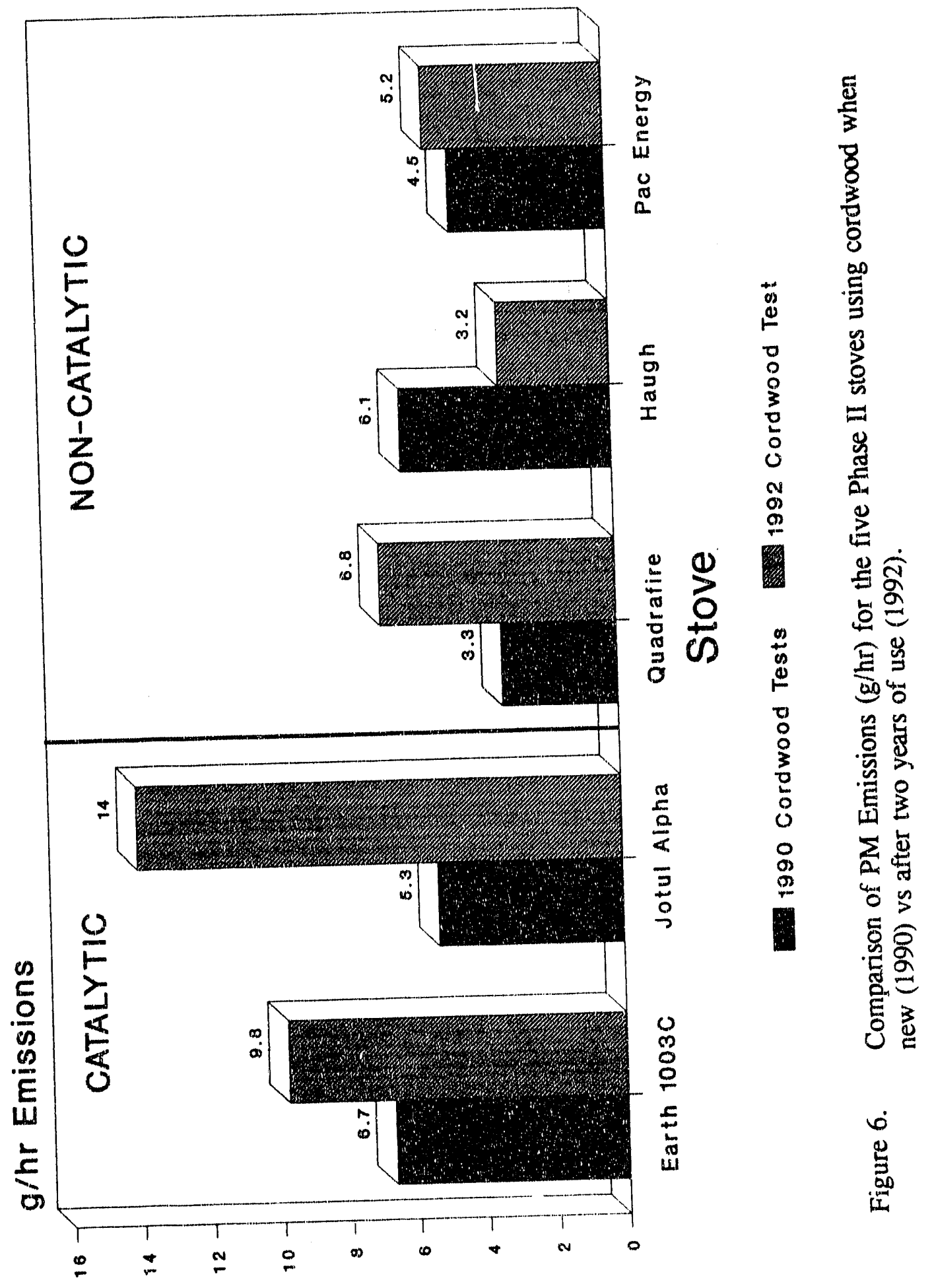


The four conventional stoves averaged $45 \mathrm{~g} / \mathrm{hr}$ using cordwood. ${ }^{4}$ Using Pres-to-Logs in conventional stoves, the emissions averaged $21 \mathrm{~g} / \mathrm{hr}$, for an average reduction of $55 \%$. The average PM emissions for the Eco-Logs in conventional stoves were $32 \mathrm{~g} / \mathrm{hr}$, representing a $30 \%$ reduction.

The overall average PM emissions for all nine stoves using cordwood were $24 \mathrm{~g} / \mathrm{hr}$. Using Pres-to-Logs, the emissions averaged $: 2 \mathrm{~g} / \mathrm{hr}$ for an average reduction of $52 \%$. The Eco-Logs averaged $19 \mathrm{~g} / \mathrm{hr}$ for a reduction of $24 \%$. It is important to note that the decrease in emissions using the densified logs occurred in spite of the fact that the average stove hurn rate during the entire study decreased from 1.39 $\mathrm{kg} / \mathrm{hr}$ during the cordwood test to $1.13 \mathrm{~kg} / \mathrm{hr}$ for the first Pres-to-Logs test, to $1.07 \mathrm{~kg} / \mathrm{hr}$ for the Eco-Log test, to $0.93 \mathrm{~kg} / \mathrm{hr}$ for the second Pres-to-Log test. Seven of the nine stoves are noncatalytic stoves and it is well known that with noncatalytic stoves, PM emissions generally increase as the burn rate decreases, making these results even more significant. Even the second Pres-to-Log test, which was at the lowest burn rate of all four test runs, had emissions that were $53 \%$ lower than the cordwood baseline values (Table 8). The implication of this is that these logs may have a wider envelope of clean-burning performance than that of cordwood, suggesting that the use of Pres-to-Logs in the fall and spring in relatively warm climates would be as effective in reducing PM emissions as their use in colder climates typical of Klamath Falis in January. A similar observation of a lack of sensitivity of PM emissions to burn rate using densified fuels was noted by Hayden and Braaten (1991).

Table 8. Burn Rate (dry $\mathrm{kg} / \mathrm{hr}$ ) for the Conventional and Phase II Stoves Using Cordwood and Densitied Fuels"

\begin{tabular}{|l|c|c|c|c|c|}
\hline \multicolumn{1}{|c|}{ Stove Type } & Cordwood & Pres-to-Logs 1 & Pres-to-Logs 2 & Pres-to-Logs Ave. & Eco-Logs \\
\hline Phase II & $1.33(5)$ & $1.19(5)$ & $0.91(5)$ & $1.05(5)$ & $1.06(5)$ \\
\hline Conventional & $1.48(4)$ & $1.05(4)$ & $0.95(4)$ & $1.00(4)$ & $1.09(4)$ \\
\hline Overall & $1.39(9)$ & $1.13(9)$ & $0.93(9)$ & $1.03(9)$ & $1.07(9)$ \\
\hline
\end{tabular}

a. All numbers in parentheses are the samiple sire.

4. Between this study and the 1990 study (Dernbach, 1990) seven conventional stoves have been evaluated for emissions in Klamath Falls. The seven-stove average for PM is $44 \mathrm{~g} / \mathrm{hr}$, which is about twice the EPA's AP-42 value. The higher, regional, conventional stove average in Klamath Falls reflects the regional sales pattern of conventional stoves. It appears that large stoves of the Earth 101 type may have dominated the Klamath Falls market (five of the seven conventional stoves studied were Earth 101s). 
In summary, the use of Pres-to-Logs reduced PM emissions by 52\%, while the Eco-Logs only reduced emissions by $24 \%$. The overall Pres-to-Log reduction was similar for both Phase II and conventional stoves and is as great at low burn rates as at higher burn rates. It should be noted that emissions reduction took place for all nine stoves when Pres-to-Logs were used.

\section{CO Emissions}

CO emissions did not decrease as markedly from the use of densified fuels as PM emissions did (Tables 9 and 10, Figure 4). For a stove-by-stove comparison, see Figure 7. The average Phase II stove emissions were $70 \mathrm{~g} / \mathrm{hr}$ using cordwood, $56 \mathrm{~g} / \mathrm{hr}$ using Pres-to-Logs, and $71 \mathrm{~g} / \mathrm{hr}$ using Eco-Logs. The densified $\log \mathrm{CO}$ emission values represent reductions from the cordwood baseline of $19 \%$ and $2.4 \%$ for the Pres-to-Logs and Eco-Logs, respectively.

Table 9. Average CO Emissions (g/hr) from the Conventional and Phase II Stoves Using Cordwood and Densified Fuels ${ }^{\mathrm{a}}$

\begin{tabular}{|l|r|r|r|r|r|}
\hline Stove Type & Cordwood & Pres-to-Logs 1 & Pres-to-Logs 2 & Pres-to-Logs Ave. & Eco-Logs \\
\hline Phase II & $69.8(4)$ & $49.5(4)$ & $63.1(4)$ & $56.3(4)$ & $71.5(3)$ \\
\hline Conventional & $202.5(3)$ & $145.4(3)$ & $135.9(3)$ & $140.6(3)$ & $142.9(3)$ \\
\hline Overall & $126.7(7)$ & $90.6(7)$ & $94.3(7)$ & $92.4(5)$ & $109.2(6)$ \\
\hline
\end{tabular}

a. Numbers in parentheses are the sample size.

Table 10. Average Percent Reduction in CO Emissions Using Densified Fuels vs. Cordwood in the Conventional and Phase Il Stoves ${ }^{\mathrm{a}}$

\begin{tabular}{|l|c|c|c|c|}
\hline \multicolumn{1}{|c|}{ Stove Type } & Pres-to-Logs 1 & Pres-to-Logs 2 & Pres-to-Logs Ave. & Eco-Logs \\
\hline Phase II & $29.1(4)$ & $9.6(4)$ & $19.5(4)$ & $2.4(3)$ \\
\hline Conventional $^{\prime}$ & $28.2(3)$ & $32.9(3)$ & $30.6(3)$ & $29.4(3)$ \\
\hline Overall $^{\mathrm{b}}$ & $28.5(7)$ & $25.6(7)$ & $27.0(7)$ & $22.3(6)$ \\
\hline
\end{tabular}

a. Numbers in parentheses are the sample size.

b. The overall average percent reduction was found by calculating the percent reduction of the total emissions of all nine homes combined. 
For the conventional stoves, the average CO emissions using cordwood were $203 \mathrm{~g} / \mathrm{hr}$. The CO emissions for conventional stoves using Pres-to-Logs was $141 \mathrm{~g} / \mathrm{hr}$. This represents a $31 \%$ reduction. The Eco-Logs averaged $143 \mathrm{~g} / \mathrm{hr}$ for conventional stoves, for a $29 \%$ reduction.

The overall average $\mathrm{CO}$ emissions for all nine stoves were $127 \mathrm{~g} / \mathrm{hr}$ using cordwood. Using the Pres-toLogs, the overall average was $93 \mathrm{~g} / \mathrm{hr}$, for a $27 \%$ reduction. The average overall emissions with the EcoLogs were $107 \mathrm{~g} / \mathrm{hr}$, for an $22 \%$ reduction. In this case, the Pres-to-Logs appear to have performed only slightly better than the Eco-Logs.

In summary, $\mathrm{CO}$ emissions were only reduced about half as much as PM emissions from use of Pres-toLogs. Pres-to-Logs did not significantly outperform the Eco-Logs.

\section{Total VOC Emissions}

The reduction in total VOC emissions was somewhere between that of the PM and the CO emissions (Tables 11 and 12 and Figure 4). For a stove-by-stove comparison, see Figure 8. The average total VOC emissions for the Phase II stoves using cordwood were $18 \mathrm{~g} / \mathrm{hr}$. The average Pres-to-Log emissions for the Phase II stoves were $9.7 \mathrm{~g} / \mathrm{hr}$, representing a $46 \%$ reduction. Average total VOC emissions for the Eco-Logs were $3.6 \mathrm{~g} / \mathrm{hr}$ for Phase II stoves, representing a $79 \%$ reduction.

Table 11. Average Total VOC Emissions ( $/ \mathrm{hr}$ ) from the Conventional and Phase II Stoves Using Cordwood and Densified Fuels ${ }^{\mathrm{a}}$

\begin{tabular}{|l|r|r|r|r|r|}
\hline \multicolumn{1}{|c|}{ Stove Type } & Cordwood & Pres-to-Logs 1 & Pres-to-Logs 2 & Pres-to-Logs Ave. & Eco-Logs \\
\hline Phase II & $17.9(4)$ & $9.9(4)$ & $9.6(4)$ & $9.7(4)$ & $3.6(2)$ \\
\hline Conventional & $24.8(3)$ & $20.0(3)$ & $13.9(3)$ & $16.9(3)$ & $22.2(2)$ \\
\hline Overall & $20.8(7)$ & $14.2(7)$ & $11.4(7)$ & $12.8(7)$ & $12.9(4)$ \\
\hline
\end{tabular}

a. Numbers in parenthesis are the sample size. 


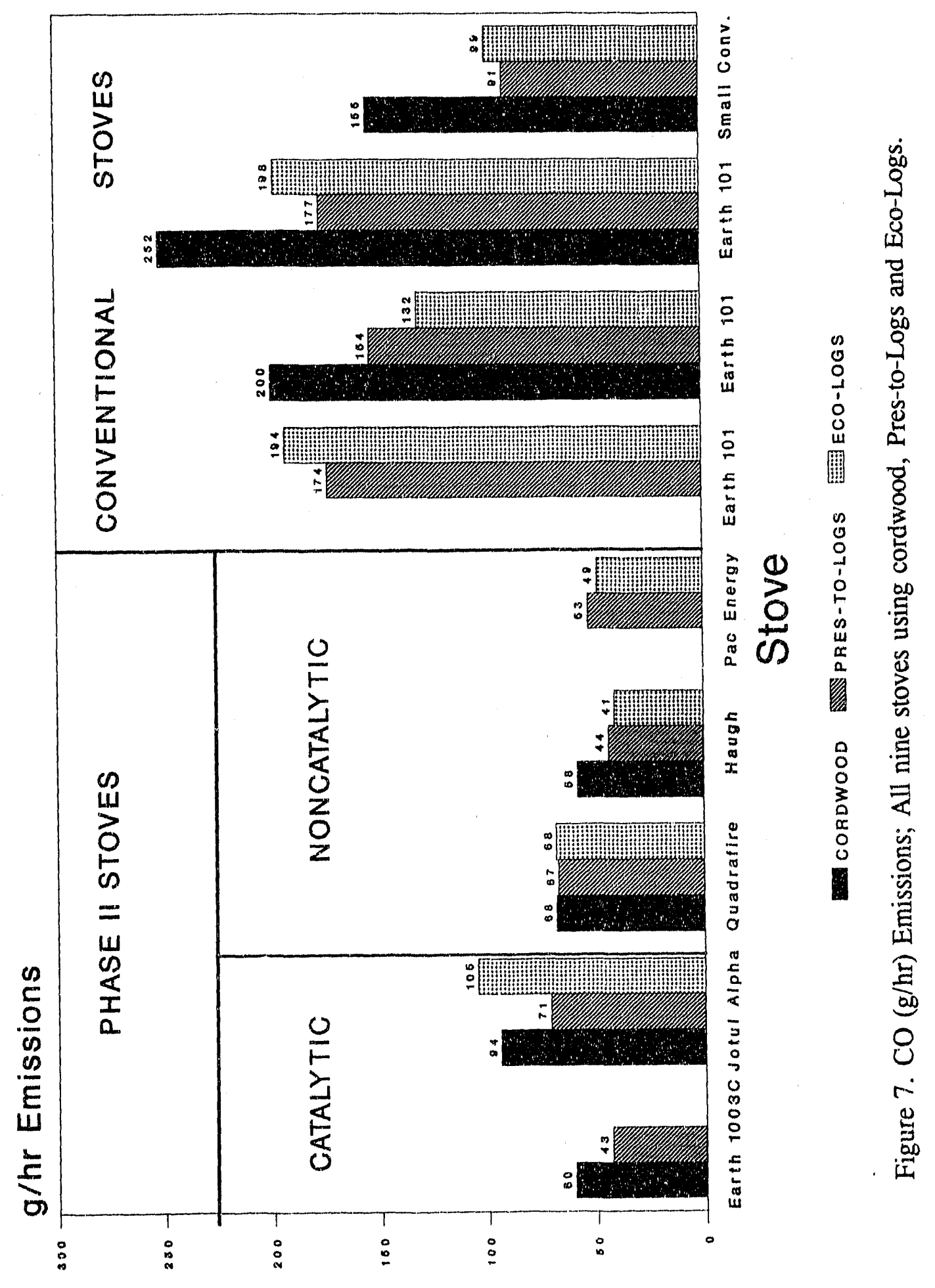




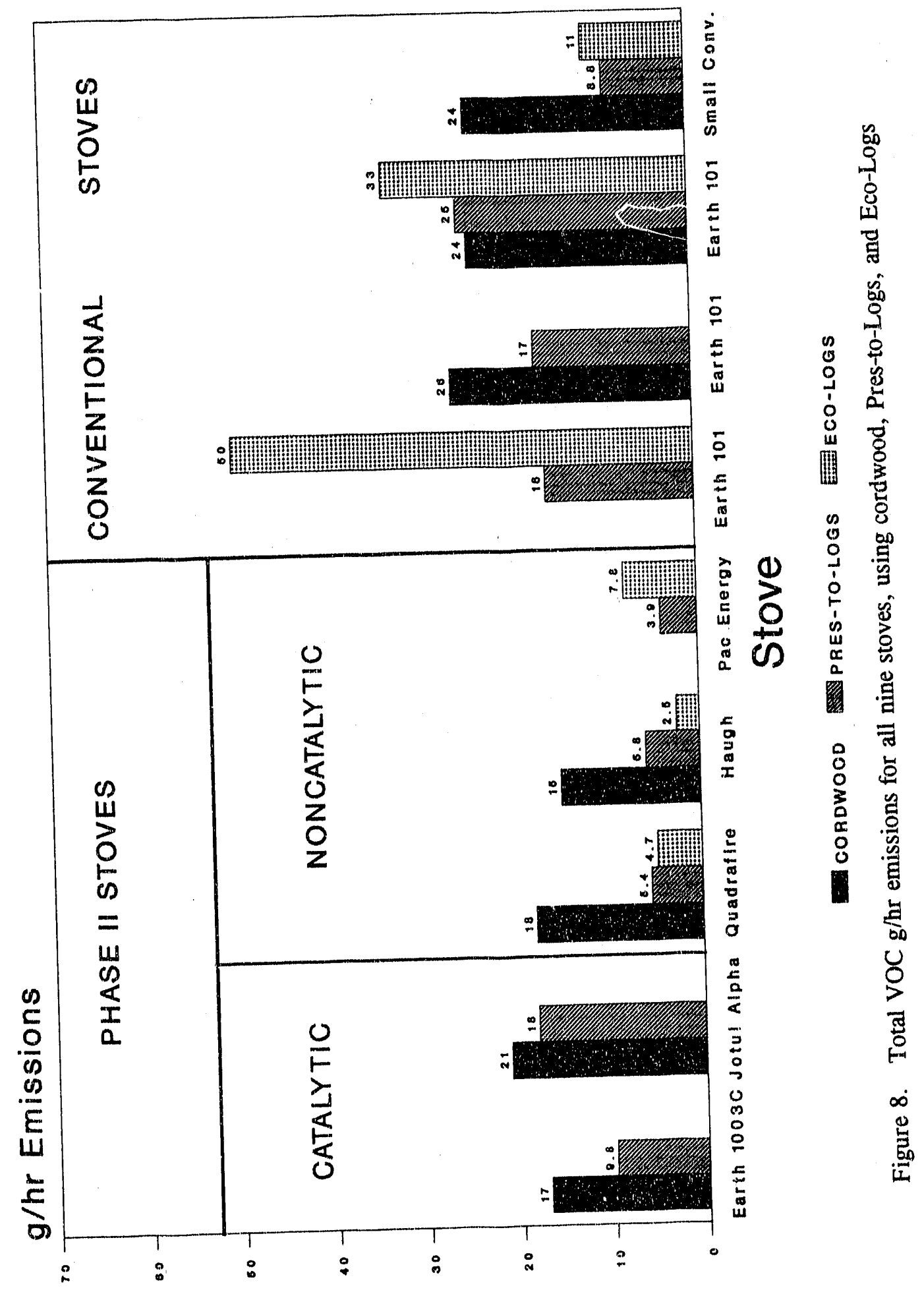


Table 12. Average Percent Reduction of total VOC $\mathrm{g} / \mathrm{hr}$ Emissions Using Densified Fuels vs. Cordwood in the Conventional and Phase II Stoves ${ }^{a}$

\begin{tabular}{|l|c|c|c|c|}
\hline \multicolumn{1}{|c|}{ Stove Type } & Pres-to-Logs 1 & Pres-to-Logs 2 & Pres-to-Logs Ave. & Eco-Logs \\
\hline Phase II & $44.7(4)$ & $46.4(4)$ & $45.5(4)$ & $78.5(2)$ \\
\hline Conventional & $19.4(3)$ & $44.0(3)$ & $31.8(3)$ & $7.7(2)$ \\
\hline Overall $^{\mathrm{b}}$ & $32.1(7)$ & $45.5(7)$ & $38.5(7)$ & $36.6(4)$ \\
\hline
\end{tabular}

a. Numbers in parenthesis are the sample size.

b. The overall average percent reduction was found by calculating the percent reduction of the total emissions of all nine homes combined.

Total VOC from the conventional stoves averaged $25 \mathrm{~g} / \mathrm{hr}$ using cordwood. The Pres-to-Log average for conventional stoves was $17 \mathrm{~g} / \mathrm{hr}$, for a reduction of $32 \%$. The average for conventional stoves using Eco-Logs was $22 \mathrm{~g} / \mathrm{hr}$, for a reduction of $7.7 \%$.

The overall average for all nine stoves for total VOC was $21 \mathrm{~g} / \mathrm{hr}$ using cordwood. The Pres-to-Logs averaged $13 \mathrm{~g} / \mathrm{hr}$, for a reduction of $39 \%$. The Eco-Logs averaged $13 \mathrm{~g} / \mathrm{hr}$, for a reduction of $37 \%$.

It should be noted that since some VOC samples were lost in processing, the sample sizes for VOCs, particularly for the Eco-Logs, are very small.

In summary, total VOC emissions were reduced by approximately about the same amount (37-39\%) by the use of both densified $\log$ brands. See Tables 2 through 4 for methane emission values.

\section{Net Energy Efficiency}

Average net energy efficiencies showed no statistically significant difference when cordwood, Pres-toLogs, or Eco-Logs were used (Table 13). The overall average for the nine stoves using cordwood was $61 \%$. Using the Pres-to-Logs, the average was $64 \%$, and when the Eco-Logs were used, the average was $62 \%$. 
Table 13. Net Efficiency Using Stack Exit Temperature for Conventional and Phase II Stoves Using Cordwood and Densified Fuels ${ }^{\mathfrak{a}}$

\begin{tabular}{|l|r|r|r|r|r|}
\hline \multicolumn{1}{|c|}{ Stove Type } & Cordwood & Pres-to-Logs 1 & Pres-to-Logs 2 & Pres-to-Logs Ave. & Eco-Logs \\
\hline Phase II & $66.8(5)$ & $69.8(5)$ & $66.6(5)$ & $68.2(5)$ & $66.8(5)$ \\
\hline Conventional & $54.7(4)$ & $59.9(4)$ & $56.9(4)$ & $58.4(4)$ & $56.7(4)$ \\
\hline Overall & $61.4(9)$ & $65.4(9)$ & $62.3(9)$ & $63.8(9)$ & $62.3(9)$ \\
\hline
\end{tabular}

a. All numbers in parentheses are the sample size.

It does not necessarily follow that if the combustion efticiency is improved-as it is slightly from the use of densified fuels (Tables 1-3)-that the overall efficiency will follow suit. Overall or net efficiency equals combustion efficiency multiplied by heat transfer efficiency. There are therefore a number of variables to consider. Generally with woodstoves, the most highly variable aspect of overall efficiency is the heat transfer efficiency. Heat transfer efficiency is a function of the exit stack temperature and the dilution factor, which is a function of excess air. Small changes in either of these factors can have a significant effect on the heat transfer and hence the overall efficiency. Another potentially significant factor is that the burn rate decreased throughout the project. This could affect both combustion and heat transfer efficiency. It turned out for the densified fuels that combustion efficiency increased slightly with their use, net efficiency increased about the same amount, and heat transfer efficiency was essentially unaffected.

\section{Comparison of Stove Operating Costs Using Cordwood vs. Densified Logs}

An important criterion in the acceptance of a product is its cost-effectiveness of operation. In this section, the cost of operating woodstoves with cordwood versus the two densified fuels is analyzed. Both densified log brands are considered together, hecause their net energy efficiencies and cost are almost the same.

The most common way to refer to the operating cost of a heating device is the cost per delivered million BTUs of energy. In an analysis using wood, several variables have to be taken into consideration. "The first is the cost of the unit of energy that is purchased. For cordwood, it is the cost per cord and for the densified logs it is the cost per pallet or ton. The next factor to consider is the weight of wood fiber 
contained in the purchased unit. Other variables in the analysis include the energy per pound of fuel, moisture of the fuel, and the efficiency of the appliance in burning the fuel. The values used for this analysis include the cost for a 1,900 lb pallet of densified logs at $\$ 150$ dollars; the cost of lodgepole pine in the Klamath Falls area at $\$ 70$ per cord; the cost of Douglas fir in the Willamette Valley at $\$ 135$ per cord and the cost for oak in the Willamette Valley at $\$ 175$ per cord. An energy content of 8600 BTU per pound for all the wood products is used. The moisture content of the cordwood is assumed to be $20 \%$ whereas for the densified logs, it is $8 \%$. The overal diciency of the nine stoves is $61 \%$ when using cordwood and $63 \%$ when using densified logs. This analysis uses the stove population ratio in this project of five Phase II stoves to four conventional stoves. This is probably not the case in the real world currently, so efficiency is probably slightly overstated in this analysis.

The results of the analysis indicate that the cost of operating a woodstove using the densified fuels is approximately $\$ 14.50$ per delivered million BTUs. This compares to a cost of about $\$ 7$ using lodgepole pine cordwood in Klamath Falls. Thus, using the densified logs is about 2.2 times as expensive. The situation in the Willamette Valley is different, however, because cordwood costs are higher. The cost per delivered million BTUs of using Douglas fir is about $\$ 10.50$ and for oak, it is about $\$: 0$. This means that the operating cost of using densified logs is only about 1.4 times as expensive in the Willamette Valley. The point at which the cost of operating stoves using densified logs is the same as using cordwood (the break-even point) is about $\$ 185$ per cord for Douglas fir and $\$ 2,50$ per cord for oak. These prices are not common in Oregon, but in other parts of the country, such as urban California, these prices for cordwood are common. In those areas, it is therefore relatively economical to operate woodstoves using densified logs. It is possible that the added convenience of using densified lugs as noted by the project participants (Appendix C) could also affect a homeowner's decision to use them.

The cost of cordwood and, to some extent, densified logs, ${ }^{5}$ varies from region to region in the United States. In most areas, the use of densified logs is not economical compared to the use of cordwood. That is especially true in Klamath Falls where cordwood is very inexpensive. This is unfortunate, because the Klamath Falls area is in serious need of woodsmoke-induced pollution abatement.

5. According to Derald Kuhnhausen of Spokane Pres-to-Log, the retail cost of their logs currently ranges from $\$ 115$ per pallet in Spokane, Washington to $\$ 135-150$ in the Seattle-Portland area, to $\$ 180-185$ in California. 


\section{The Relationship Between PM, CO, and VGCs}

The relationship between $\mathrm{CO}$ and PM has been well documented for a variety of woodburning device types. Grams per kilogram is used in this analysis because it reflects the combustion process better than grams per hour does. Figure 9 shows a compilation of data from a number of studies of noncatalytic and catalytic woodstoves, certified and exempt pellet stoves, and the current project. This relationship is curvilinear when the full range of clean-burning to conventional stoves is included in the plot. The relationship is generally moderately correlated. Its curvilinearity indicates that as appliance design becomes progressively more successful at lowering PM emissions, $\mathrm{CO}$ emissions are reduced at a relatively lower rate until stoves are quite clean (less than about $10 \mathrm{~g} / \mathrm{kg}$ ). After that point, the CO decreases rapidly. Figure 10 shows that this same relationship and level of correlation are present in the current study data.

Because VOC have not been analyzed previously from in situ woodstoves, it is not known how representative the current data is. Figure 11 shows the relationship of total VOCs to PM for the nine stoves in this project. The data appear to have about the same level of correlation as does the CO-PM relationship, with the exception of an apparent single outlier of VOC at about $40 \mathrm{~g} / \mathrm{kg}$. The total VOC-PM relationship is also curvilinear, very reminiscent of the CO-PM relationship. These data relationships suggest that if total VOC is plotted versus CO it should produce a linear relationship, and Figure 12 indicates that this is so. The correlation coefficient (R), however, is considerably lower at 0.72 .

\section{Conclusions}

The results of this study indiclate that densified logs have the potential to significantly reduce emissions compared to cordwood. This is particularly true for PM emissions, where the Pres-to-Logs reduced grams per hour emissions by $52 \%$. CO emissions were more modestly reduced by $27 \%$ and total VOC emissions by $39 \%$. A second confirmation test was run using Pres-to-Logs, and the results were nearly the same as the first test. The second test was run at the lowest burn rate of all four tests. Its low emissions indicate that the logs may have a wider envelope of good performance with regard to burn rate than does cordwood. This is important for relatively warm climate nonattainment areas.

OMNI Environmental Services, Inc. (80117-06.007) 


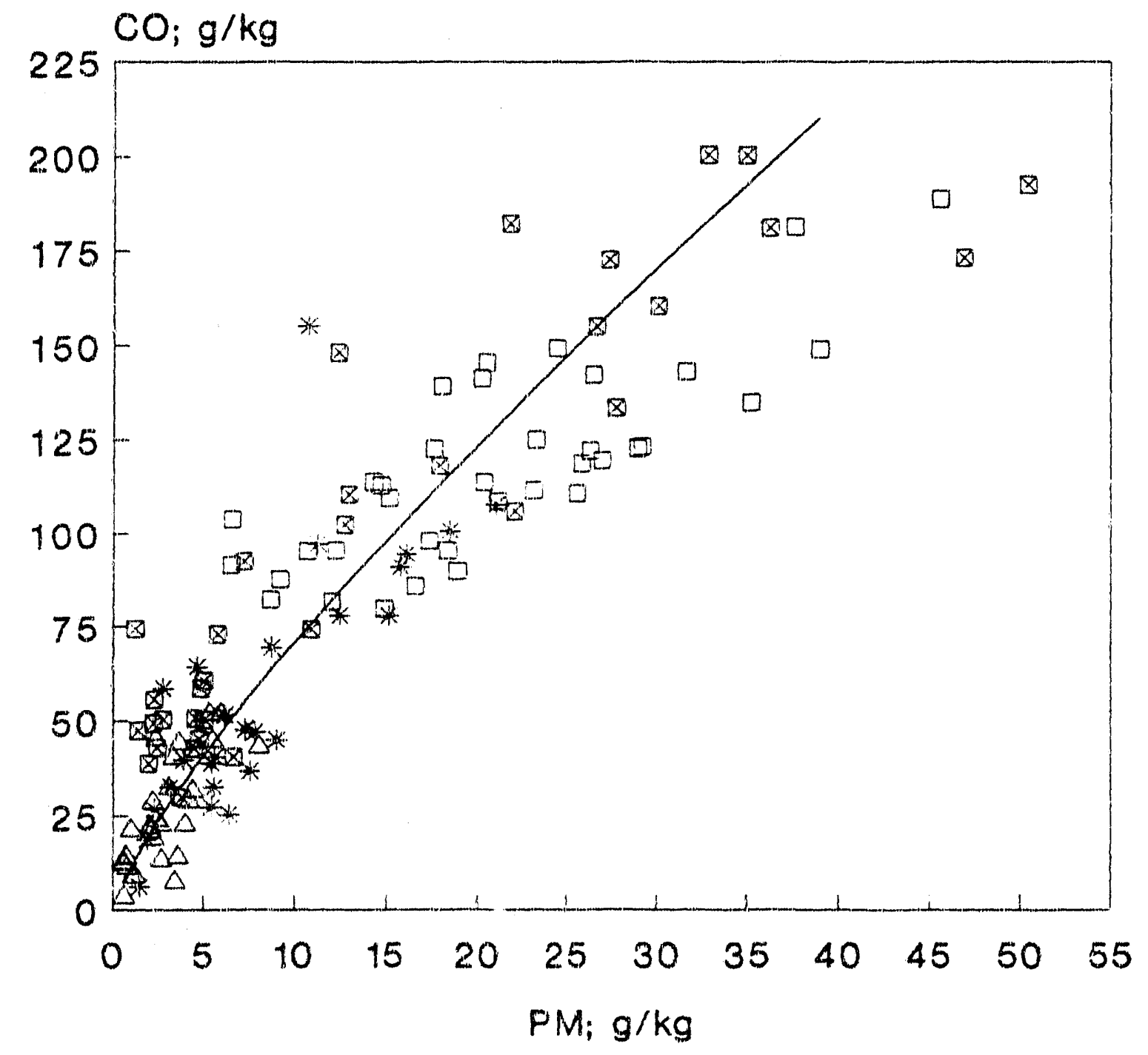

$\triangle$ K. FALLS, '92 $\square$ NONCATALYTIC * CATALYTIC

$\triangle$ PELLET - CALCULATED LINE

$N=138 ; R=0.89 ; Y=11.253 * X \wedge 0.7988$

Figure 9. $\mathrm{CO} \mathrm{g} / \mathrm{hr}$ vs PM from several field projects. 


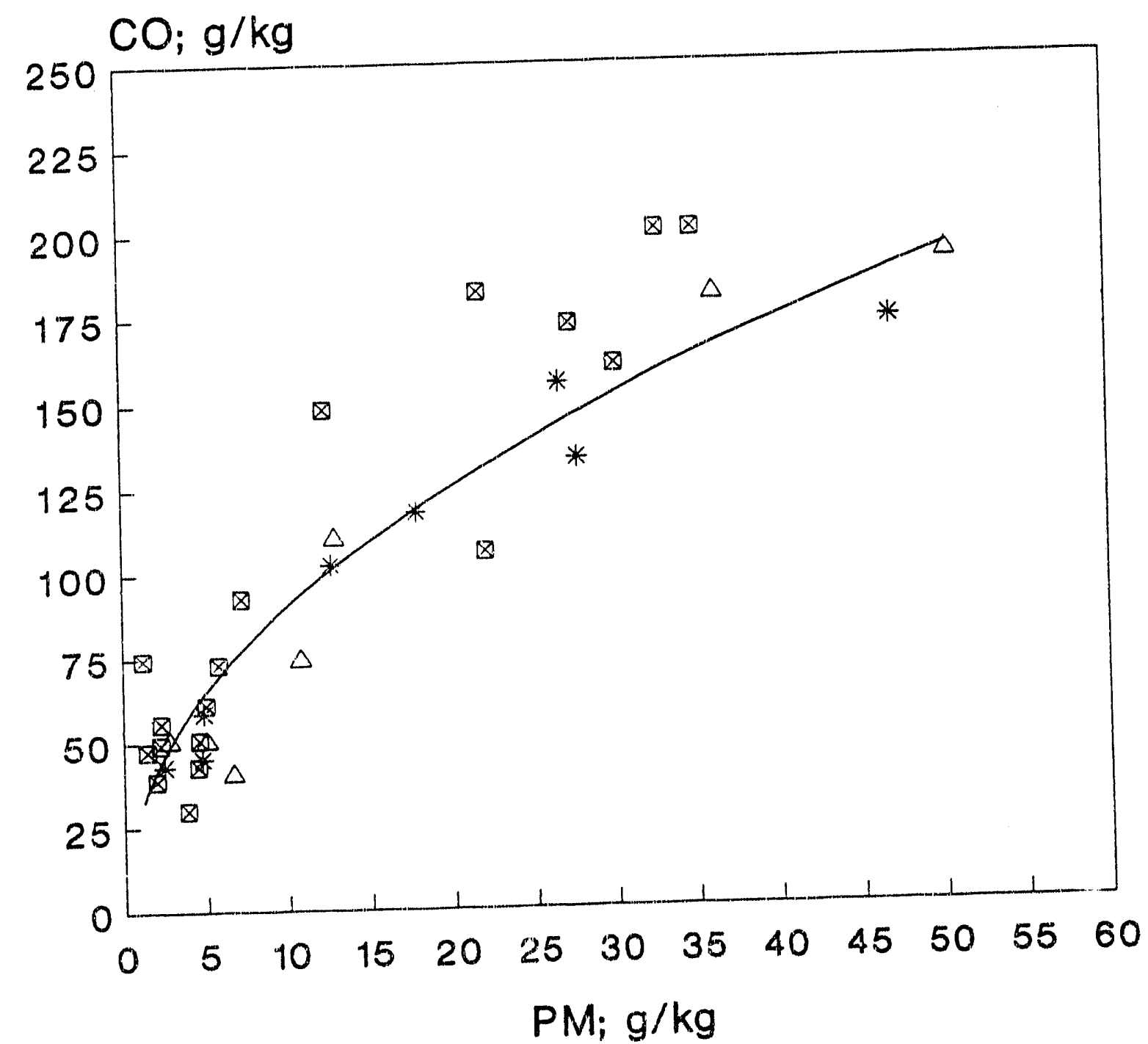

$\triangle$ CORDWOOD

- calculated line

$\otimes$ PRES-TO-LOGS

* ECO-LOGS

$N=33 ; R=0.88 ; Y=30.138 * X^{\wedge} 0.4755$

Figure 10. CO (g/hr) vs PM, All tests Klamath Falls densified fuels project. 


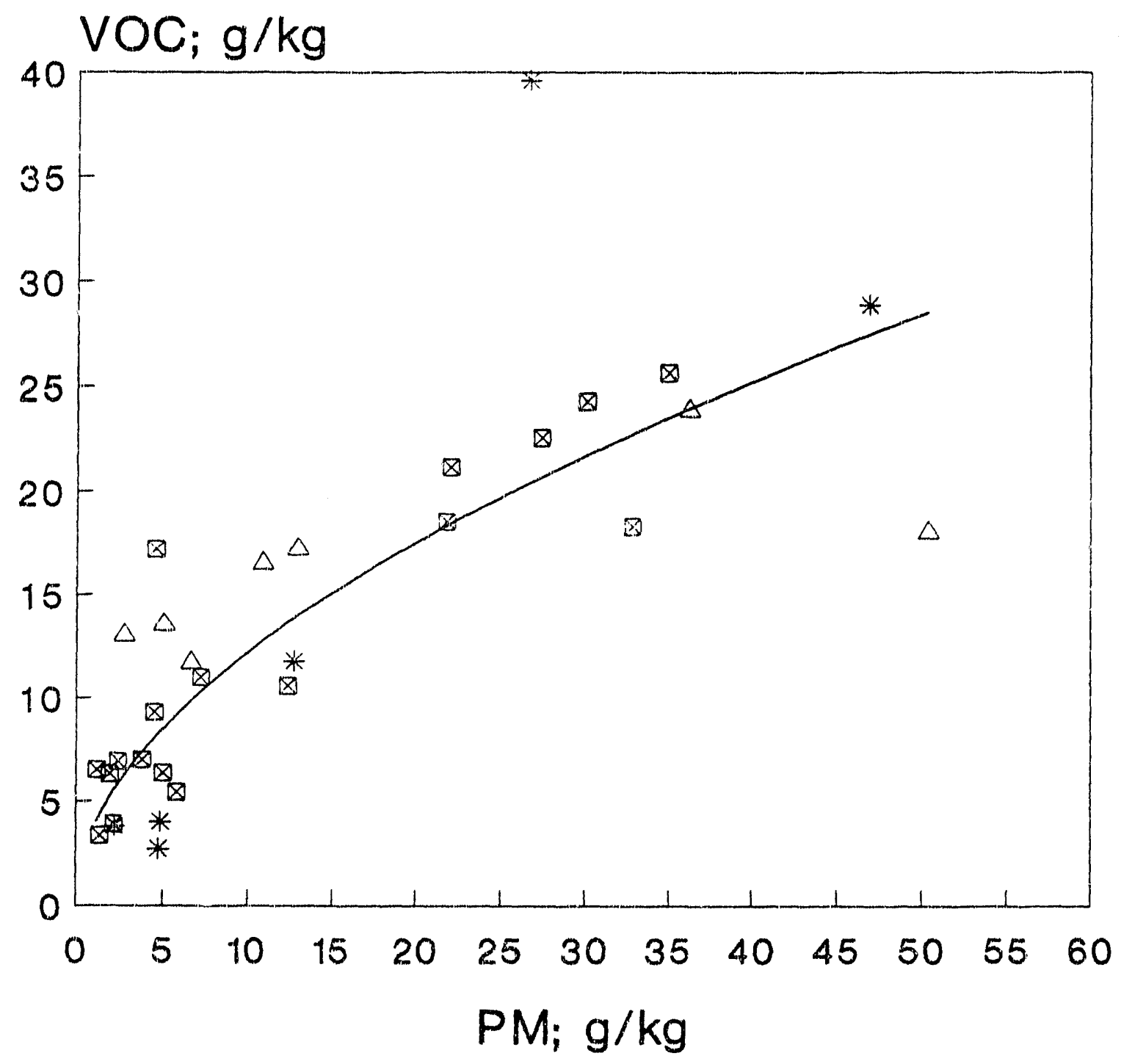

$\triangle$ CORDWOOD CALCULATED LINE * densified fir logs $\otimes$ densified pine logs

$N=31 ; R=0.82 ; Y=3.649 * X \sim 0.5248$

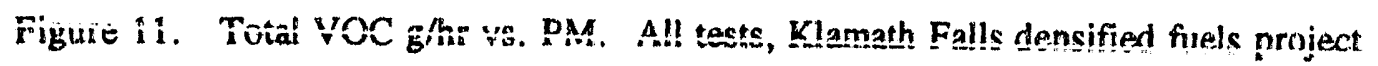




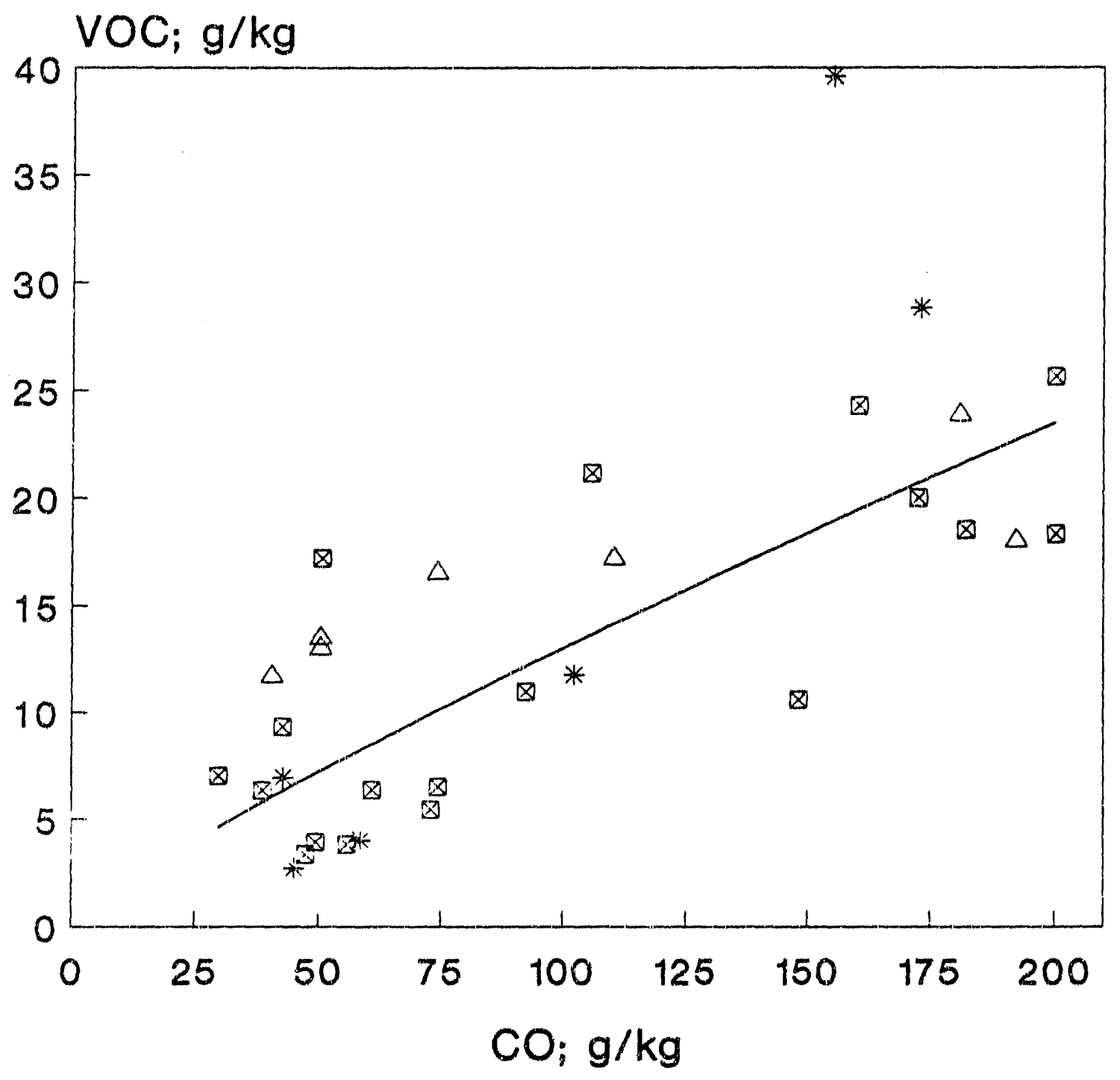

$\triangle$ CORDWOOD - CALCULATED LINE

$\bowtie$ DENSIFIED PINE LOGS * DENSIFIED FIR LOGS

$N=31 ; R=0.72 ; Y=0.257 * X^{\wedge} 0.8522$

Figure 12. Total VOC g/hr vs. CD. All tests, Klamath Falls densified fuels project 
The use of the Eco-Logs did not reduce emissions as much as the Pres-to-Logs, particularly for PM emissions, which were only reduced by $24 \%$. It is not known exactly why the Eco-Logs were not as effective as the Pres-to-Logs. Each log was made on the same machine and they are the same size and density. The only apparent difference is the feedstock. Pres-to-Logs use a mixture of approximately $40 \%$ Ponderosa pine and a $60 \%$ mixture of red fir and larch; Eco-Logs use only Douglas fir.

This information, along with some qualitative results of burning other types of densified logs at OMNI, suggests that emissions may be significantly affected by the type of densified log that is used. It would not be appropriate, given the state of current knowledge, to approve the use of all densified log types as an emissions control strategy at this time without further study.

While densified logs positively affected emissions, the same is not true for energy efficiency. There was no statistically significant difference in net energy efficiency between the use of cordwood, Pres-to-Logs, or Eco-Logs.

The relative cost of using Pres-to-Logs and Eco-Logs rather than cordwood varies greatly from area to area. In Klamath Falls, one of the most heavily woodstove-polluted airsheds in the country, the need for these logs is great. However, because local cordwood is currently available for about $\$ 70$ per cord, densified logs at $\$ 150$ a ton cost 2.2 times as much. In the Willamette Valley, cordwood prices are considerably higher and these densified logs would cost about 1.4 times as much. Only in areas with very high cordwood prices, such as parts of California, are the densified logs currently be cost-effective for stove owners. The cost factors, as well as the fact that the majority of the woodburning in the more heavily polluted airsheds is generally associated with people who use woodstoves as their primary source of heat and who obtain their firewood often by cutting it themselves, suggest that in the areas where densified fuels are most needed, their relative economic feasibility is lowest. However, lumber supply changes appear to be driving cordwood prices up in the Pacific Northwest.

As a result of the relatively high costs of densified fuels, strategies for optimizing emissions should probably involve public education on densified logs' clean-burning attributes and burn-ban regulations that require the use of these logs only during high-pollution episodes. The logs could also be used at the beginning of stagnation periods, before ambient PM emissions have significantly risen, to minimize the rate of increase in ambient emissions and perhaps avoid a high pollution episode. Local jurisdictions 
could consider subsidizing the cost of these logs to further encourage their use. This type of scenario would not require the purchase or use of large quantities of these logs by any one woodburner.

Assistance in establishing a local manufacturing source for densified logs in nonattainment areas could prove beneficial. Shipping costs are a significant component in the total delivered cost. Elimination of shipping costs could result in delivered costs comparable to Pres-to-Logs in Spokane of $\$ 115$ per pallet.

\section{Future Research Needs}

This study investigated logs that are commercially available and use waste biomass. There are other biomass waste feedstock materials for which there may be a more pressing need for conversion into densified logs, due to escalating landfill problems and/or field-burning problems. A good example would be the wheat straw waste produced in many of the western states, grain straw in Oregon, and rice straw in California. Residues of these wastes are currently being field-burned and regulations phasing out this burning exist in several states. The use of this biomass refuse as a densified log product appears to have considerable potential. It is recommended that logs made with combinations of wood and straw waste be investigated under an in-home testing situation following the format of the current project.

The sensitivity of performance logs to composition and other variables such as particle size, degree of compaction, size of the log, and type of manufacturing process used, indicates that further study is needed to optimize the performance of densified fuels. Very likely the best-perform'ng combination, given both the available feedstock in a geographic area and log manufacturing processes, has not yet been identified. A project which systematicaliy changes variables and evaluates them is needed to accomplish this goal.

Another project important for emissions reduction would be to evaluate the effectiveness of Pres-to-Logs in reducing emissions from fireplaces under in-home conditions. Given the findings of the current project and previous laboratory tests, there is a good chance that such a project would yield similar results. This information would be particularly valuable to regulators in those resort areas where fireplace emissions contribute significantly to air pollution. In these resorts, control over the type of wood burned could be tight, and a large-scale switch to densified logs could be readily accomplished. 


\section{References}

Barnett, S. G., 1985, Handbook for Measuring Woodstove Emissions and Efficiency Using the Condar (Oregon Method 41) Sampling System. Condar Company, August 1985.

Barnett, S. G., 1991, Relationship of the AWES to EPA Methods 5H and 5G. Prepared for the U.S. Environmental Protection Agency, December 1991.

Barnett, S. G., 1990, In-Home Evaluation of Emissions Characteristic of EPA-Certified High Technology Noncatalytic Woodstoves in Klamath Falls, Oregon. Prepared for the Centre for Mineral and Energy Technology, Energy Mines and Resources Canada, DSS File No. 14SQ.23440-91-9230, June 1990.

Barnett, S. G. and P. G. Fields, 1991, In-Home Performance of Exempt Pellet Stoves in Medford, Oregon. Prepared for U.S. Department of Energy, Oregon Department of Energy, Tennessee Vailey Authority, and Oregon Department of Environmental Quality, July 1991.

Dernbach, S., 1990, Woodstove Field Performance in Klamath Falls, Oregon. F'repared for the Wood Heating Alliance, April 1990.

Hayden, A. C. S. and R. W. Braaten, 1991, Reduction of Fireplace and Woodstove Pollutant Emissions Through the Use of Manufactured Firelogs. Presented at Air and Waste Management Association's 84th Annual Meeting, June 1991. 91-129.1.

McCrillis, R. C. and D. R. Jaasma, 1991, Comparability between various field and laboratory woodstove emission measurement methods. Presented at the Air and Waste Management Association's 84th Annual Meeting, June 1991. 
Appendix A

Photographs of Stove Installations 


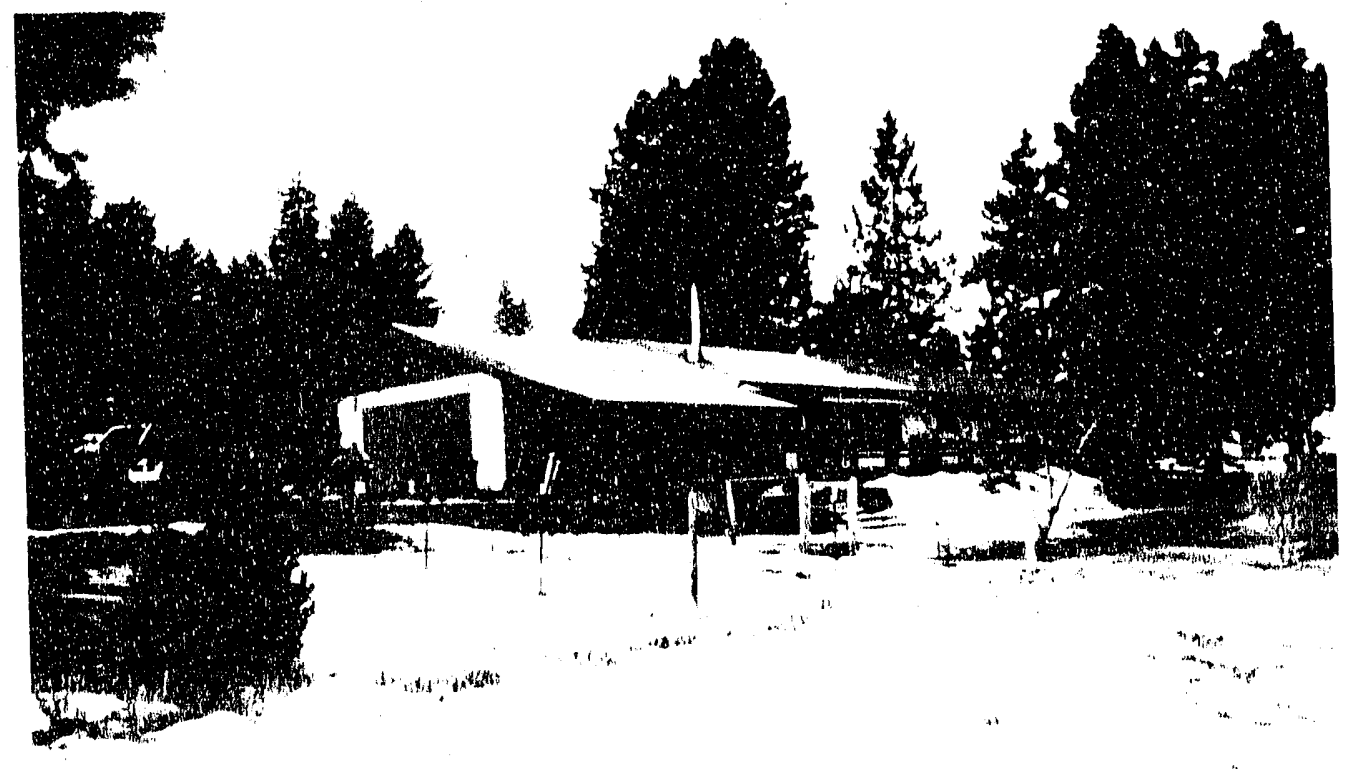

40 (t)

bignes A.1. Exterine view of house Klol.

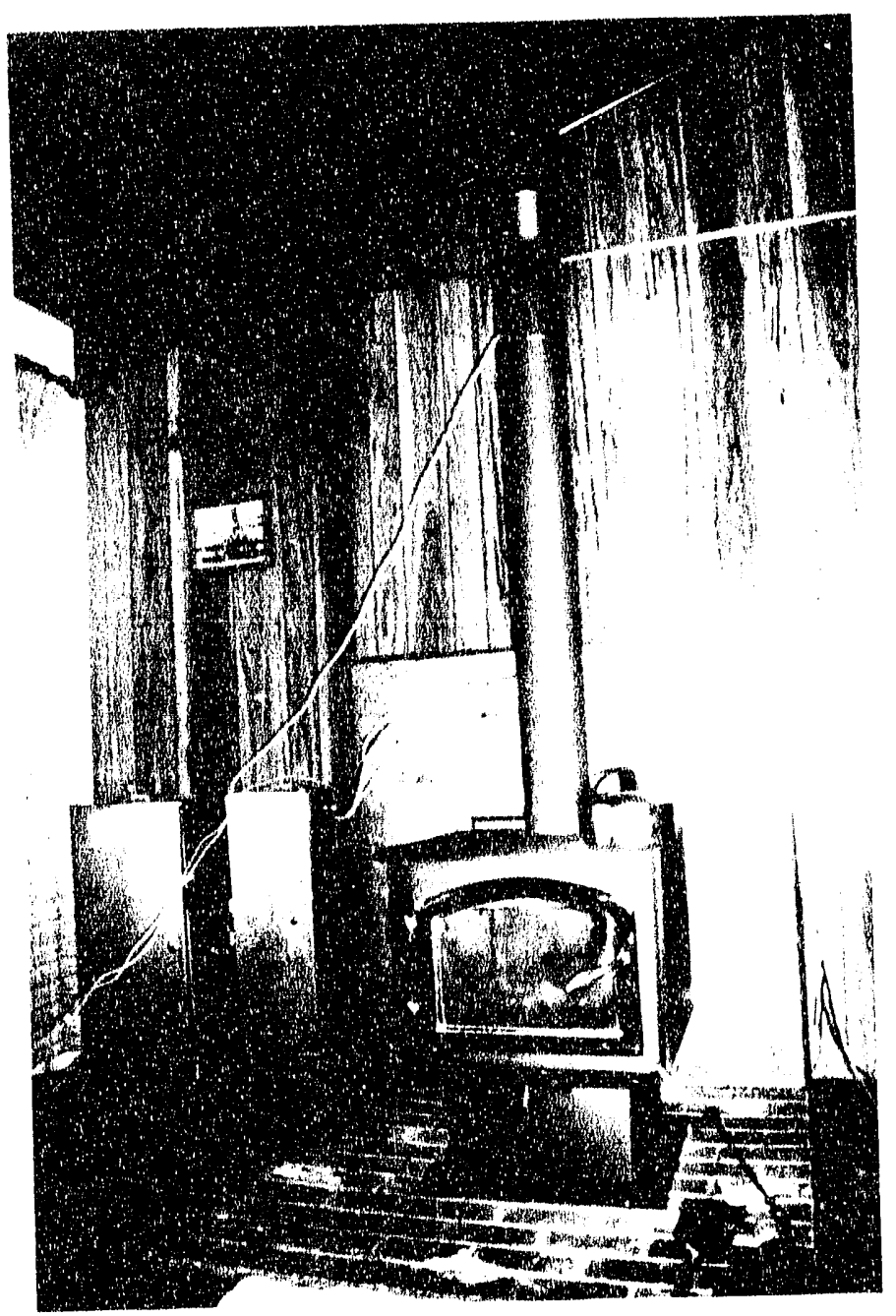

Figure A-2. Installation of Quadrafire 3100 noncatalytic Phase II stove and AWES sampling system. 


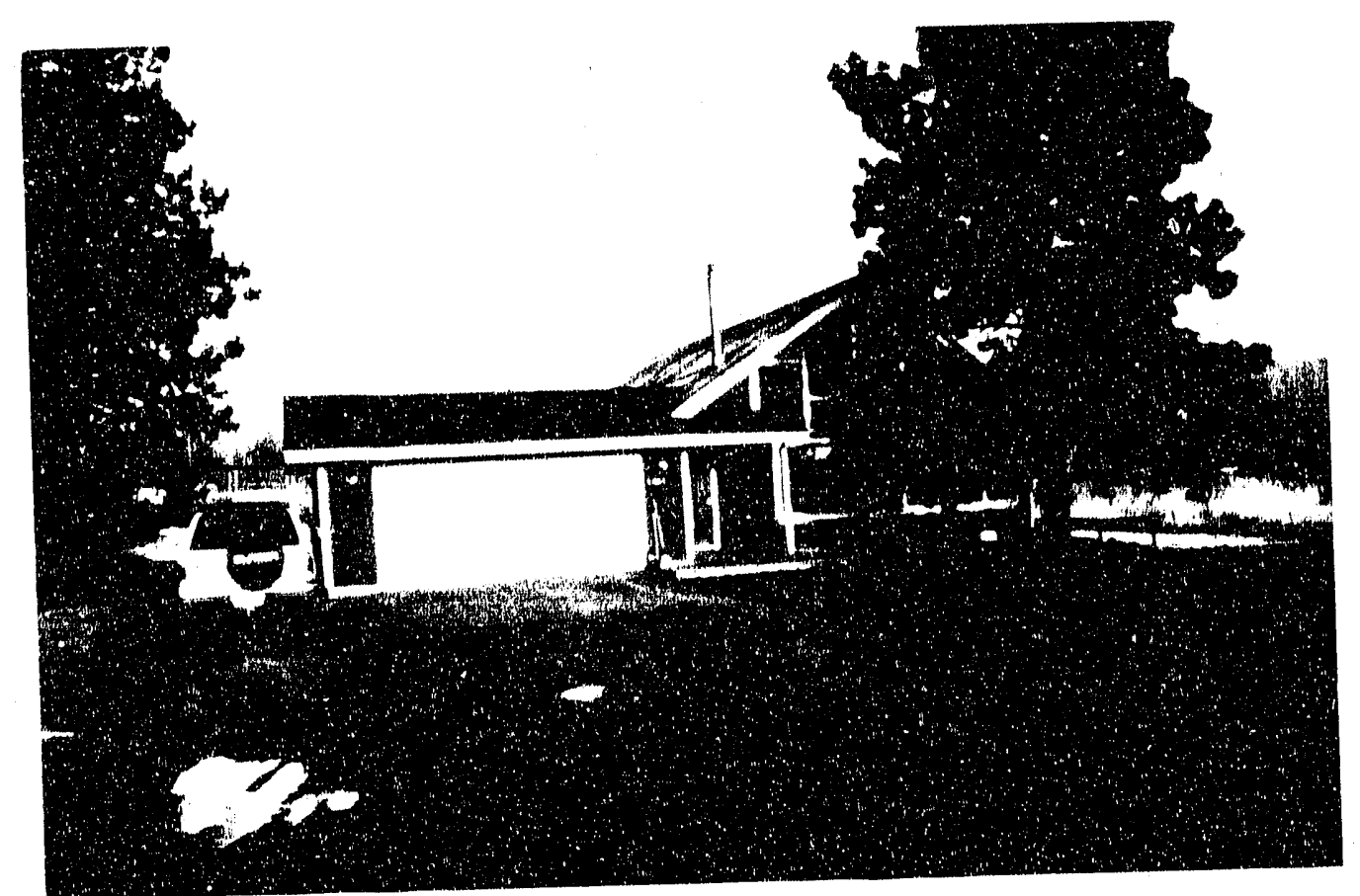

Figure A-3. Exterior view of house KF02.

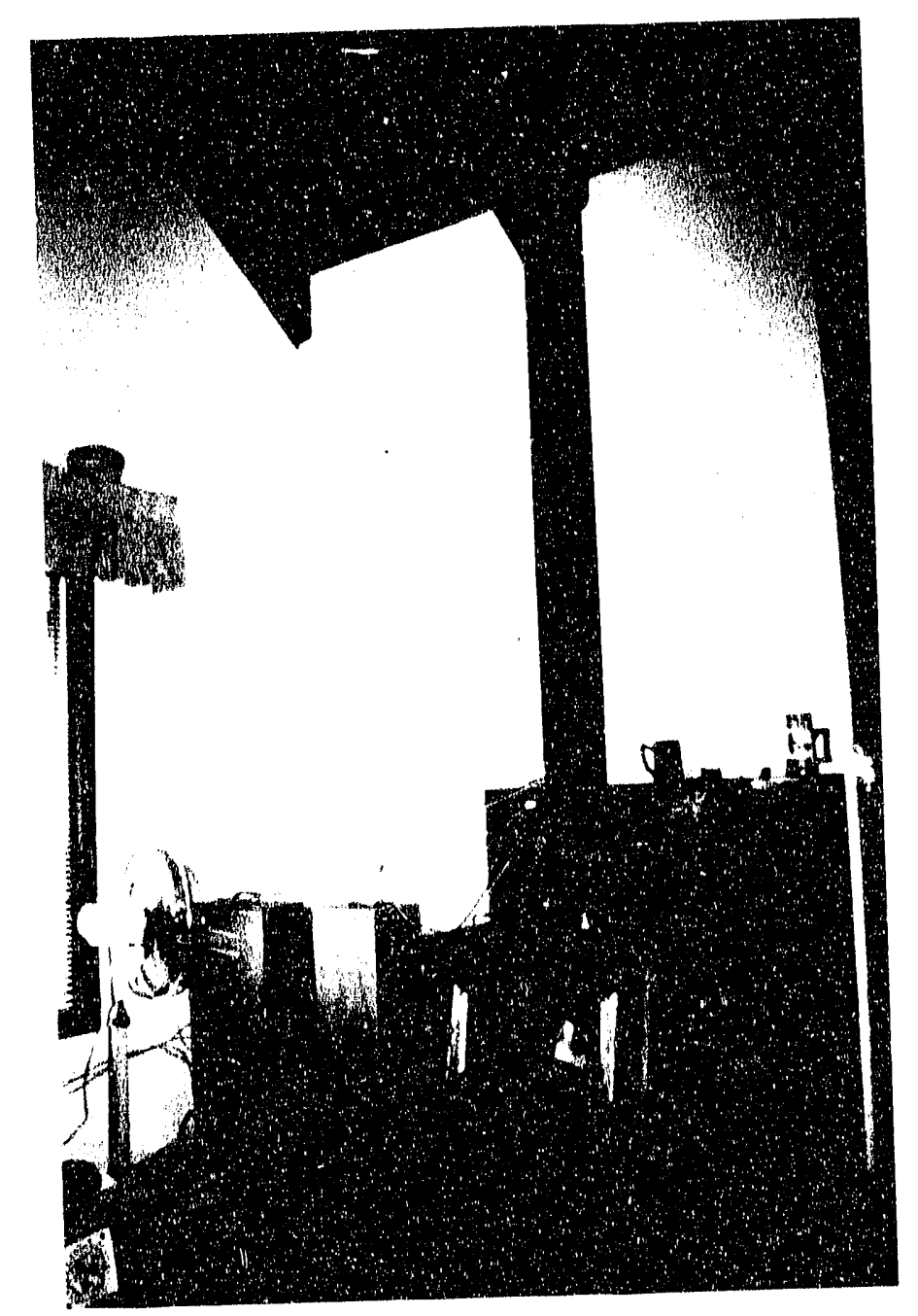

Figure A-4. Installation of Earth Stove $1003 \mathrm{C}$ catalytic Phase II stove and AWES sampling system. 


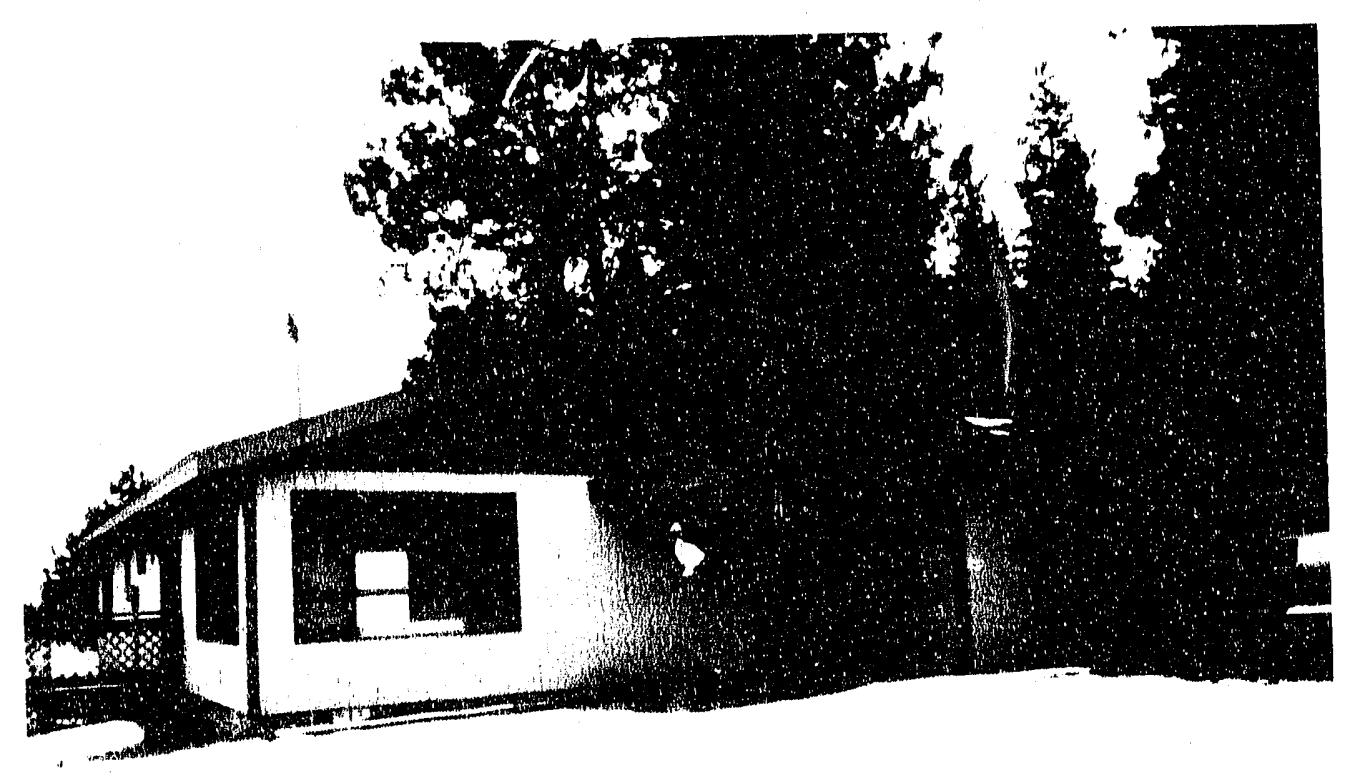

Figure A-5. Exterior view of house KF03.

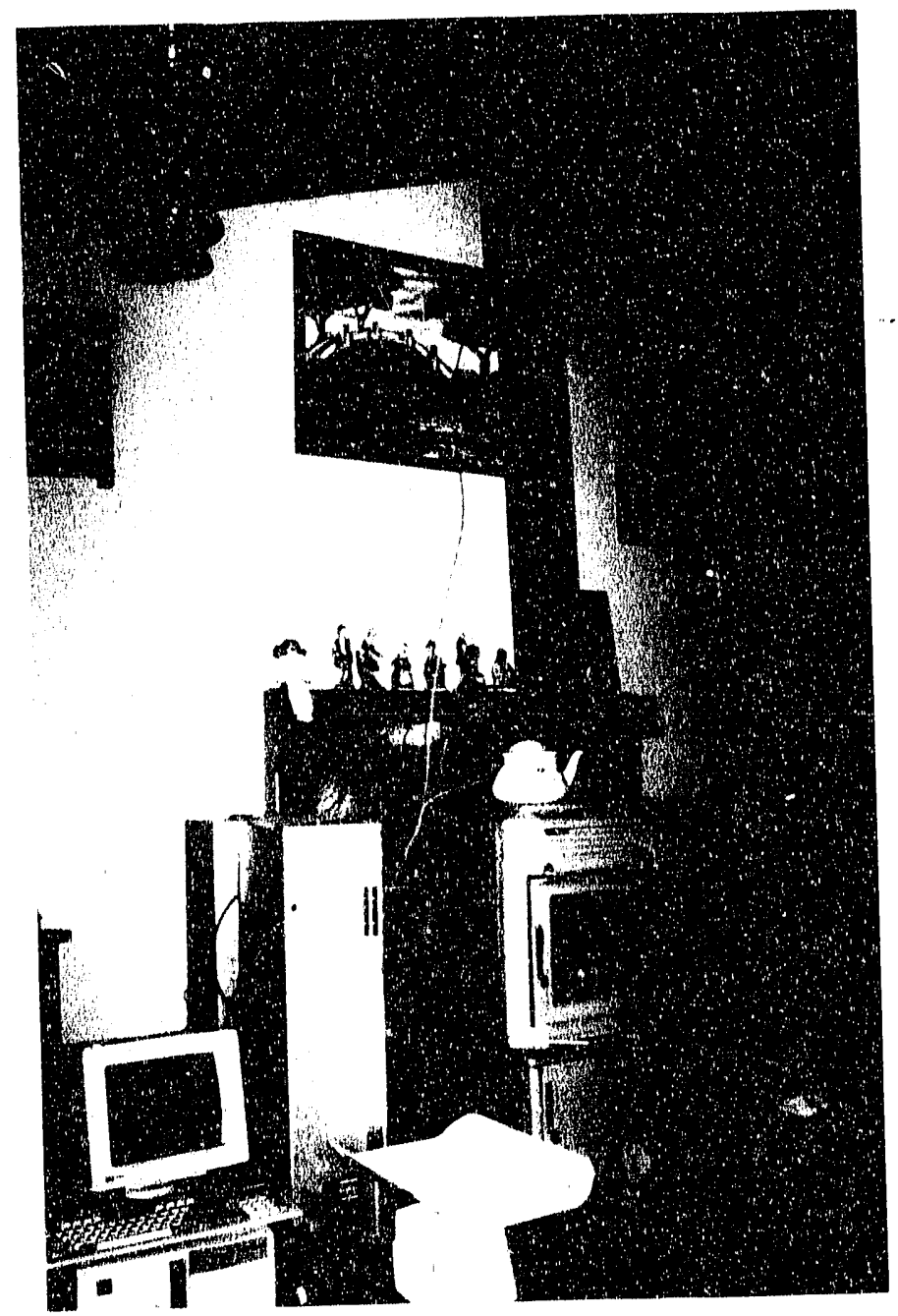

Figure A-6, Installation of Jotul Alpha catalytic Phase II stove and AWES sampling system. 


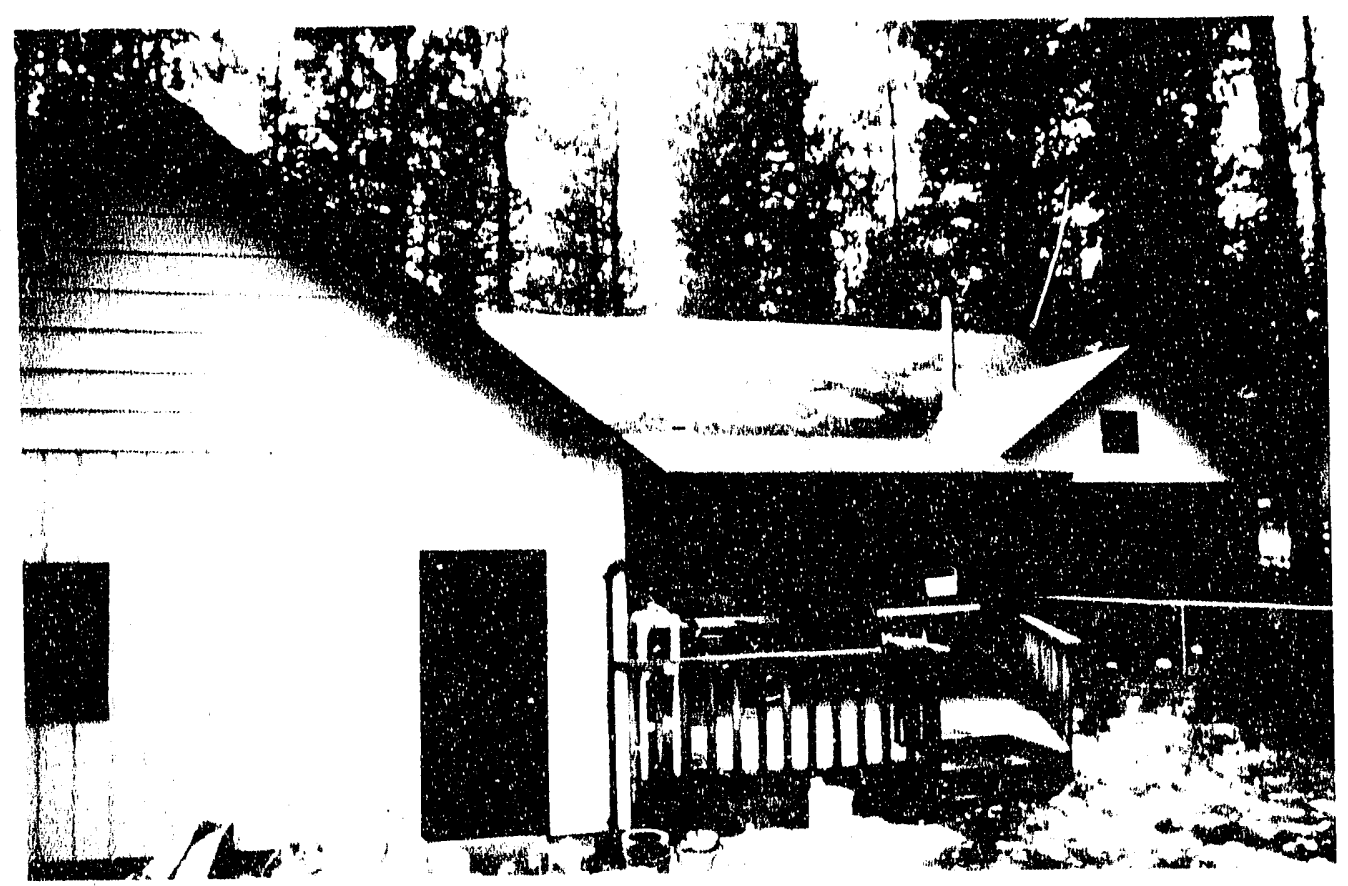

Figure A-7. Exterior view of house KF()4.

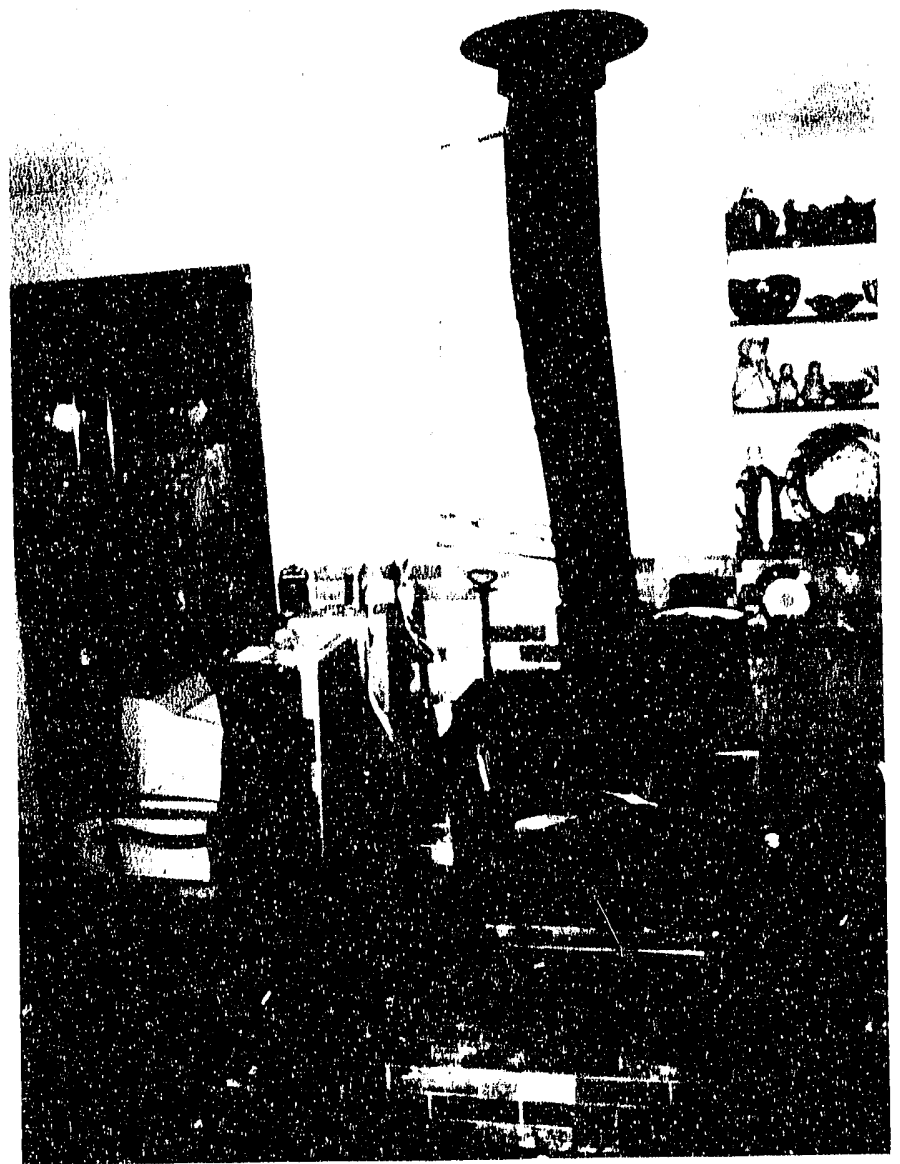

Figure A-8. Installation of Haugh noncatalytic Phase II stove and AWES sampling system. 


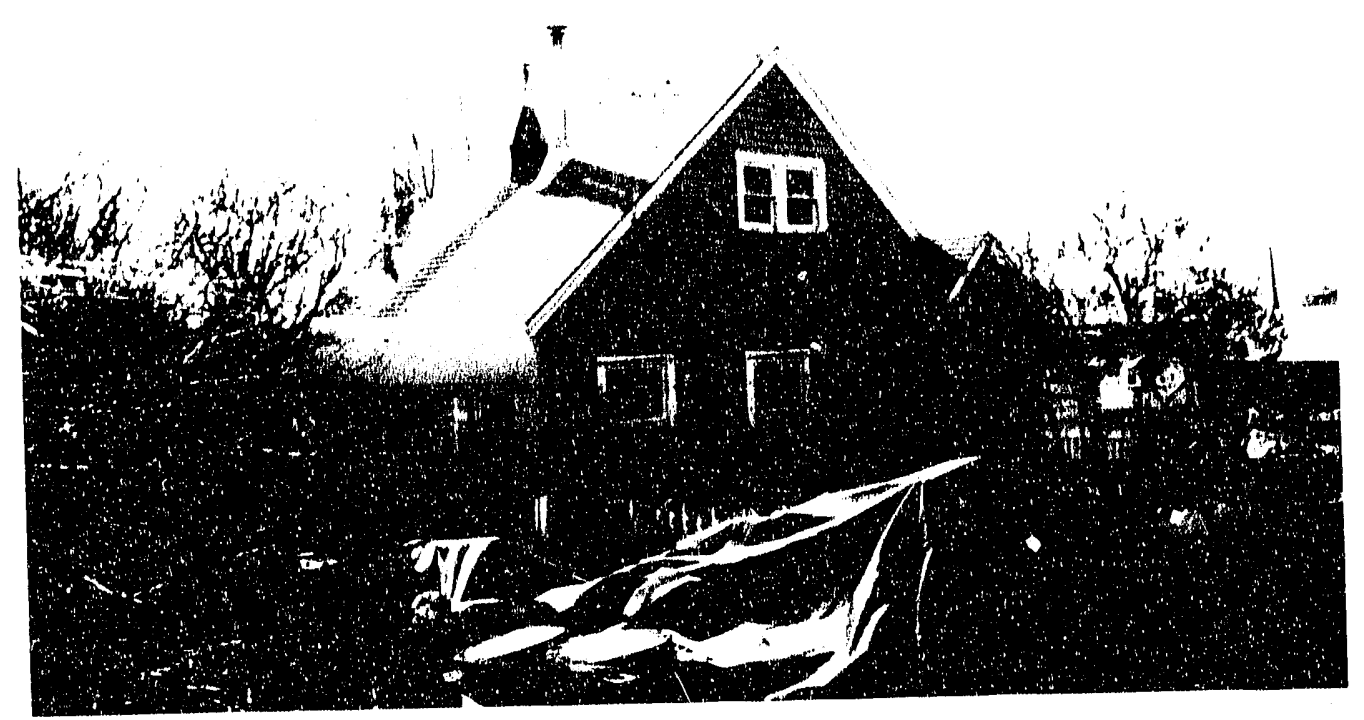

Figure A-9. Exterior view of house KF05.

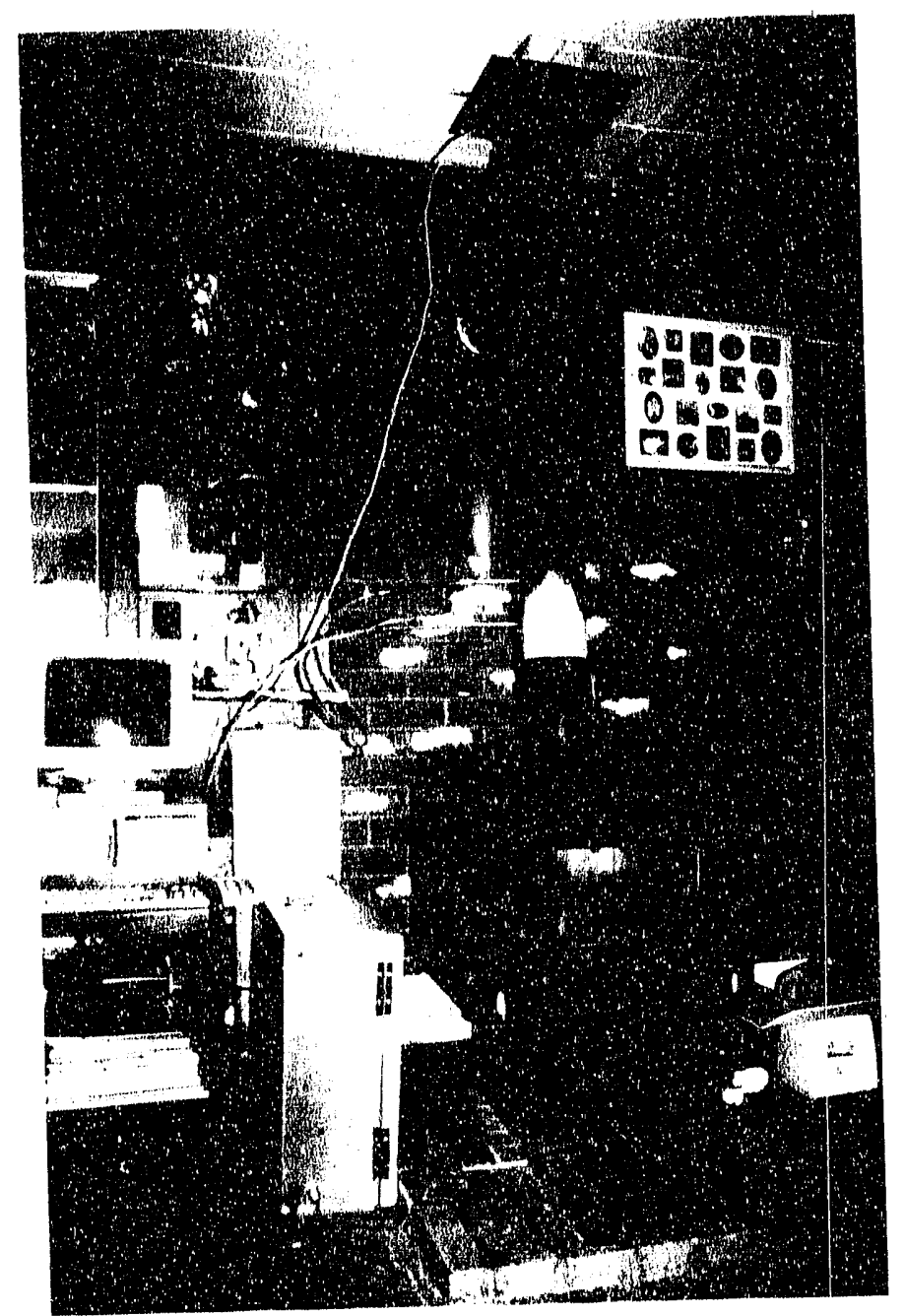

Figure A-10. Installation of Pacific Energy Super Series noncatalytic Phase II stove and AWES sampling system. 


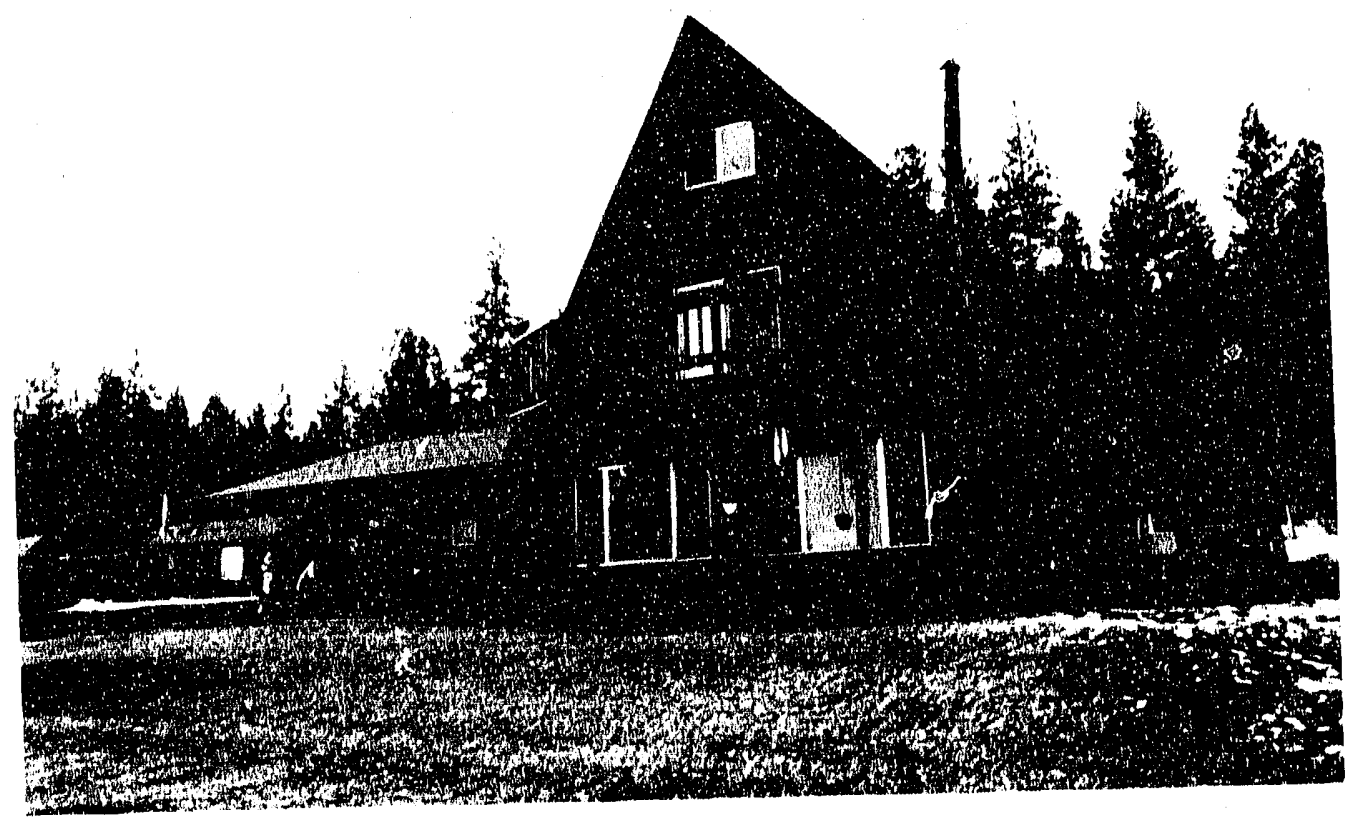

Figure A-11. Exterior view of house KF06.

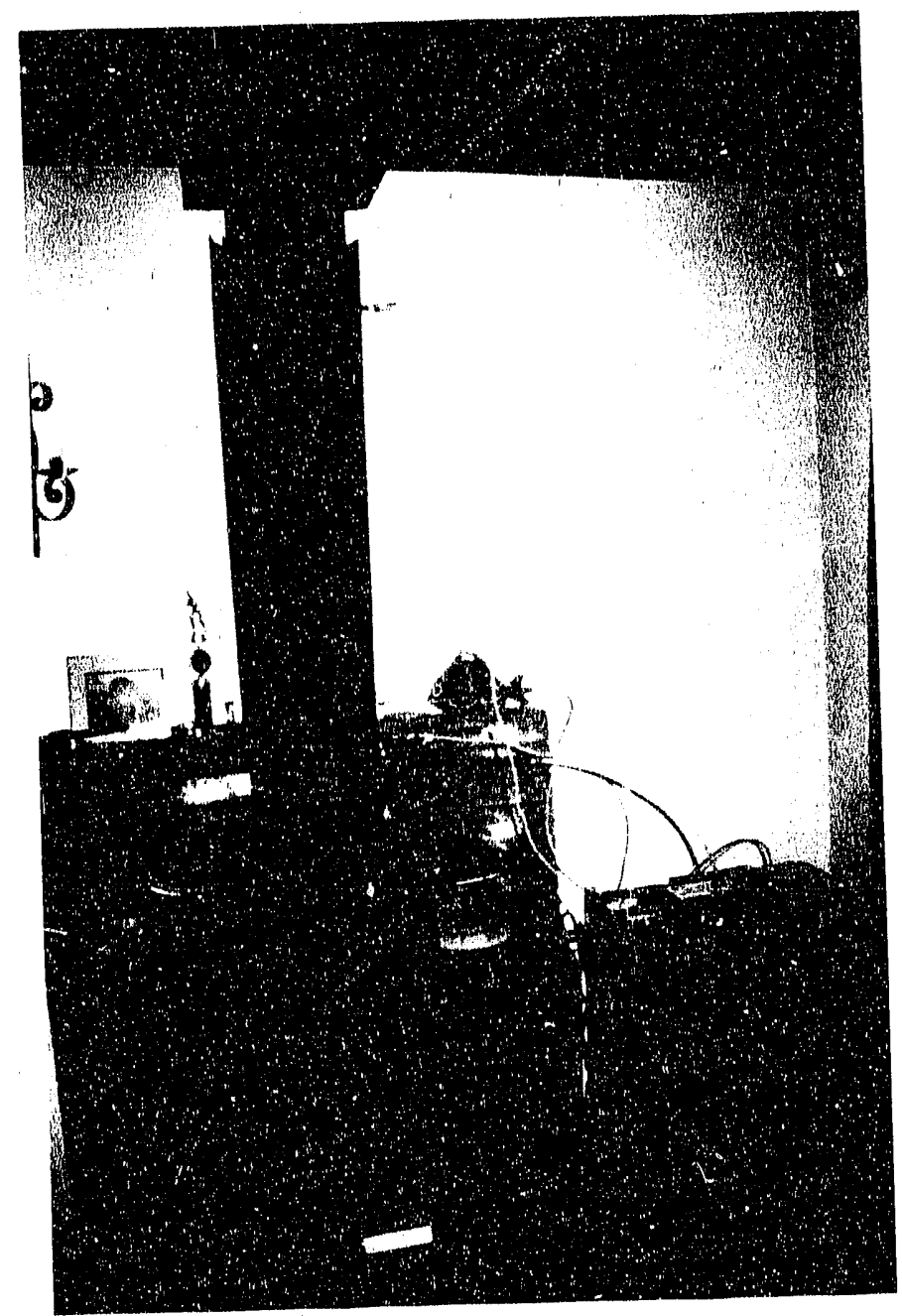

Figure A-12. Installation of Earth Stove 101 conventional stove and AWES sampling system. 

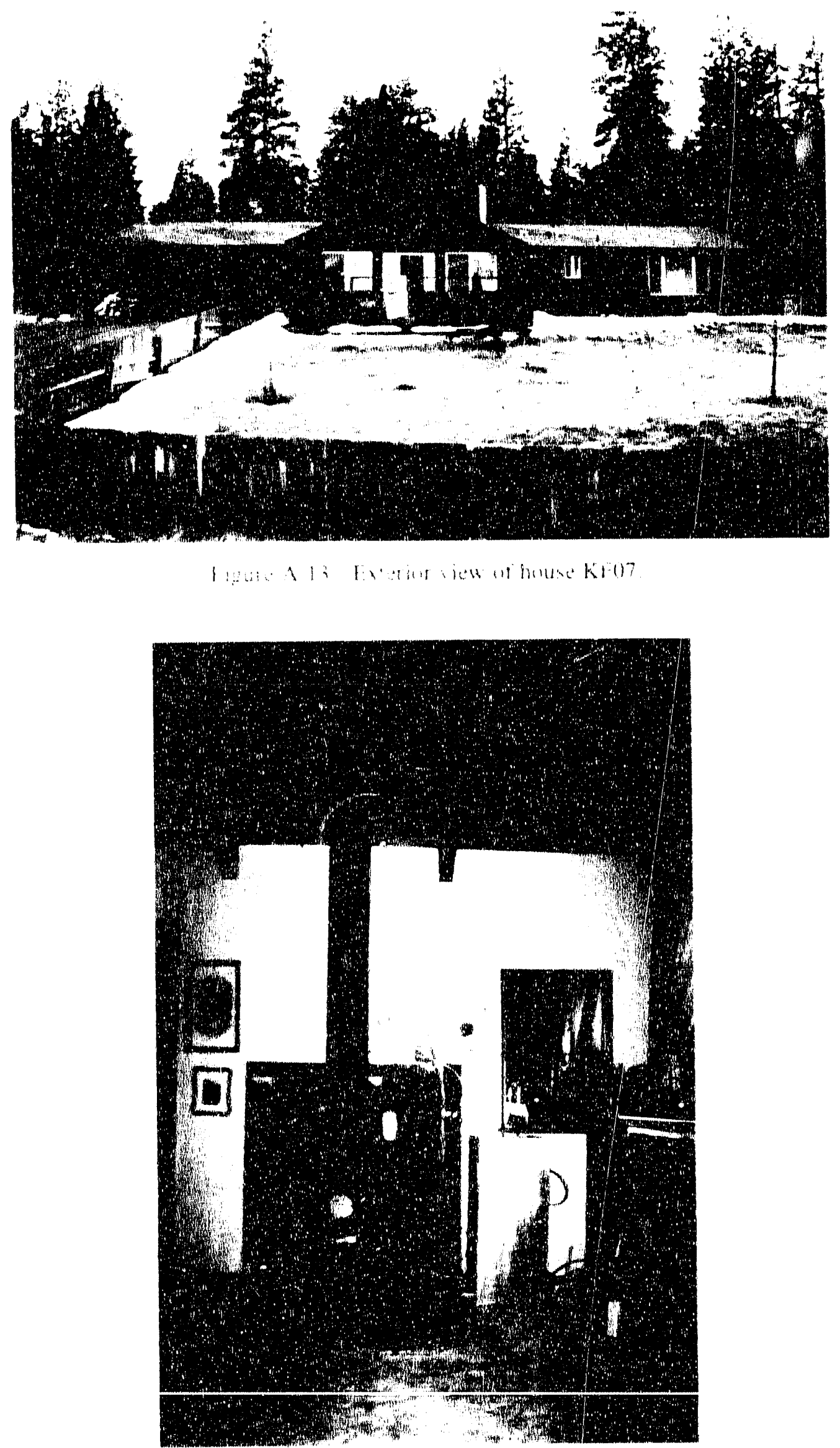

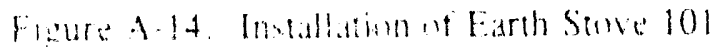

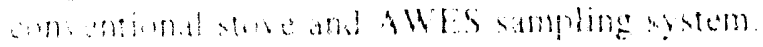




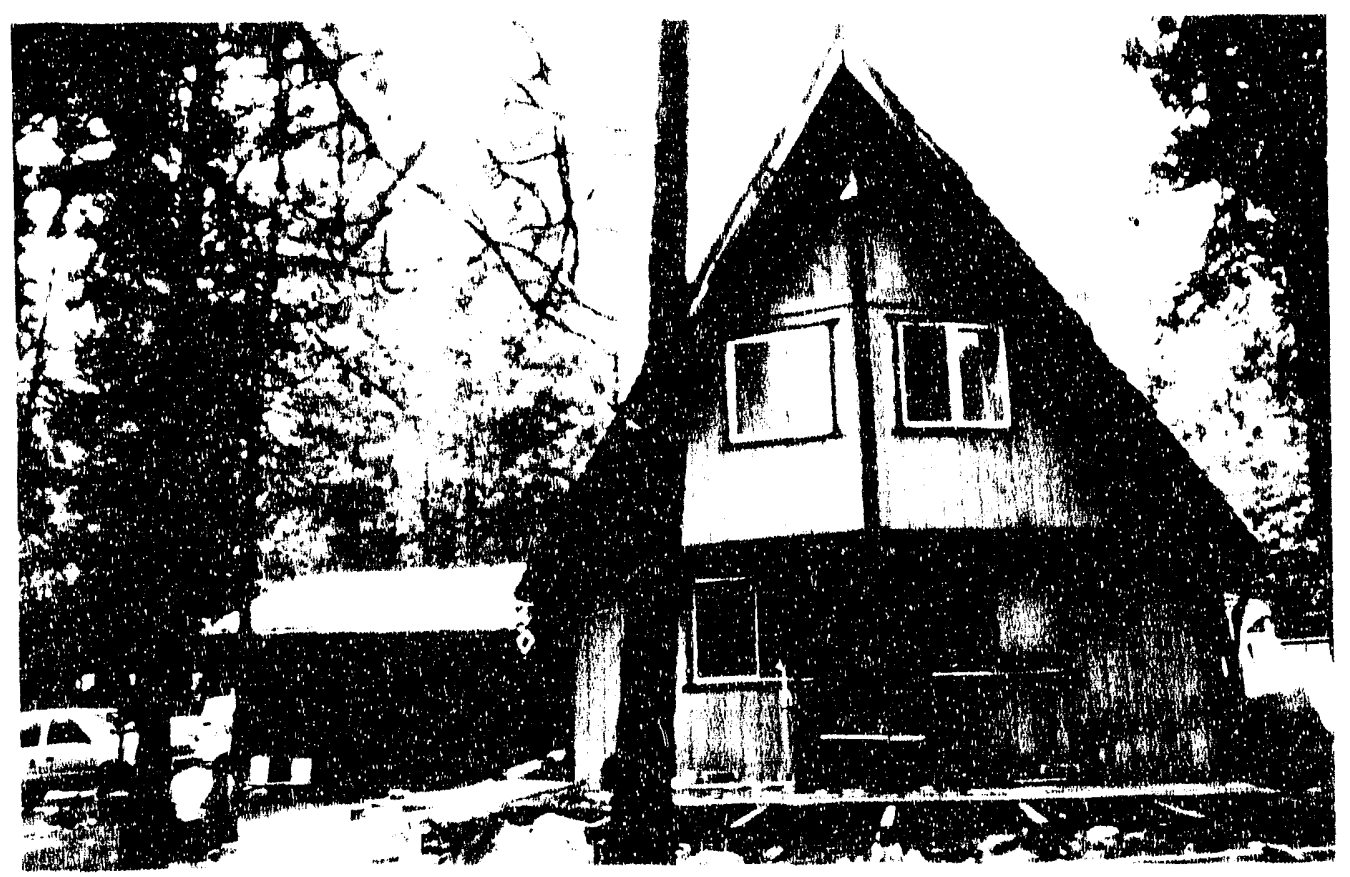

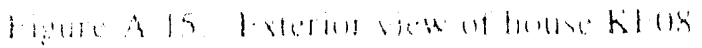

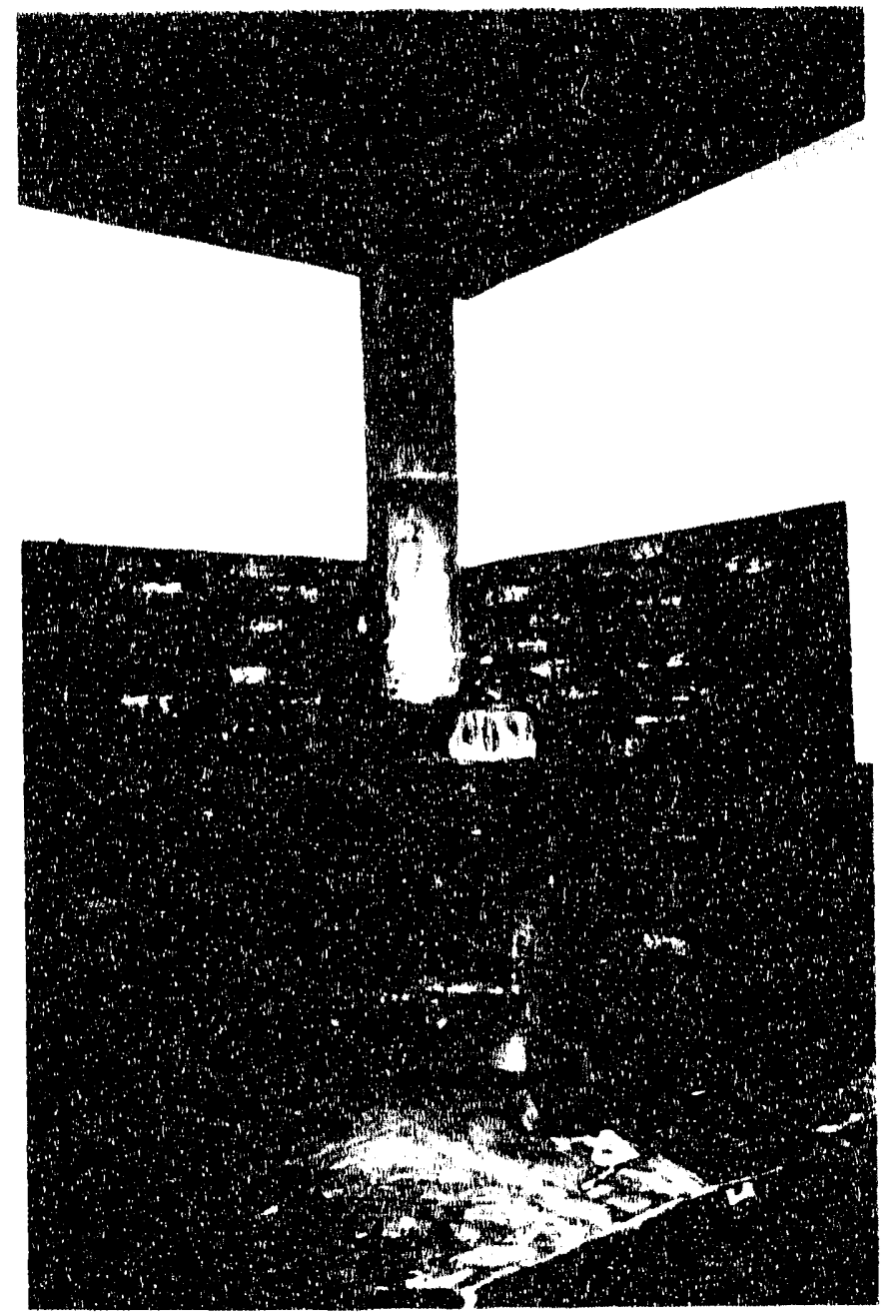

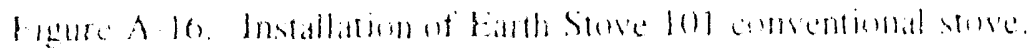

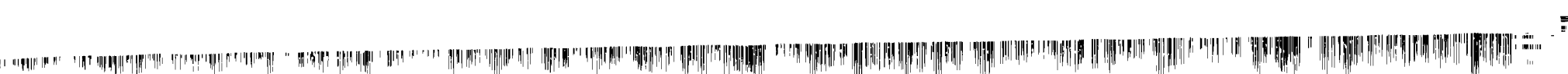




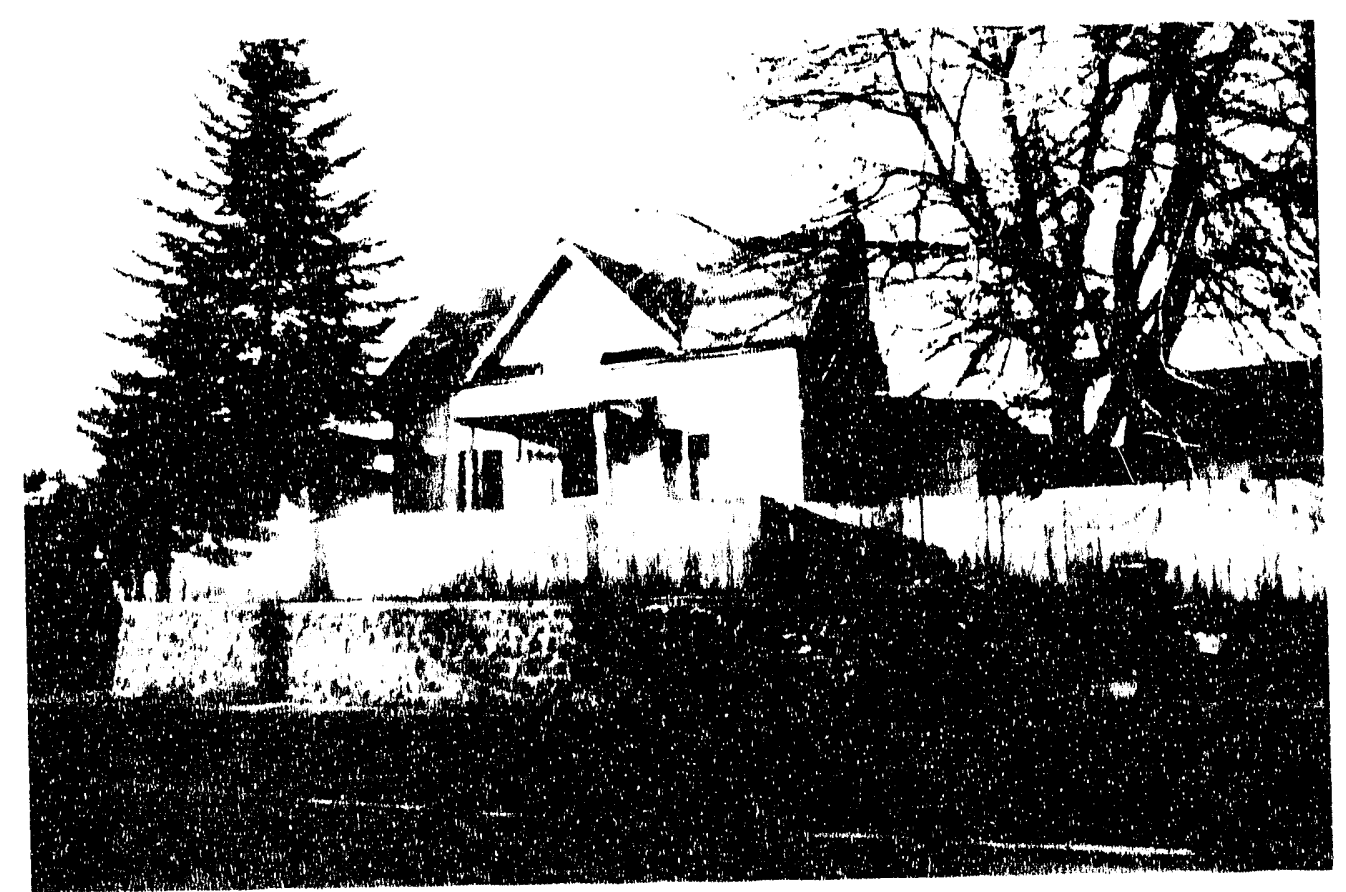

linge: A-17. Hexerior view of house KFo?



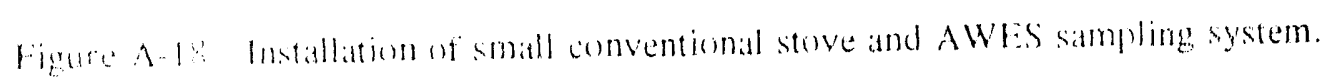




\section{Appendix B}

\section{Graphs of Data from Emissions Tests}


HOUSE \& RUN:

SAMPLE DATES:

STOVE TYPE:

FUEL TYPE:

STACK TEMP AND BURN RATE
ALL 7 DAYS. HOUSE AND RUN:
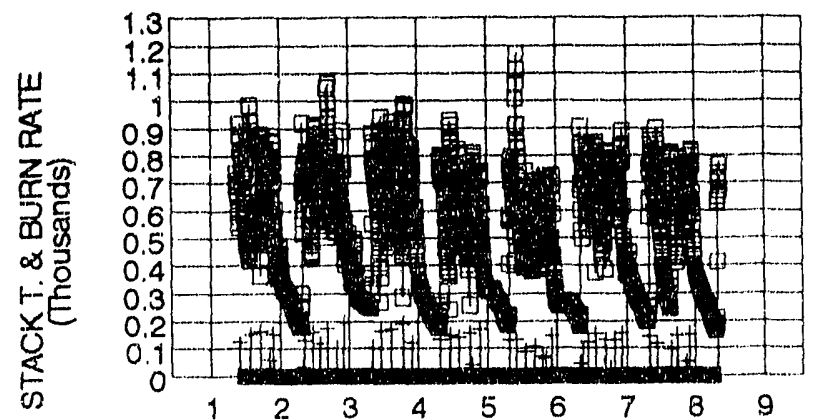

DAY NUMBER

口 STACK TEMP + DRY KG/HAX X100

STACK OXYGEN \% FOR ALL 7 DAYS HOUSE AND RUN:

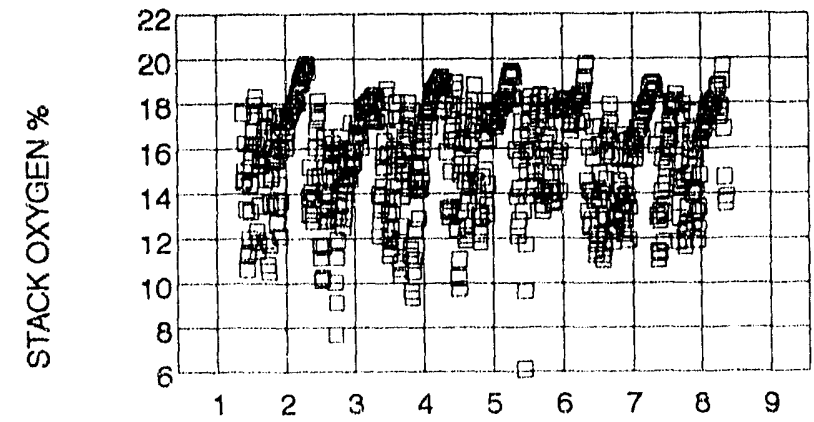

DAY NUMBEF

$\square$ STACK OXYGEN \%

HOUSE AMBIENT TEMPERATURE
HOUSE AND RUN:

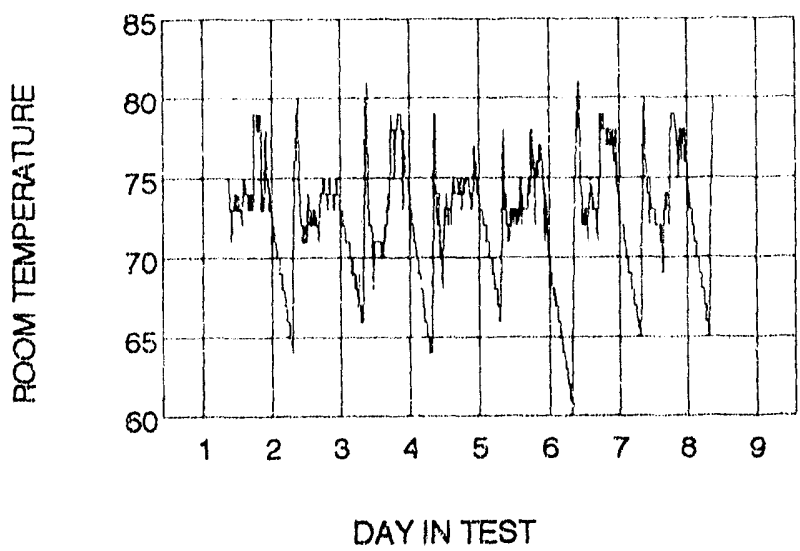

KF0101

$1 / 7-14 / 92$

QUAD 3100

LODGEPOLE, JUNIPER

STACK TEMP AND BURN RATE $(\times 100)$

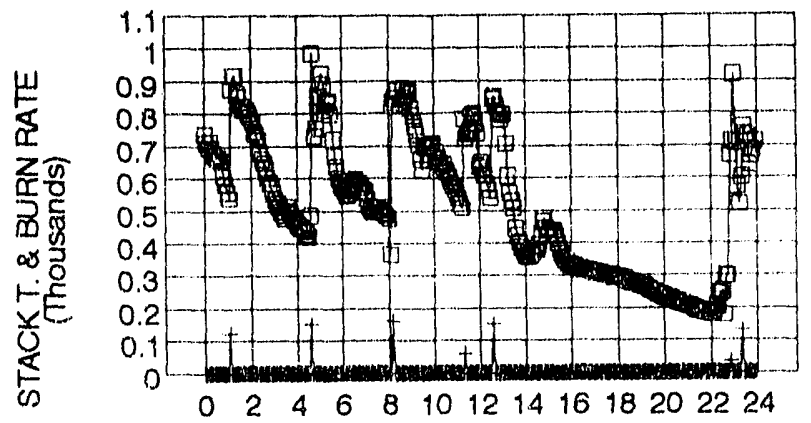

HOUR IN DAY

D STACK TEMP + DRY KG/HR X100

DISTRIBUTION OF WOOD LOAD WEIGHTS
HOUSE AND RUN:

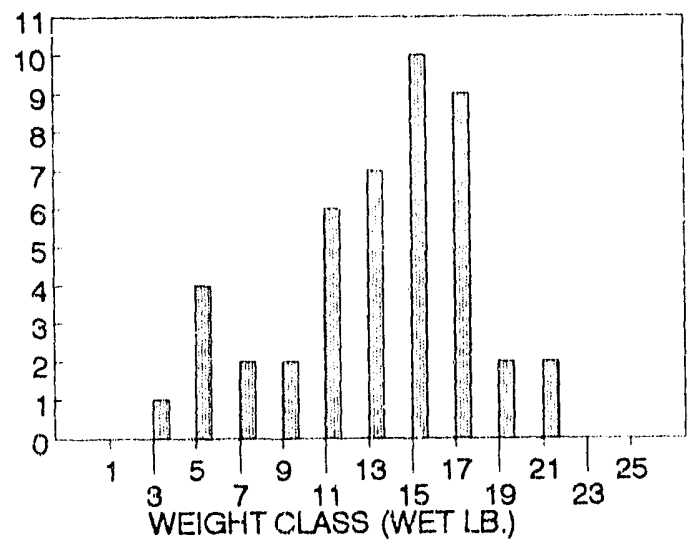

STACK T.VS OXYGEN: RAW DATA
HOUSE AND RUN:

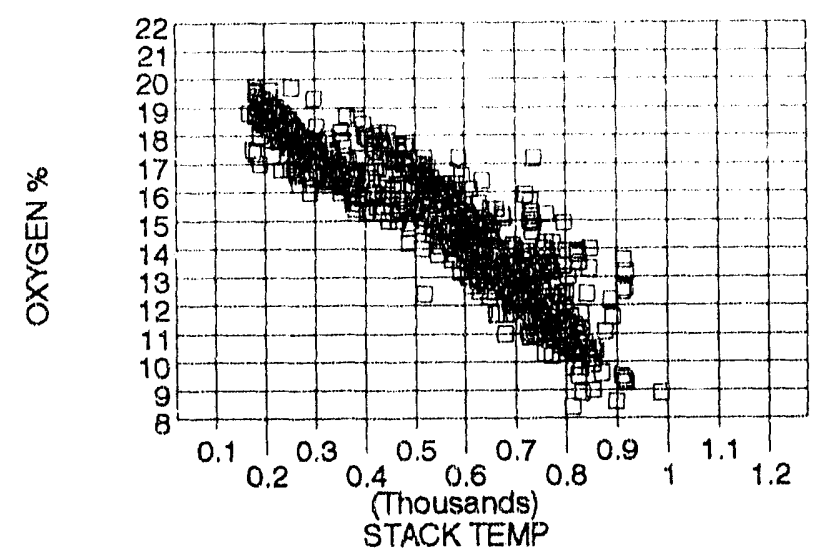


HOUSE \& RUN:

SAMPLE DATES:

STOVE TYPE:

FUEL TYPE:

STACK TEMP AND BUAN RATE
ALL 7 DAYS. HOUSEAND RUN:

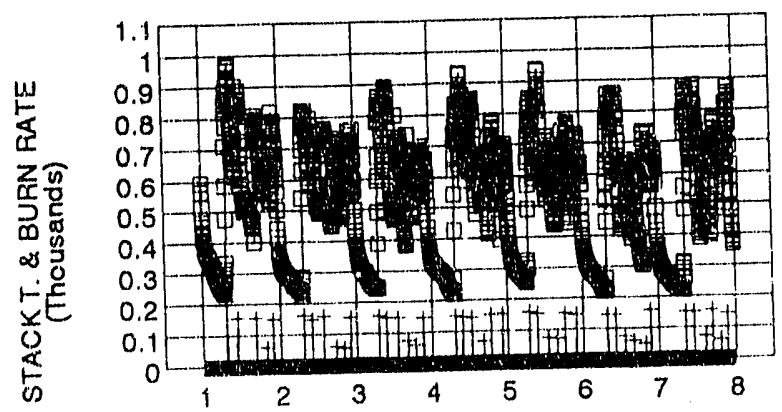

DAY NUMBER

D STACK TEMP + DRY KG/HR X100

STACK OXYGEN \% FOR ALL 7 DAYS

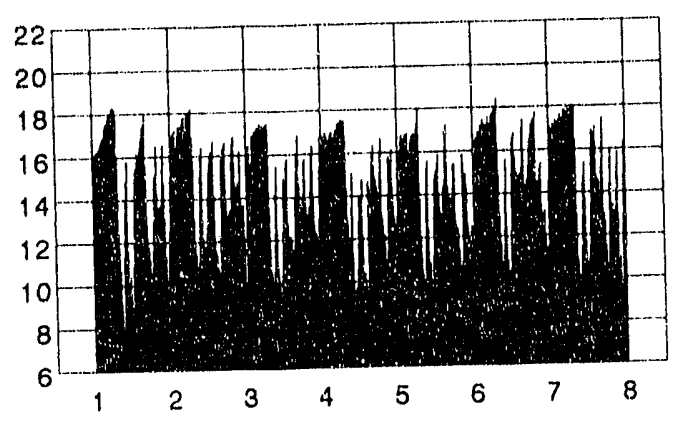

DAY NUMBEA

- STACK OXYGEN \%

HOUSE AMBIENT TEMPERATURE HOUSE AND RUN:

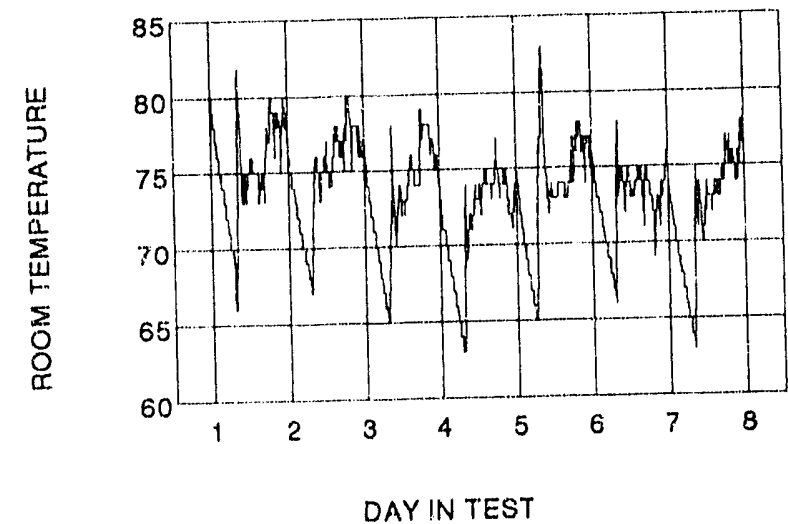

KF0102

$1 / 16-22 / 92$

QUADRAFIRE 3100

PRES-TO-LOGS

STACK TEMP AND BURN RATE $(X 100)$ DAY 1 , HOUSE AND RUN:

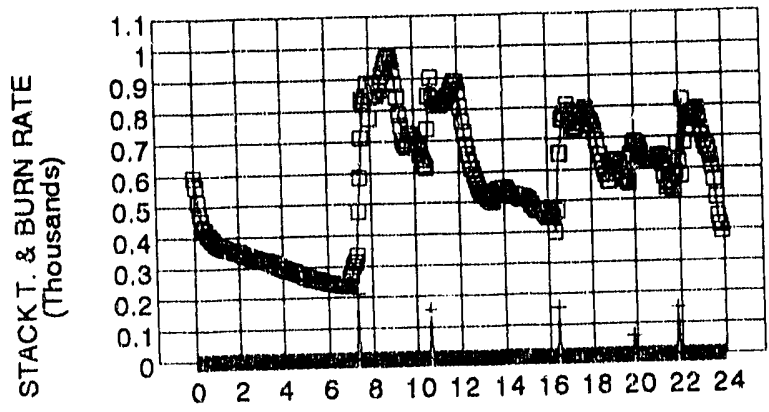

HOUR IN DAY

D STACK TEMP + DRY KG/HR X100

DISTRIBUTION OF WOOD LOAD WEIGHTS HOUSE AND RUN:

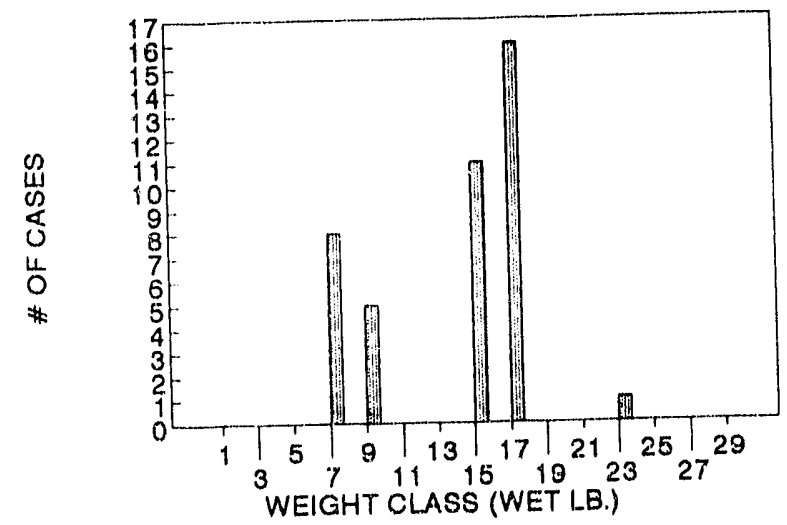

STACK T. VS OXYGEN RAW DATA HOUSE AND FUN:

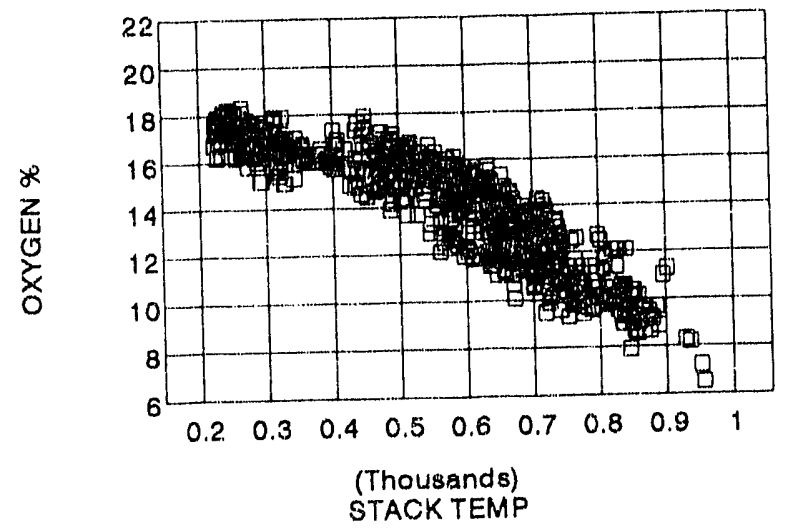


HOUSE \& RUN:

SAMPLE DATES:

STOVE TYPE:

FUEL TYPE:

STACK TEMP AND WOOD LOADS $(\times 10)$

ALL 7 DAYS. HOUSE AND RUN:
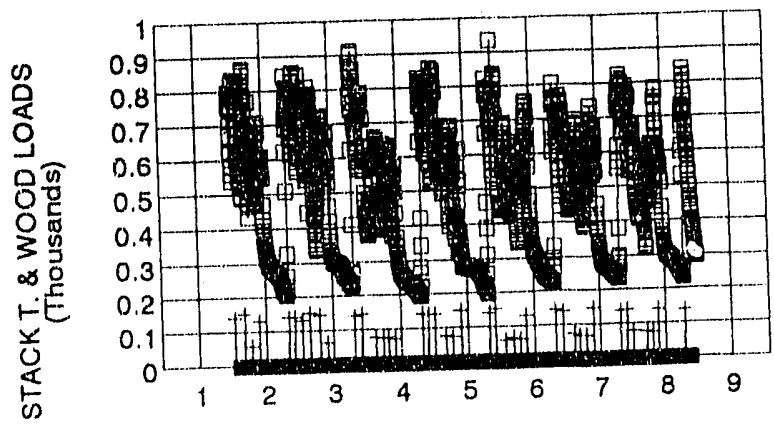

DAY NUMBER

D STACK TEMP + DRY KG/HRX100

STACK OXYGEN \% FOR ALL 7 DAYS HOUSE AND RUN:

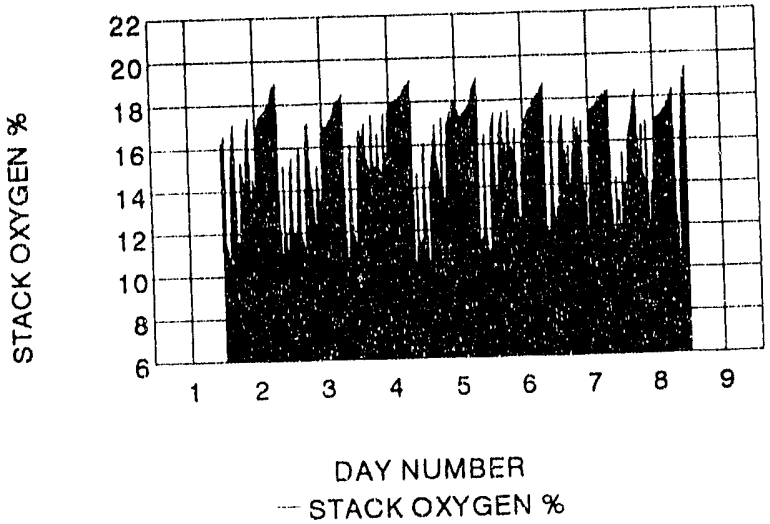

HOUSE AMBIENT TEMPERATURE HOUSE AND RUN:

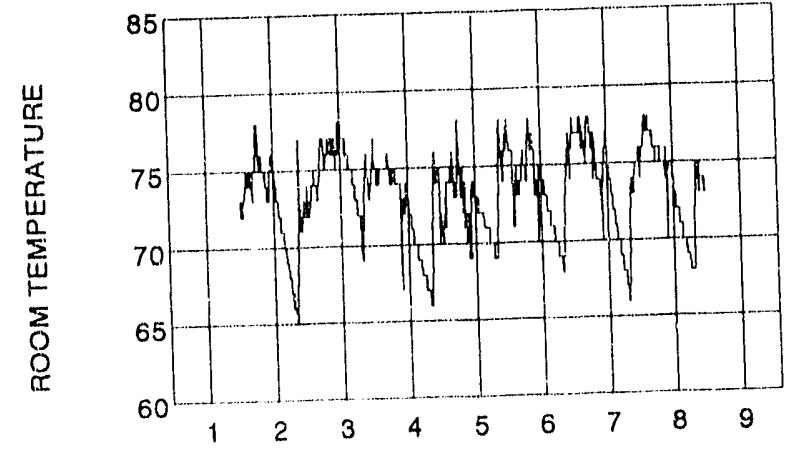

DAY IN TEEST
KF0103

$1 / 23-29 / 92$

QUAD 3100

ECO--LOGS

STACK TEMP AND WOOD LOADS $(X 10)$ DAY 1, HOUSE AND RUN

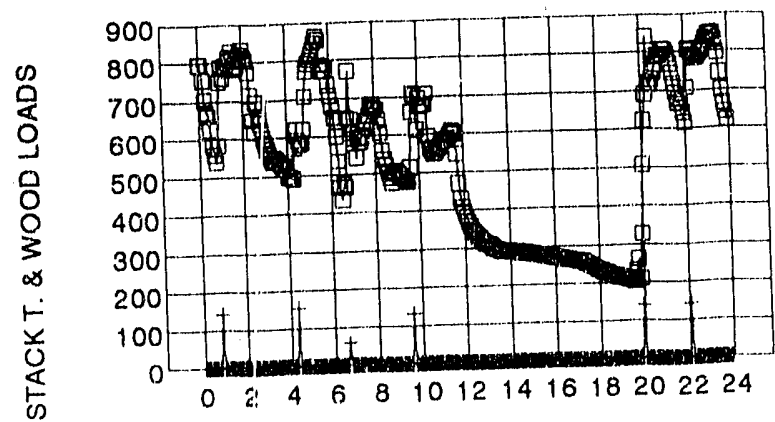

HOUR IN DAY

D STACK TEMP + DRY KG/HA X 100

DISTRIBUTION OF WOOD LOAD WEIGHTS HOUSE AND RUN

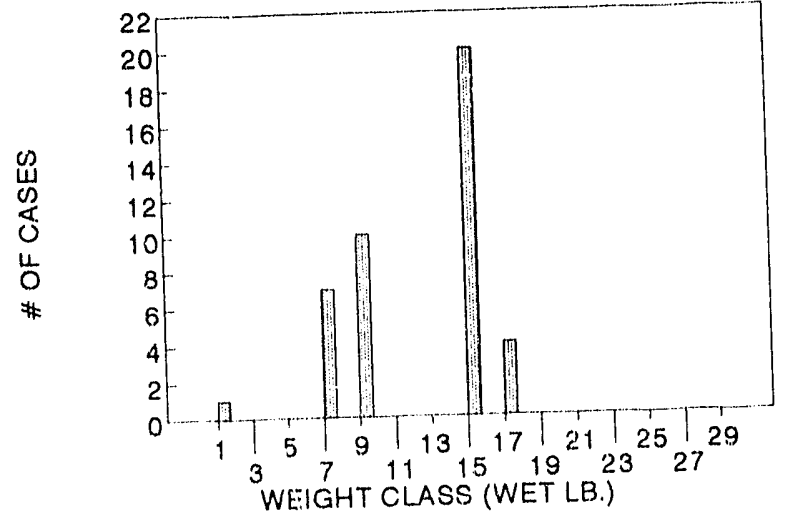

STACK T VS OXYGEN: RAW DATA HOUSE AND RUN:

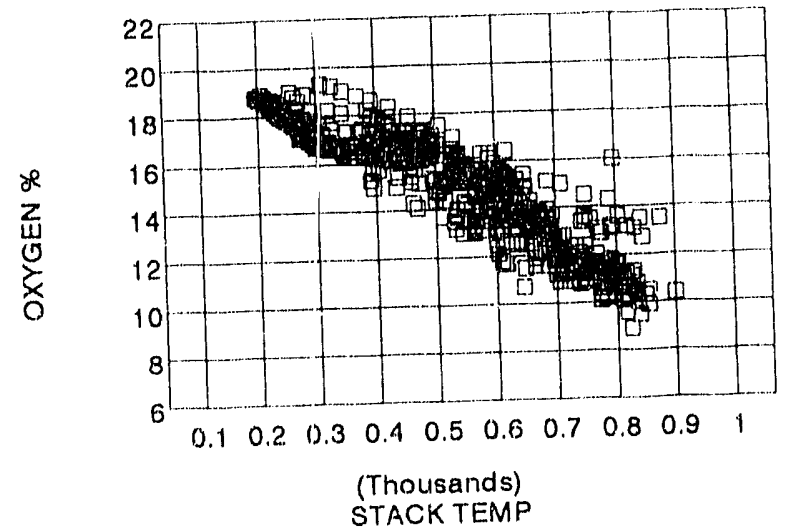


HOUSE \& RUN:

SAMPLE DATES:

STOVE TYPE:

FUEL. TYPE:

STACK TEMP AND WOOD LOADS $(X 10)$

ALL 7 DAYS. HOUSE AND RUN:
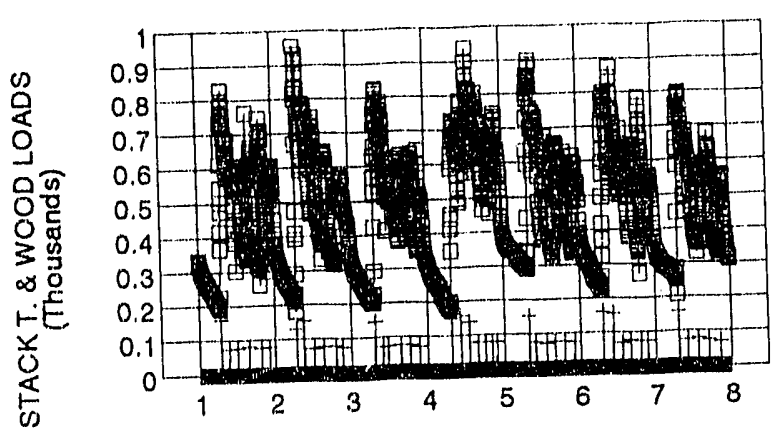

DAY NUMBER

$\square$ STACK TEMP + WOOD LOAD $(X 10)$

STACK OXYGEN \% FOR ALL $P$ DAYS HOUSE AND RUN:

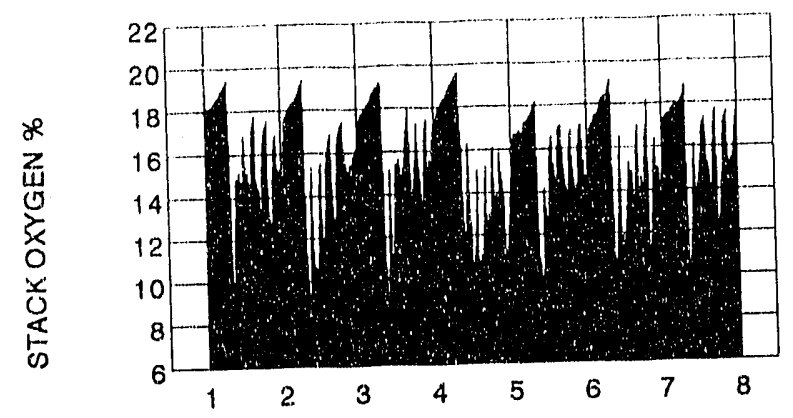

DAY NUMBER

.... STACK OXYGEN \%

HOUSE AMBIENT TEMPERATURE HOUSE AND RUN

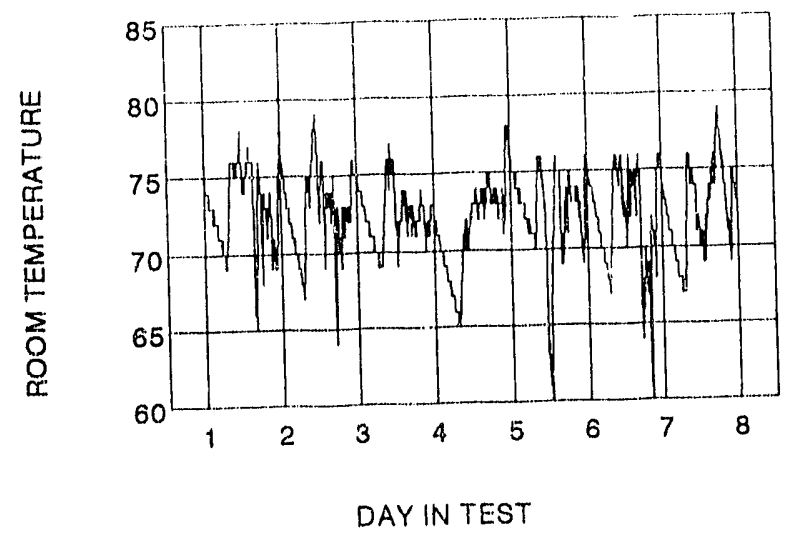

KF0104

3/3-9/92

QUAD 3100

PRES-TO-LOGS

STACK TEMP AND WDOD LOADS $(X 10)$ DAY 1 , HOUSE AND RUN:

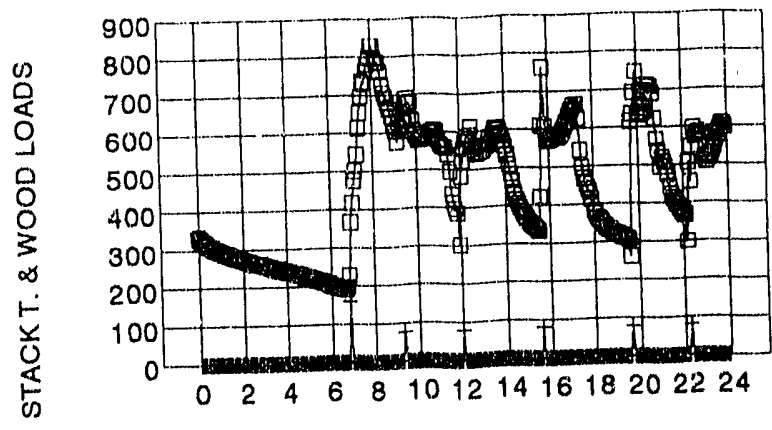

HOUP IN DAY

口 STACK TEMP + WOOD LOAD (X10)

DISTAIBUTION OF WOOD LOAD WEIGHTS HOUSE AND RUN:

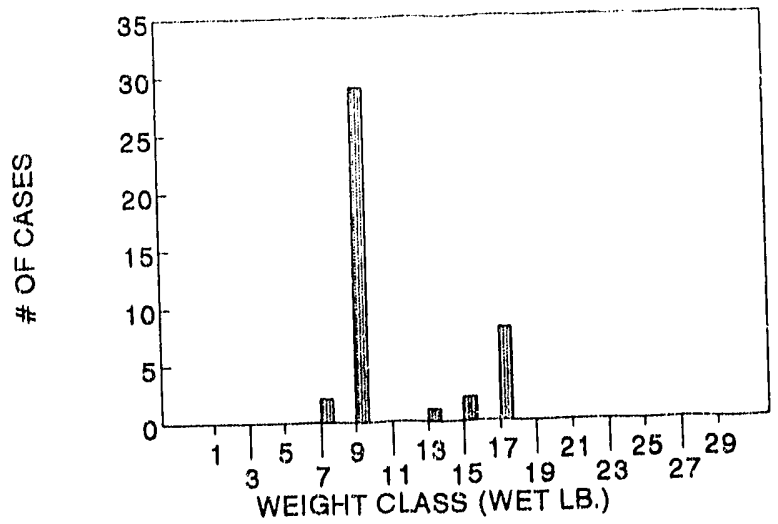

STACK T. VS OXYGEN; RAW DATA HOUSE AND RUN

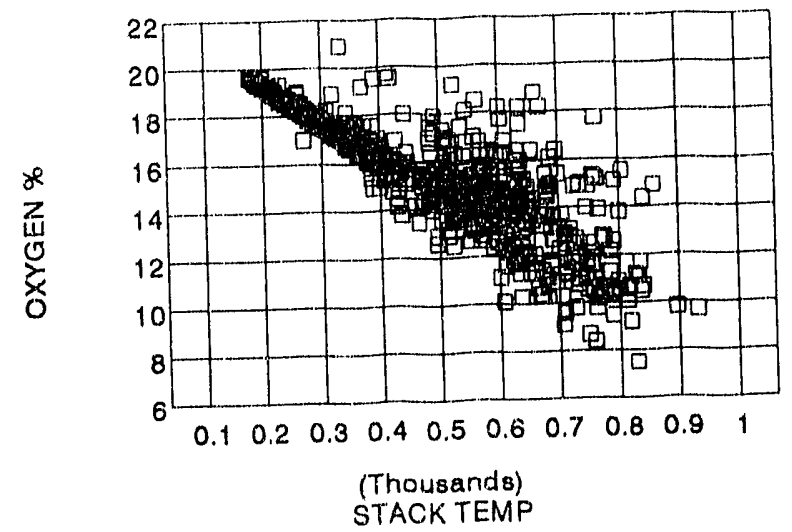


HOUSE \& RUN: KF0201

SAMPLE DATES: $\quad 1 / 07-13 / 92$

STOVE TYPE: $\quad$ EARTH 1000 CAT

FUEL TYPE: LODGEPOLE

TEMPERATUPES AND WOOD LOADS (WT $\times 10)$
DAY $Y$, HOUSE AND RUN:

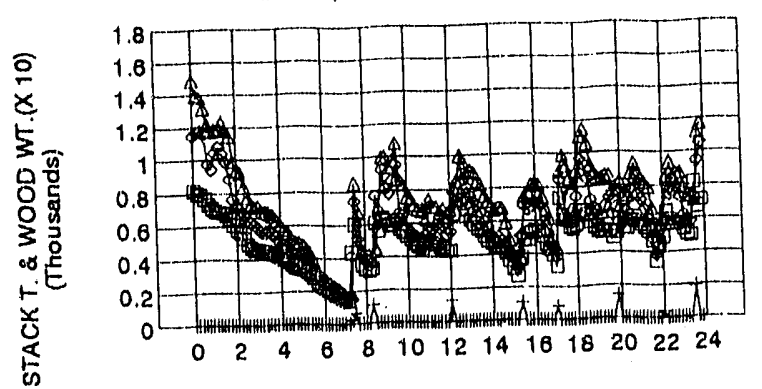

HOUR IN DAY

D STACK TEMP + WOOD WT. X YO O PRE-CAT $\triangle$ CATALYST

CATALYST TEMP, VS. DELTA T HOUSE AND RUN:

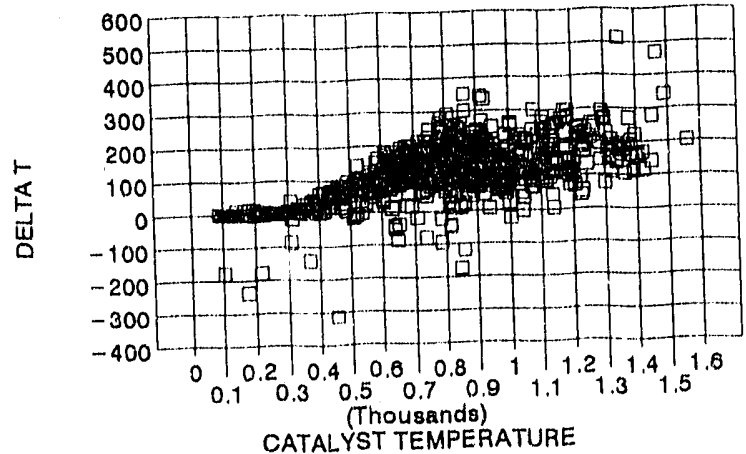

HISTOGRAM OF WOOD LOADS (WET LBS) HOUSE AND RUN:

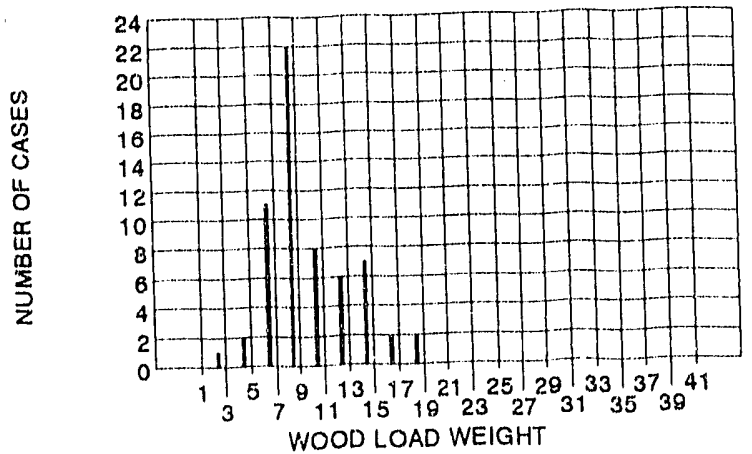

STACK OXYGEN
HOUSE AND RUN:

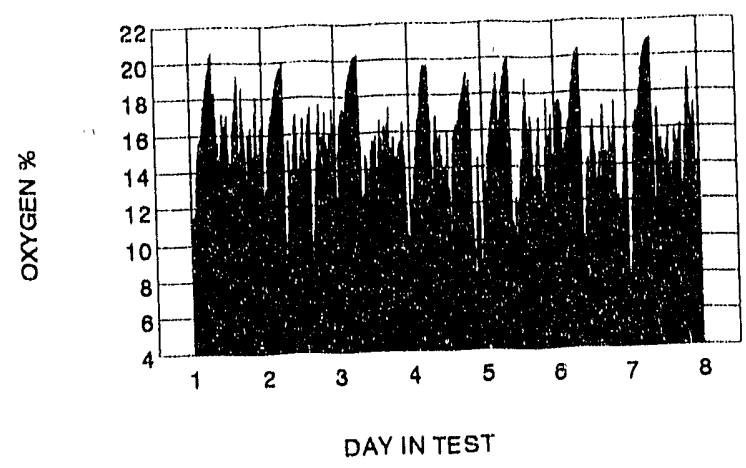

PERCENT OF TIME CATALYST IS HOTTER THAN SELECTED TEMPS: HOUSE AND RUN:

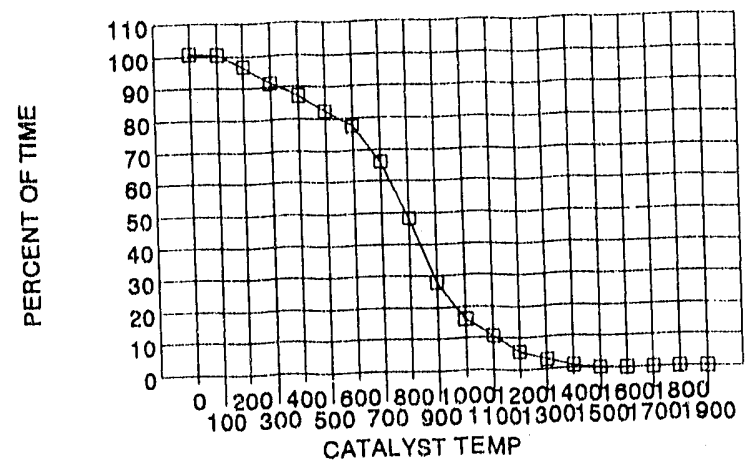

CATALYST VS OXYGEN HOUSE AND RUN:

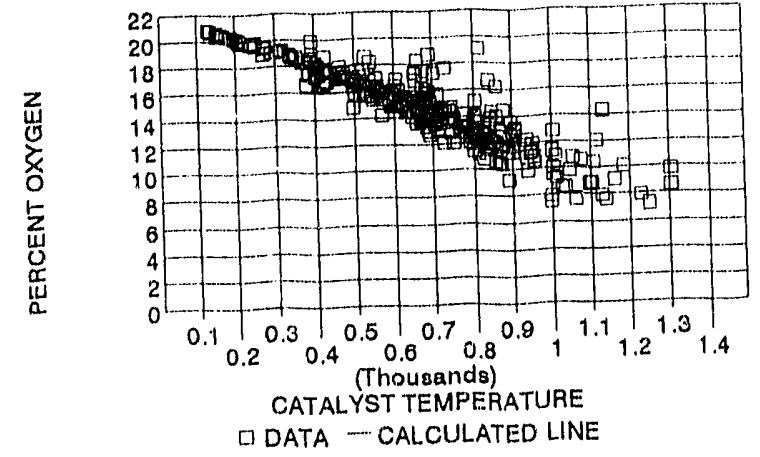


HOUSE \& RUN:

SAMPLE DATES:

STOVE TYPE:

FUEL TYPE:

TEMPEAATURES AND WOOD LOADS (WT X 10) DAY 1 , HOUSE AND RUN:

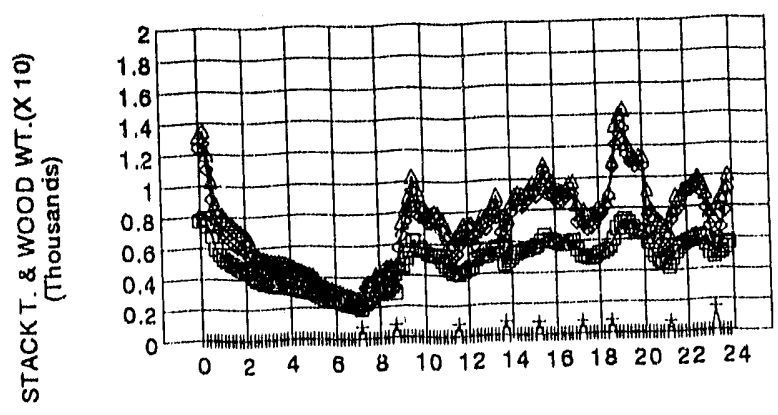

HOUR IN DAY

[ STACKTEMP + WOODWT. $X 10 \diamond$ PAE-CAT $\triangle$ CATALYST CATALYST TEMP VS, DELTA T HOUSE AND RUN:

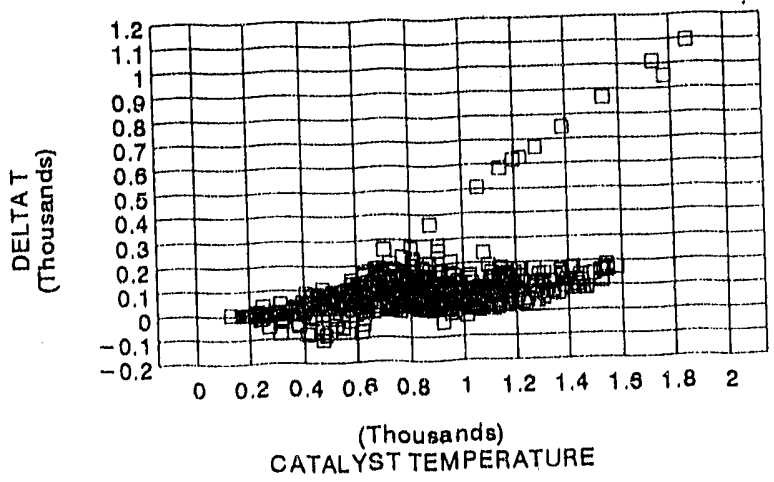

HISTOGRAM OF WOOD LOADS (WET LBS) HOUSE AND RUN:

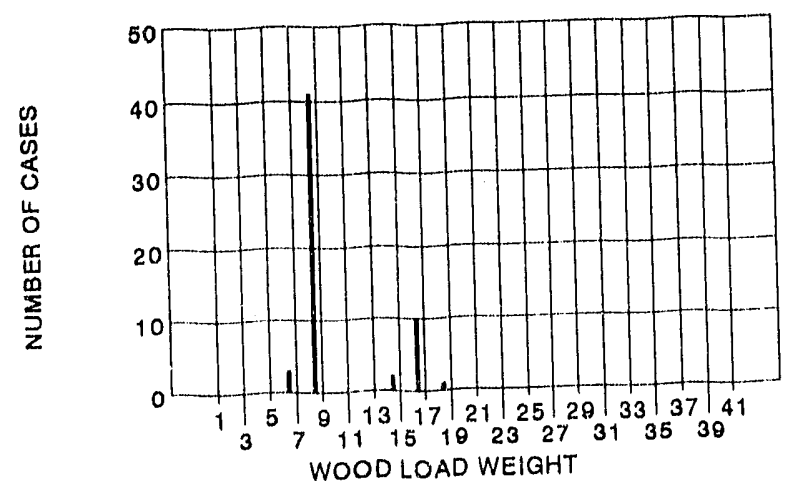

KF0202

1/16-22/92

EARTH $1003 \mathrm{C}$

PRES-TO-LOGS

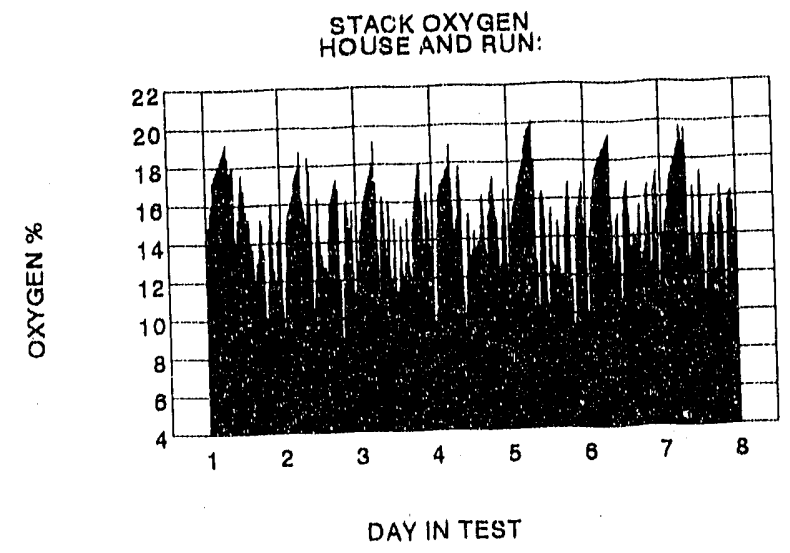

PERCENT OF TIME CATALYST IS HOTTER THAN SELECTED TEMPS: HOUSE AND RUN:

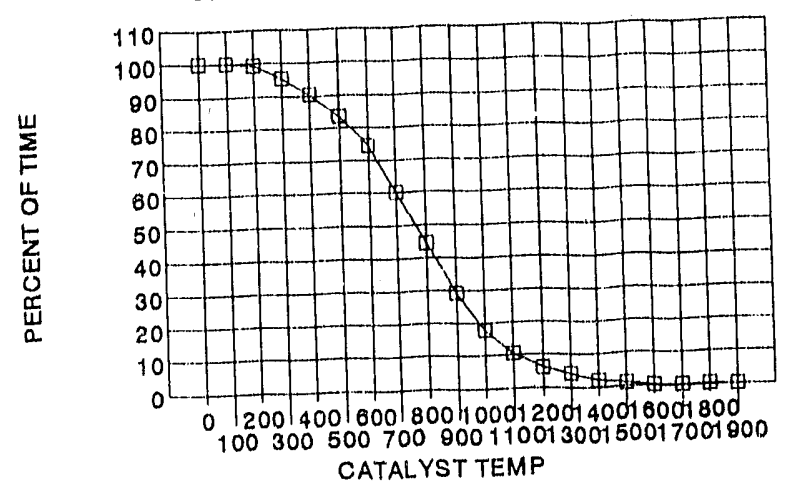

CATALYST VS OXYGEN
HOUSE AND RUN:

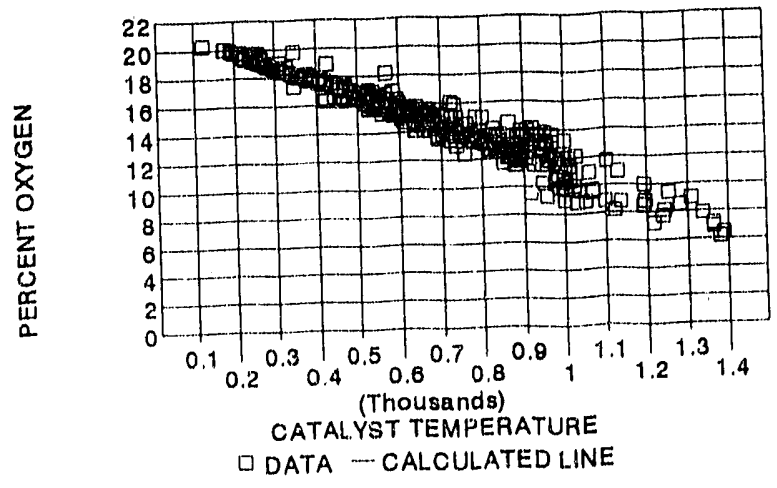


HOUSE \& RUN:

SAMPLE DATES:

STOVE TYPE:

FUEL TYPE:

TEMPERATURES AND WOOD LOADS (WT X 10) DAY 1 , HOUSE AND RUN:

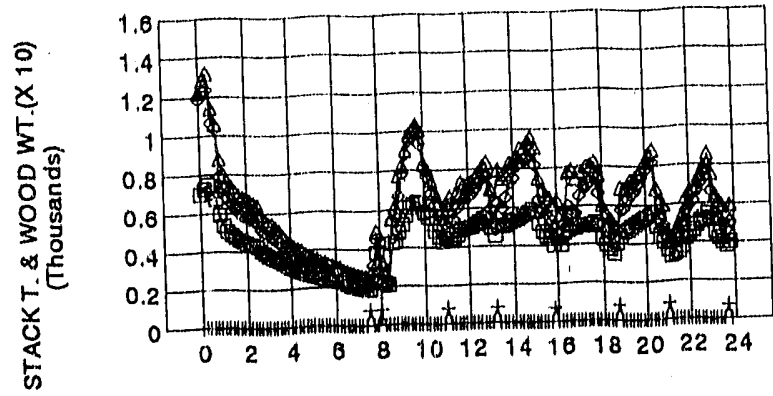

HOUR IN DAY

D STACK TEMP + WOODWT, $X 10 \diamond$ PRE-CAT $\triangle$ CATALYST

CATALYST TEMP VS, DELTA T
HOUSE AND RUN:

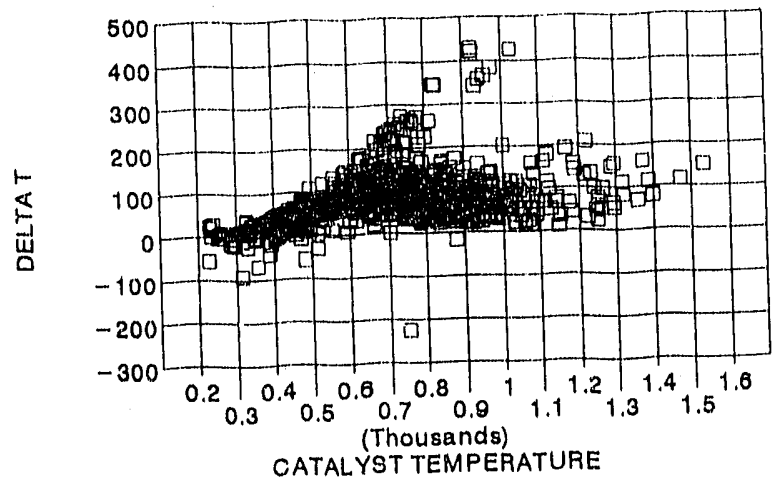

HISTOGRAM OF WOOD LOADS (WET LBS) HOUSE AND RUN:

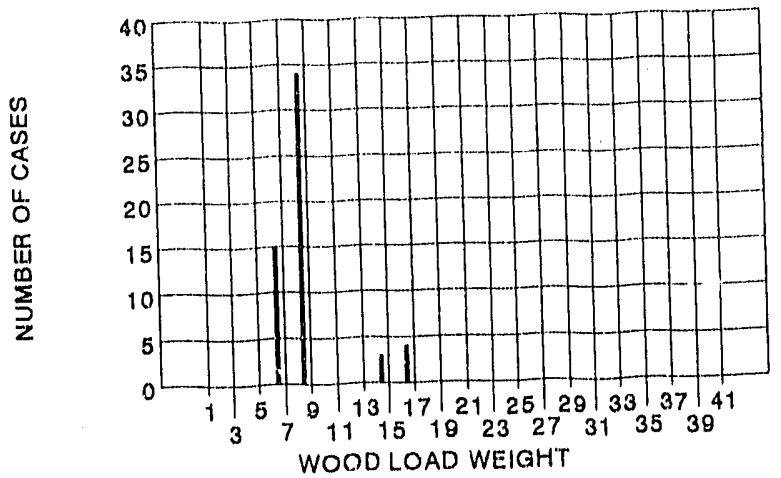

KF0203

$1 / 24-30 / 92$

EARTH $1003 \mathrm{C}$

ECO-LOGS

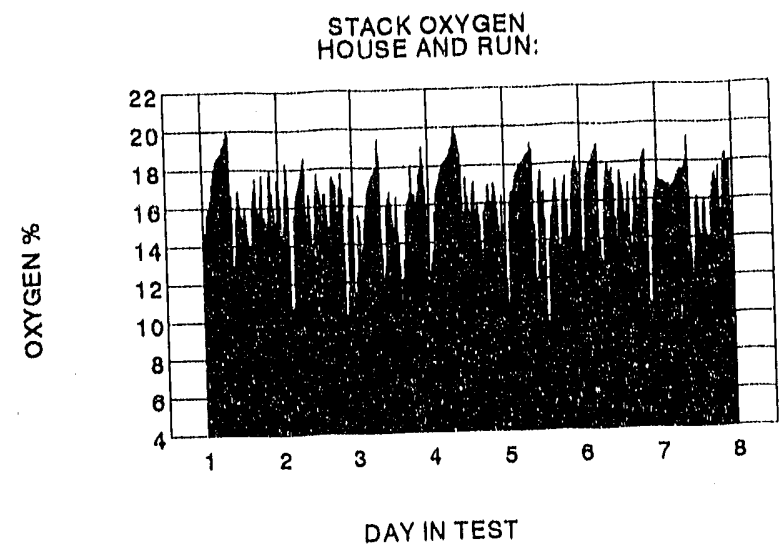

PERCENT OF TIME CATALYST IS HOTTER THAN

SELECTED TEMPS: HOUSE AND RUN:

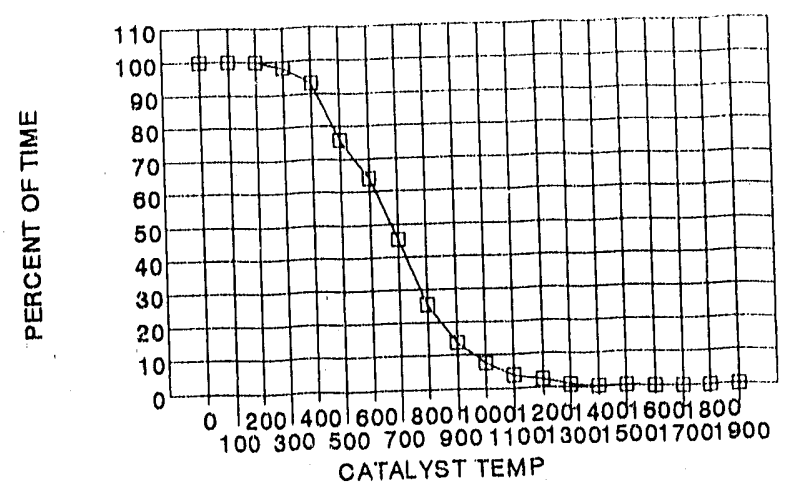

CATALYST VS OXYGEN

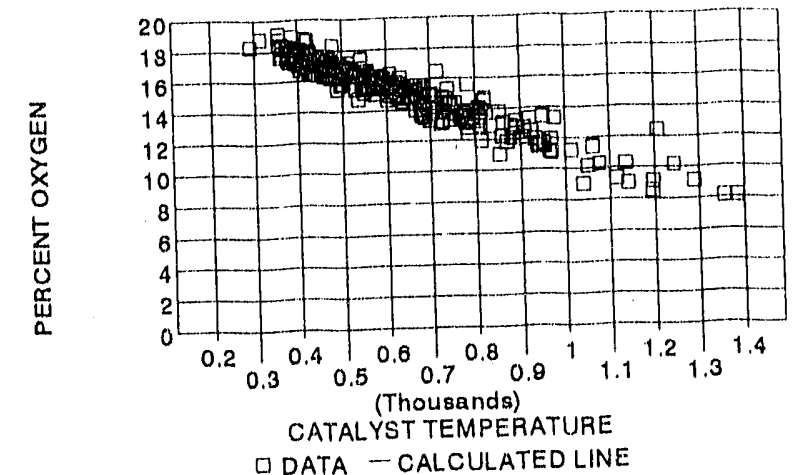


HOUSE \& RUN:

SAMPLE DATES:

STOVE TYPE:

FUEL TYPE:

TEMPERATURES AND WOOD LOADS (WT X 10) DAY 1, HOUSE AND FUN:

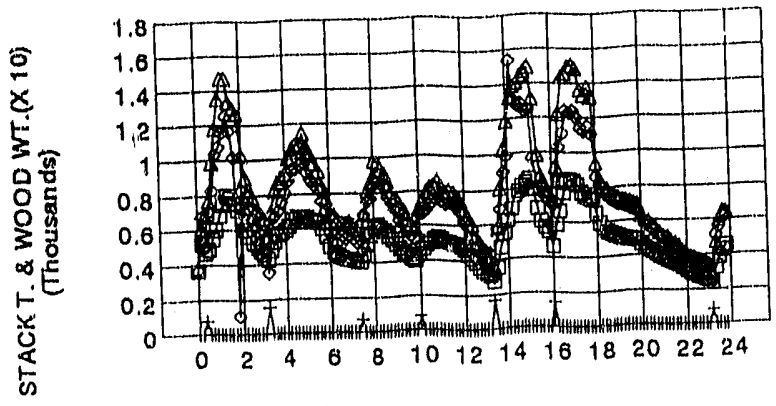

HOUR IN DAY

G STACK TEMP + WOODWT, $X$ TO OPRE-CAT $\triangle$ CATALYST

CATALYST TEMP. VS, DELTA T

HOUSE AND RUN:

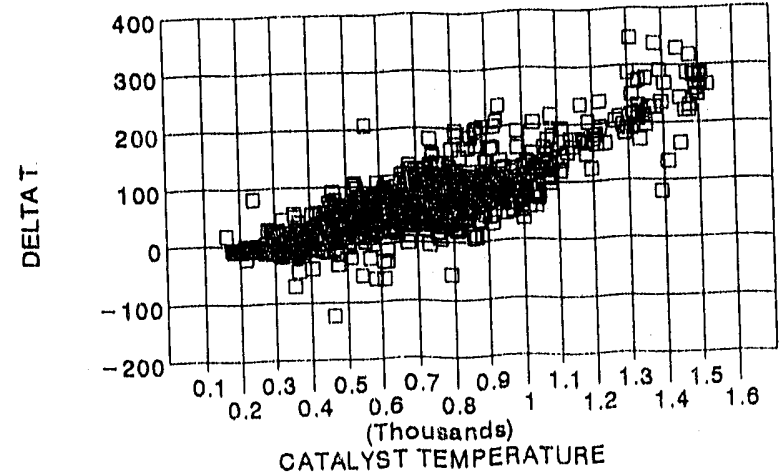

HISTOGAAM OF WOOD LOADS (WET I.BS) HOUSE AND HUN:

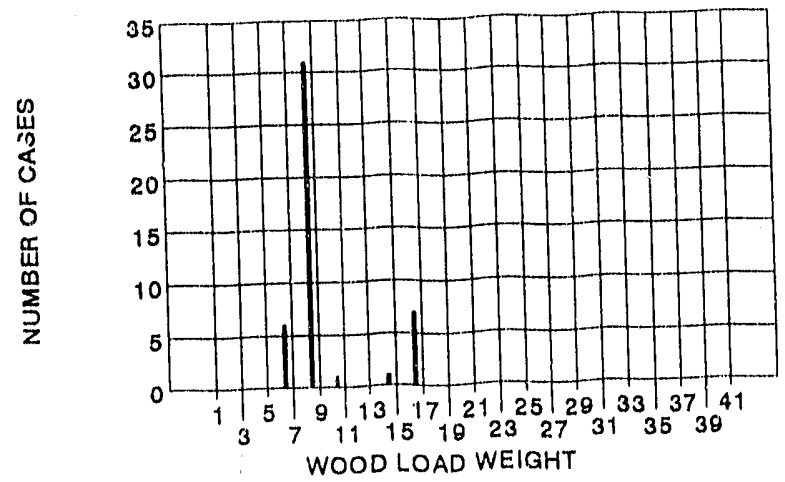

KF0204

EARTH STOVE 1003C

PRES-TO-LOGS

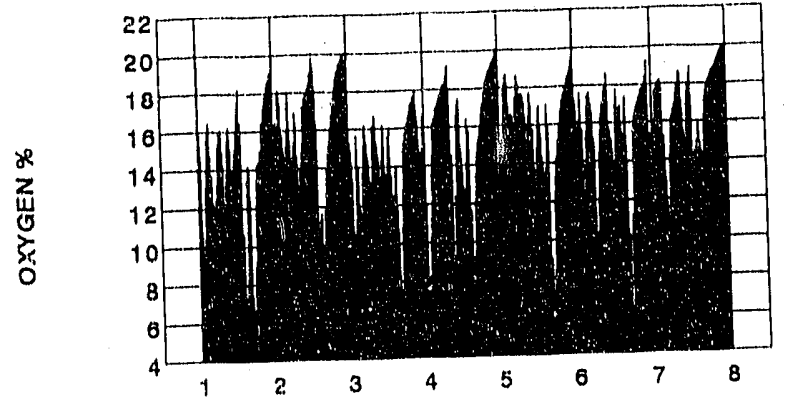

DAY IN TEST

PERCENT OF TIME CATALYST IS HOTTER THAN SELECTED TEMPS: HOUSE AND RUN:

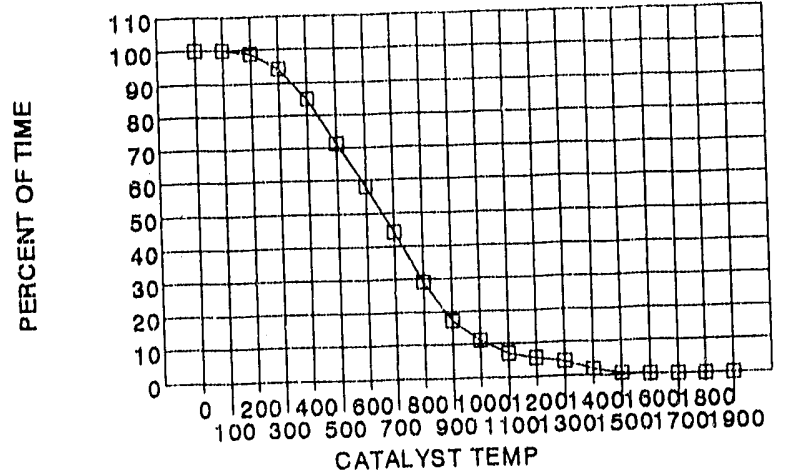
CATALYST VS OXYGEN: RAW DATA
HOUSE AND HUN:

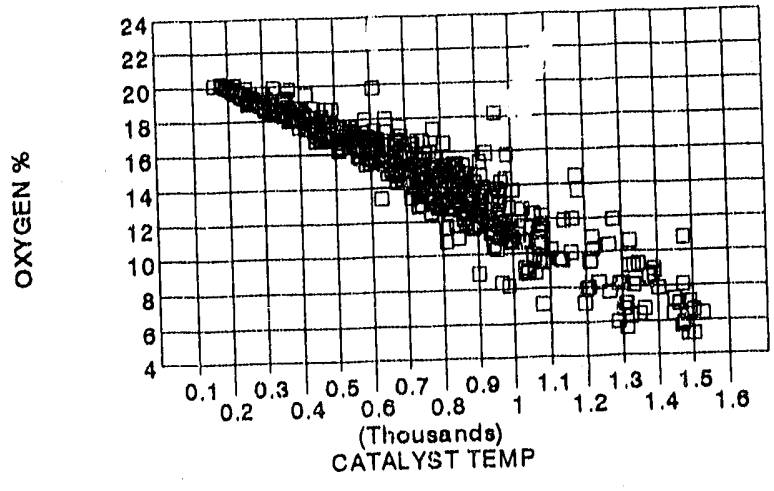


HOUSE \& RUN:

SAMPLE DATES:

STOVE TYPE:

FUEL TYPE:

TEMPERATURES AND WOOD LOADS (WT X 10) DAY 1 , HOUSE AND RUN:
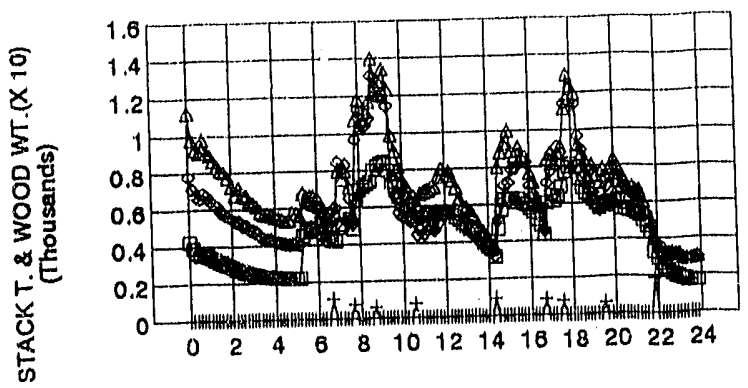

HOUR IN DAY

U STACK TEMP + WOOD WT.X 10 ○ PRE-CAT $\triangle$ CATALYST

CATALYST TEMP, VS, DELTAT HOUSE AND RUN:

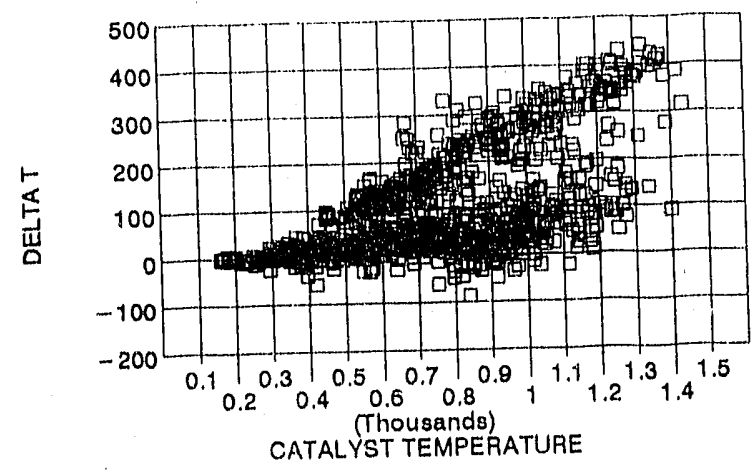

HISTOGRAM OF WOOD LOADS (WET LBS) HOUSE AND RUN:

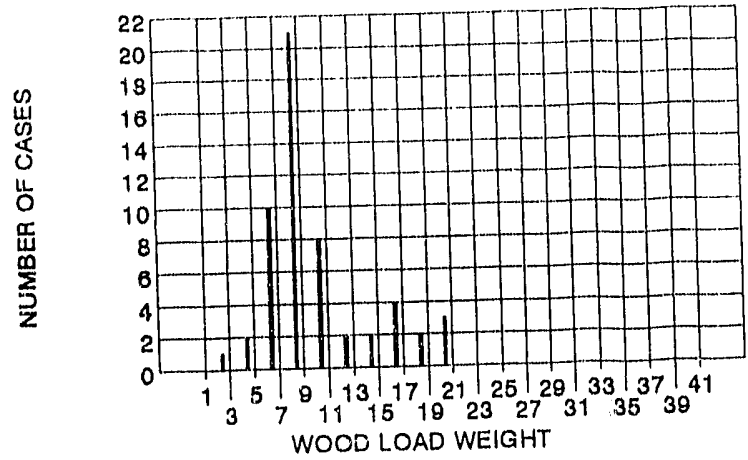

KF0301

1/08-14/92

JOTUL ALPHA

LODGEPOLE PINE

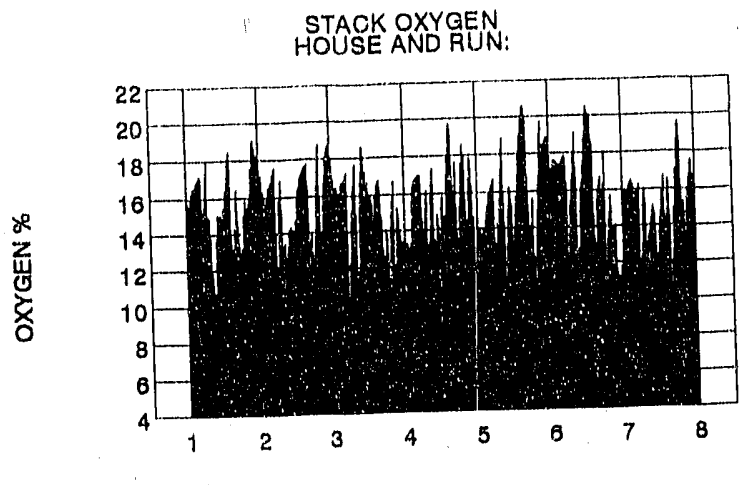

DAY IN TEST

PERCENT OF TIME CATALYST IS HOTTER THAN SELECTED TEMPS: HOUSE AND RUN:

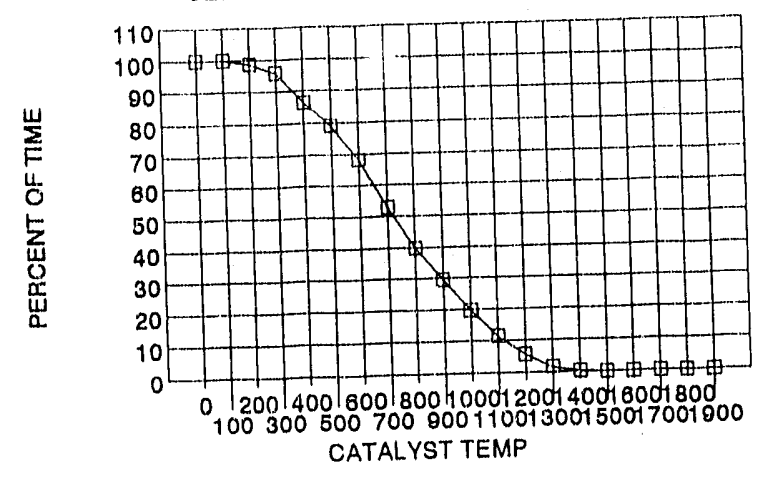

CATALYST VS OXYGEN
HDUSE AND RUN:

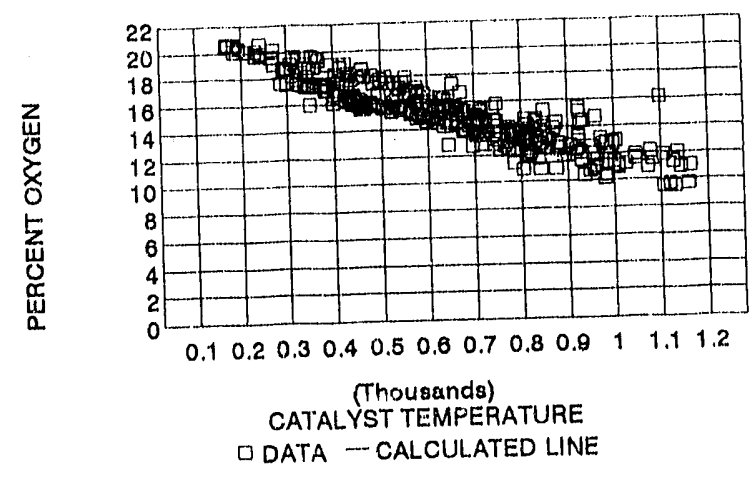


HOUSE \& RUN:

SAMPLE DATES:

STOVE TYPE:

FUEL TYPE: TEMPEHATURES AND WOOD LOADS (WT $\times 10)$
DAY 1 , HOUSE AND RUN:
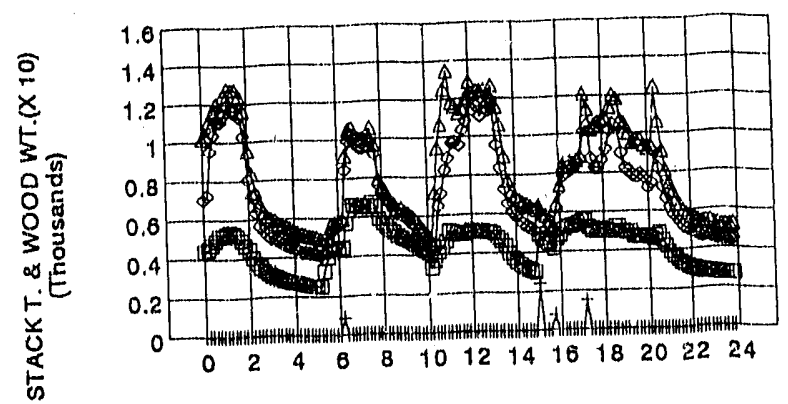

HOUR IN DAY

G STACK TEMP + WOODWT. X 10 OPRE-CAT $\triangle C^{\prime}$ ALYST CATALYST TEMP, VS, DELTA T
HOUSE AND RUN:

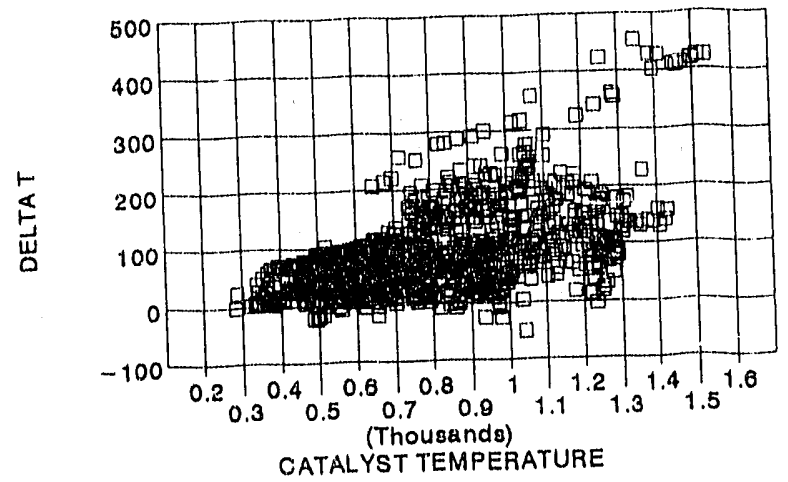

HISTOGAAM OF WOOD LOADS (WET LBS) HOUSE AND RUN:

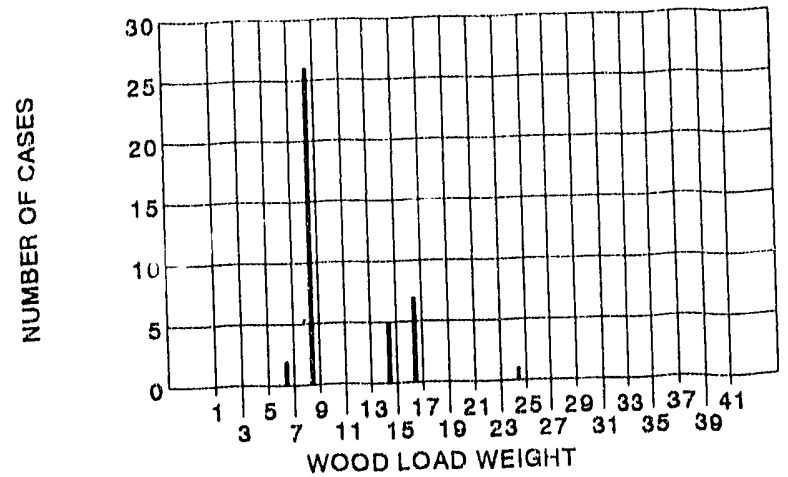

KF0302

$1 / 17-23 / 92$

JOTUL ALPHA

PRES-TO-LOGS

STACK OXYGEN

HOUSE AND RUN:

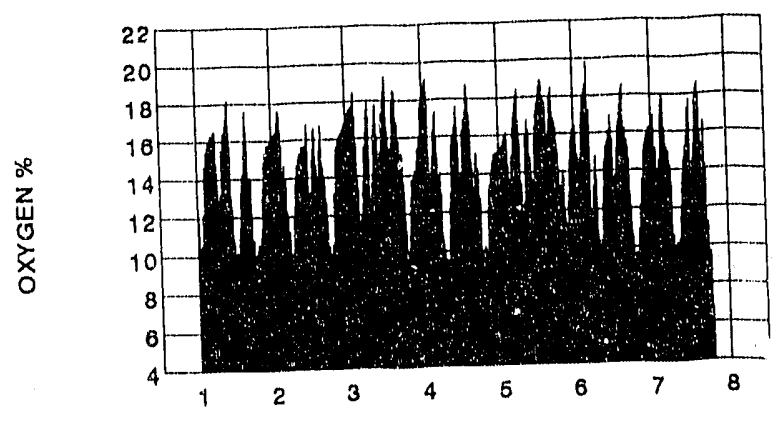

DAY IN TEST

PERCENT OF TIME CATALYST IS HOTTEA THAN SELECTED TEMPS: HOUSE AND RUN:

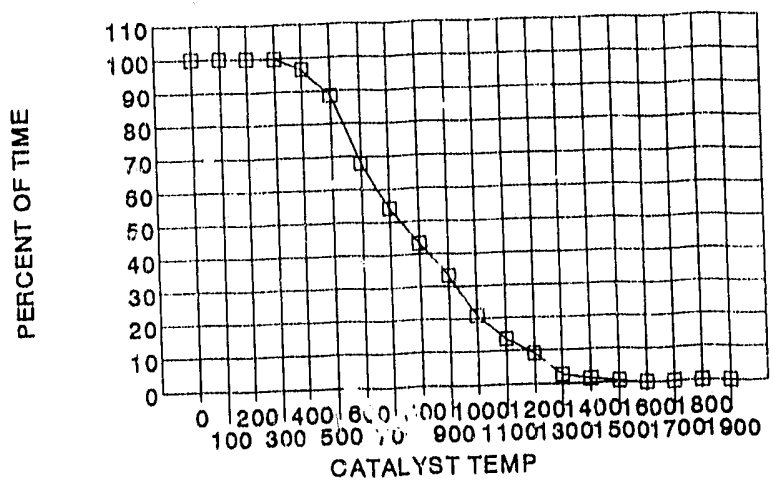

CATALYST VS OXYGEN HOUSE AND RUN:

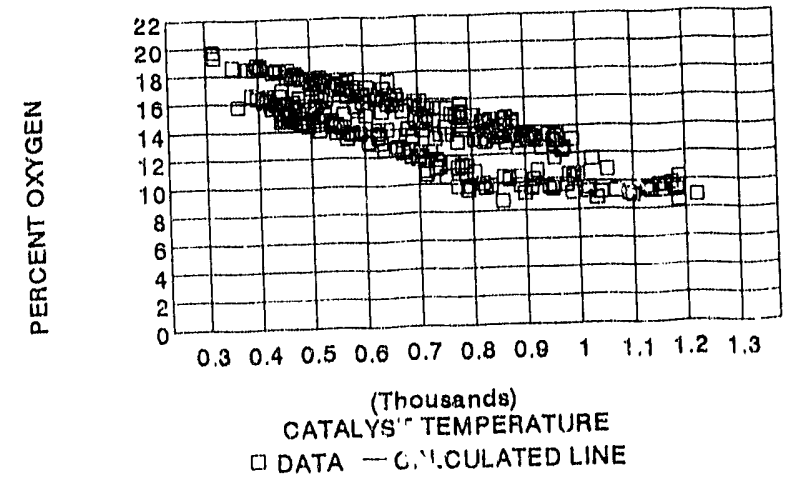


HOUSE \& RUN:

SAMPLE DATES:

STOVE TYPE:

FUEL TYPE:

TEMPERATURES AND WOOD LOADS (WT X 10) DAY $T$, HOUSE AND RUN:

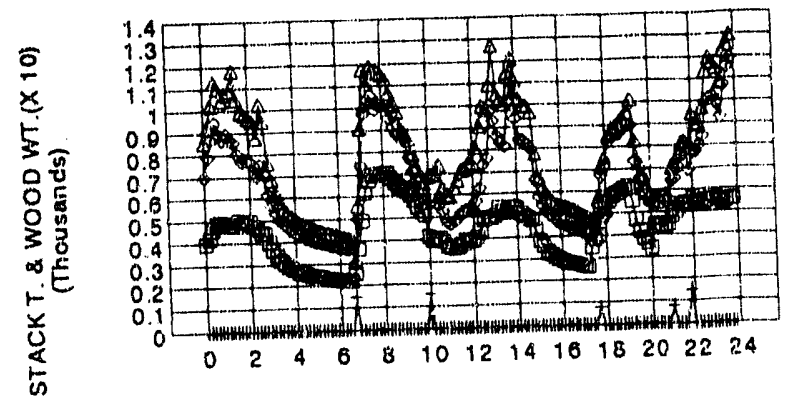

HOUR IN DAY

D STACK TEMP + WOOD WT. 10 \%PRE-CAT I CATALYST CATALYST TEMP VS DELTAT

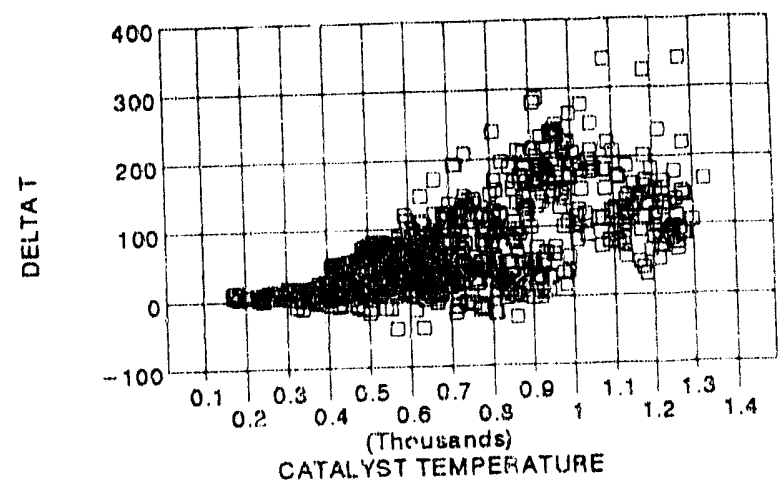

HISTOGRAM OF WOOD LOADS (WET LES) HOUSE AND RUN:

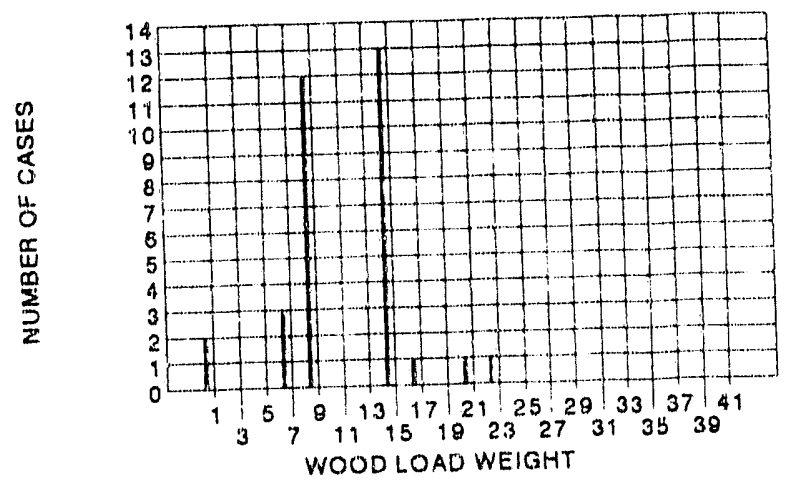

$\mathrm{KFO} 303$

1/25-31

JOTUL ALPHA

ECO-LOGS

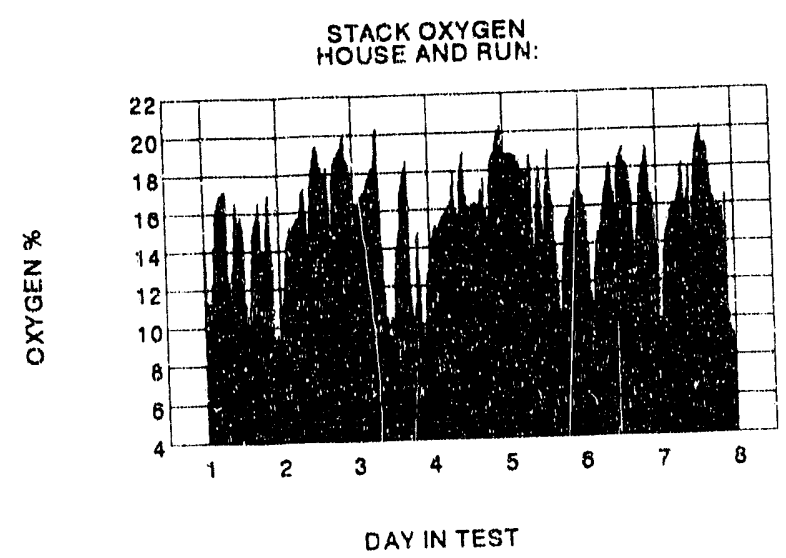

PERCENT OF TIME CATALYST IS HOTTER THAN SEIECTED TEMPS: HOUSE MND RUN:

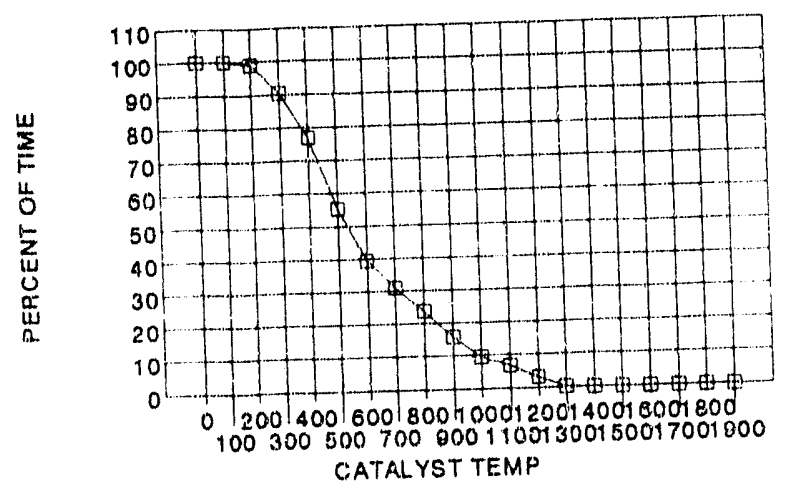

CATALYST VSOXYGEN

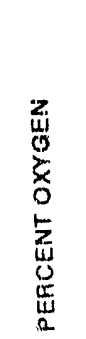

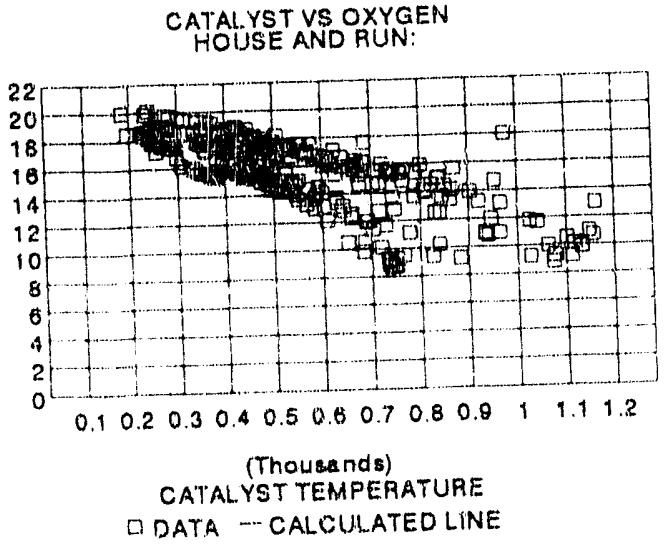


HOUSE \& RUN:

SAMPLE DATES:

STOVE TYPE:

FUEL TYPE:

TEMPERATURES AND WOOD LOADS (WT $\times 10$ ) DAY 1, HOUSE AND RUN:

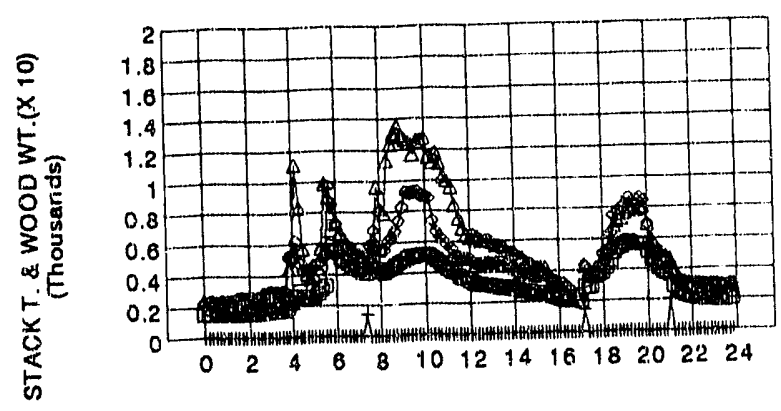

HOUR IN DAY

D STACKTEMP + WOODWT. X 10 OPRE-CAT $\triangle$ CATALYST

CATALYST TEMP VS. DELTAT T
HOUSE AND RUN:

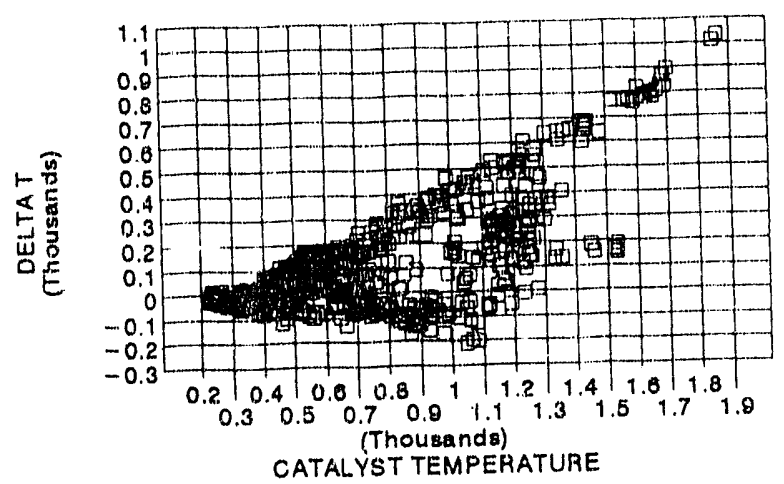
HISTOGRAM OF WOOD LOADS (WET LBS)
HOUSE AND RUN:

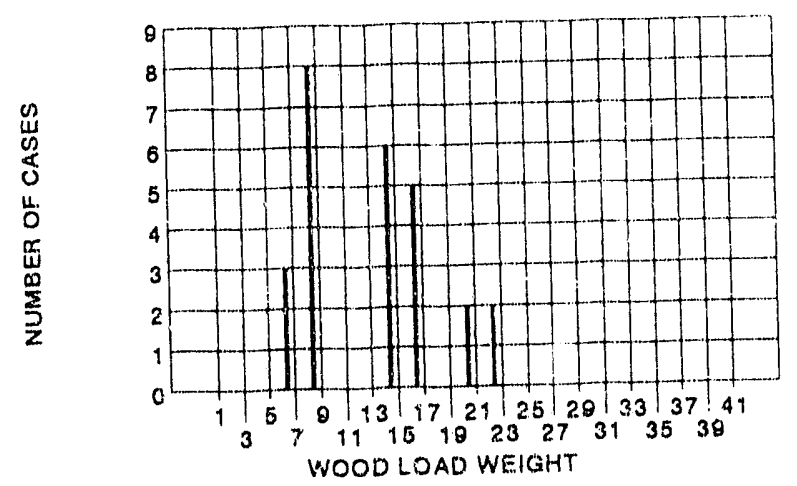

KF0304

3/4-11/92

JOTUL ALPHA

PRES-TO-LOGS

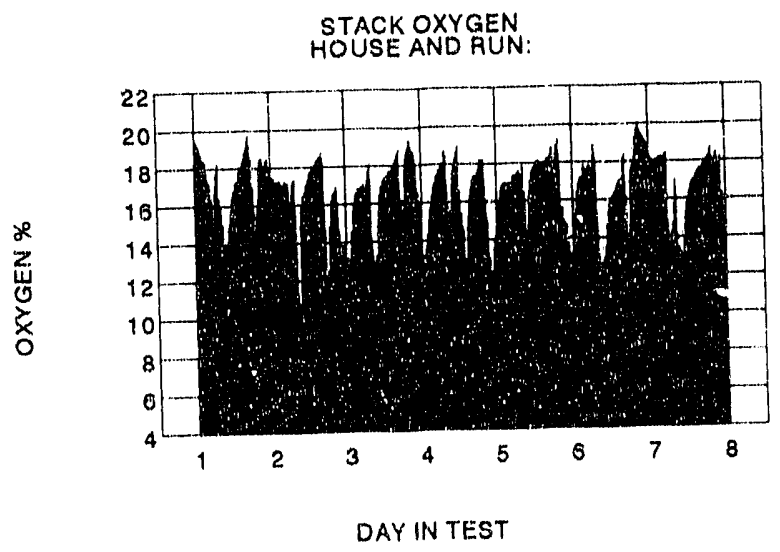

PERCENT OF TIME CATALYST IS HOTTER THAN SELECTED TEMPS: HOUSE AND RUN:

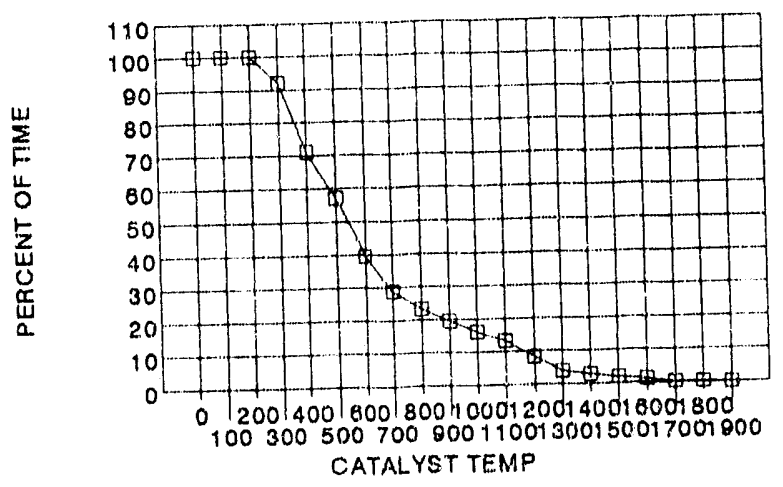

CATALIYST VS OXYGEN

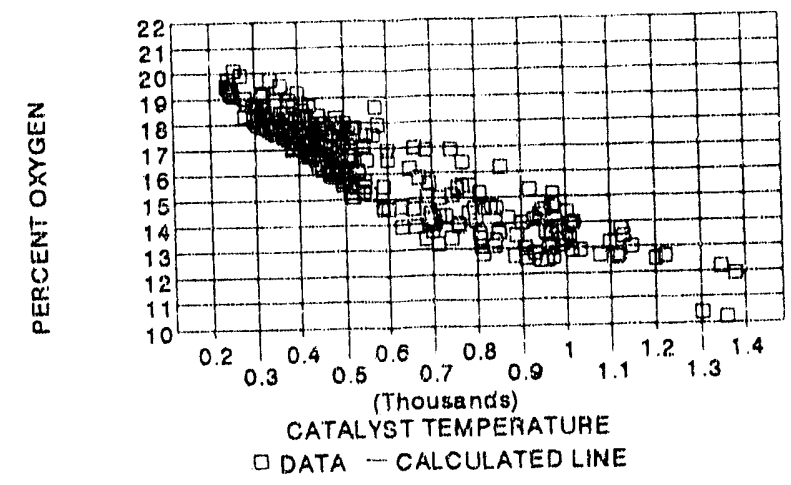


HOUSE \& RUN: F0401

SAMPLE DATES: $\quad 1 / 08-14 / 92$

STOVE TYPE: HAUGH

FUEL TYPE:

LODGEPOLE, D. FIR
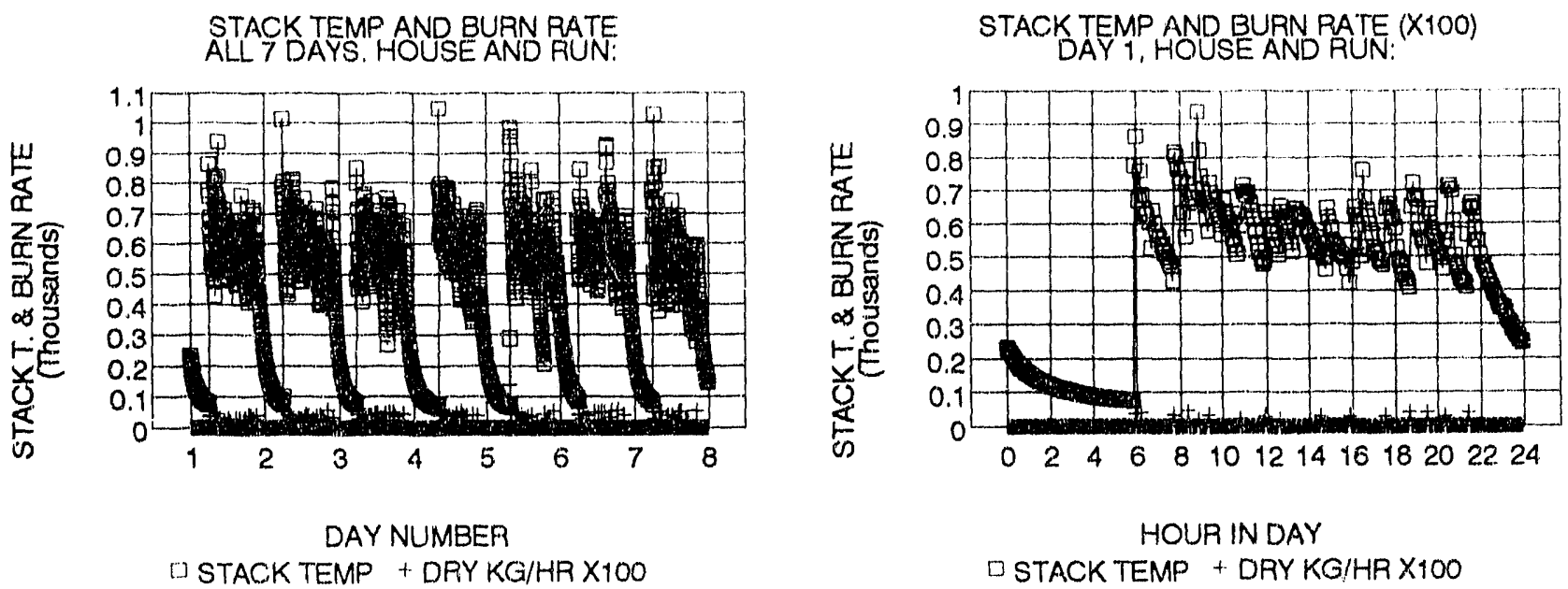

STACK OXYGEN \% FOR ALL 7 DAYS
HOUSE AND RUN:
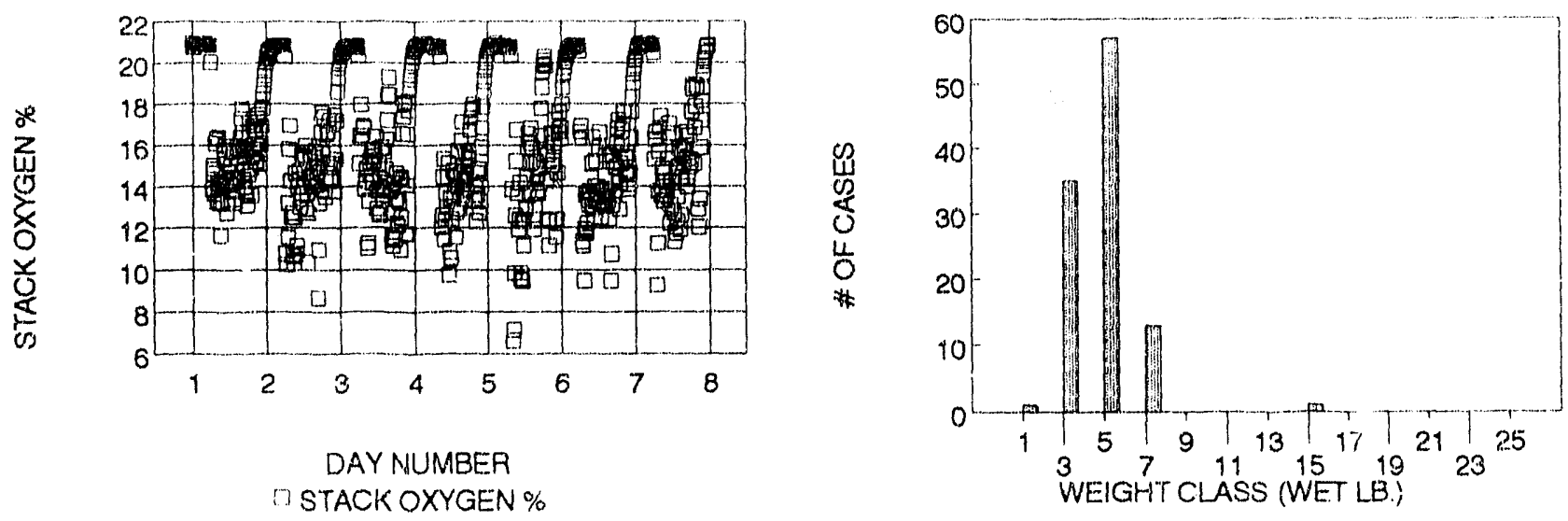

HOUSE AMBIENT TEMPERATURE HOUSE AND RUN:

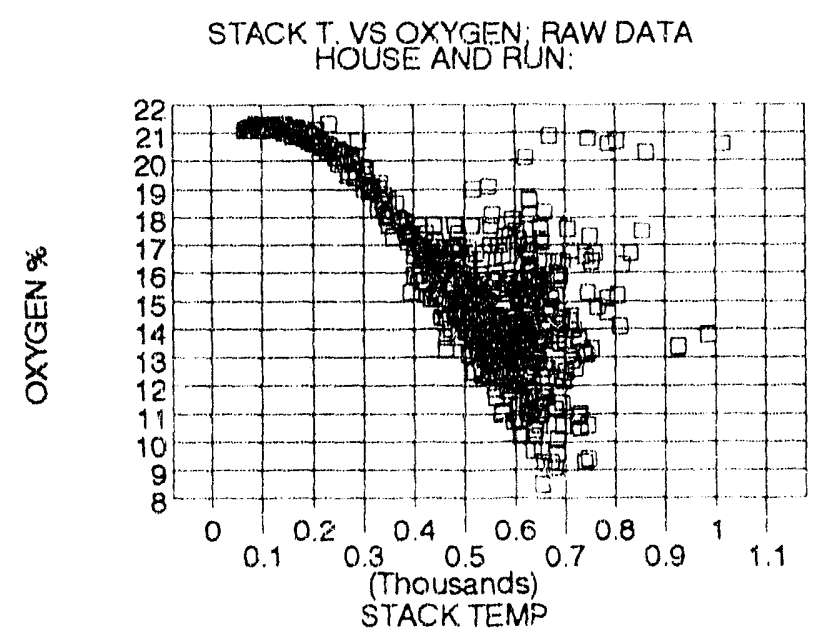

DAY!N TEST 
HOUSE \& RUN:

SAMPLE DATES:

STOVE TYPE:

FUEL TYPE:

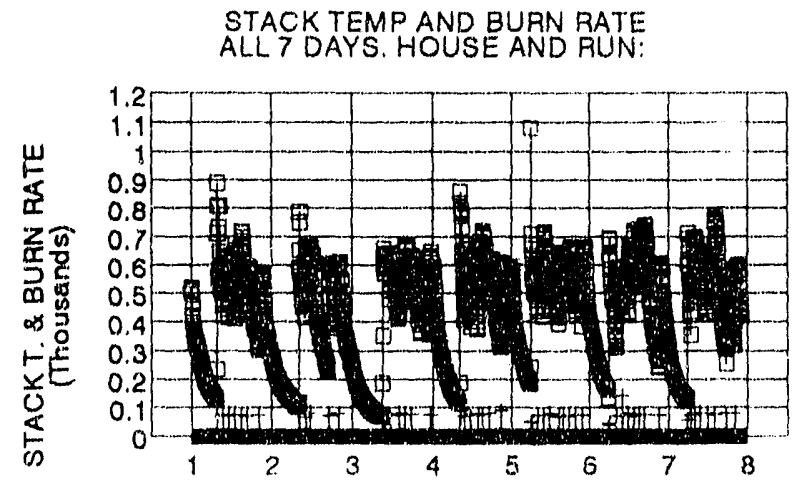

DAY NUMBER

1.) STACK TENDPY KG/HA $\times 100$

STACK OXYGEN \% FOR ALL 7 DAYS HOUSE AND RUN:

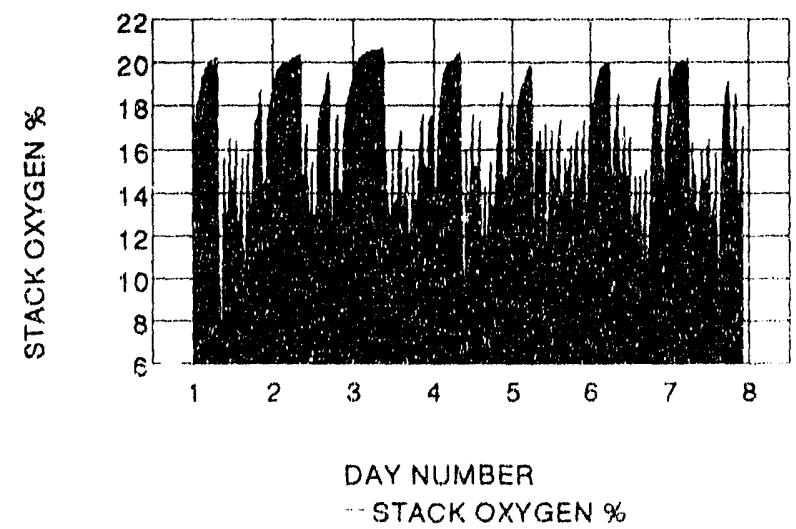

HOUSE AMBIENT TEMPERATUAE HOUSE AND FUN

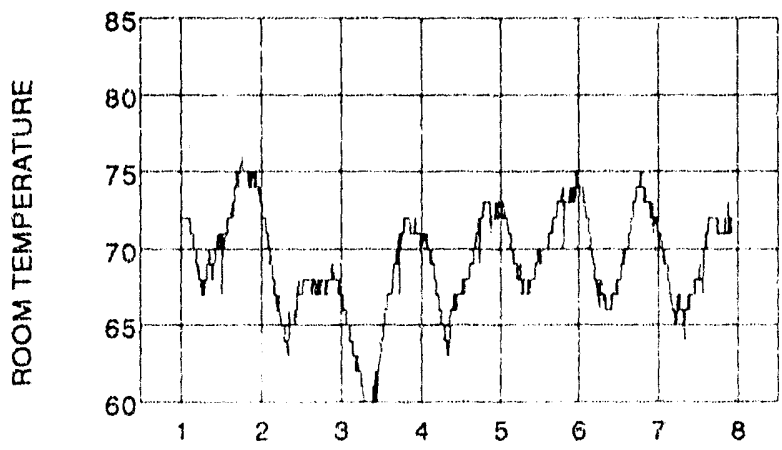

DAY IN TEST
KF0402

$1 / 17-23 / 92$

HAUGH

PRES-TO-LOGS

STACK TEMP AND BURN RATE $(X 100)$ DAY 1, HOUSE AND RUN:

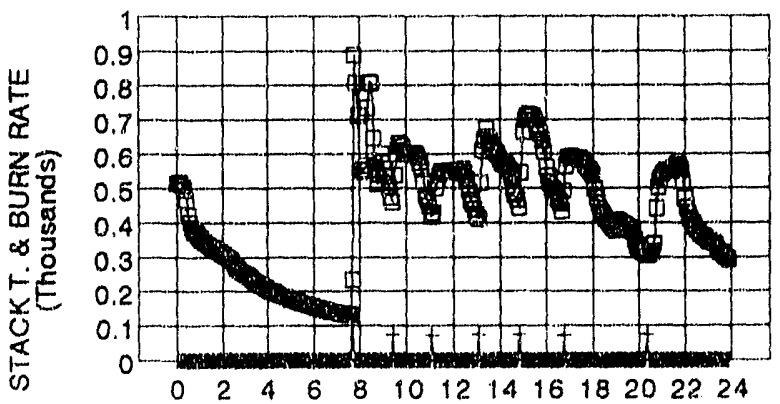

HOUR IN DAY

DSTACK TENDPY KG/HR $\times 100$

DISTRIBUTION OF WOOD LOAD WEIGHTS HOUSE AND RUNA:

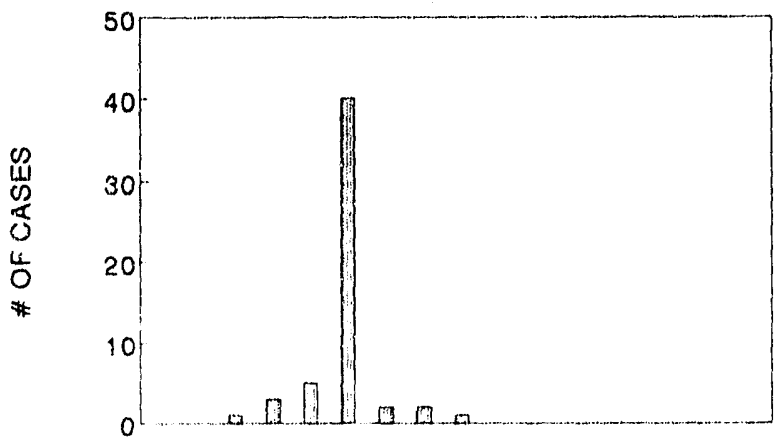

1357911131517192123252729 WEIGHT CLASS (WET LB.)

STACK T. VS OXYGEN; RAW DATA HOUSE AND RUN:

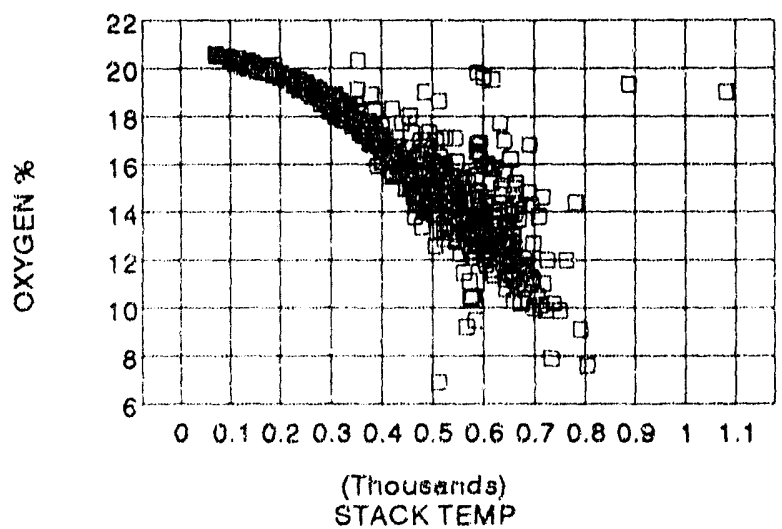


HOUSE \& RUN: KF0403

SAMPLE DATES: $\quad 1 / 25-31 / 92$

STOVE TYPE:

HAUGH

FUEL. TYPE:

STACK TEMP AND WOOD LOADS $\left(X_{10}\right)$

ALLL 7 DAYS. HOIJSE AND RUN:

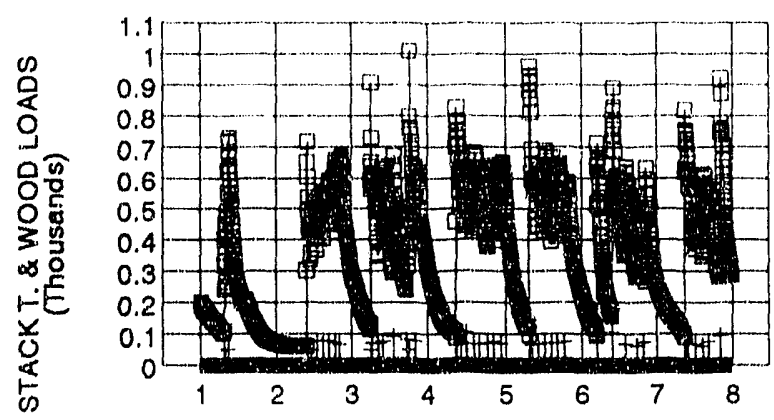

DAY NUMBER

1.) STACK TEMP + WOOO LOAD $(X 10)$

STACK DXYGEN \% FOA ALL 7 DAYS HOUSE AND RUN:

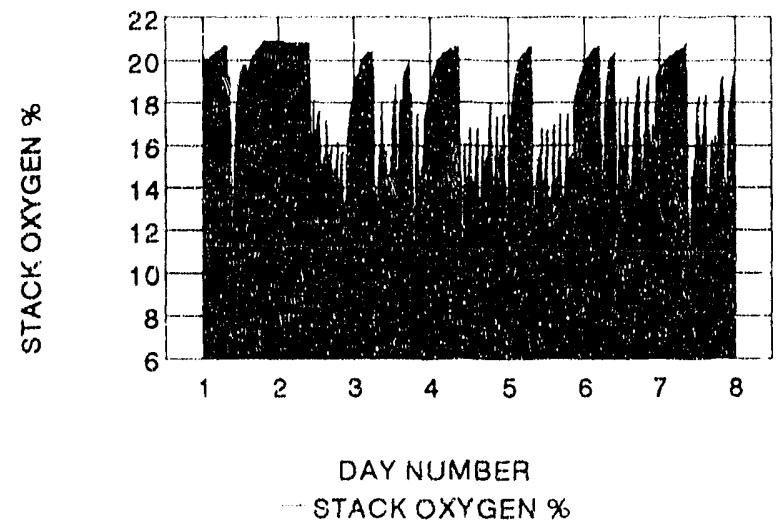

HOUSE AMBIENT TEMPERATURE HOUSE AND RUN:

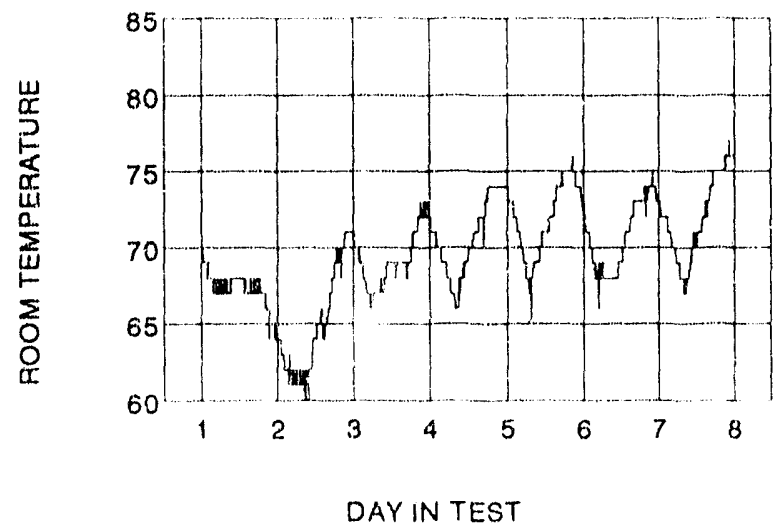

STACK TEMP AND WOOD LOADS (X10) DAY 1, HOUSE AND RUN:

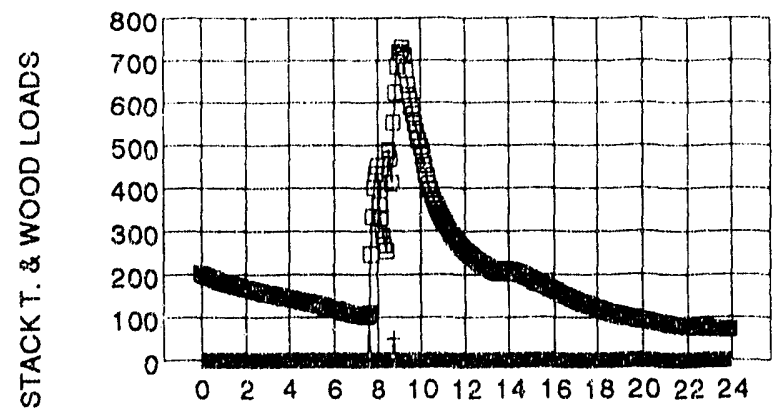

HOUR IN DAY

I STACK TEMP + WOOD LOAD $\left(X_{10}\right)$

DISTRIBUTION OF WOOD LOAD WEIGHTS HOUSE AND RUN:

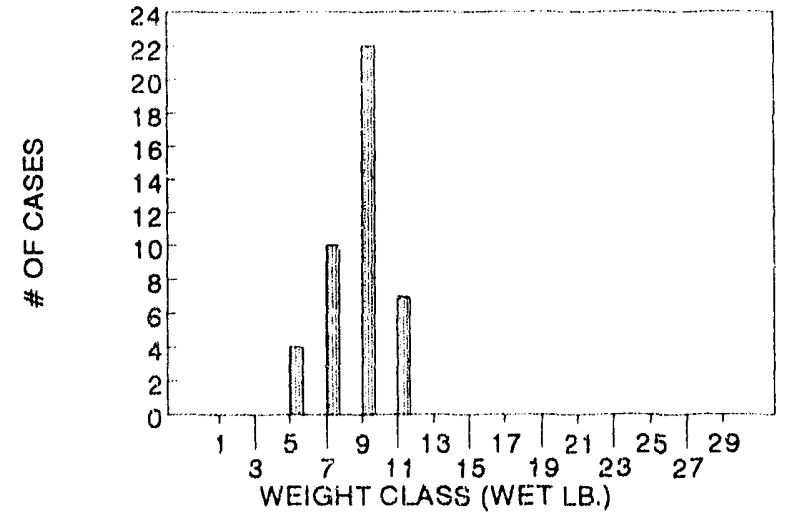

STACK T, VS OXYGEN; RAW DATA HOUSE AND RUN:

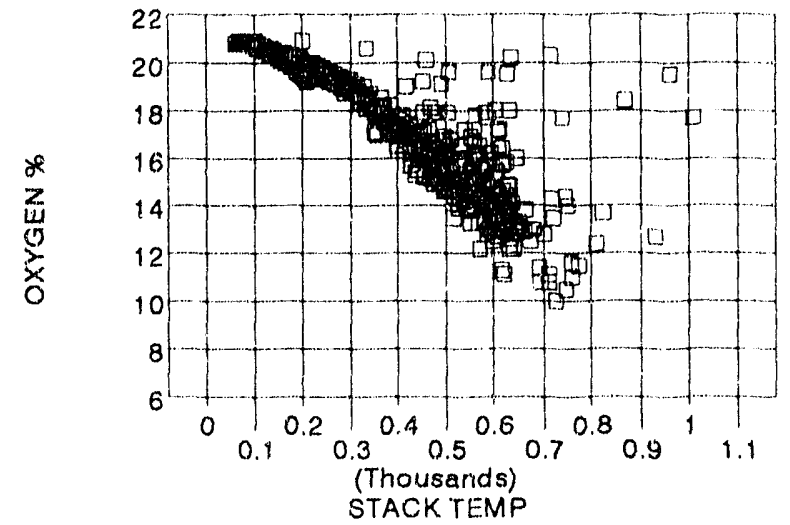


HOUSE \& RUN:

SAMPLE DATES:

STOVE TYPE:

FUEL TYPE:

STACK TEMP AND WOOD LOADS (X10)
ALL 7 DAYS. HOUSE AND RUN:
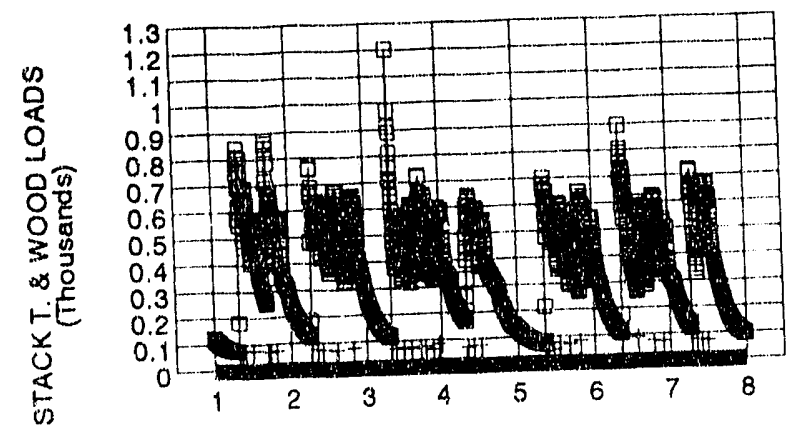

DAY NUMBER

1] STACK TEMP + WOOD LOAD $(X 10)$

STACK OXYGEN \% FOR ALL 7 DAYS HOUSE AND RUN:

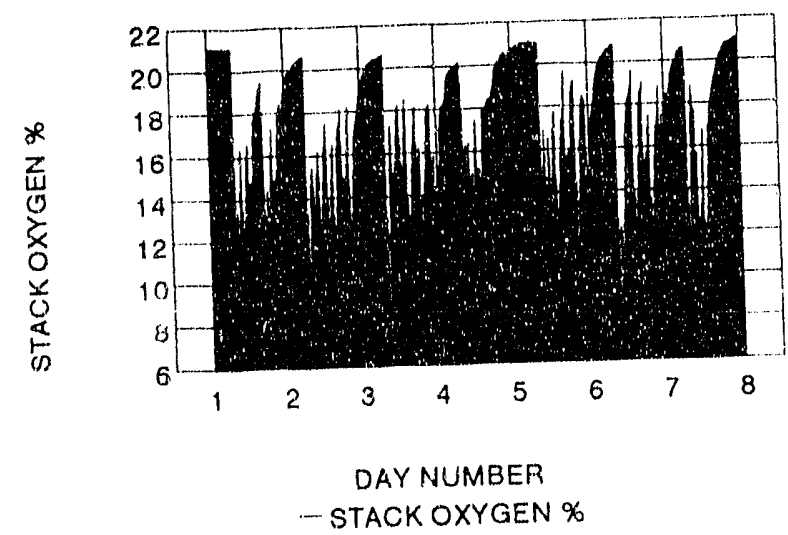

HOUSE AMBIENT TEMPERATURE HOUSE AND RUN:

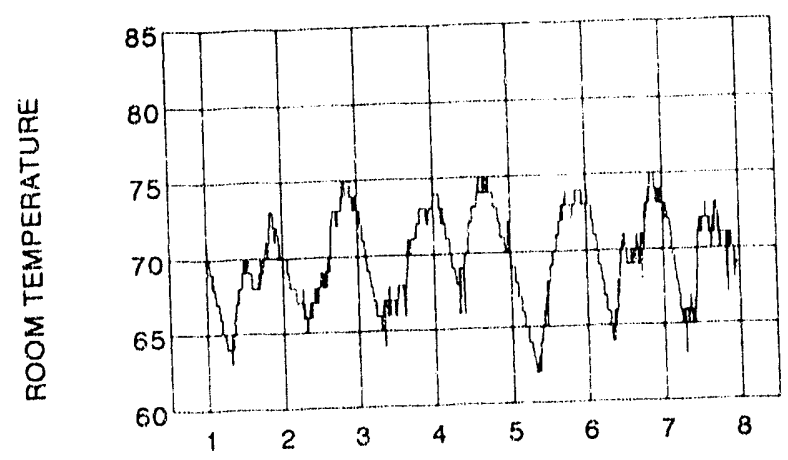

DAY IN TEST
KF0404

3/04-11/92

$\mathrm{HAUGH}$

PRES-TO-LOGS

STACK TEMP AND WOOD LOADS $(X 10)$ DAY 1 , HOUSE AND RUN:
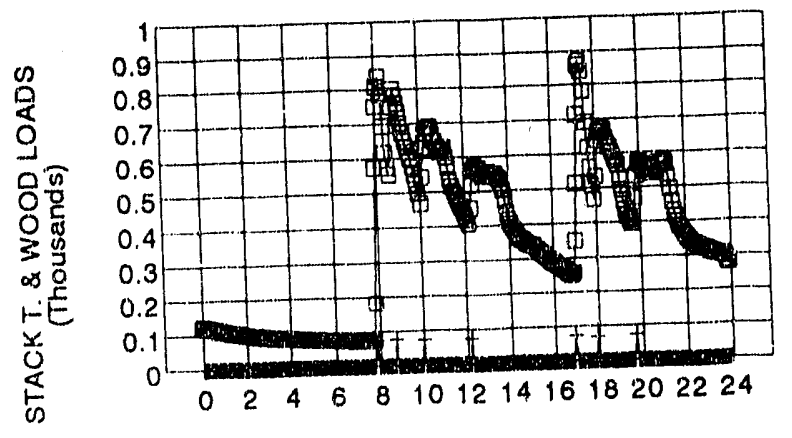

HOUR IN DAY

$\square$ STACK TEMP + WOOD LOAD (X10)

DISTAIBUTION OF WOOD LOAD WEIGHTS HOUSE AND RUN:

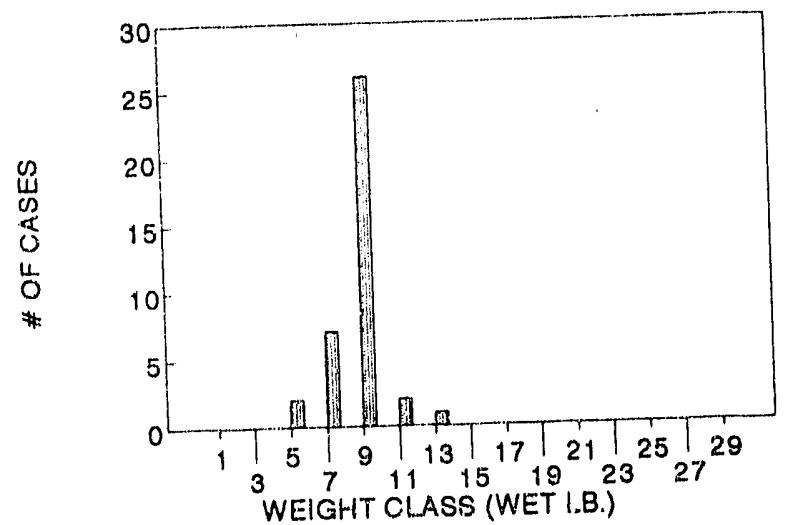

STACK T, VS OXYGEN; RAW DATA HOUSE AND RUN:

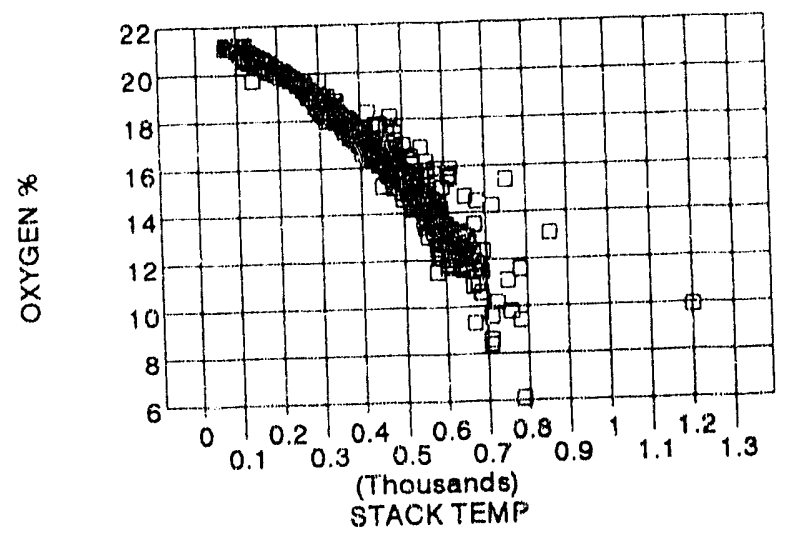


HOUSE \& RUN:
SAMPLE DATES:

STOVE TYPE:

FUEL TYPE:

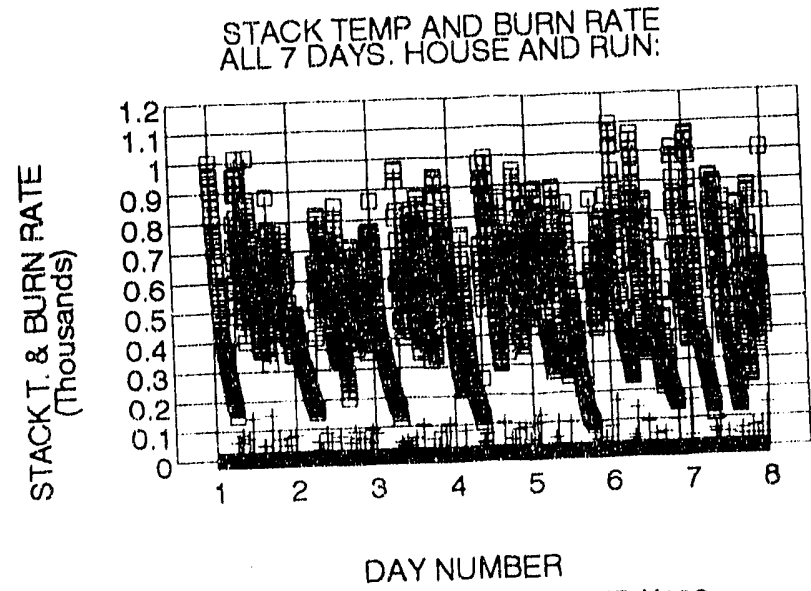

1. STACK TEMP + DRY KG/HR $\times 100$ HOUSE AND RUN:

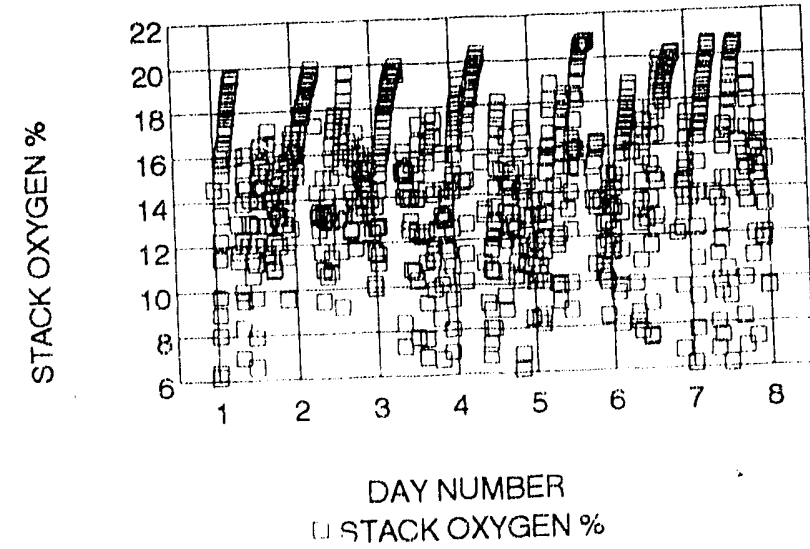

HOUSE AMBIENT TEMPERATURE HOUSE AND RUN:

崩
STACK OXYGEN \% FOR ALL 7 DAYS
KF0501

1/9-15/9?

PACIFIC ENERGY

LODGEPDLE STACK TEMP AND BURN RATE $(X 100)$
DAY 1 , HOUSE AND RUN:

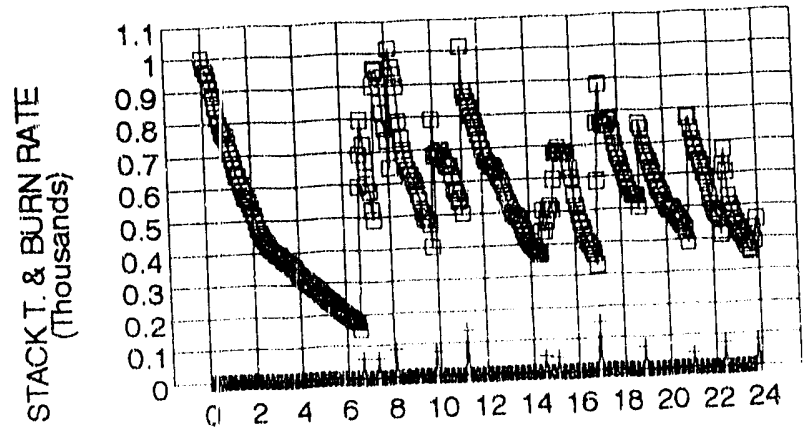

HOUR IN DAY

I STACK TEMP + DAY KG/HR $\times 100$

DISTRIBUTION OF WOOD LOAD WEIGHTS

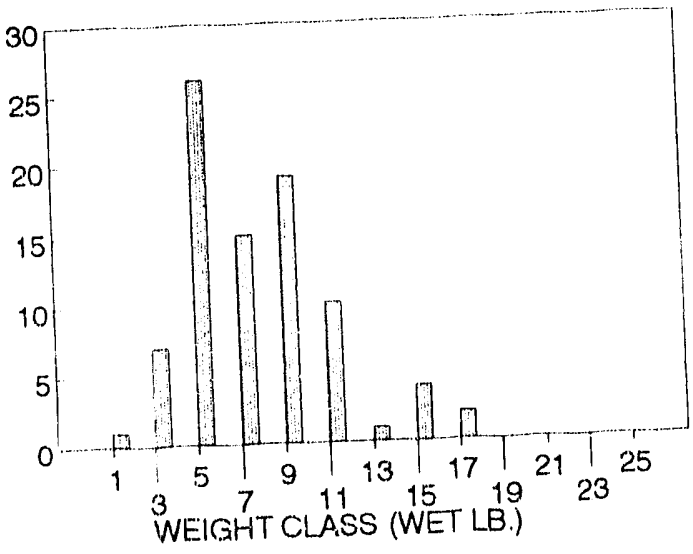

STACK T VS OXYGEN RAW DATA HOUSE AND RUN:

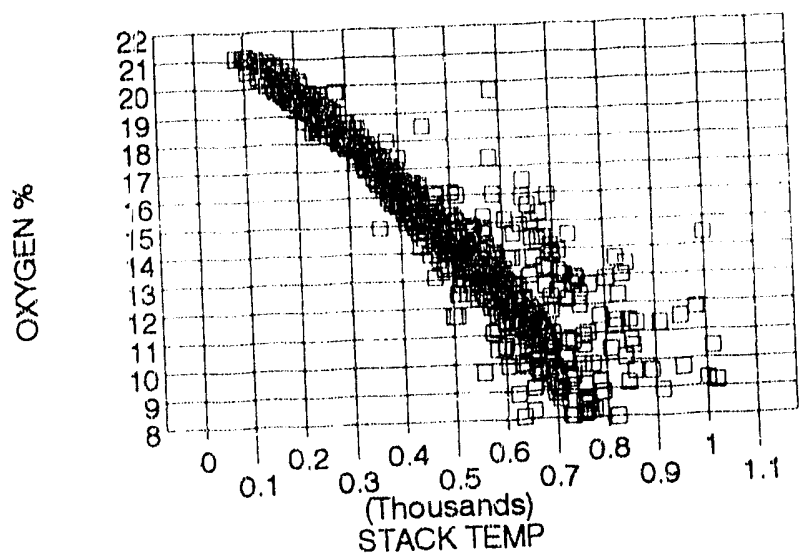


HOUSE \& RUN:

SAMPLE DATES:

STOVE TYPE:

FUEL TYPE:

STACK TEMP AND BURN RATE

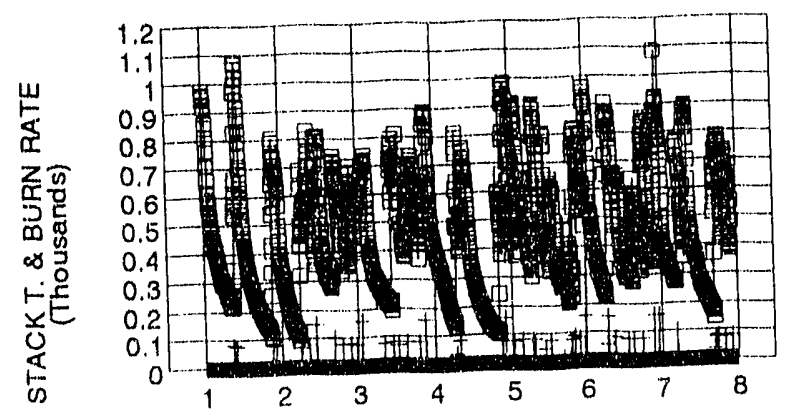

DAY NUMBER

D STACK TEMP + DAY KG/HR X100

STACK OXYGEN \% FOR ALL 7 DAYS HOUSE AND RUN:

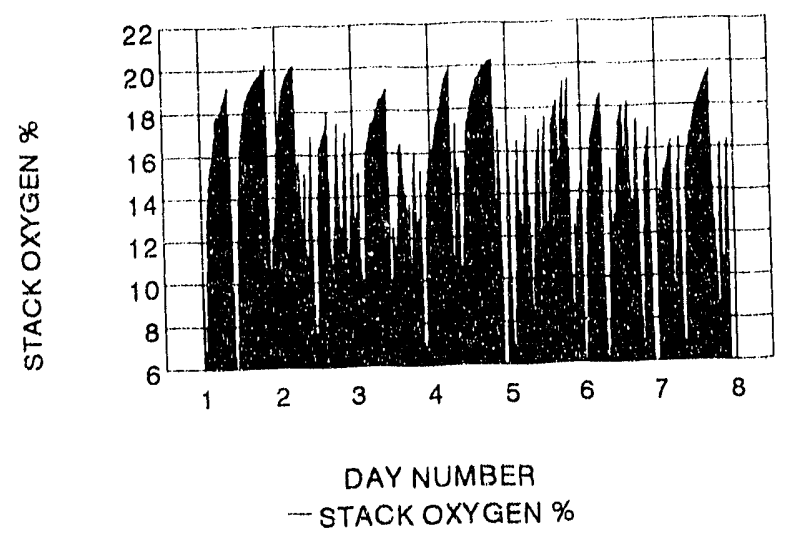

HOUSE AMBIENT TEMPERATURE HOUSE AND RUN:

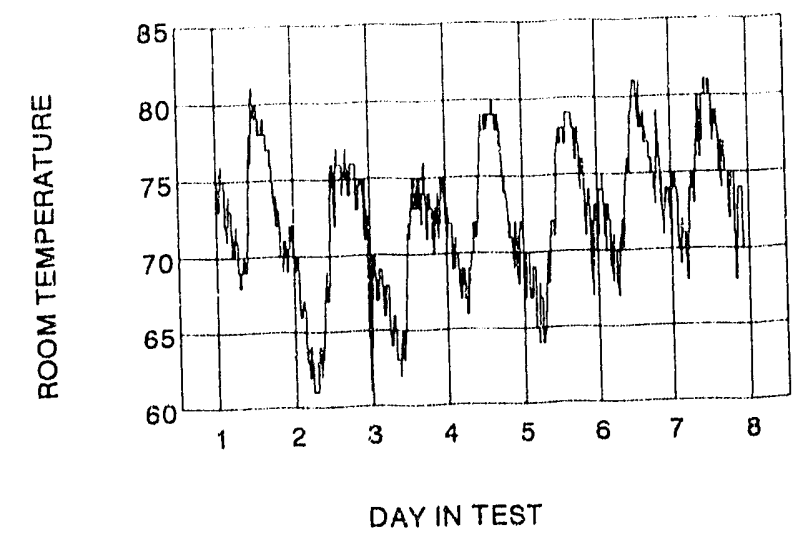

KF0502

1/18-24/92

PACIFIC ENERGY

PRES-TO-LOGS

STACK TEMP AND BURN RATE $(X 100)$ DAY 1 , HOUSE AND RUN:

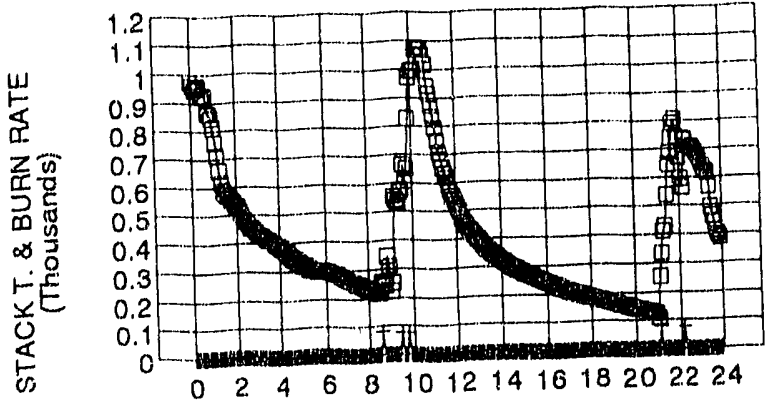

HOURIN DAY

口 STACK TEMP + DAY KG/HR $\times 100$

DISTRIBUTION OF WOOD LOAD WEIGHTS HOUSE AND RUN:

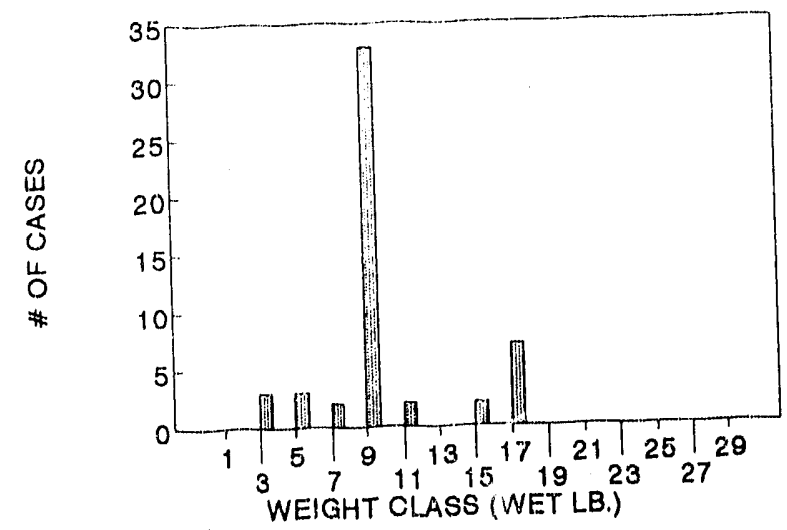

STACK T. VS OXYGEN: RAW DATA HOUSE AND RUN:

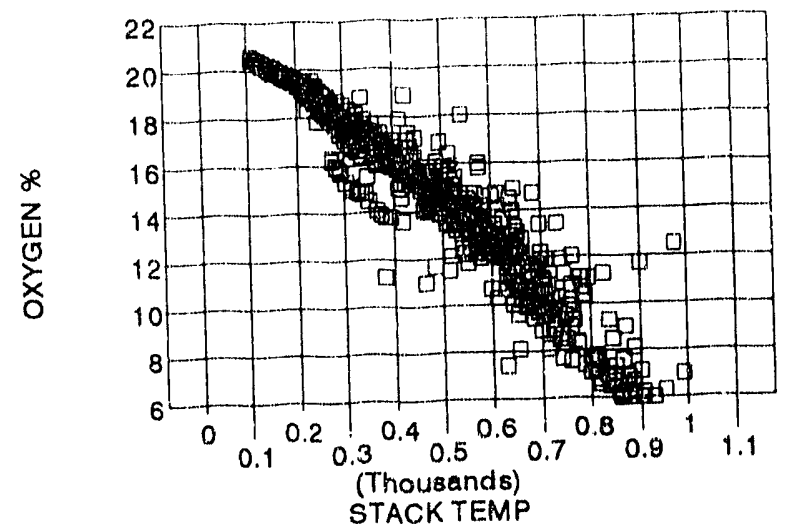


HOUSE \& RUN:

SAMPLE DATES:

STOVE TYPE:

FUEL TYPE:

STACK TEMP AND WOOD LOADS $(\times 10)$

ALL 7 DAYS, HOUSE AND RUN:

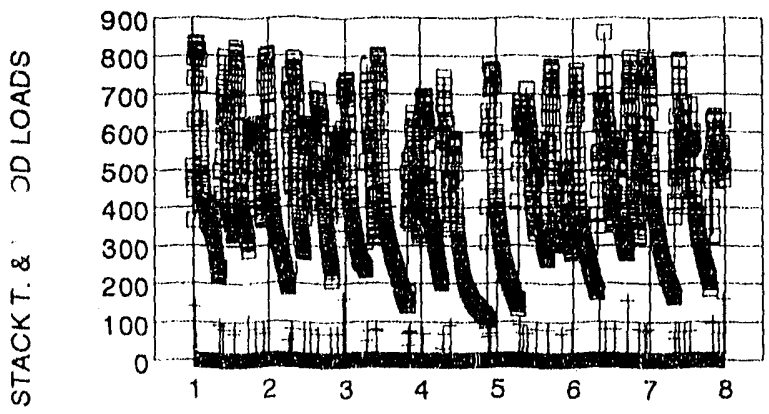

DAY NUMBER

[ STACK TEMP + WOOD LOAD $(X ; 0)$

STACK OXYGEN \% FOR ALL 7 DAYS HOUSE AND RUN:

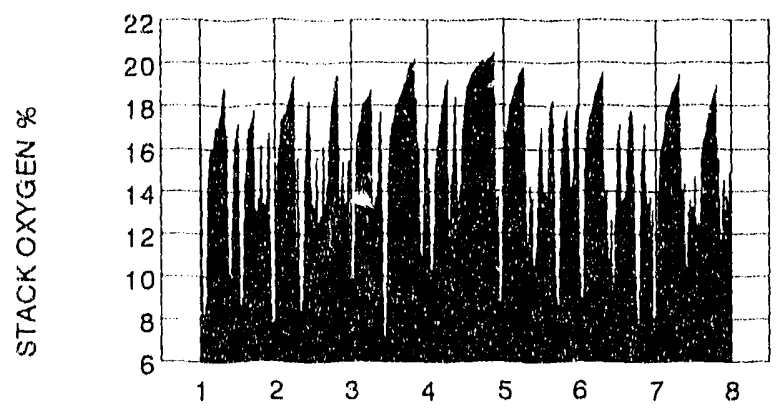

DAY NUMBER

STACK OXYGEN \%

HOUSE AMBIENT TEMPERATURE HOUSE AND RUN:

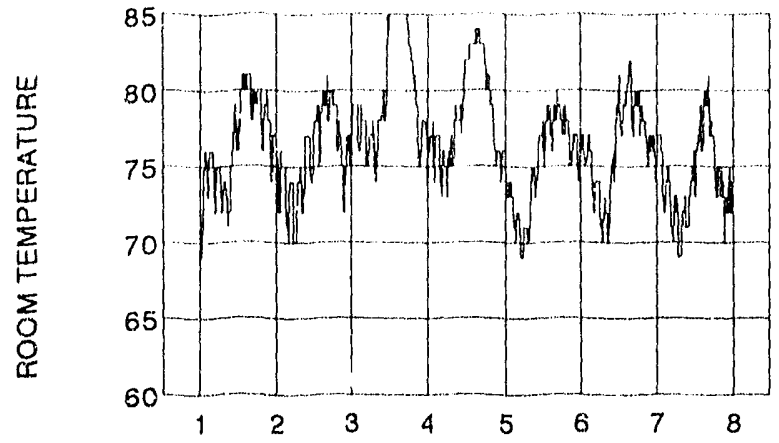

DAYIN TEST
$\mathrm{KF} 0503$

$1 / 26-2 / 1 / 92$

PACIFIC ENERGY

ECO-LOGS

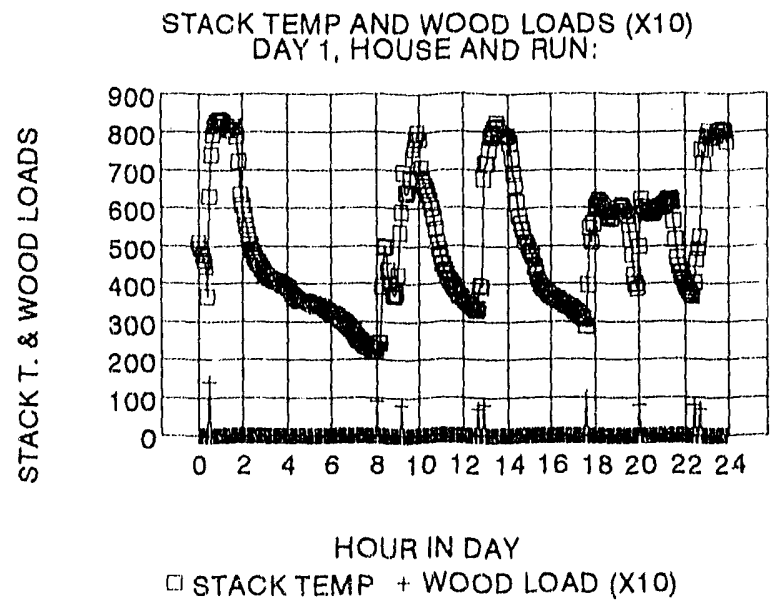

DISTRIBUTION OF WOOD LOAD WEIGHTS HOUSE AND RUN:

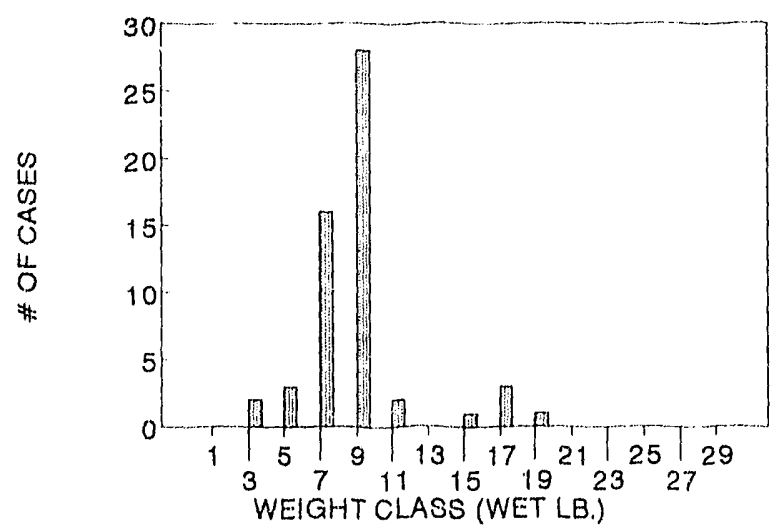

STACK T. VS OXYGEN; FAW DATA HOUSE AND RUN:

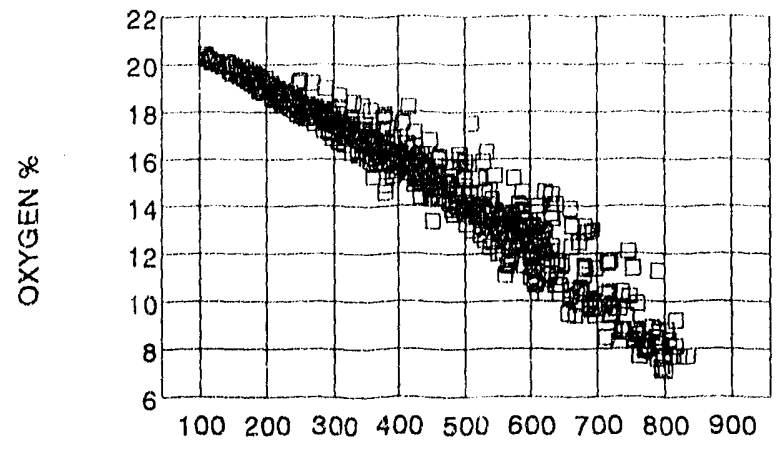

STACK TEMP 
HOUSE \& RUN:

SAMPLE DATES:

STOVE TYPE:

FUEL TYPE:

STACK TEMPAND WOOD LOAOS $(\times 10)$
ALL 7 DAYS. HOUSE AND RUN:

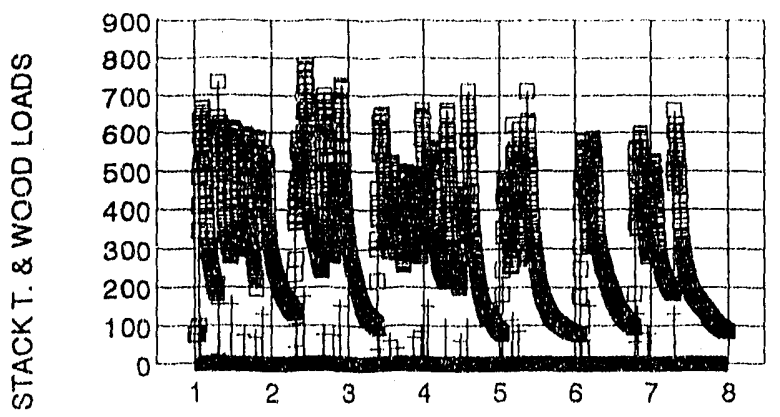

DAY NUMBER

1. STACK TEMP + WOOD LOAD $\left(X_{10}\right)$

STACK OXYGEN \% FOR ALL 7 DAYS HOUSE AND RUN:

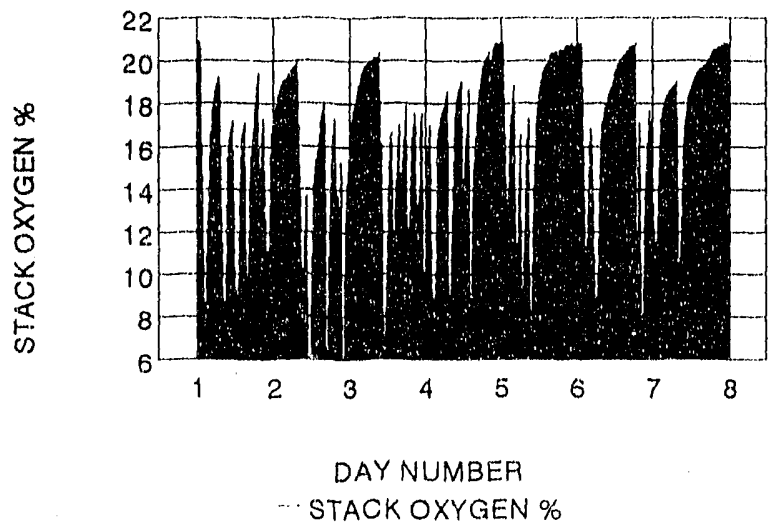

HOUSE AMBIENT TEMPERATURE HOUSE AND RUN:

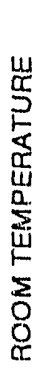

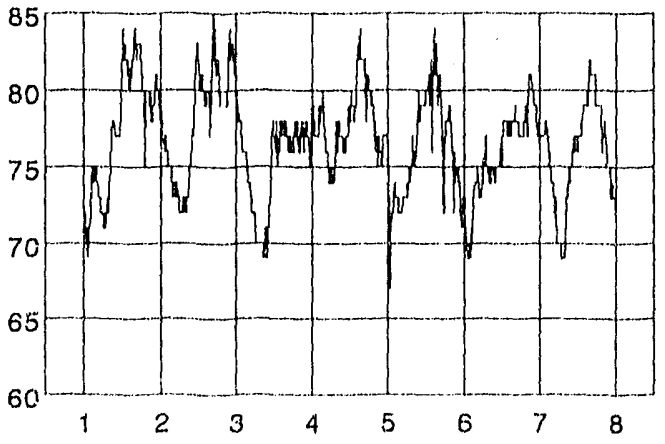

DAY IN TEST
KF0504

3/04-10/92

PAC. ENERGY

PRES-TO-LOGS

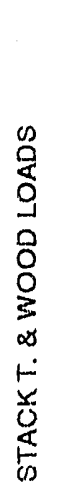
STACK TEMP AND WOOD LOADS $(\times 10)$
DAY 1 , HOUSE AND RUN:

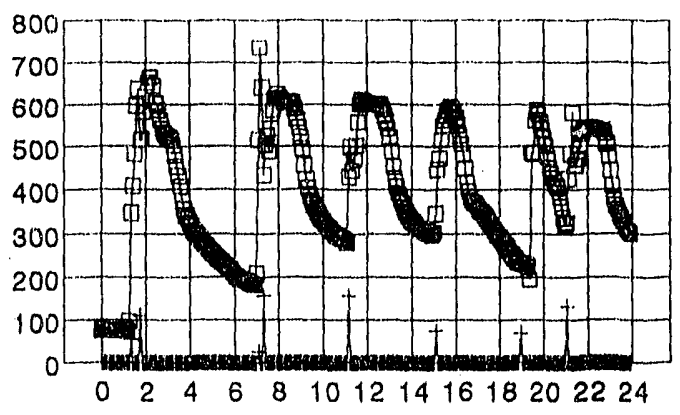

HOUAIN DAY

G. STACK TEMP + WOOD LOAD $(X 10)$

DISTRIBUTION OF WOOD LOAD WEIGHTS
HOUSE AND RUN:

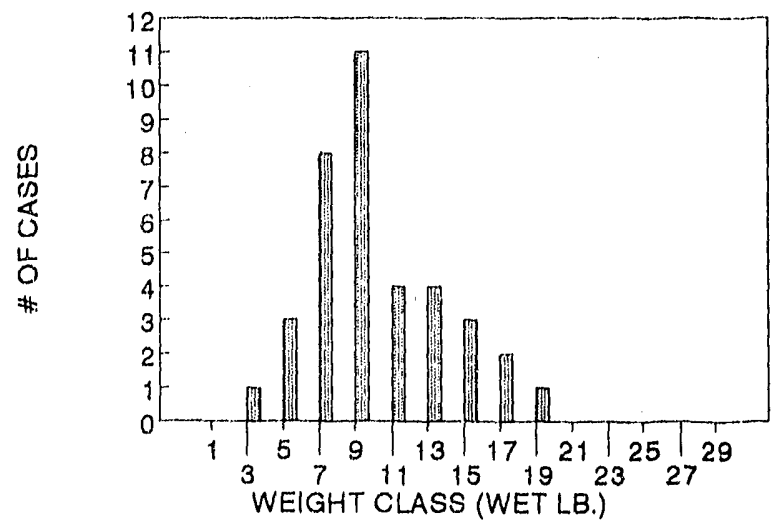

STACK T. VS OXYGEN: RAW DATA HOUSE AND RUN:

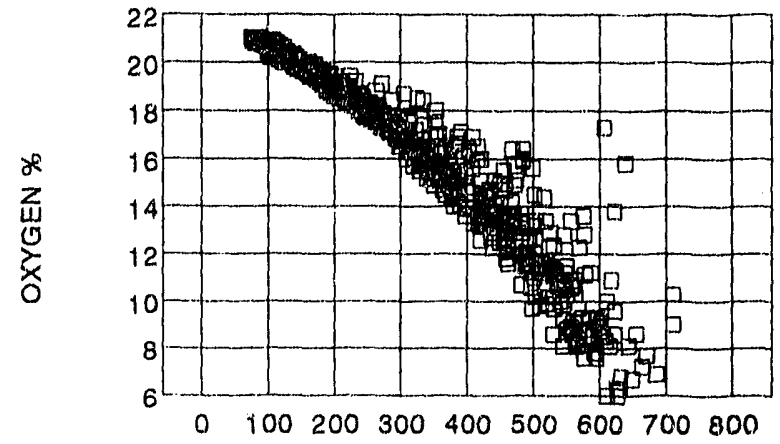

STACK TEMP 
HOUSE \& RUN:

SAMPLE DATES:

STOVE TYPE: FUEL TYPE:

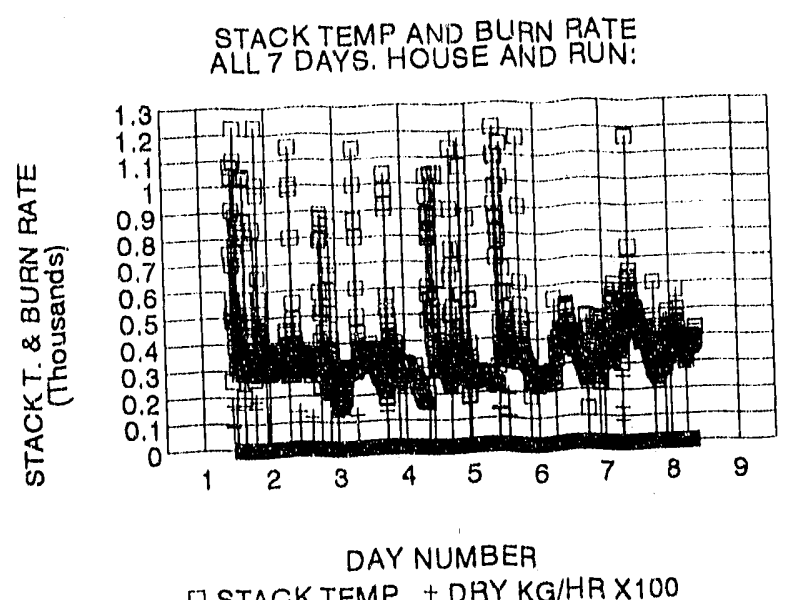

STACK OXYGEN \% FOR ALL 7 DAYS HOUSE AND RUN:

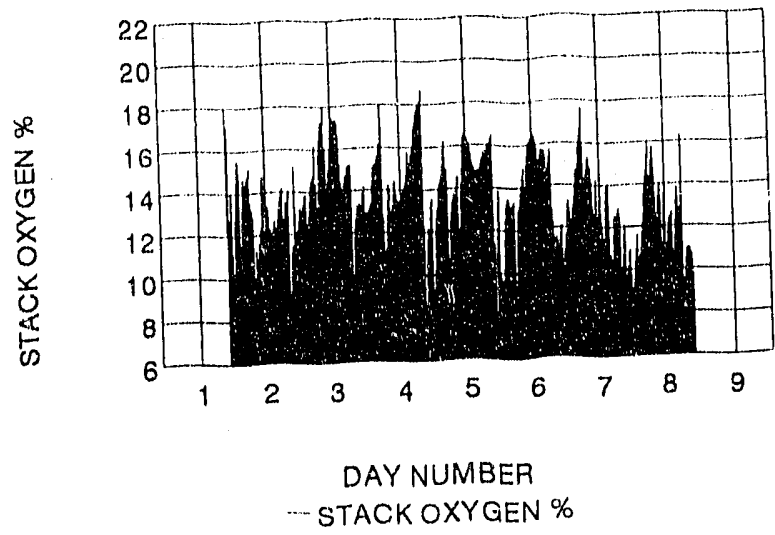

HOUSE AMBIENT TEMPERATURE HOUSE AND RUN:

殅

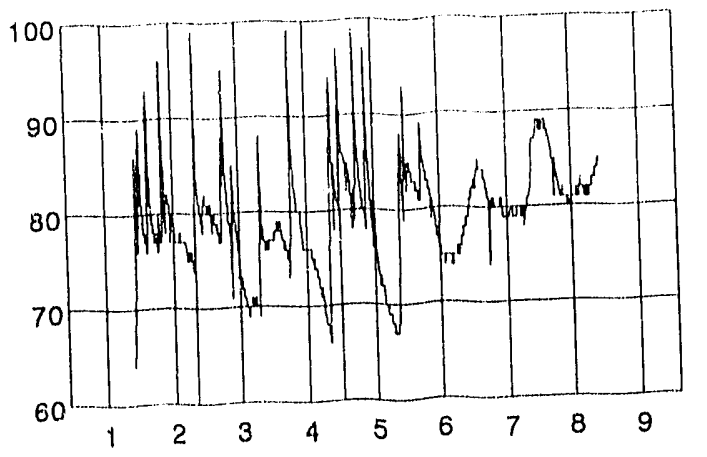

DAY IN TEST
F0601

1/08-14/92

EARTH CONVENTIONAL LODGEPOLE, ALDER

STACK TEMP AND BUPN RATE (X100) DAY 1 , HOUSE AND RUN:

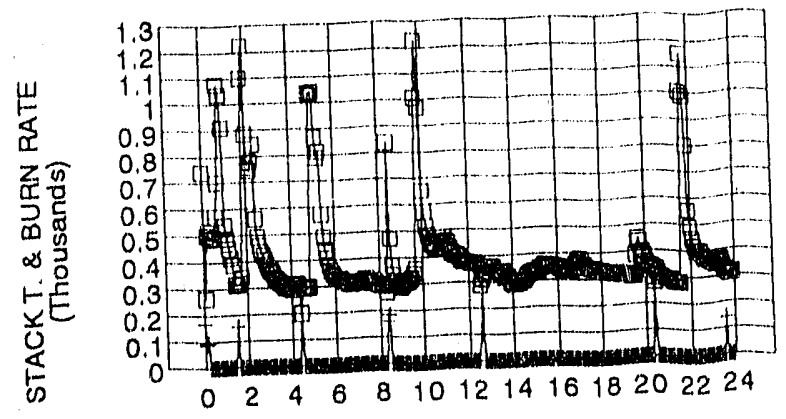

HOUR IN DAY

D STACK TEMP + DAY KG/HAX100

\section{DISTRIBUTION OF WOOD LOAD WEIGHTS} HOUSE AND RUN:

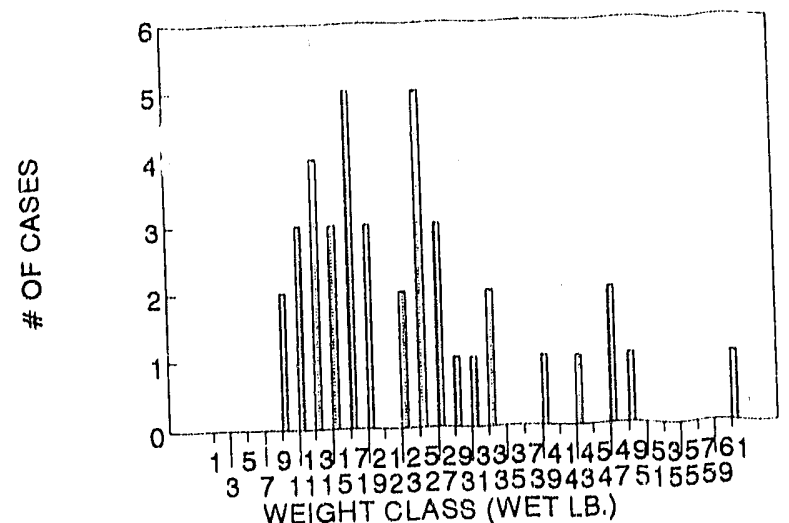

STACK T VS OXYGEN; RAW DATA HOUSE AND RUN:

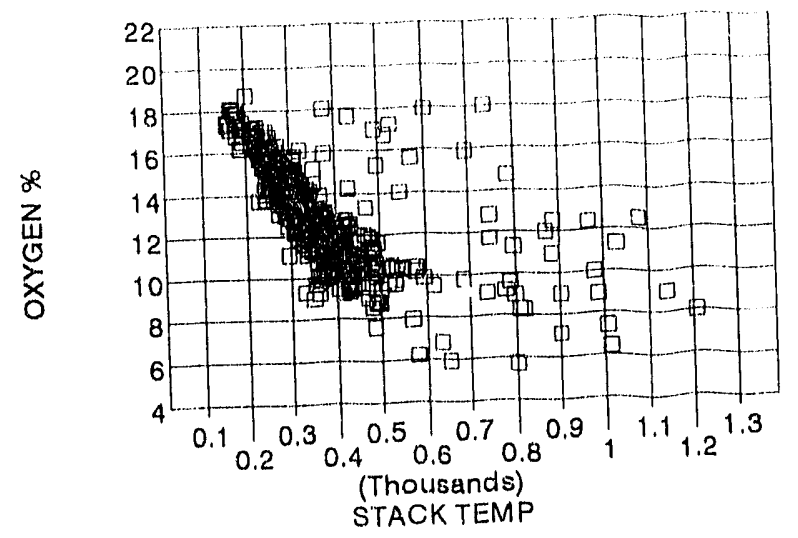


HOUSE \& RUN:

SAMPLE DATES:

STOVE TYPE:

FUEL TYPE:

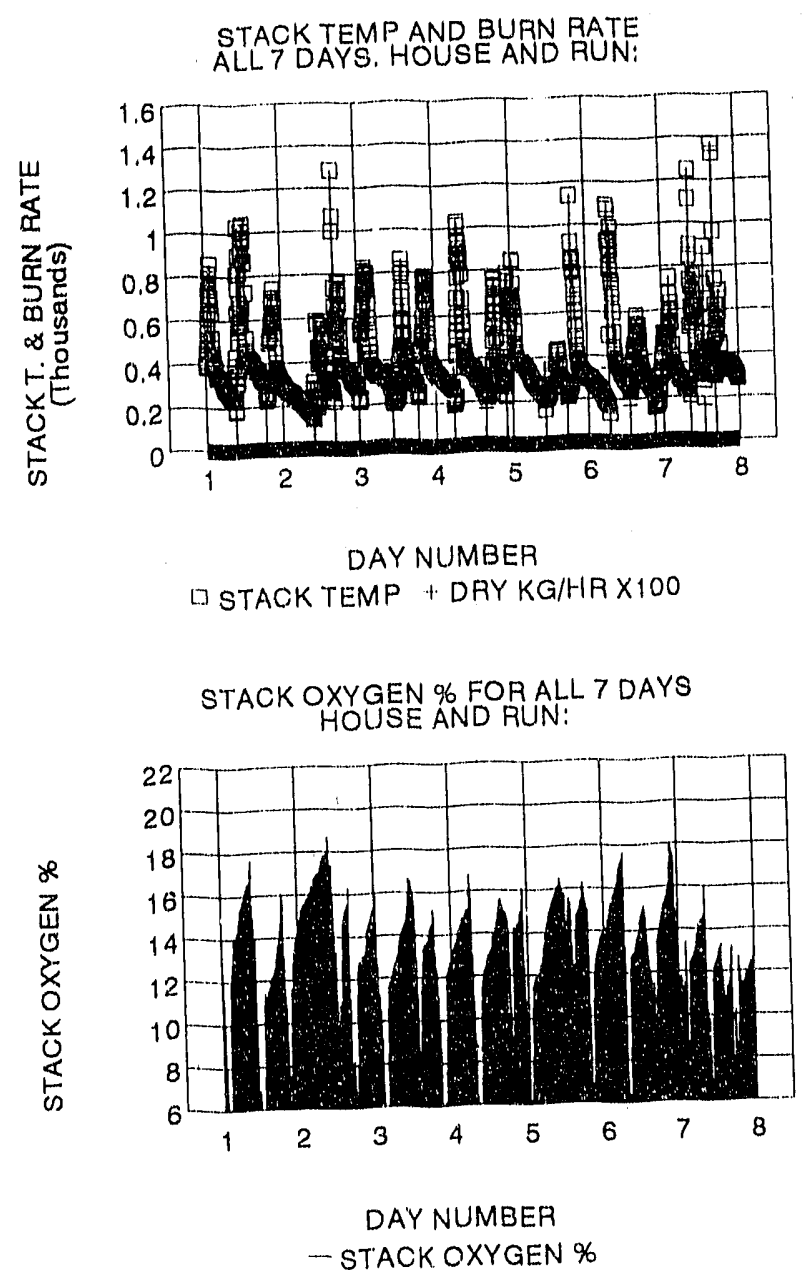

HOUSE AMBIENT TEMPERAT'JRE HOUSE AND RUN:

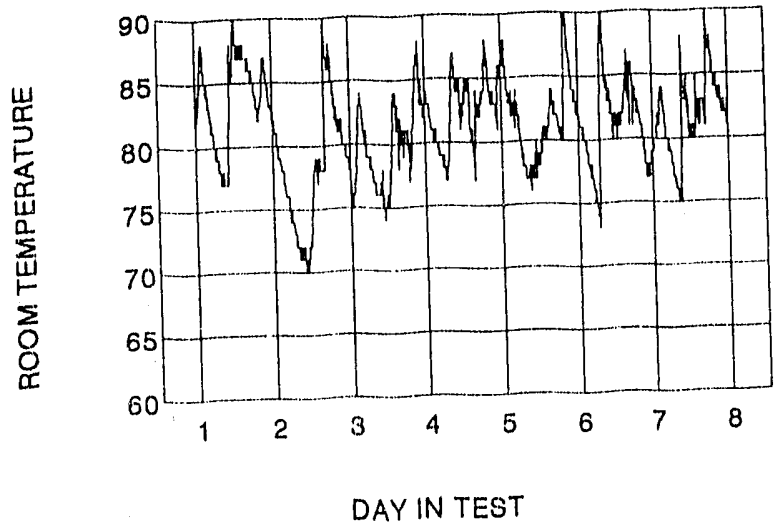

KF0602

$1 / 18-24 / 92$

EARTH 101; CONVENTIONAL PRES-TO-LOGS

STACK TEMP AND BURN PATE (X100) DAY 1 , HOUSE AND RUN:

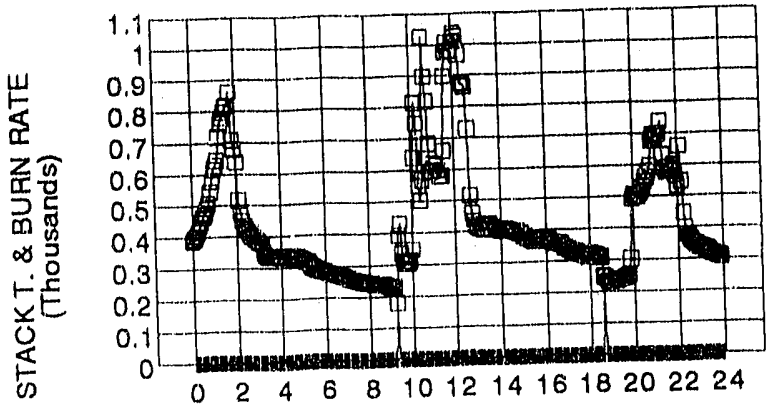

HOUR IN DAY

口 STACK TEMP + DRY KG/HA X100

DISTRIBUTION OF WOOD LOAD WEIGHTS HOUSE AND RUN:

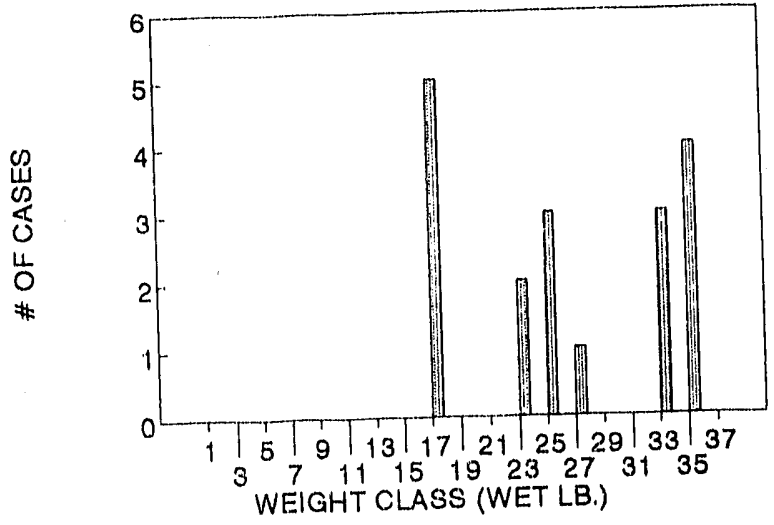

STACK T VS OXYGEN RAW DATA HOUSE AND RUN:

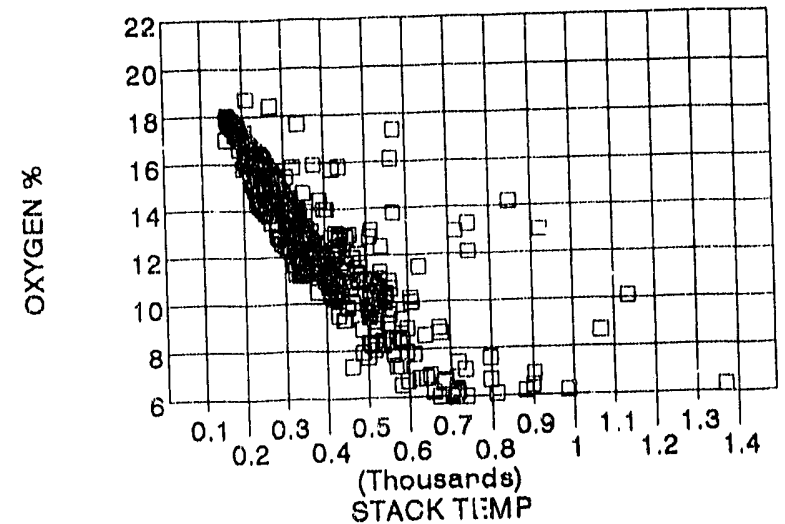


HOUSE \& RUN:

SAMPLE DATES:

STOVE TYPE:

FUEL TYPE:

STACK TEMP AND WOOD LOADS $(X 10)$

ALI 7 DAYS. HOUSE AND RUN:
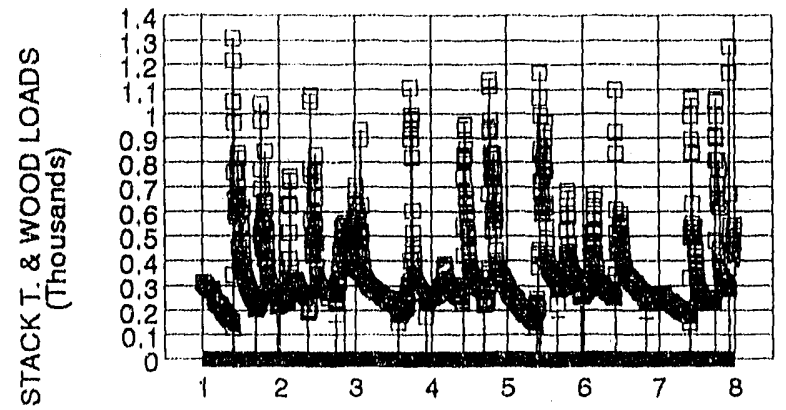

DAY NUMBER

I. STACK 'TEMP + WOOD LOAD $(X 10)$

STACK OXYGEN \% FOR ALL 7 DAYS HOUSE AND RUN:

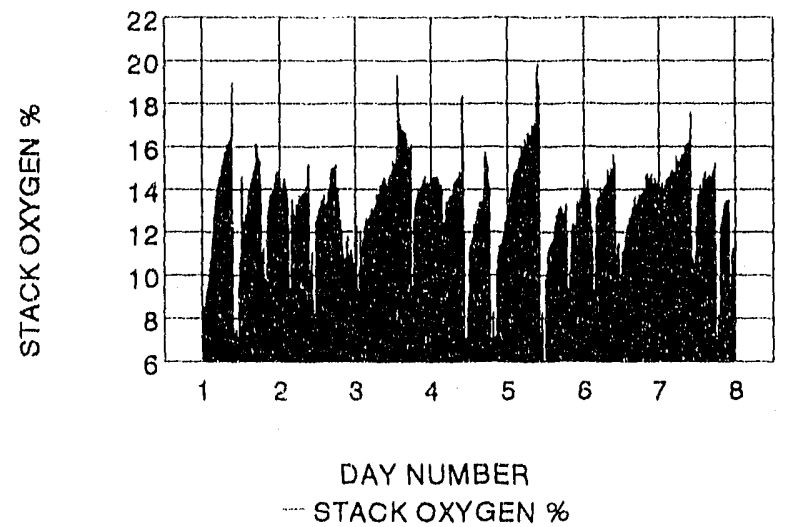

HOUSE AMBIENT TEMPERATURE HOUSE AND RUN

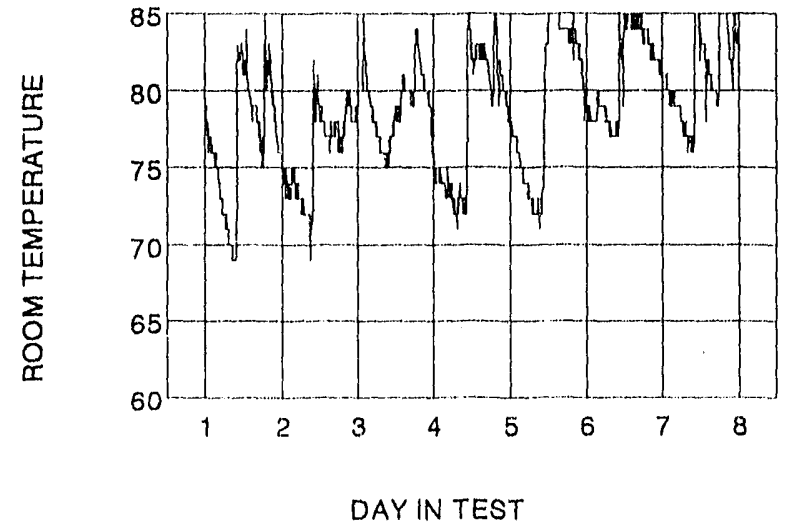

$\mathrm{KF} 0603$

$1 / 26-2 / 1 / 92$

EARTH 101

\section{ECO-LOGS}

STACK TEMP AND WOOD LOADS $(X 10)$ DAY 1, HOUSE AND RUN:
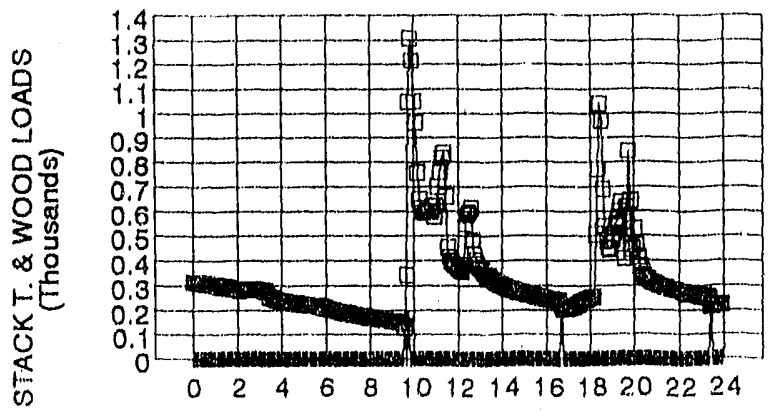

HOUA IN DAY

口 STACK TEMP + WOOD LOAD (X10)

DISTRIBUTION OF WOOD LOAD WEIGHTS HOUSE AND RUN:

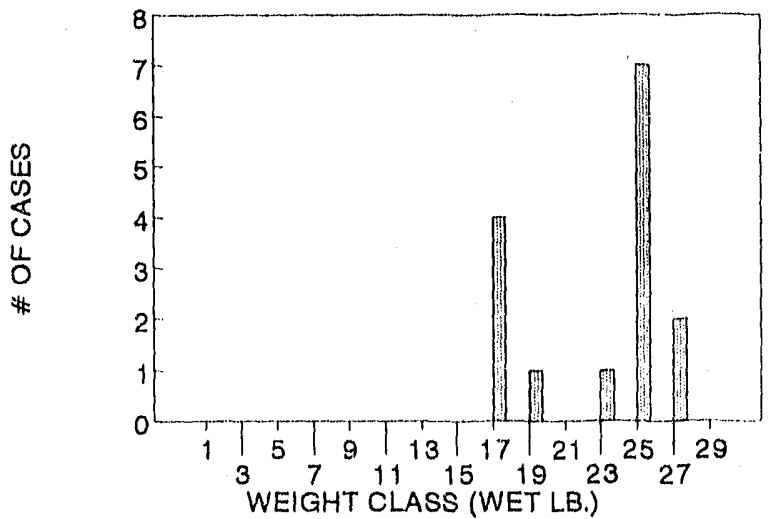

STACK T, VS OXYGEN: RAW DATA HOUSE AND RLNN:

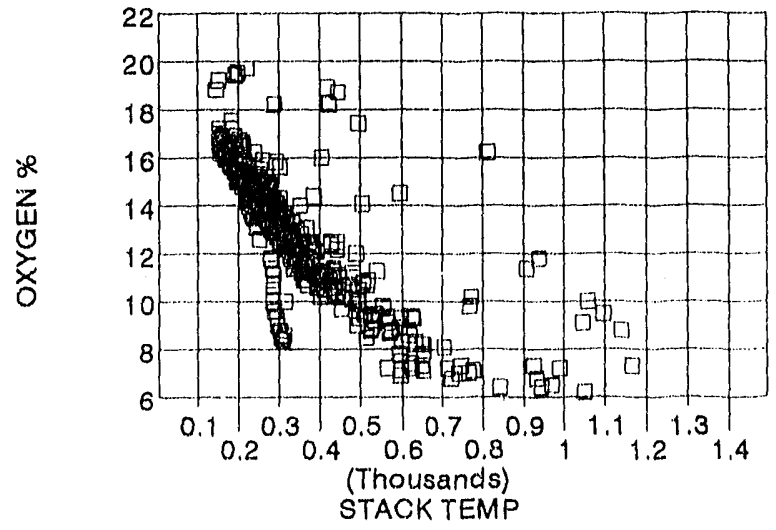


HOUSE \& RUN:

SAMPLE DATES:

STOVE TYPE:

FUEL TYPE:

STACK TEMP AND WOOD LOADS (X10)

ALL 7 DAYS. HOUSE AND RUN:
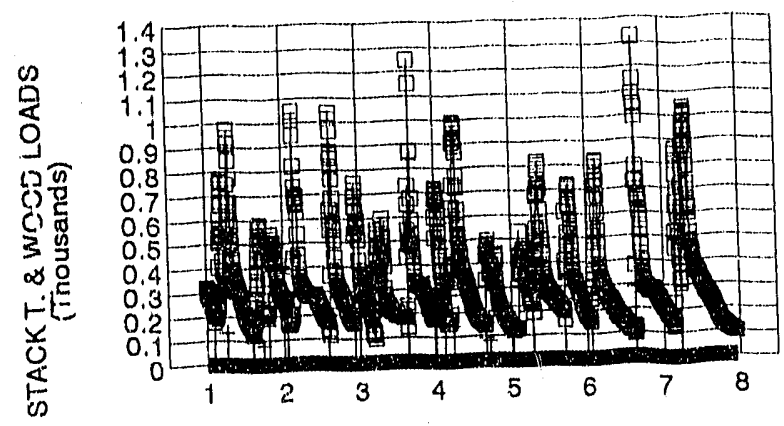

DAY NUMBEA

口 STACK TEMP + WOOD LOAD $\left(X_{10}\right)$

STACK OXYGEN \% FOR ALL. 7 DAYS HOUSE AND RUN:

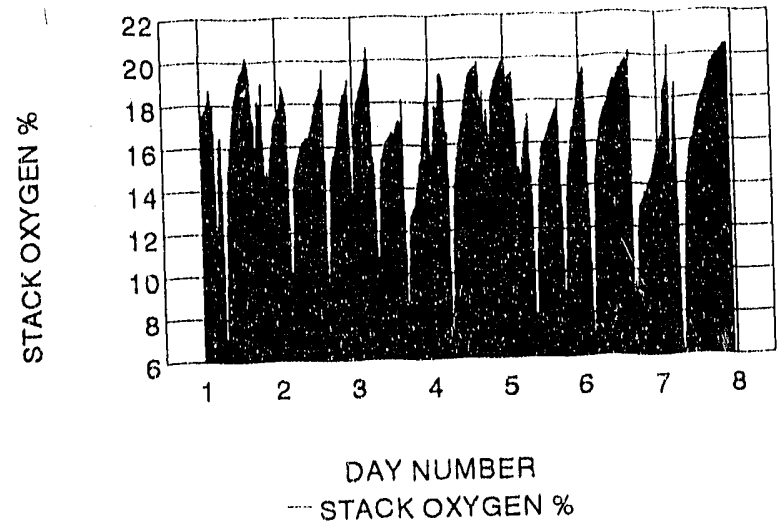

HOUSE AMBIENT TEMPERATURE HOUSE AND RUN:

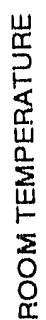

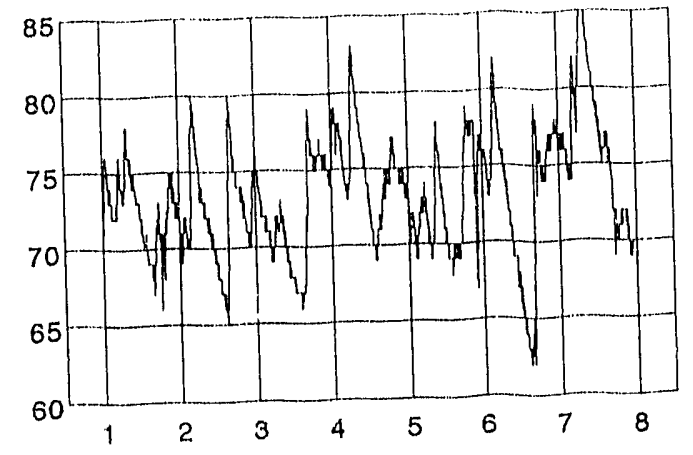

DAY IN TEST
KF0604

3/4-11/92

EARTH STOVE 101

PRES-TO-LOGS

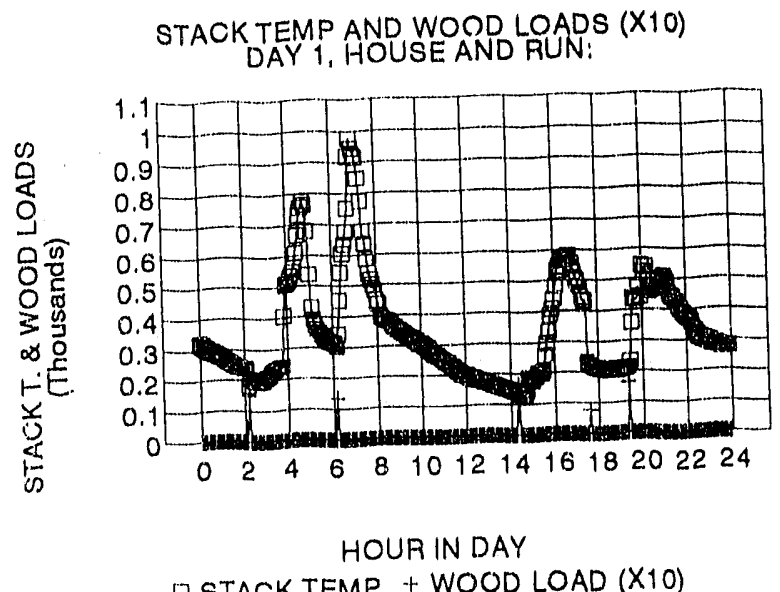

DISTRIBUTION OF WOOD LOAD WNEIGHTS HOUSE AND RUN:

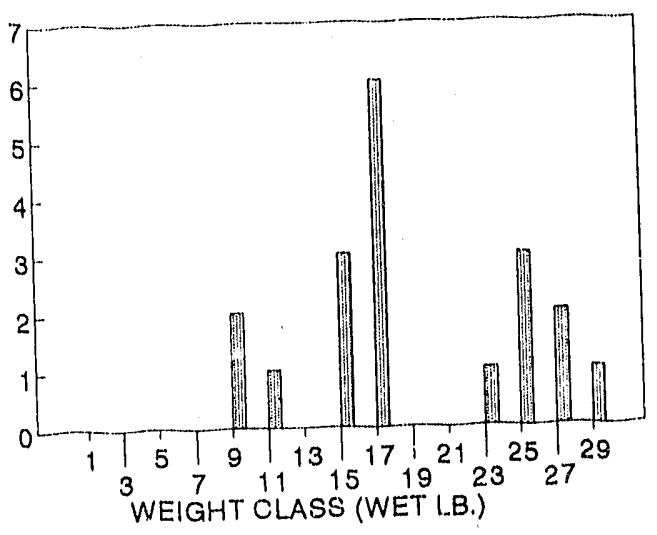

STACK T, VS OXYGEN: RAW DATA HOUSE AND RULN:

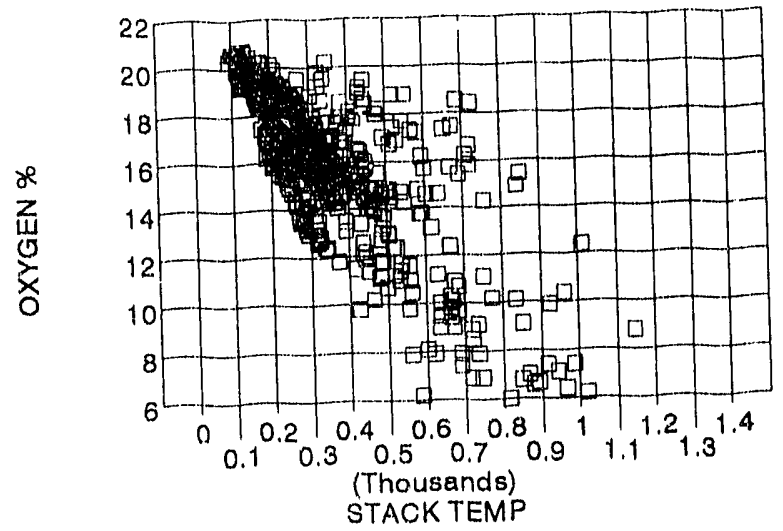


HOUSE \& RUN:

SAMPLE DATES: STOVE TYPE:

FUEL TYPE:

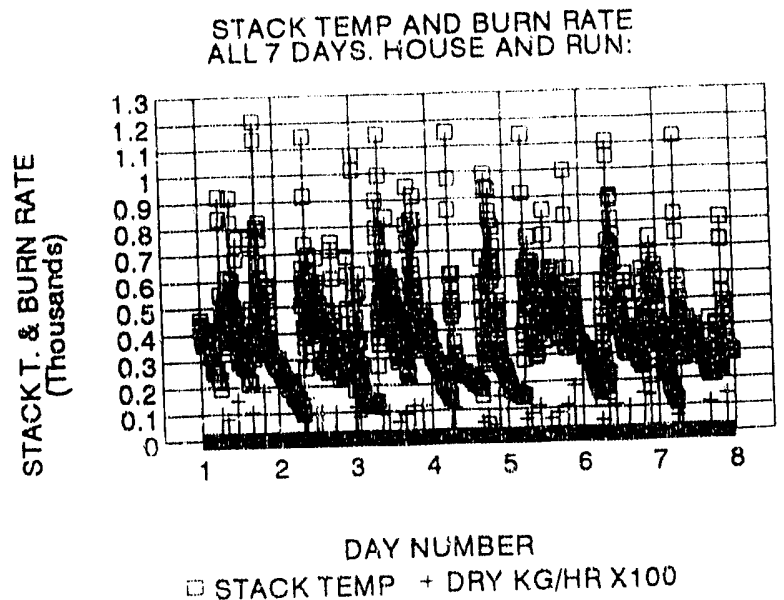

STACK OXYGEN \% FOR ALL 7 DAYS HOUSE AND RUN

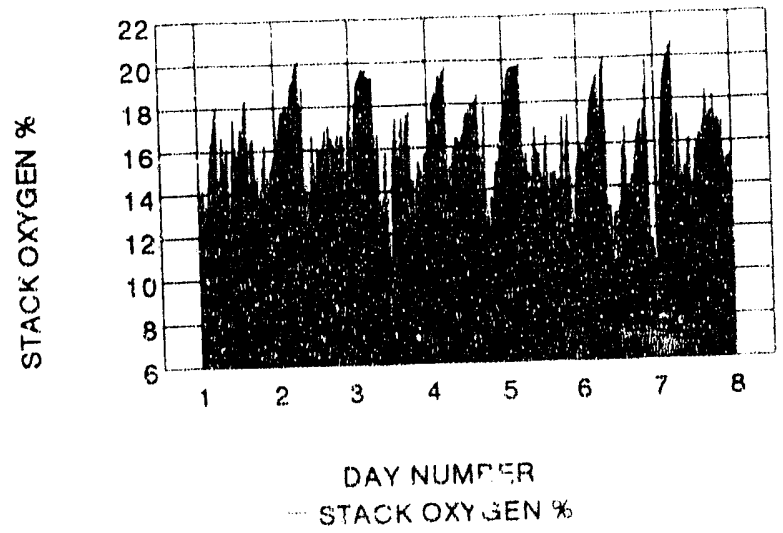

HOUSE AMBIENT TEMPERATURE HOUSE AND RUN

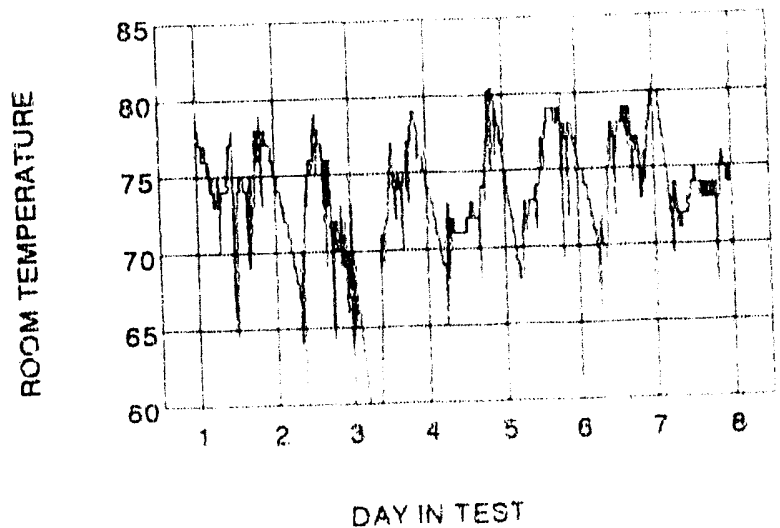

F0701

$1 / 10-16 / 92$

EARTH CONVENTIONAL

LODGEPOLE

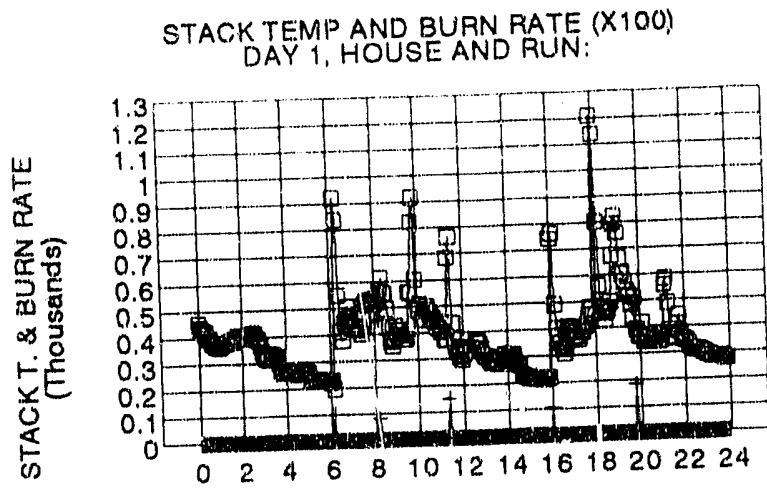

HOUA IN DAY

D STACK TEMP + DRY KG/HA $\times 100$

DISTRIBIJTION OF VYOOD LOAD WEIGHTS HOUSE AND RUN:

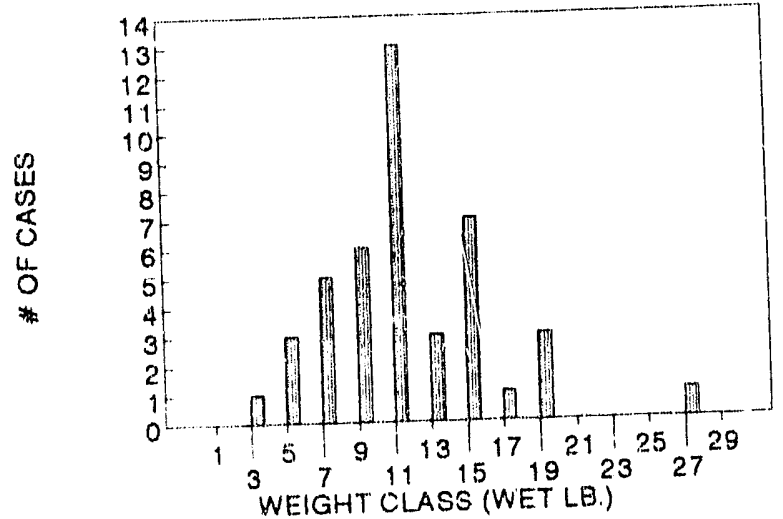

STACKT. VS OXYGEN; RAW DATA HOUSE AND RLN

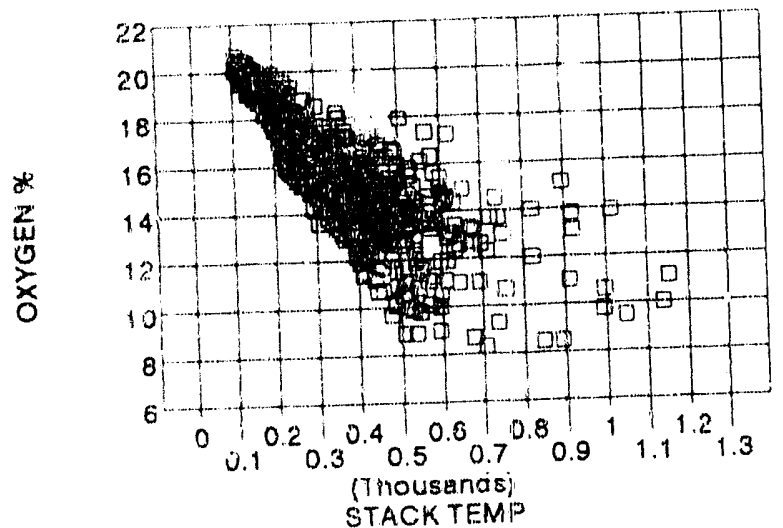


HOUSE \& RUN:

SAMPLE DATES:

STOVE TYPE: FUEL TYPE:
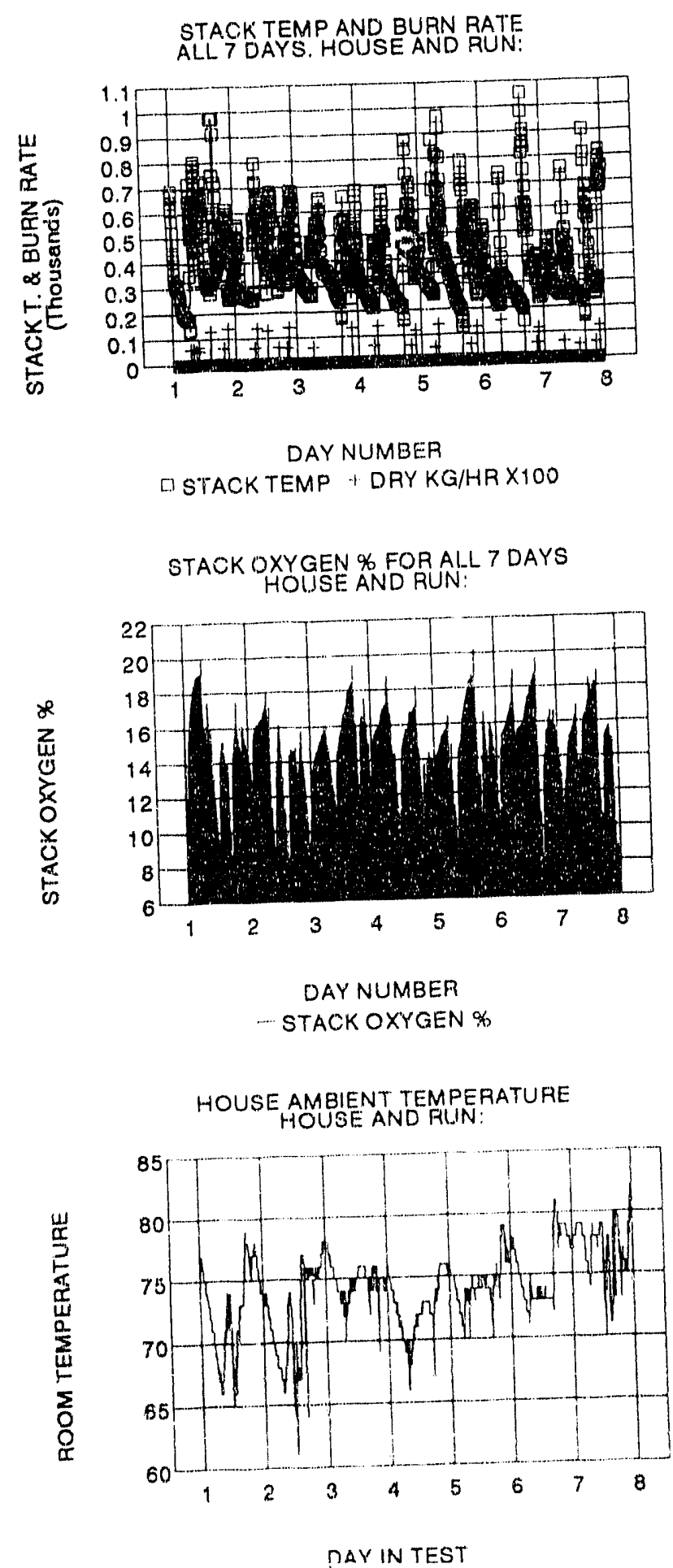

KF0702

$1 / 19-25 / 92$

EARTH 101: CONVENTIONAL

PRES - TO-..LOGS

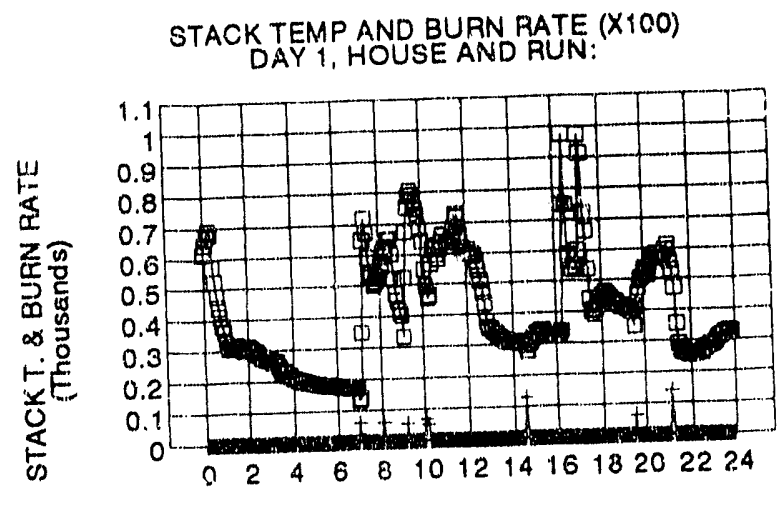

HOUR IN DAY

] STACK TEMP + DHY KG/HR X100 DISTRIBUTION OF WOOD LOAD WEIGHTS
HOUSE AND RUN:

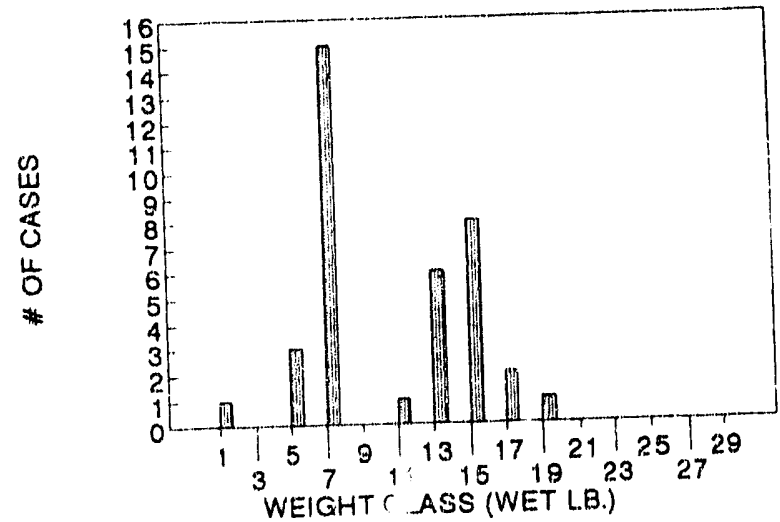

STACK T. VS OXYGEN; PAW DATA HOUSE AIND RUN:

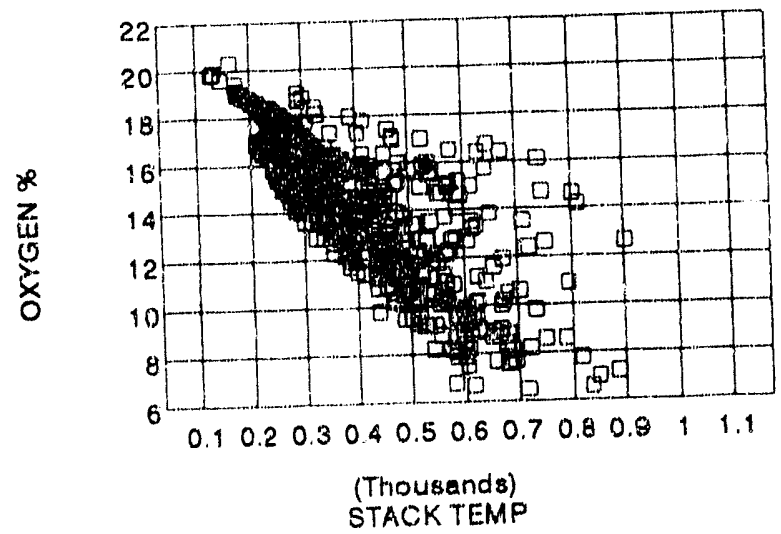


HOUSE \& RUN:

SAMPLE DATES:

STOVE TYPE:

FUEL TYPE:

STACK TEMP AND WOOD L.OADS $\left(X_{10}\right)$

ALL 7 DAYS. HOUSE AND RUN:
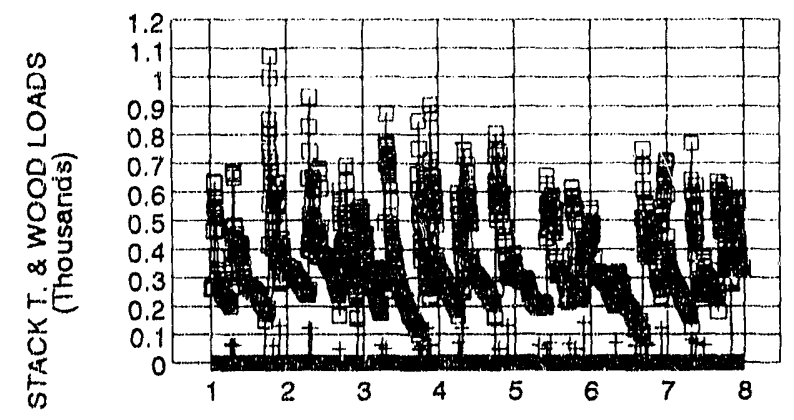

DAY NUMBER

ए STACK TEMP + WOOD LOAD (X10)

STACK OXYGEN \% FOR ALL 7 DAYS HOUSE AND RUN:

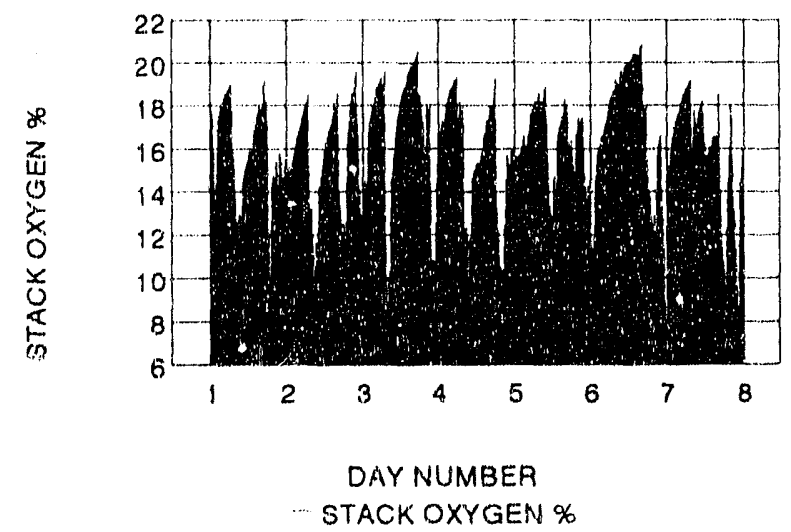
HOUSE AMBIENT TEMPERATURE
HOUSE AND RUN:

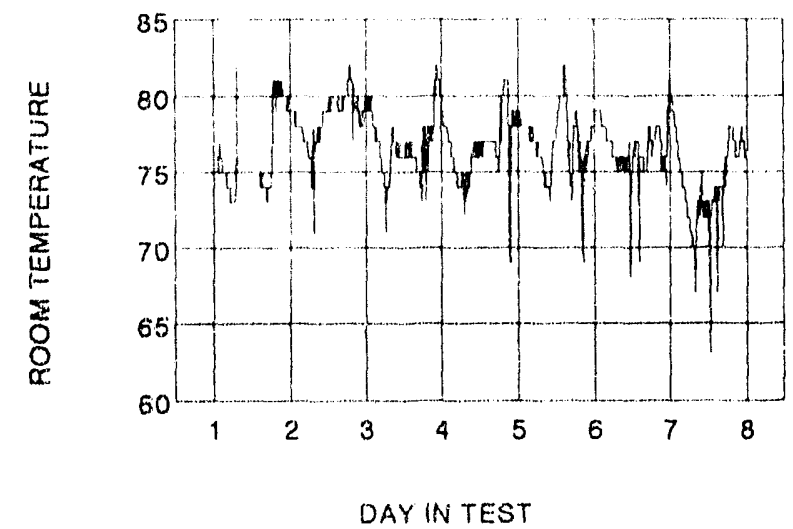

KF0703

1/27-2/2/92

EARTH 101

ECO-LOGS

STACK TEMP AND WOOD LOADS $(\times 10)$ DAY 1 , HOIJSE AND RUN:
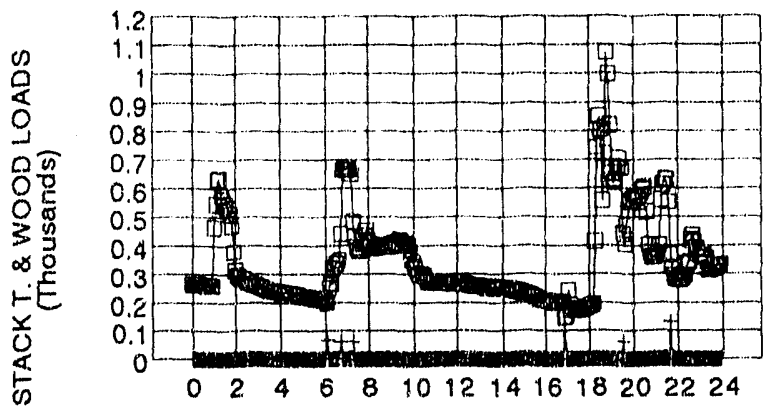

HOUR IN DAY

1.] STACK TEMP + WOOD LOAD (X10)

DISTRIBUTION OF WOOD LOAD WEIGHTS HOUSE AND RUN:

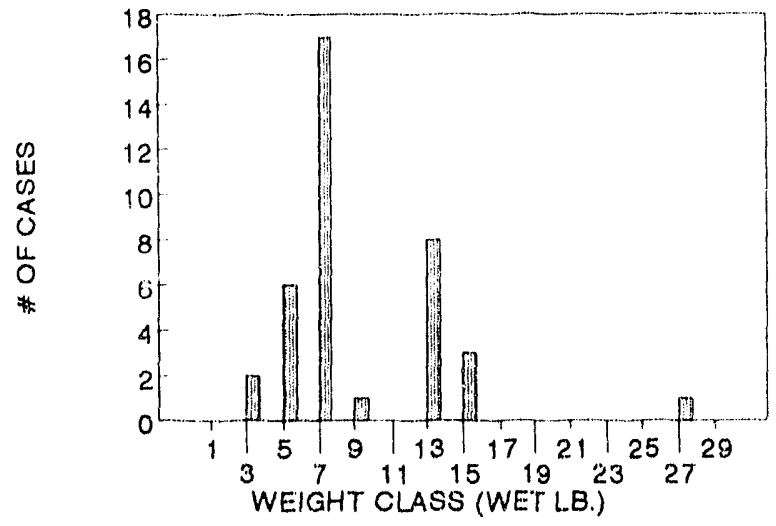
STACK T' VS OXYGEN RAW DATA
HDUSEAND RUN:

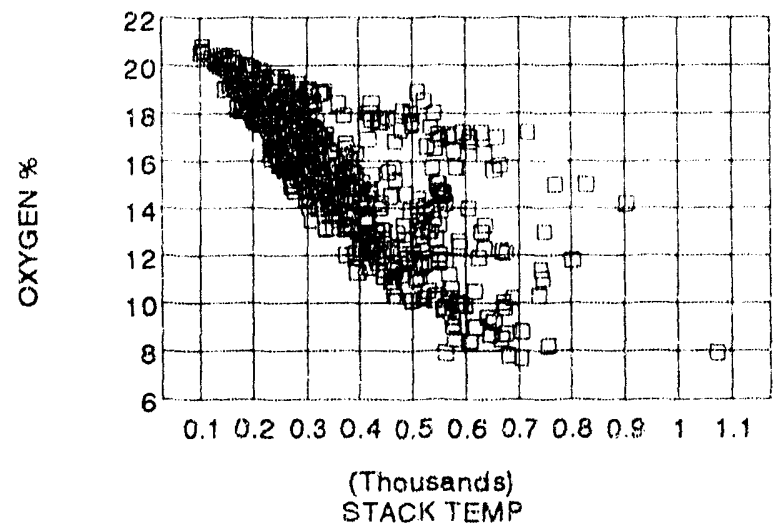


HOUSE \& RUN:

SAMPLE DATES:

STOVE TYPE:

FUEL TYPE:

STACK TEMP AND WOOD LOADS $\left(X_{10}\right)$ ALL 7 DAYS. HOUSE AND RUN
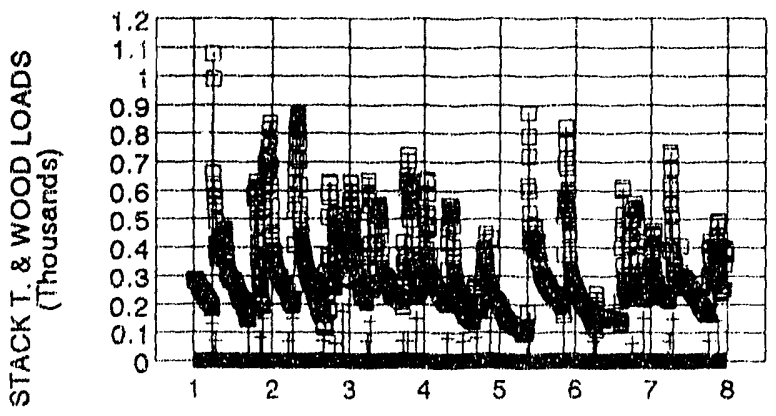

DAY NUMBER

] STACKTEMP + WOOD LOAD (X10)

STACK OXYGEN \% FOR ALL. 7 DAYS HOUSE AND RUN:

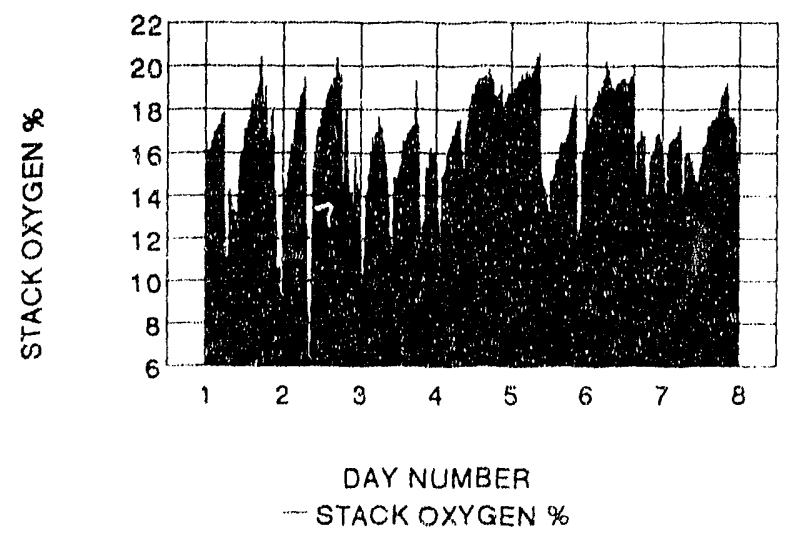

HOUSE AMBIENT TEMPERATURE HOUSE AND RUN:

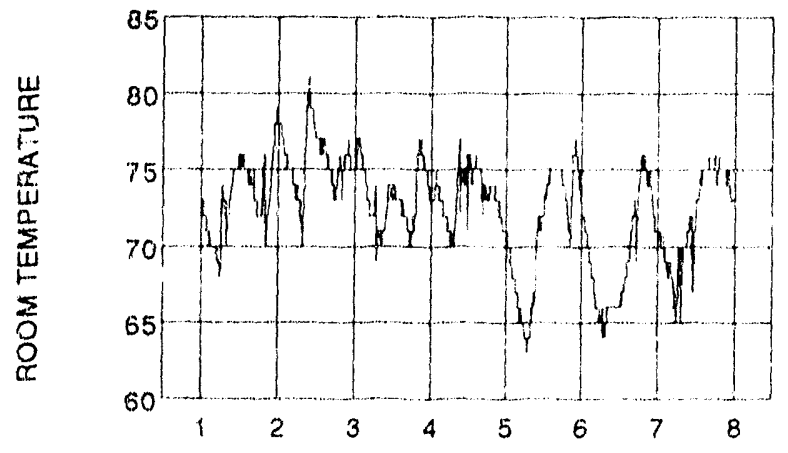

DAY IN TEST
KF0704

3/4-11/92

EARTH STOVE 101

PRES-TO-LOGS

STACK TEMP AND WOOD LOADS $\left(X_{10}\right)$ DAY 1 , HOUSE AND RUN:
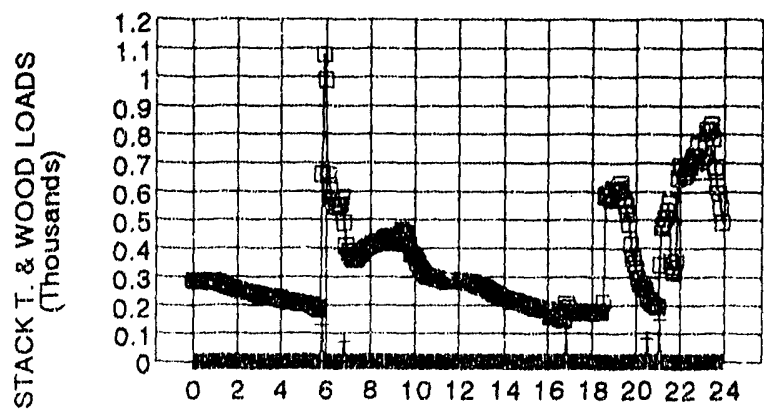

HOUR IN DAY

D STACK TEMP + WDOD LOAD (X10) DISTRIBUTION OF WOOD LOAD WEIGHTS
HOUSE AND RUN:

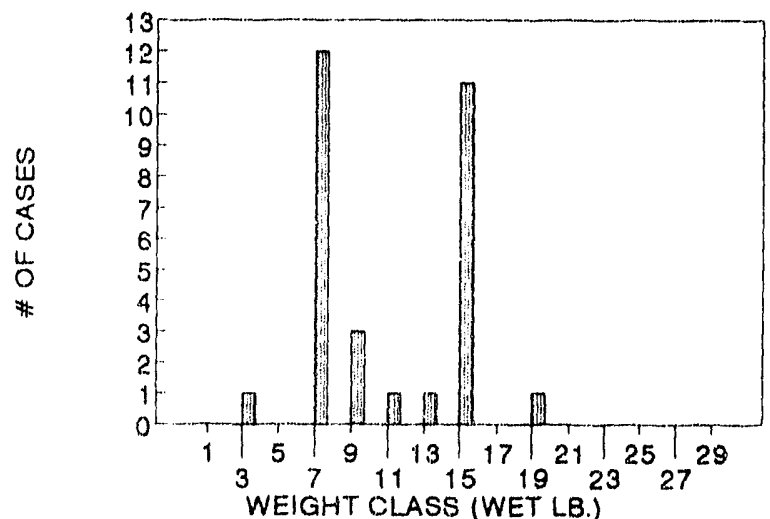

STACK T. VS OXYGEN: RAW DATA HOUSE AND RUN:

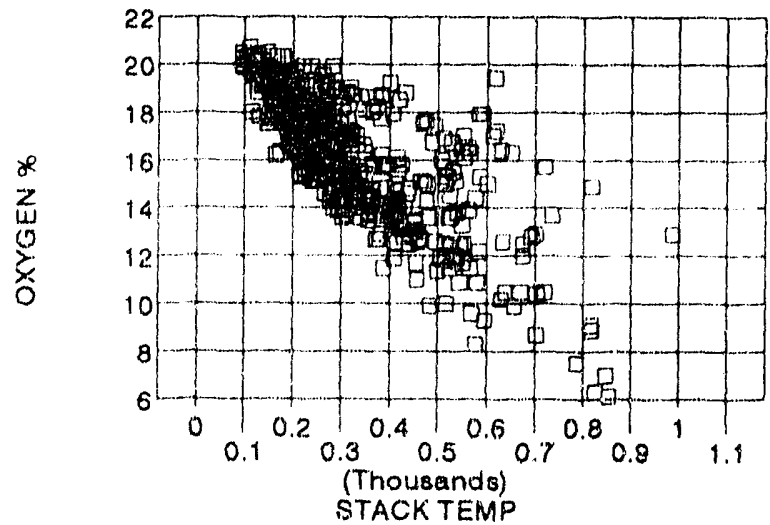


HOUSE \& RUN:

SAMPLE DATES:

STOVE. TYPE:

FUEL TYPE:
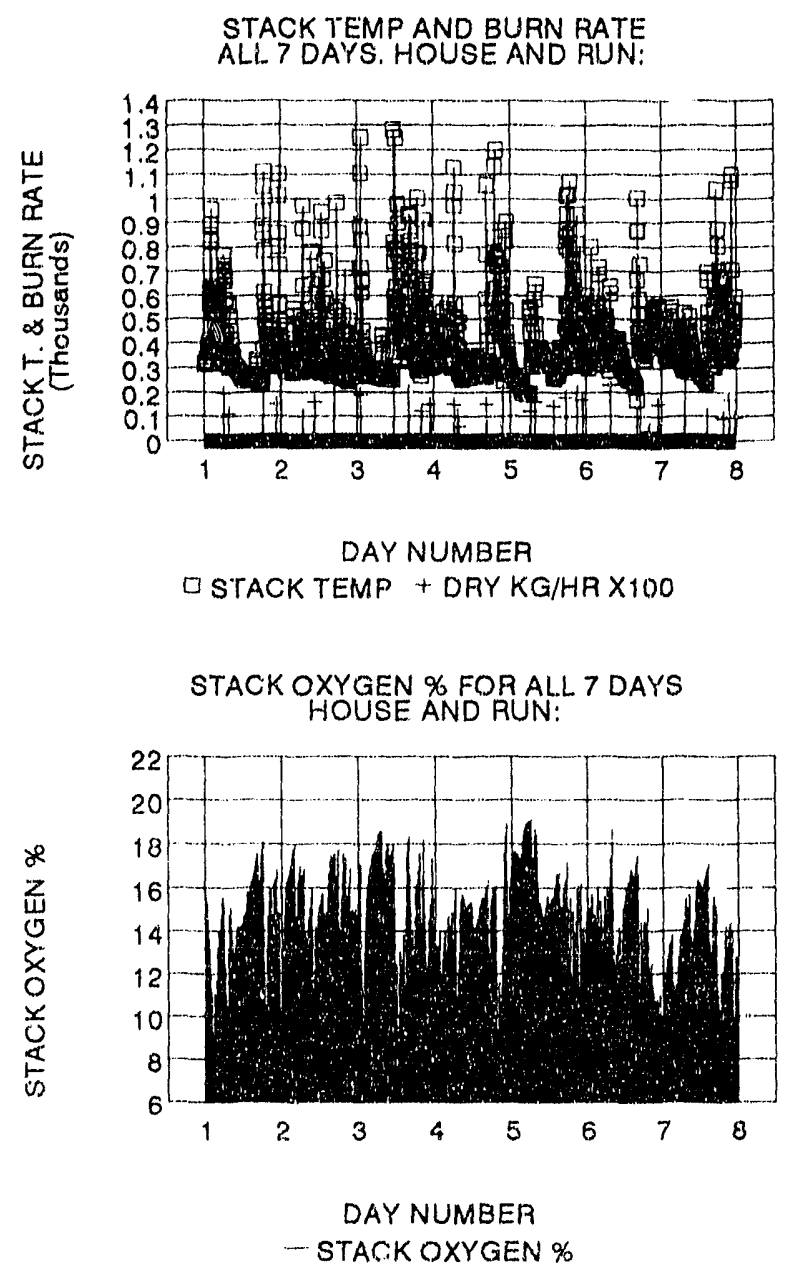

HOUSE AMBIENT TEMPEAATUAE

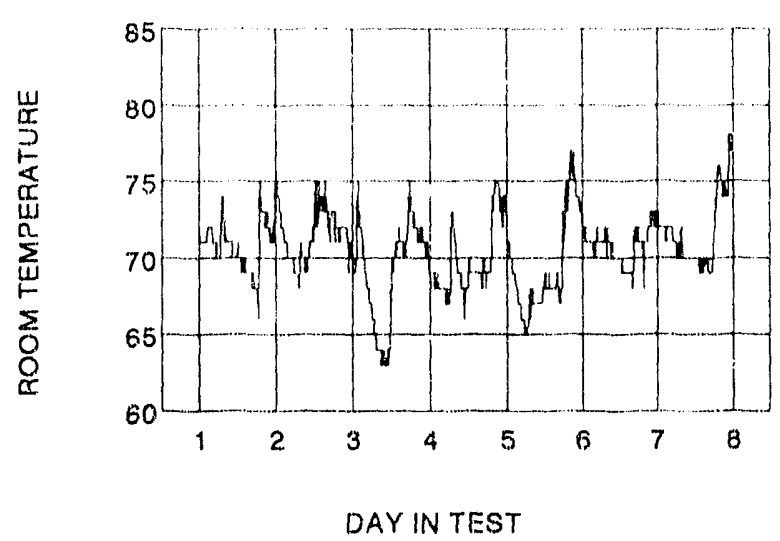

KF0801

$1 / 10-16 / 92$

EARTH 101, CONVENTIONAL

LODGEPOLE STACK TEMP AND BURN RATE $(X 100)$
DAY 1 , HOUSE AND RUN:
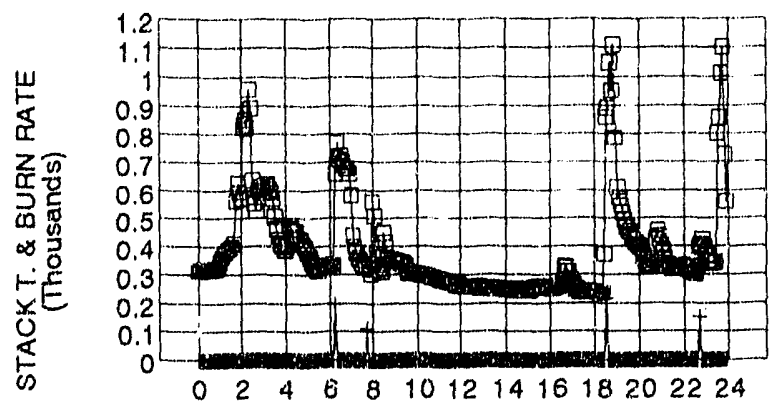

HOUR IN DAY

$\square$ STACK TEMP + DRY KG/HR $\times 100$

DISTRIBUTION OF WOOD LOAD WEIGHTS
HOUSE AND RUN:

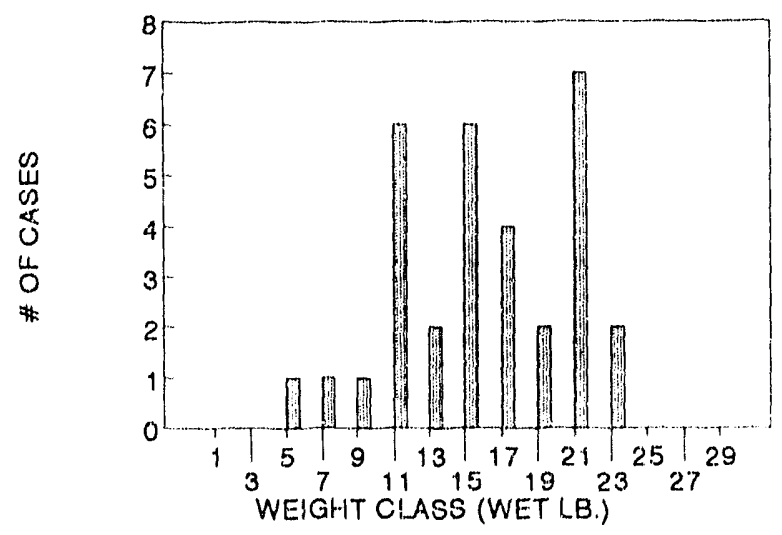
STACK T, VS OXYGEN; RAW DATA
HOUSE AND RUN:

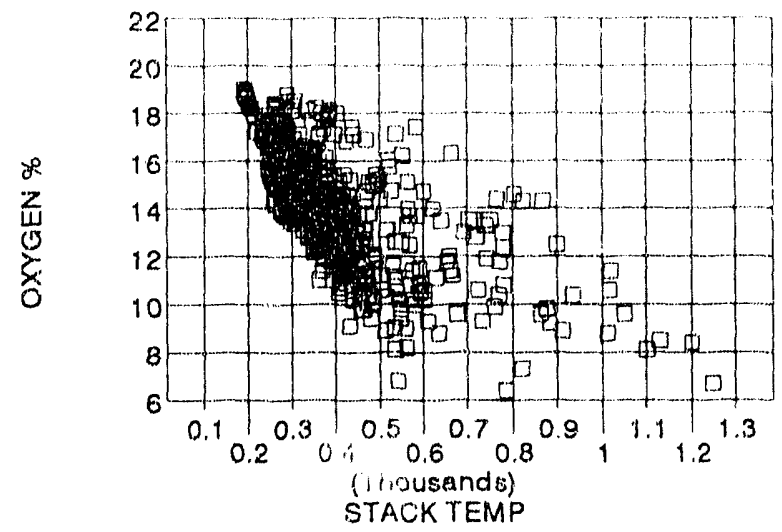


HOUSE \& RUN:

SAMPLE DATES:

STOVE TYPE: FUEL TYPE:
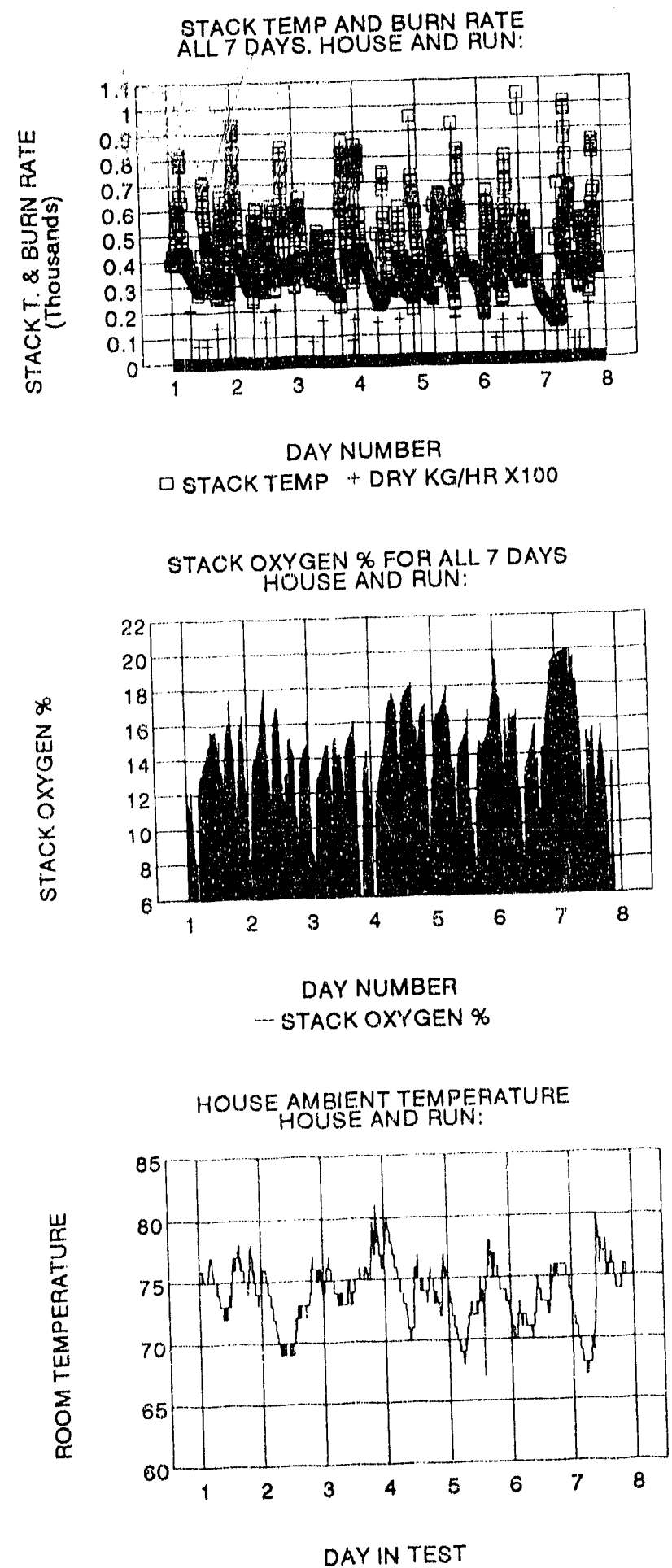

KF0802

$1 / 19-25 / 92$

EARTH 101; CONVENTIONAL PRES--TO-LOGS

STACK TEMP AND BUPN RATE $(X 100)$ DAY $\uparrow$, HOUSE AND RUN:

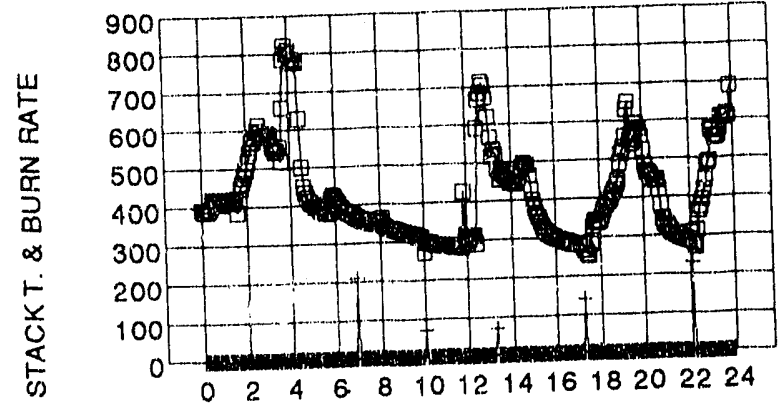

HOUR IN DAY

口 STACK TEMP + DRY KG/HAX 100

DISTAIBUTION OF WOOD LOAD WEIGHTS HOUSE AND RIJN:

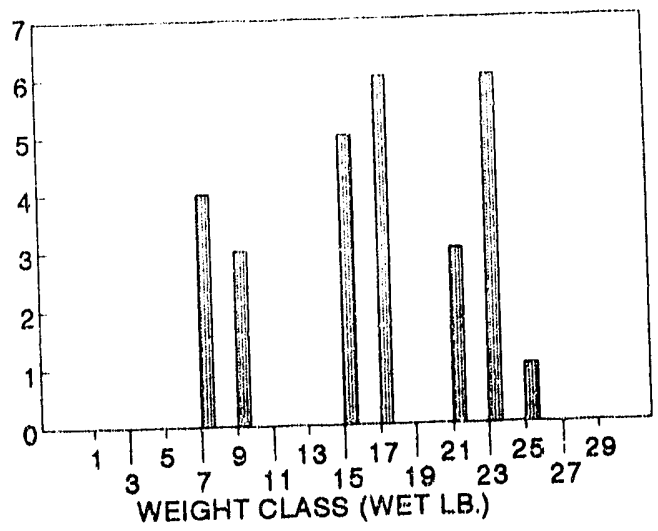

STACK T. VS OXYGEN RAW DATA HOUSE AND RUN

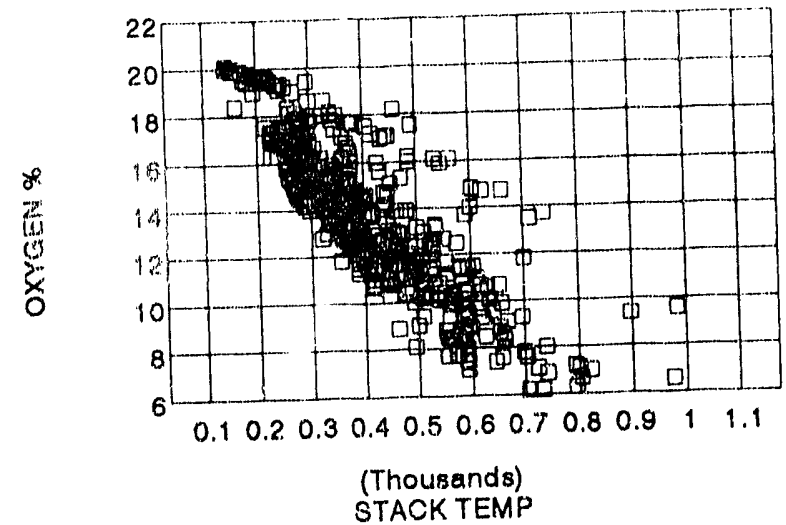


HOUSE \& RUN:

SAMPLE DATES:

STOVE TYPE:

FUEL TYPE:

STACK TEMP AND WOOD LOADS (X10)

ALL 7 DAYS. HOUSE AND RUN:

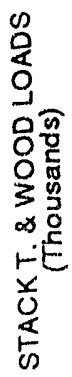

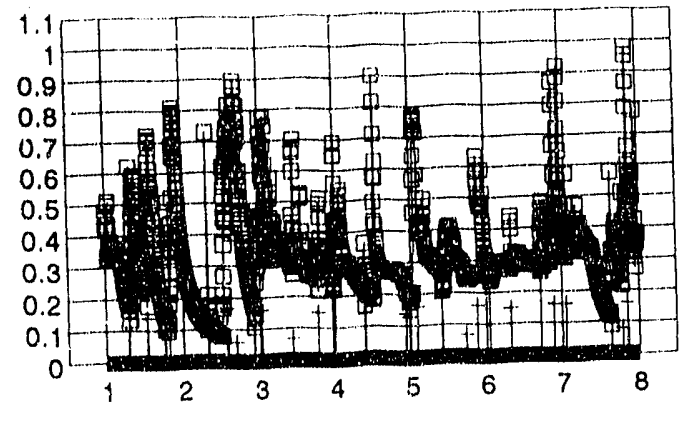

DAY NUMBER

[.) STACK TEMP + WOOD LOAD $(X 10)$

STACK OXYGEN \% FOR ALL 7 DAYS HOUSE AND RUN:

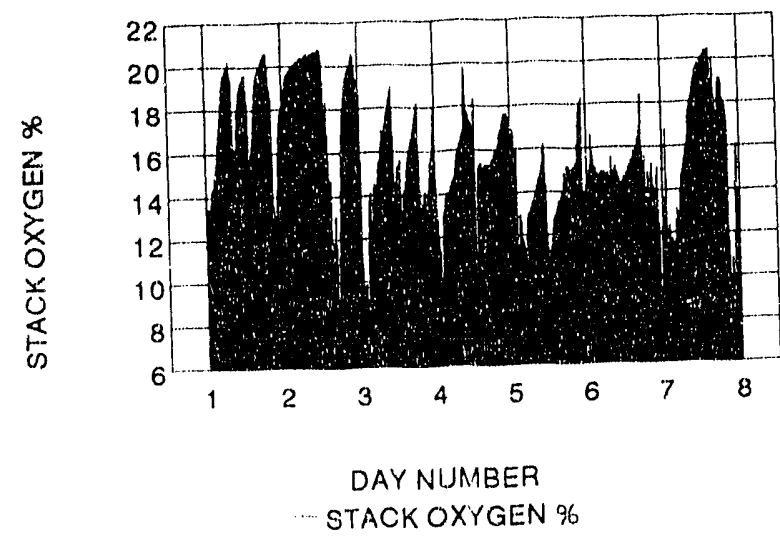

HOUSE AMBIENT TEMPERATURE HOUSE AND RUN:

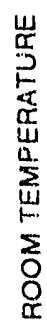

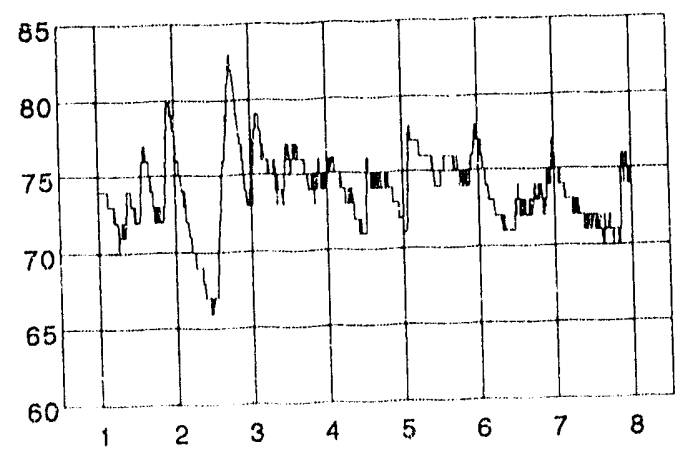

DAY IN TEST
$\mathrm{F} 0803$

1/27-2/2/92

EARTH 101

ECO-LOGS

STACK TEMP AND WOOD LOADS $(X 10)$ DAY $\{$, HOUSE AND RUN:

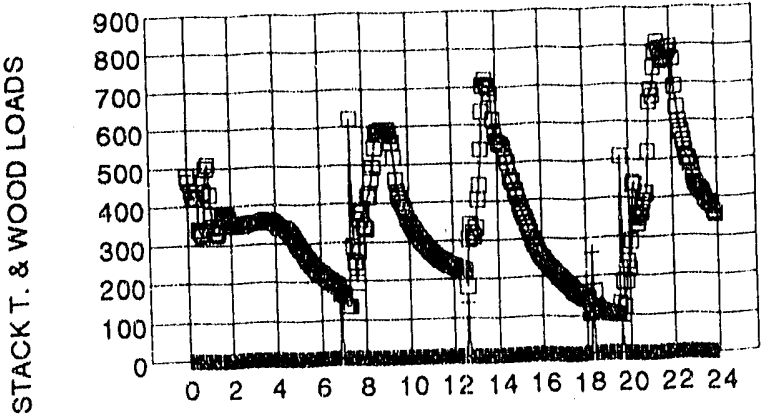

HOUR IN DAY

U STACK TEMP + WOOD LOAD (XYO)

DISTRIBUTION OF WOOD LOAD WEIGHTS HOUSE AND RUN:

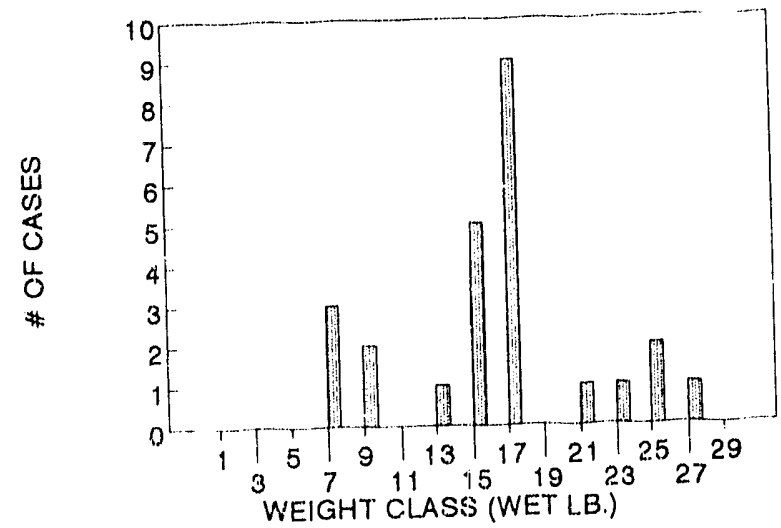

STACK T VS OXYGIEN RAW DATA HOUSE AND RUN:

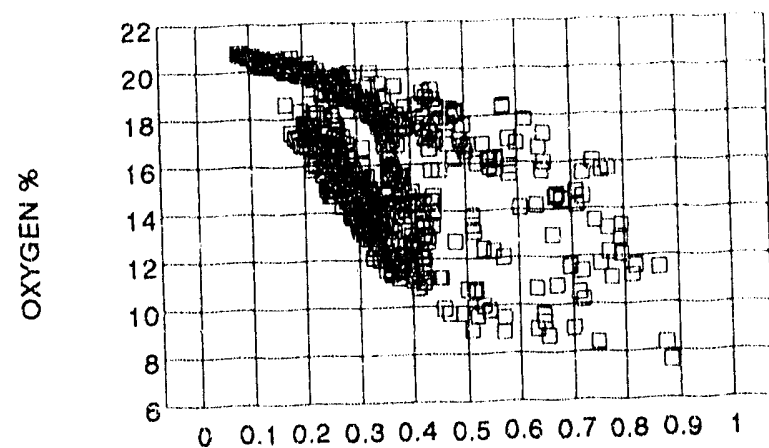

(Thousands)

STACK TEMP 
HOUSE \& RUN:

SAMPLE DATES:

STOVE TYPE:

FUEL TYPE:

STACK TEMP AND WOOD LOADS $\left(X_{10}\right)$

ALL 7 DAYS. HOUSE AND RUN:
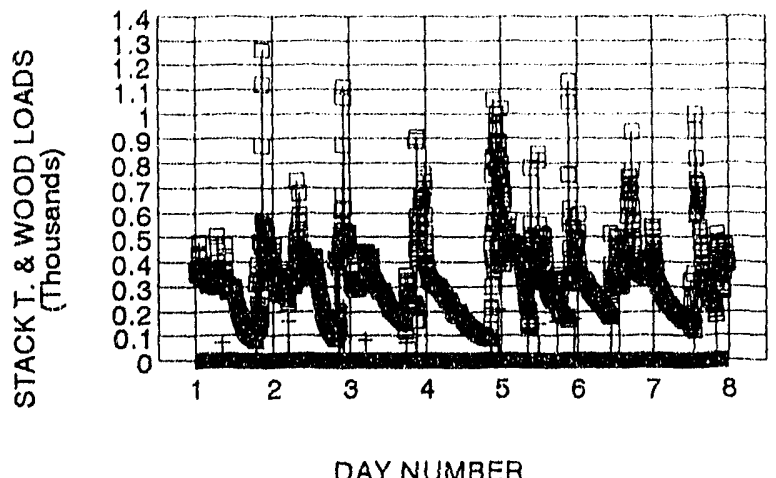

1. STACK TEMP + WOOD LOAD $\left(X_{10}\right)$

STACK OXYGEN \% FOR ALL 7 DAYS HOUSE AND RUN:

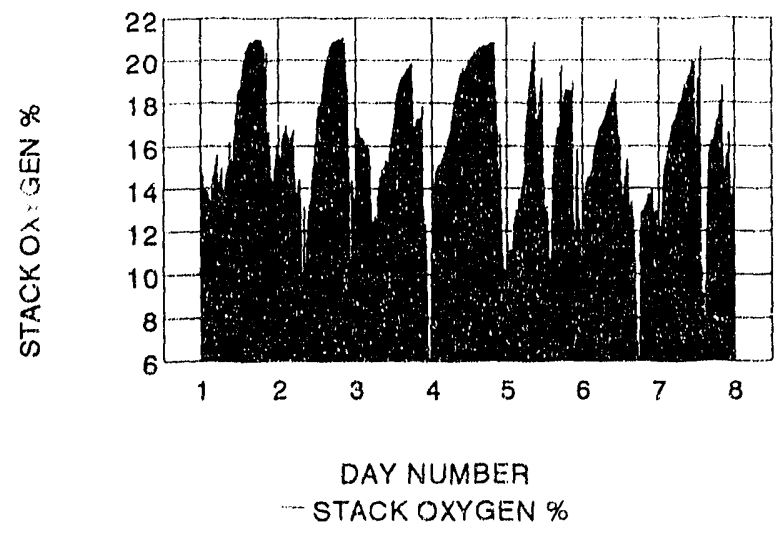

HOUSE AMBIENT TEMPERATURE HOUSE AND RUN:

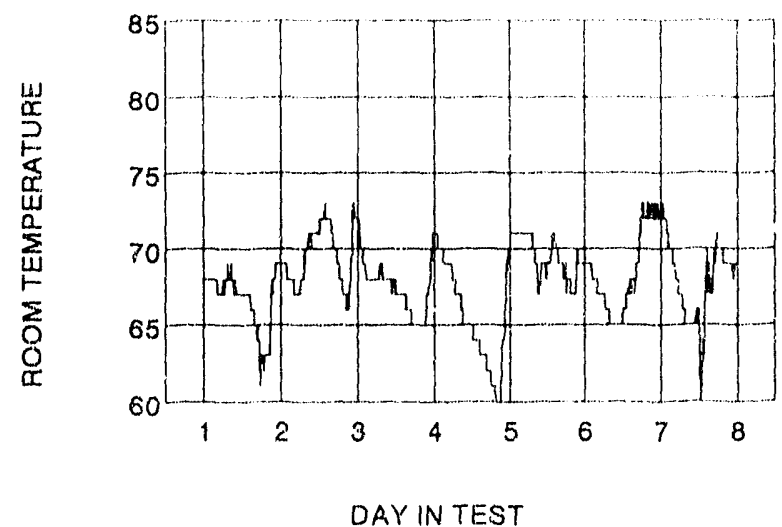

KF0804

3/02-8/92

EARTH 101

PRES-TO-LOGS

STACK TEMP AND WOOD LOADS (X10) DAY 1, HOUSE AND RUN:
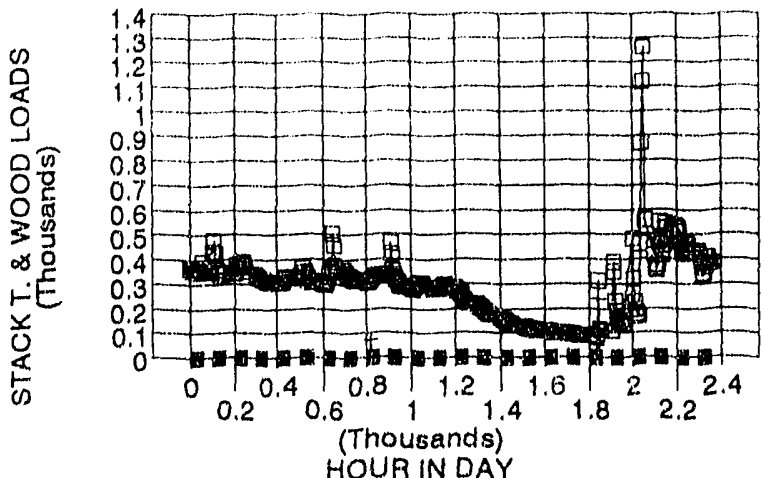

D STACK TEMP + WOOD LOAD (X10) DISTRIBUTION OF WOOD LOAD WEIGHTS
HOUSE AND RIUN:

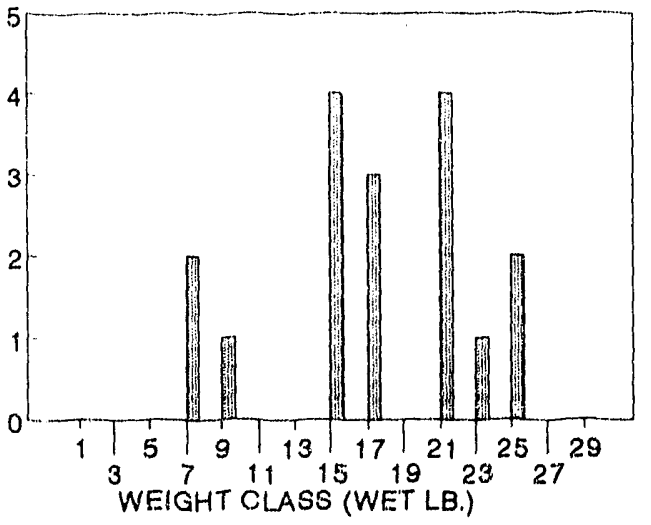

STACK T. VS OXYGEN; RAW DATA HOUSE AND RUN:

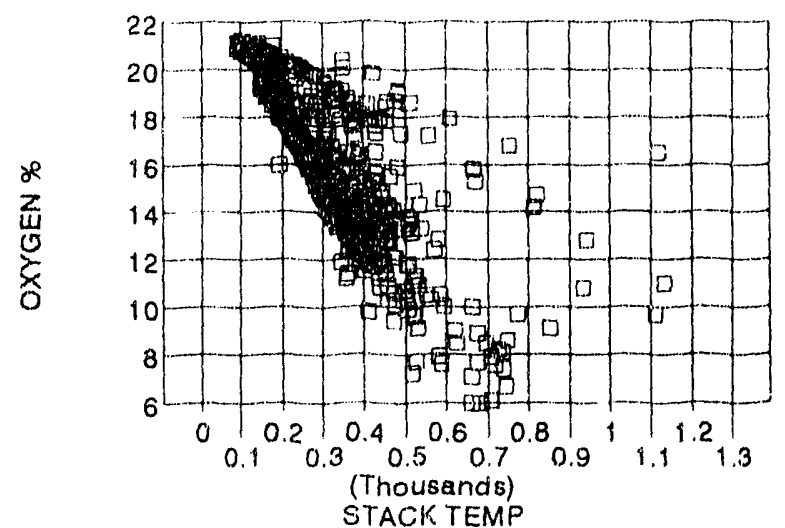


HOUSE \& RUN:

SAMPLE DATES: STOVE TYPE: FUEL TYPE:

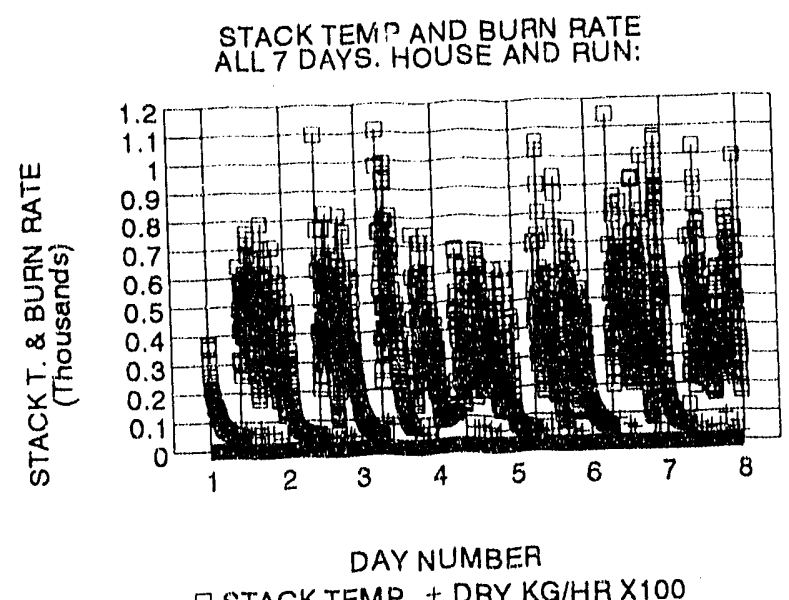

$\square$ STACK TEMP + DRY KG/HR X100

STACK CXYGEN \% FOR ALL 7 DAYS HOUSE AND RUN:

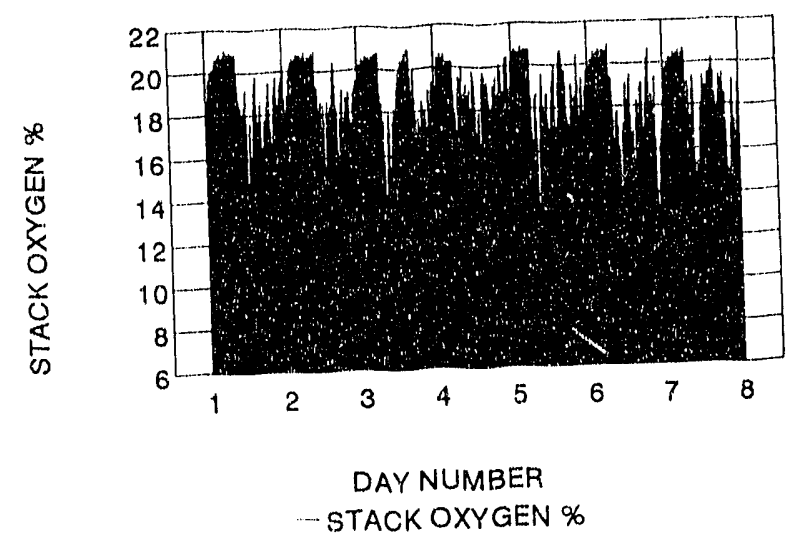

HOUSE AMBIENT TEMPERATURE HOUSE AND RUN:

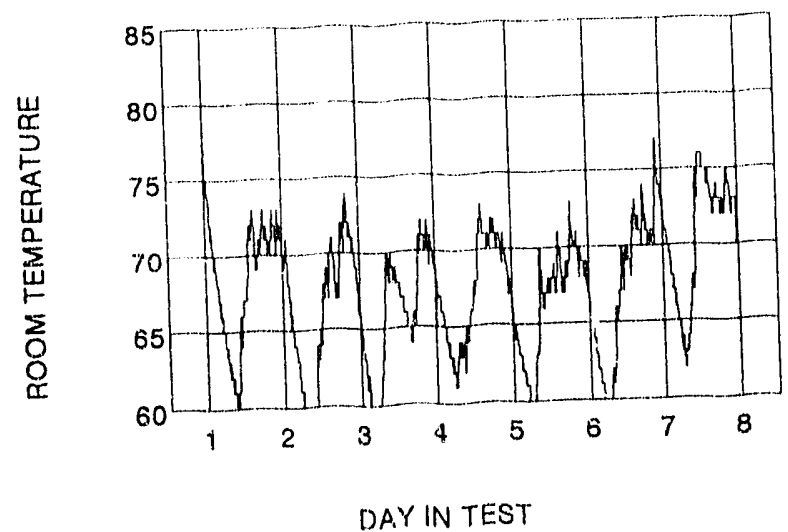

F0901

1/11-17/92

SMALL CONVENTIONAL LODGEPOLE PINE

STACK TEMP AND BURN RATE (X100) DAY 1 , HOUSE AND RUN:

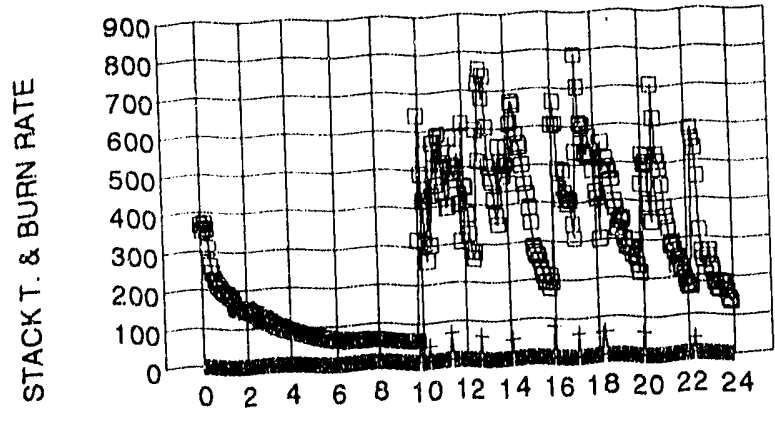

HOUR IN DAY

$\square$ STACK TEMP + DRY KG/HR X100

DISTRIBUTION OF WOOD LOAD WEIGHTS HOUSE AND RUN:

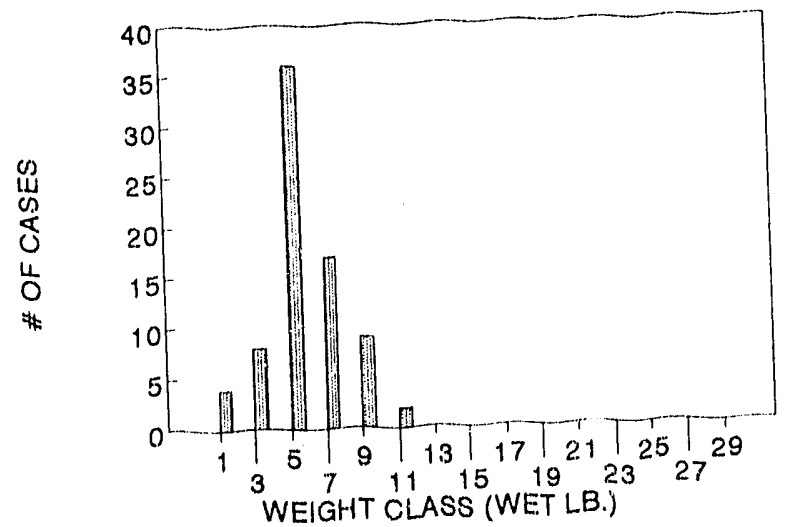

STACK T VS OXYGEN: RAW DATA

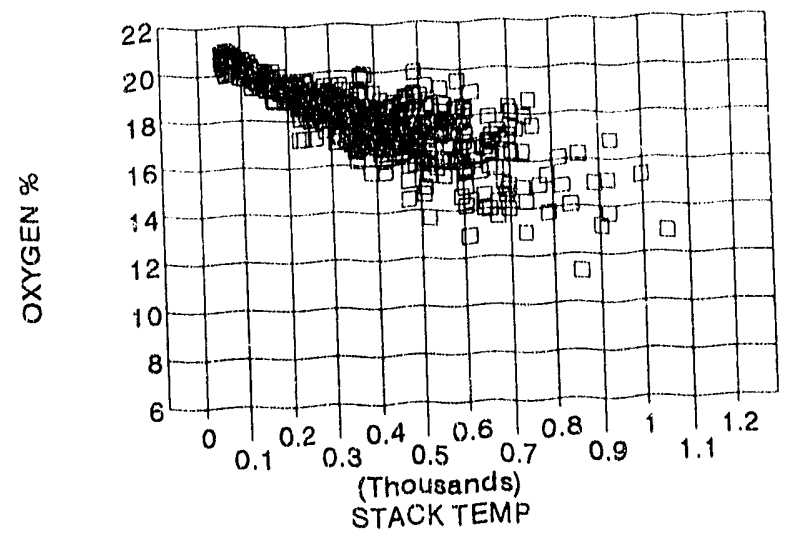


HOUSE \& RUN:

SAMPLE DATES:

STOVE TYPE:

FUEL TYPE:

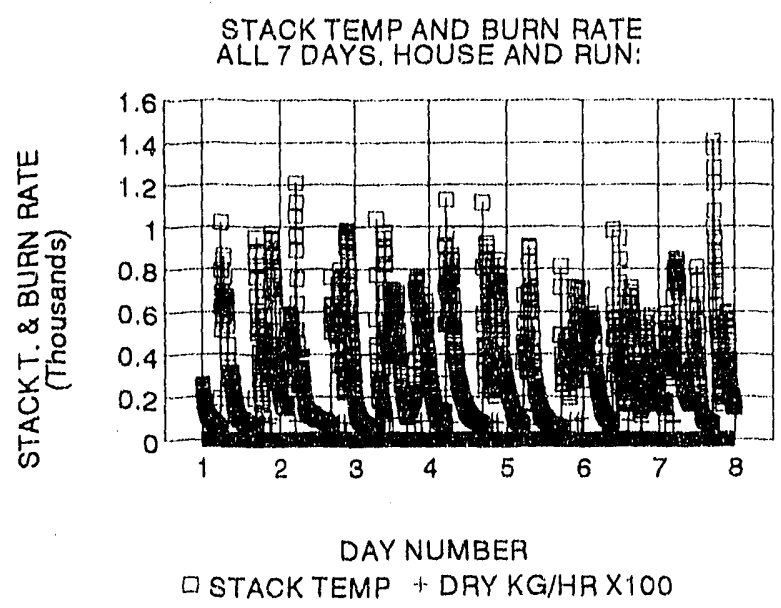
STACK OXYGEN \% FOA ALL 7 DAYS
HOUSE AND RUN:

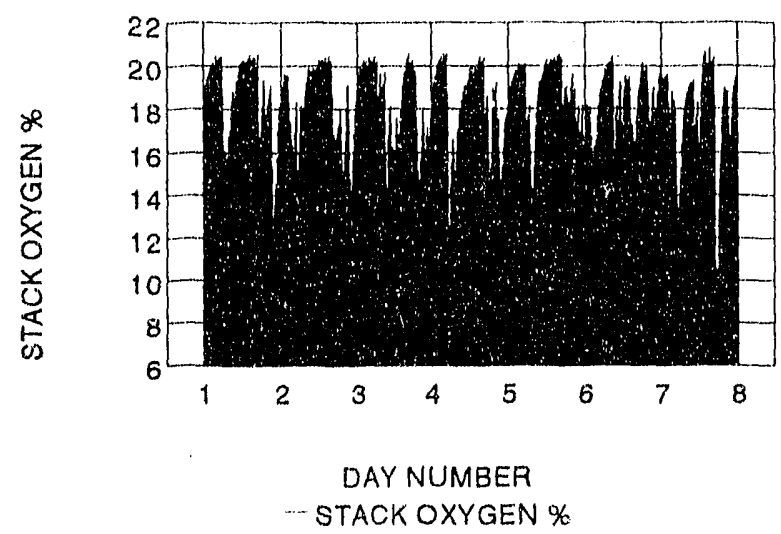

HOUSE AMBIENT TEMPERATURE HOUSE AND RUN:

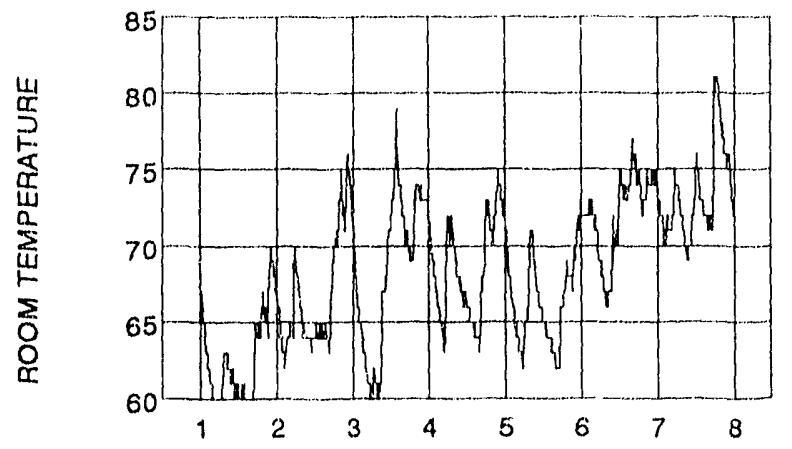

DAY IN TEST
KF0902

1/20-26/92

SMALL CONVENTIONAL

PRES-TO-LOGS

STACK TEMP AND BURN RATE (XYOO) DAY 1 , HOUSE AND RUN:

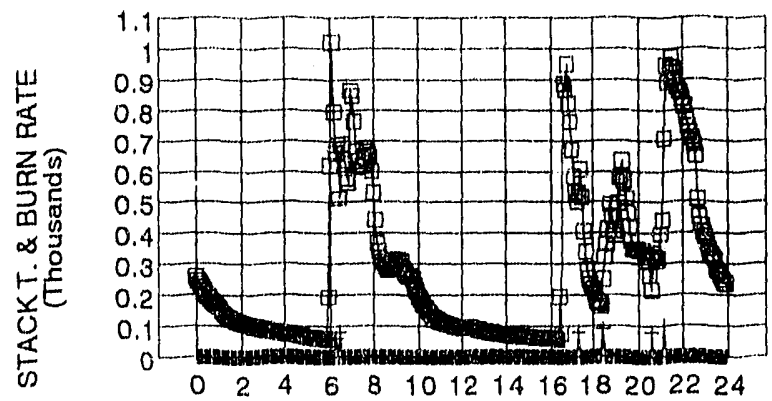

HOUR IN DAY

D STACK TEMP + DAY KG/HR X100

DISTRIBUTION OF WOOD LOAD WEIGHTS HOUSE AND RUN:

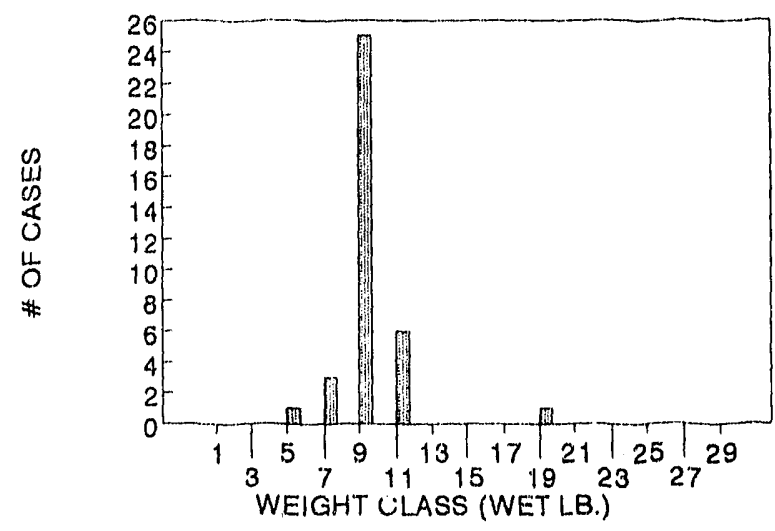

STACK T. VS OXYGEN: RAW DATA HOUSE AND RUN:

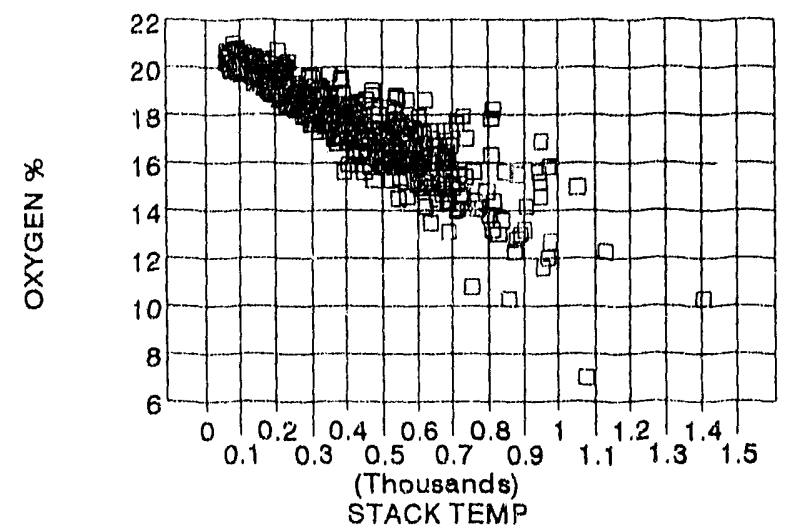


HOUSE \& RUN:

SAMPLE DATES:

STOVE TYPE:

FUEL TYPE:

STACK TEMP AND WOOD LOADS $\left(X_{10}\right)$ ALL 7 DAYS. HOUSE AND RUN:

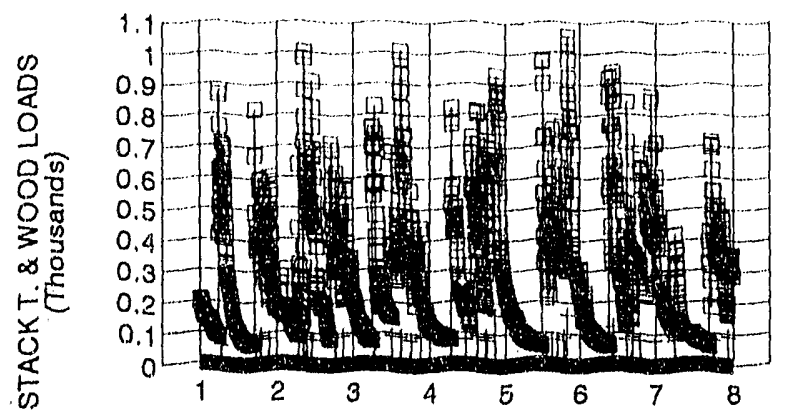

DAY NUMBEA

D STACK TEMP + WOOD LOAD $(X 10)$

STACK OXYGEN \% FOR ALL 7 DAYS HOUSE AND RUN:

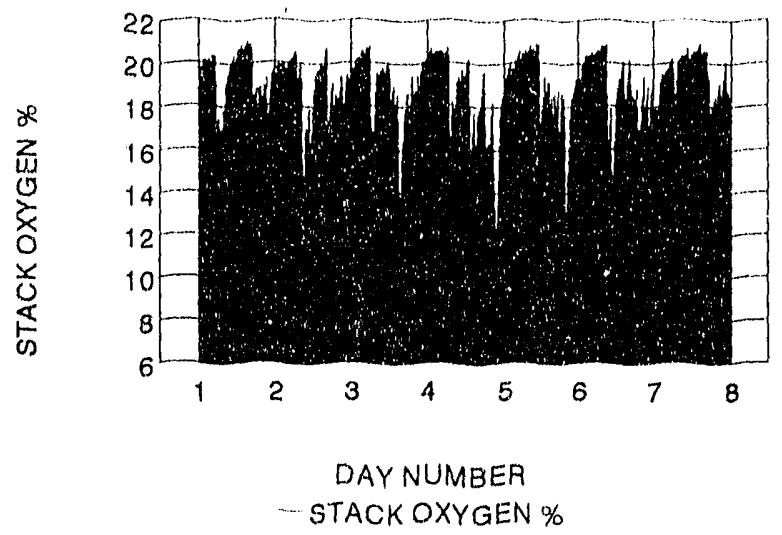

HOUSE AMBIENT TEMPERATURE HOUSE AND RUN

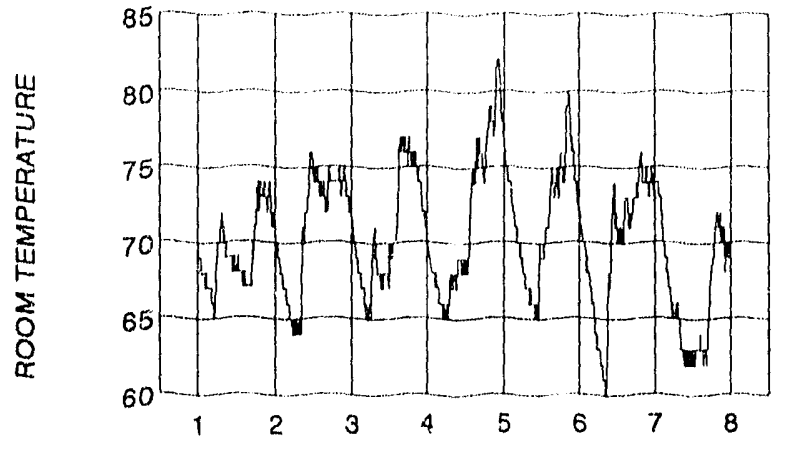

DAY IN TEST
KF0903

1/28-2/3/92

SMALL CONVENTIONAL

ECO-LOGS

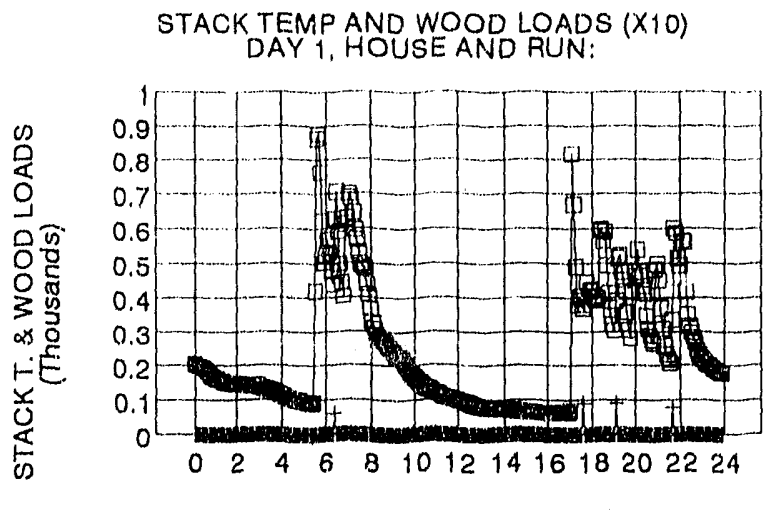

HOUAIN DAY

T.) STACK TEMP + WOOD LOAD $\left(X_{10}\right)$

DISTRIBUTION OF WOOD LOAD WEIGHTS HOUSE AND RUN:

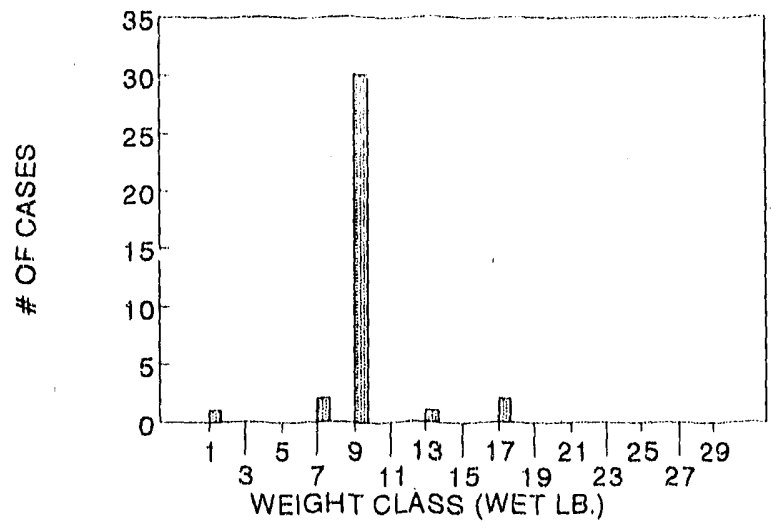

STACK T. VS OXYGEN RAW DATA HOUSE AND RUN:

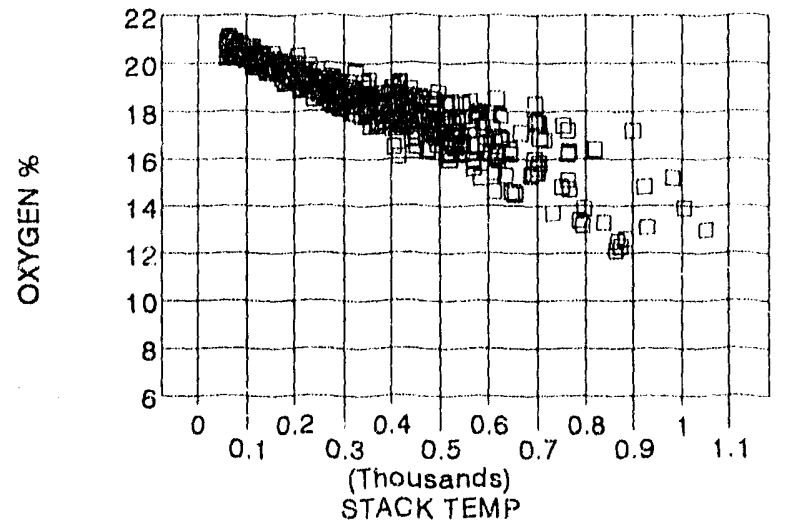


HOUSE \& RUN:

SAMPLE DATES:

STOVE TYPE:

FUEL TYPE:

STACK TEMP AND WOOD LOADS $(X 10)$

ALL 7 DAYS. HOUSE AND RUN:
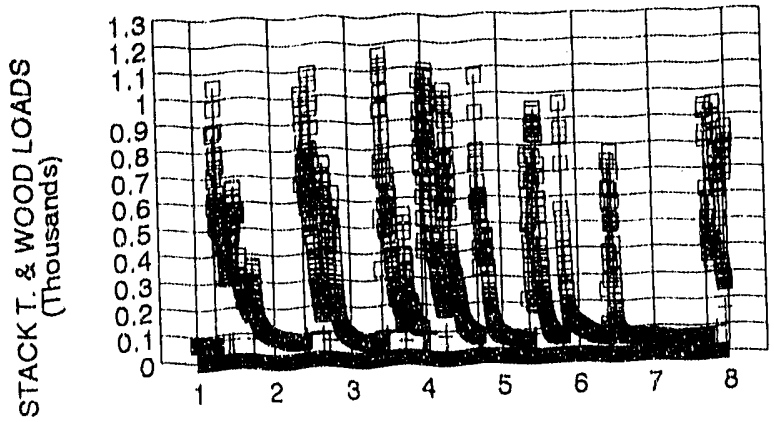

DAY NUMBER

DSTACK TEMP + WOOD LOAD $\left(X_{10}\right)$

STACK OXYGEN \% FOR ALL 7 DAYS HOUSE AND RUN:

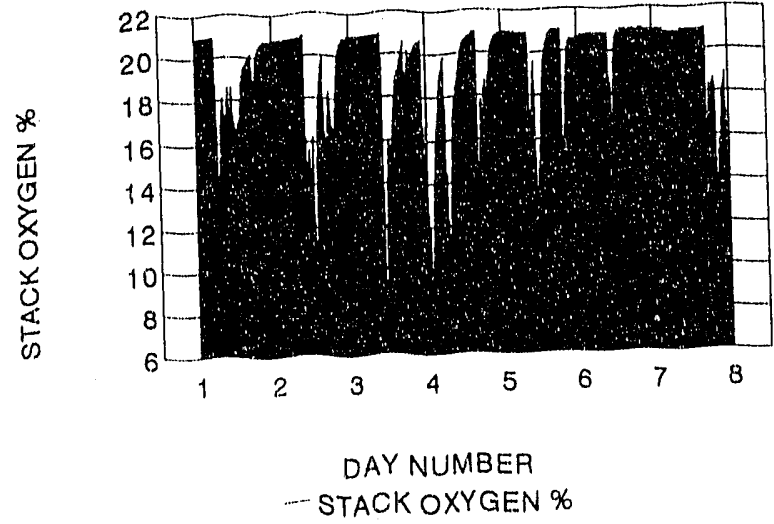

HOUSE AMBIENT TEMPERATURE HOUSE AND RUN:

㭊
KF0904

$3 / 03-9 / 92$

CONVENTIONAL

PRES--TO-LOGS

STACK TEMP AND WOOD LOADS (X10) DAY 1, HOUSE AND RUN:
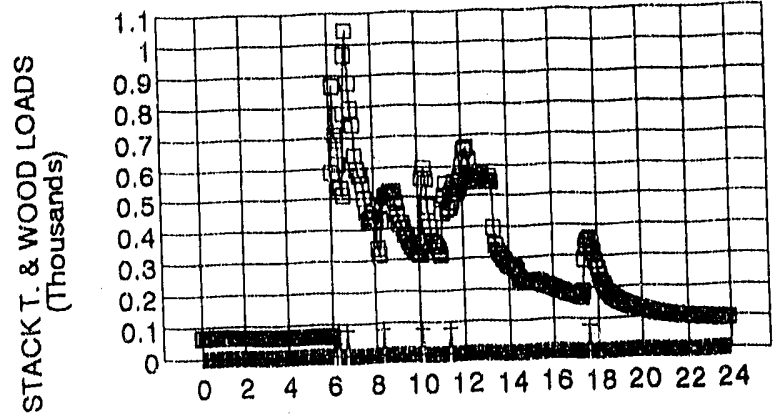

HOUR IN DAY

口 STACK TEMP + WOOD LOAD (X10)

DISTRIBUTION OF WOOD LOAD WEIGHTS HOUSE AND RUN:

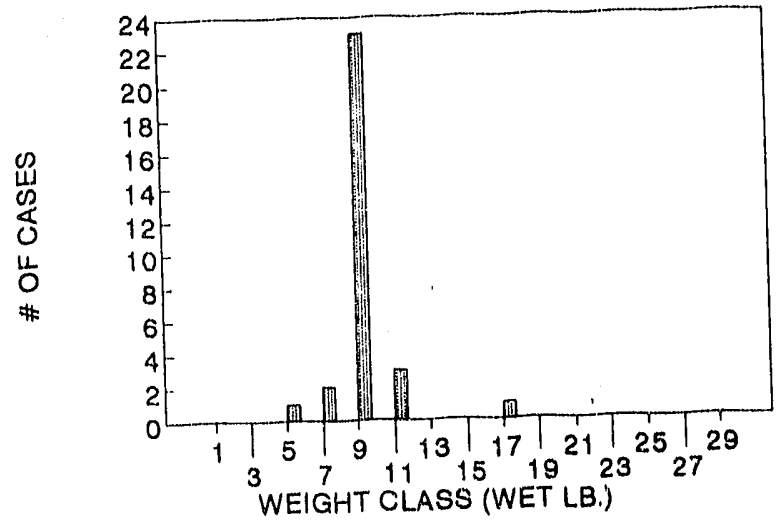

STACK T, VS OXYGEN: RAW DATA HOUSE AND RUN:

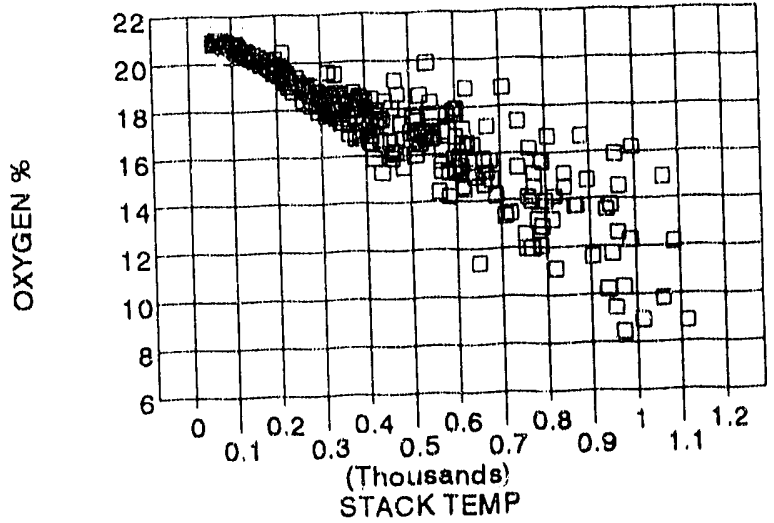

DAY IN TEST

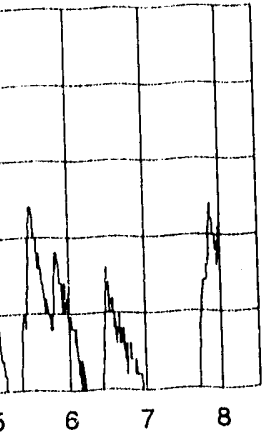


Appendix C

\section{Homeowner Comments on Densified Fuels}




\section{Homeowner Comments on Densified Fuels}

Stove Type:

Home Code:

Homeowner's Name:
Quadralire noncatalytic Phase II stove

KF01

Rickert

Q: $\quad$ Please note below any observations you have made while burning the three fuel types. Also please compare burning densified logs to burning your normal cordwood.

A: Eco-Log is cleaner to handle and has less ash than both Pres-to-Log and cordwood. Eco-Log is lighter-weight than Pres-to-Log. Heat is easier to control with Eco-Log than with Pres-to-Log; the Eci-Log is cooler, more like cordwood. Eco-Log doesn't last as long as Pres-to-Log. Prefer to Eco-Log to cordwood and Pres-to-Log. Eco-Log has less smoke than either Pres-to-Log or cordwood.

Preference: 1. Eco-Log

2. Juniper

3. Pres-to-Log (had too many "pitchy" logs)

Stove Type:

Earth 1003 C catalytic Phase II stove

Home Code:

KF02

Homeowner's Name: Loud

$\mathrm{Q}$ : $\quad$ Please note below any observations you have made while burning the three fuel types. Also please compare burning densified logs to burning your normal cordwood.

A: The E $\quad$ Logs leave less ash than the Pres-to-Logs. Both put out plenty of heat and do not have á lot of dust coming out when you open the door. 


\title{
Homeowner Comments on Densified Fuels
}

\author{
Stove Type: $\quad$ Jotul-Alpha catalytic Phase II stove \\ Home Code: KF03 \\ Horneowner's Name: Harris
}

Q: Please note below any observations you have made while burning the three fuel types. Also please compare burning densified logs to burning your normal cordwood.

A: Eco-Logs burn longer than Pres-to-Logs but do not produce as much heat. Eco-Logs produce more ash. Heat with hoth types is very even. Two logs at night will leave plenty of coals in the morning.

Densitied logs have much longer burn-time between loadings than cordwood, probably due to their greater weight and density.

$\begin{array}{ll}\text { Stove Type: } & \text { Haugh noncatalytic Phase Il stove } \\ \text { Home Code: } & \text { KF04 } \\ \text { Homeowner's Name: } & \text { Neuhert }\end{array}$

O: Please note below any observations you have made while burning the three fuel types. Also please compare burning densified logs to burning your normal cordwood.

A: I thought the Pres-to-Log burned better. Pres-to-Logs seemed to last longer and be more consistent in heat. 


\title{
Homeowner Comments on Densified Fuels
}

\author{
Stove Type: \\ Pacific Energy Super 27 noncatalytic Phase Il stove \\ Home Code: \\ KF05 \\ Homeowner's Name: Killian
}

Q: Please note below any observations you have made while burning the three fuel types. Also please compare burning densified logs to burning your normal cordwood.

A: Pres-to-Logs were easier to handle in rnost cases. Starting a fire in a cold seemed slow compared to cordwond. But pound for pound it burnt about the same heat per amount of time. Pres-toLogs did seem to leave less ash.

Pres-to-Logs and Eco-Logs were different some, too. Being the same approximate weights. Pres-to-Logs were easier to start a fire than Eco-Logs, mayte the difference in moisture. EcoLogs were harder to break up. Both left about the same ash. Eco-Logs hurned a bit longer than Pres-\{0-Logs. For both makes of log, two logs did hurn better together instead of one at a time.

Cold logs of either kind seemed slow in burning and logs at room temperature took off better.

$\begin{array}{ll}\text { Stove Type: } & \text { Earth } 101 \text { conventional stove } \\ \text { Home Code: } & \text { KF06 } \\ \text { Homeowner's Name: } & \text { Freeman }\end{array}$

Q: Please note below any observations you have made while burning the three fuel types. Also please comnare burning densified logs to burning your normal cordwood.

A: My observation is the Pres-to-Logs were superior to the Eco-Logs. The Pres-to-Log burned hotter and was easier to control with the stove. We got our house filled with smoke a few times with the Eco-Logs. The densified logs we.e nice to handle compared to cordwood and you didn't have some of the smells associated with hurning cordwood. I think the densified logs would costprohibitive over a complete winter. 


\title{
Homeowner Comments on Densified Fuels
}

\author{
Stove Type: \\ Earth 101 conventional Stove \\ Home Code: \\ KF07 \\ Homeowner's Name: Stout
}

Q: Please note below any observations you have made while burning the threa fuel types. Also please compare burning densified logs to burning your normal cordwood.

A: Eco-logs seemed to last longer and we liked burning them better than the pine. Densified logs are much easier, lighter, less cumbersome, and tidier than cordwood. It is, however, harder to start a fire with them. Eco-Logs are easier to control the temperature with and burn nice and hot.

Advantages: Pres-to-Logs are more convenient, easier to handle. More burn time per log, better coaling, longer hurning, higher temperatures, keep house warmer, seem more efficient.

Disadvantages: Back pruffing if damped down, hard starting, slower heating when first started. (Takes longer to heat house when first started.) Not as flashy as cordwood.

$\begin{array}{ll}\text { Stove Type: } & \text { Earth } 101 \text { conventional stove } \\ \text { Stove Code: } & \text { KF08 } \\ \text { Homeowner's Name: } & \text { Goodrich }\end{array}$

Q: $\quad$ Please note below any observations you have made while burning the three fuel types. Also please compare burning densified logs to burning your normal cordwood.

A: The Pres-to-Logs are much easier to handle \& less messy than wood (bark). It took three Presto-Logs to produce proper room heat compared to loading stove to fulf capacity with wood.

We prefer the Pres-to-Logs to Eco-Logs. Eco-Logs were difficult to start. There didn't seem to be a difference in temperature berween the two densified logs. 


\title{
Homeowner Comments on Densified Fuels
}

\author{
Stove Type: \\ Locally built small conventional stove \\ Home Code: \\ KF09 \\ Homeowner's Name: Epperly
}

Q: Please note below any observations you have made while burning the three fuel types. Also please compare burning densified logs to burning your normal cordwood.

A: Pres-to-Logs burned hotter and seemed to be harder to start a fire with. Eco-Logs still burned hot but not as hot as Pres-to-Logs. The Eco-Logs were easier to control temperature with because they didn't burn as hot. Personally, if I were buying densified logs to heat my home, I would buy some of each to balance out the effects of each type. 

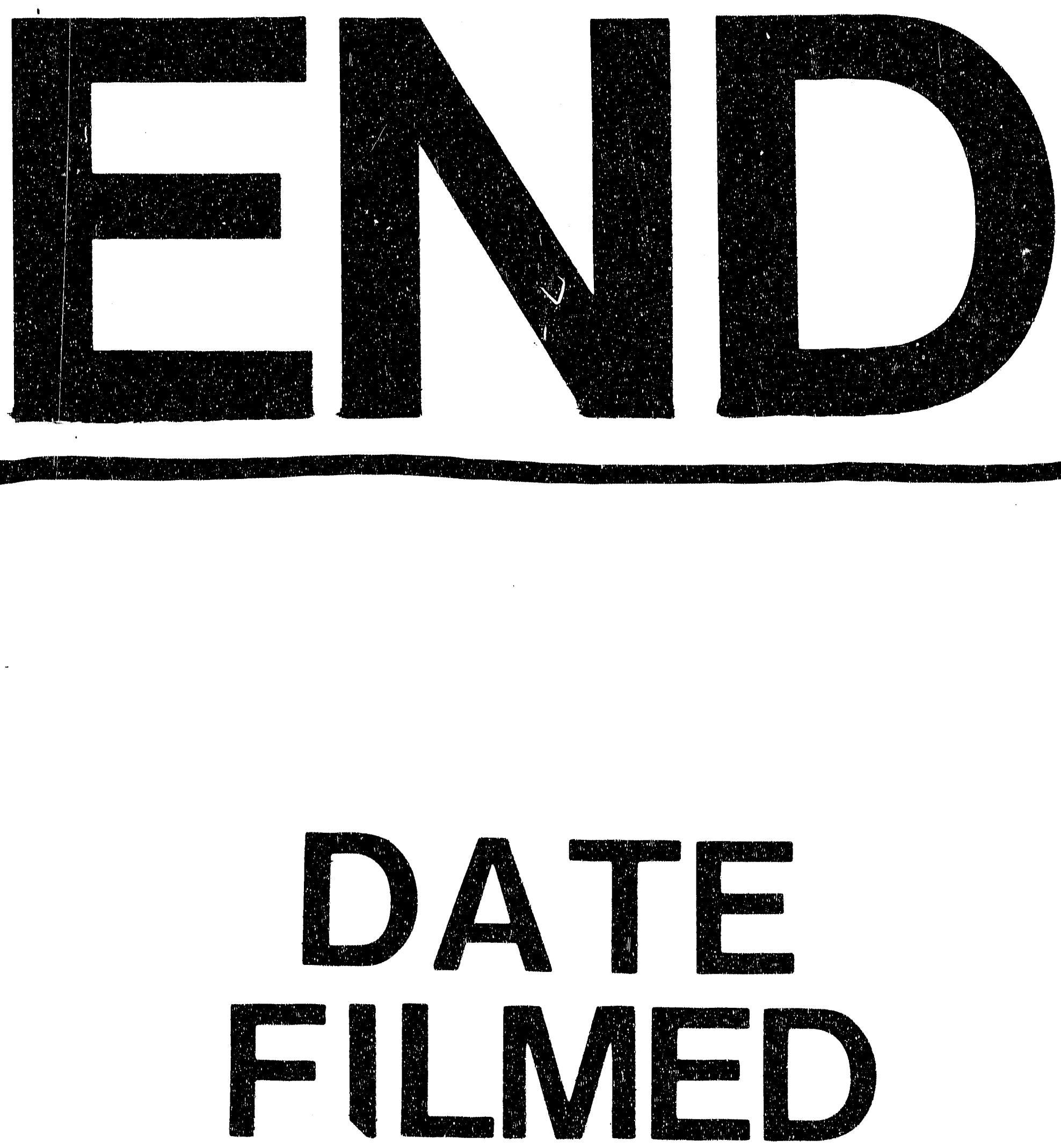

$=$

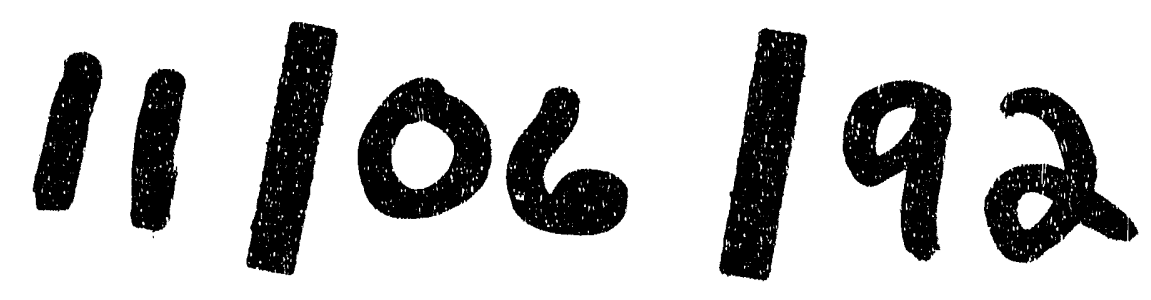




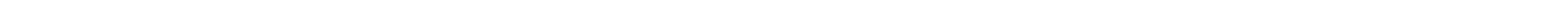

